University of Tennessee Health Science Center UTHSC Digital Commons

$12-2010$

\title{
Mitochondrial Regulation of Arterial Contractility
}

Damodaran Narayanan

University of Tennessee Health Science Center

Follow this and additional works at: https://dc.uthsc.edu/dissertations

Part of the Cardiovascular System Commons

\section{Recommended Citation}

Narayanan, Damodaran , "Mitochondrial Regulation of Arterial Contractility" (2010). Theses and Dissertations (ETD). Paper 177. http://dx.doi.org/10.21007/etd.cghs.2010.0223.

This Dissertation is brought to you for free and open access by the College of Graduate Health Sciences at UTHSC Digital Commons. It has been accepted for inclusion in Theses and Dissertations (ETD) by an authorized administrator of UTHSC Digital Commons. For more information, please contact jwelch30@uthsc.edu. 


\title{
Mitochondrial Regulation of Arterial Contractility
}

\begin{abstract}
Rationale: Physiological functions of mitochondria in contractile arterial smooth muscle cells are poorly understood. Mitochondria can uptake calcium $\left(\mathrm{Ca}^{2+}\right)$, but intracellular $\mathrm{Ca}^{2+}$ signals that regulate mitochondrial $\mathrm{Ca}^{2+}$ concentration $\left(\left[\mathrm{Ca}^{2+}\right]_{\text {mito }}\right.$ ) and physiological functions of changes in $\left[\mathrm{Ca}^{2+}\right]_{\text {mito }}$ in arterial smooth muscle cells are unclear.

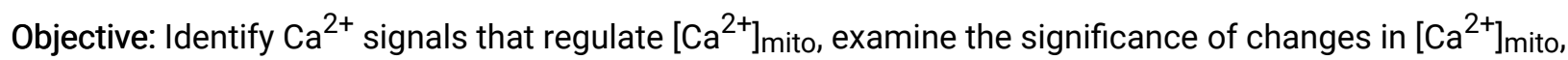
and test the hypothesis that $\left[\mathrm{Ca}^{2+}\right]_{\text {mito }}$ controls functional ion channel transcription in smooth muscle cells of resistance-size cerebral arteries.

Methods and Results: Endothelin-1 (ET-1) activated $\mathrm{Ca}^{2+}$ waves and elevated global $\mathrm{Ca}^{2+}$ concentration $\left(\left[\mathrm{Ca}^{2+}\right]_{\mathrm{i}}\right)$ via inositol 1,4,5-triphosphate receptor $\left(\mathrm{IP}_{3} \mathrm{R}\right)$ activation. IP3 $\mathrm{R}$-mediated sarcoplasmic reticulum (SR) $\mathrm{Ca}^{2+}$ release increased $\left[\mathrm{Ca}^{2+}\right]_{\text {mito }}$ and induced mitochondrial depolarization, which stimulated mitochondrial reactive oxygen species (mitoROS) generation that elevated cytosolic ROS. In contrast, a global $\left[\mathrm{Ca}^{2+}\right]_{i}$ elevation did not alter $\left[\mathrm{Ca}^{2+}\right]_{\text {mito, }}$ mitochondrial potential, or mitoROS generation. ET- 1 stimulated nuclear translocation of nuclear factor kappa B (NF-KB) p50 subunit and ET-1-induced $\mathrm{IP}_{3} \mathrm{R}$-mediated mitoROS elevated NF-KB-dependent transcriptional activity. ET-1 elevated voltage-dependent $\mathrm{Ca}^{2+}$ (Cav1.2) channel expression, leading to an increase in both pressure (myogenic tone)- and depolarization-induced vasoconstriction. Baseline Cav1.2 expression and the ET-1-induced elevation in Cav1.2 expression were both reduced by $\mathrm{IP}_{3} \mathrm{R}$ inhibition, mitochondrial electron transport chain block, antioxidant treatment, and NF-KB subunit knockdown, leading to vasodilation.
\end{abstract}

Conclusions: $\mathrm{IP}_{3} \mathrm{R}-$ mediated $\mathrm{SR} \mathrm{Ca}{ }^{2+}$ release elevates $\left[\mathrm{Ca}^{2+}\right]_{\text {mito, }}$ which induces mitoRoS generation. MitoROS activate NF-KB, which stimulates Cav1.2 channel transcription. Thus, mitochondria sense $\mathrm{IP}_{3} \mathrm{R}-$-mediated $\mathrm{SR} \mathrm{Ca}{ }^{2+}$ release to control NF-KB-dependent Cav1.2 channel expression in arterial smooth muscle cells, thereby modulating arterial contractility.

Document Type

Dissertation

Degree Name

Doctor of Philosophy (PhD)

Program

Biomedical Sciences

Research Advisor

Jonathan H. Jaggar, Ph.D.

\section{Keywords}

arterial smooth muscle, calcium signaling, CaV1.2 expression, mitochondria, myogenic tone 


\section{Subject Categories}

Anatomy | Cardiovascular System | Medicine and Health Sciences 


\title{
MITOCHONDRIAL REGULATION OF ARTERIAL CONTRACTILITY
}

\author{
A Dissertation \\ Presented for \\ The Graduate Studies Council \\ The University of Tennessee \\ Health Science Center
}

In Partial Fulfillment

Of the Requirements for the Degree

Doctor of Philosophy

From The University of Tennessee

By

Damodaran Narayanan

December 2010 
Portions of Chapters 1, 3, 4, and 5 (C) 2010 by American Heart Association, Inc. All other materials (C) 2010 by Damodaran Narayanan. All rights reserved. 


\section{DEDICATION}

I dedicate this dissertation to my parents Narayanan Deenadayalan and Lakshmi Narayanan for their endless love and support. 


\section{ACKNOWLEDGMENTS}

I would like to thank my advisor Dr. Jonathan H. Jaggar for the motivation, intellectual guidance, encouragement, support, and many opportunities he has offered during my Ph.D. training. He has taught me how to think scientifically and present my research professionally. I am extremely grateful to him for the graduate education he has provided me and for instilling in me the qualities of a good scientific investigator.

I extend my gratitude to my dissertation advisory committee members Drs. Charles W. Leffler, Rennolds S. Ostrom, Radhakrishna Rao, and Christopher M. Waters for their valuable guidance, assistance, and suggestions throughout my project. Special thanks to Dr. Lawrence M. Pfeffer for his advice, guidance, and constructive criticism.

I would like to show my appreciation for all the members of Dr. Jaggar's laboratory for their help and suggestions. I would like to thank Dr. Lidia Gardner for her technical advice. I also like to thank late Mr. Gerwin and Mrs. Gerwin for awarding me the Graduate Scholarship, which motivated me a lot. Thanks to the American Heart Association for awarding me the predoctoral fellowship.

I would also like to thank Mr. Larry Tague, Ms. Shirley Hancock and the ETD group for help in formatting this dissertation. I sincerely thank all my friends and colleagues in Memphis for their support and camaraderie over the years.

I would like to thank the University of Tennessee Health Science Center for providing me with the opportunity to pursue graduate education. I am also grateful to the administrative staff of the Department of Physiology and the College of Graduate Health Science for all their help and cooperation.

I express my sincere gratitude and appreciation to Mr. N.V. Reddy for his inspiration. I am forever indebted to my father, mother, and brother for their unconditional love, patience, and support during my graduate education. Finally, I would like to thank God for everything that I have achieved today. 


\begin{abstract}
Rationale: Physiological functions of mitochondria in contractile arterial smooth muscle cells are poorly understood. Mitochondria can uptake calcium $\left(\mathrm{Ca}^{2+}\right)$, but intracellular $\mathrm{Ca}^{2+}$ signals that regulate mitochondrial $\mathrm{Ca}^{2+}$ concentration $\left(\left[\mathrm{Ca}^{2+}\right]_{\text {mito }}\right)$ and physiological functions of changes in $\left[\mathrm{Ca}^{2+}\right]_{\text {mito }}$ in arterial smooth muscle cells are unclear.

Objective: Identify $\mathrm{Ca}^{2+}$ signals that regulate $\left[\mathrm{Ca}^{2+}\right]_{\text {mito }}$, examine the significance of changes in $\left[\mathrm{Ca}^{2+}\right]_{\text {mito }}$, and test the hypothesis that $\left[\mathrm{Ca}^{2+}\right]_{\text {mito }}$ controls functional ion channel transcription in smooth muscle cells of resistance-size cerebral arteries.

Methods and Results: Endothelin- 1 (ET-1) activated $\mathrm{Ca}^{2+}$ waves and elevated global $\mathrm{Ca}^{2+}$ concentration $\left(\left[\mathrm{Ca}^{2+}\right]_{\mathrm{i}}\right)$ via inositol 1,4,5-triphosphate receptor $\left(\mathrm{IP}_{3} \mathrm{R}\right)$ activation. $\mathrm{IP}_{3} \mathrm{R}$-mediated sarcoplasmic reticulum $(\mathrm{SR}) \mathrm{Ca}^{2+}$ release increased $\left[\mathrm{Ca}^{2+}\right]_{\text {mito }}$ and induced mitochondrial depolarization, which stimulated mitochondrial reactive oxygen species (mitoROS) generation that elevated cytosolic ROS. In contrast, a global $\left[\mathrm{Ca}^{2+}\right]_{\mathrm{i}}$ elevation did not alter $\left[\mathrm{Ca}^{2+}\right]_{\text {mito }}$, mitochondrial potential, or mitoROS generation. ET-1 stimulated nuclear translocation of nuclear factor kappa B (NF- $\mathrm{BB})$ p50 subunit and ET-1-induced $\mathrm{IP}_{3} \mathrm{R}$-mediated mitoROS elevated NF- $\kappa \mathrm{B}$-dependent transcriptional activity. ET-1 elevated voltage-dependent $\mathrm{Ca}^{2+}\left(\mathrm{Ca}_{V} 1.2\right)$ channel expression, leading to an increase in both pressure (myogenic tone)- and depolarization-induced vasoconstriction. Baseline $\mathrm{Ca}_{\mathrm{V}} 1.2$ expression and the ET-1-induced elevation in $\mathrm{Ca}_{\mathrm{V}} 1.2$ expression were both reduced by $\mathrm{IP}_{3} \mathrm{R}$ inhibition, mitochondrial electron transport chain block, antioxidant treatment, and NF- $\kappa$ B subunit knockdown, leading to vasodilation.
\end{abstract}

Conclusions: $\mathrm{IP}_{3} \mathrm{R}$-mediated $\mathrm{SR} \mathrm{Ca}^{2+}$ release elevates $\left[\mathrm{Ca}^{2+}\right]_{\text {mito }}$, which induces mitoROS generation. MitoROS activate NF- $\kappa B$, which stimulates $\mathrm{Ca}_{\mathrm{V}} 1.2$ channel transcription. Thus, mitochondria sense $\mathrm{IP}_{3} \mathrm{R}$-mediated $\mathrm{SR} \mathrm{Ca}^{2+}$ release to control NF$\kappa \mathrm{B}$-dependent $\mathrm{Ca}_{\mathrm{V}} 1.2$ channel expression in arterial smooth muscle cells, thereby modulating arterial contractility. 


\section{TABLE OF CONTENTS}

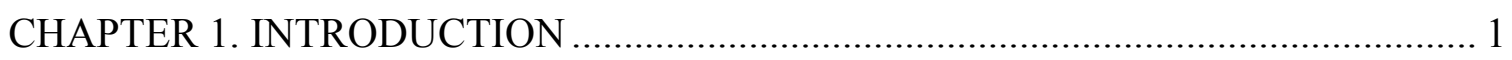

1.1. $\mathrm{Ca}^{2+}$ Signaling in Vascular Smooth Muscle Cells ................................................1

1.2. $\mathrm{Ca}^{2+}$ Transport Mechanisms across Plasma Membrane.........................................2

1.2.1. Voltage-dependent $\mathrm{Ca}^{2+}$ channels ........................................................2

1.2.2. Store-operated $\mathrm{Ca}^{2+}$ channels ............................................................. 3

1.2.3. Receptor-operated $\mathrm{Ca}^{2+}$ channels.......................................................4

1.2.4. Other $\mathrm{Ca}^{2+}$ entry channels ...............................................................4

1.2.5. Plasma membrane $\mathrm{Ca}^{2+}$-ATPases ...........................................................5

1.2.6. Plasma membrane $\mathrm{Na}^{+} / \mathrm{Ca}^{2+}$ exchanger ...................................................5

1.3. Intracellular $\mathrm{Ca}^{2+}$ Stores......................................................................6

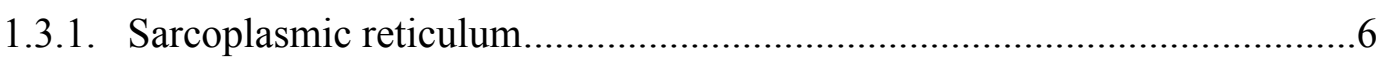

1.3.1.1. Ryanodine-sensitive $\mathrm{Ca}^{2+}$ release channels ............................6

1.3.1.2. Inositol 1,4,5-triphosphate receptors......................................

1.3.1.3. Sarcoplasmic/endoplasmic reticulum $\mathrm{Ca}^{2+}$ ATPases................... 9

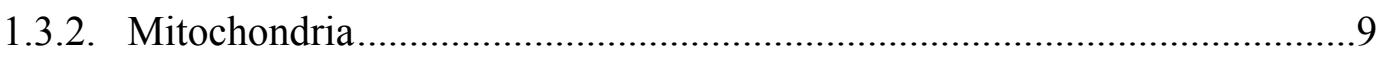

1.3.2.1. Voltage-dependent anion channel..........................................10

1.3.2.2. Mitochondrial $\mathrm{Ca}^{2+}$ uniporter.................................................. 10

1.3.2.3. Rapid uptake mode ........................................................... 10

1.3.2.4. Mitochondrial permeability transition pore ............................11

1.3.2.5. Mitochondrial $\mathrm{Na}^{+} / \mathrm{Ca}^{2+}$ exchanger.........................................11

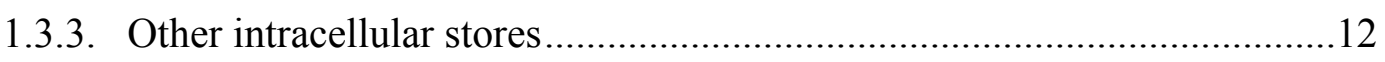

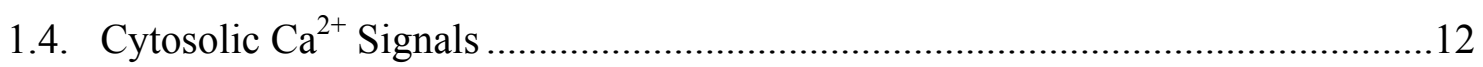

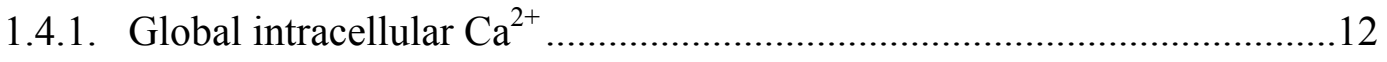

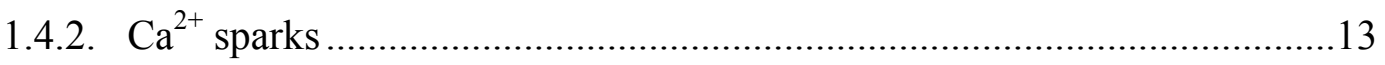

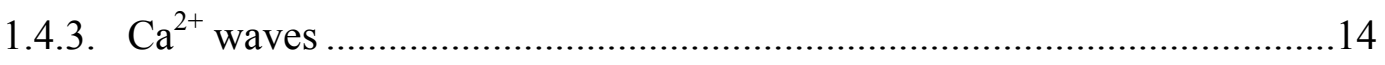

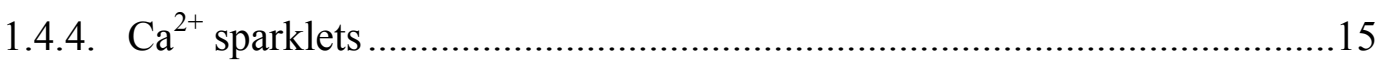

1.5. Mitochondria in Vascular Smooth Muscle Cells ................................................15

1.5.1. Electron transport chain and ATP synthesis ...........................................15

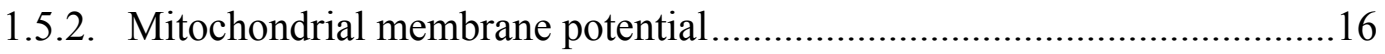

1.5.3. Spatial proximity between SR and mitochondria ..................................16

1.5.4. Interplay between mitochondria and cytosolic $\mathrm{Ca}^{2+}$ signals ......................17

1.5.5. Role of mitochondria in vascular smooth muscle cells ...........................18 
1.6. Reactive Oxygen Species in Vascular Smooth Muscle Cells

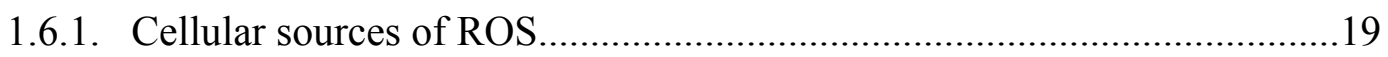

1.6.1.1. Mitochondrial ETC complexes .................................................19

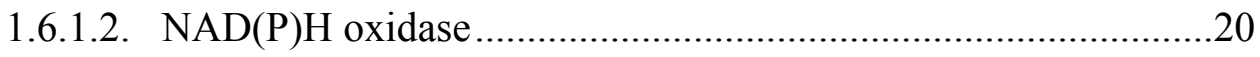

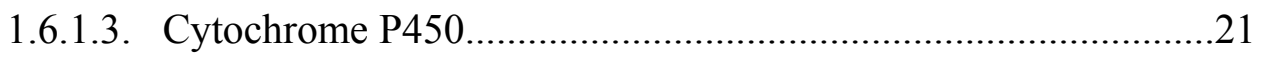

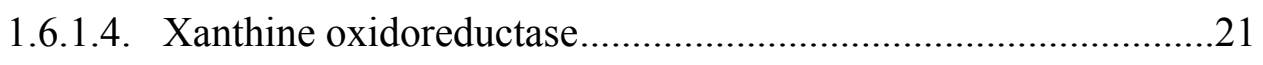

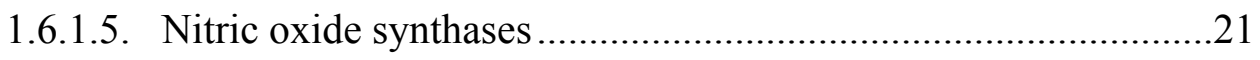

1.6.1.6. Cyclooxygenases and lipoxygenases ...........................................22

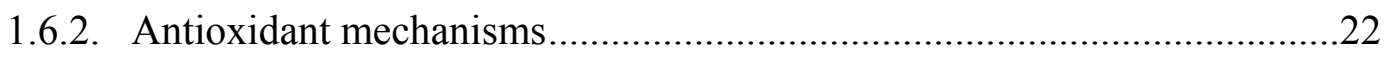

1.6.3. ROS regulation of vascular smooth muscle cell functions ........................22

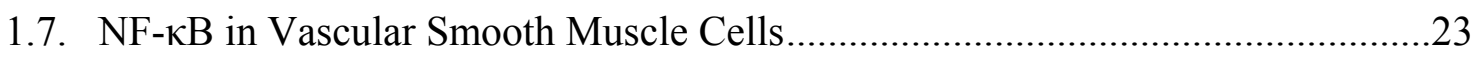

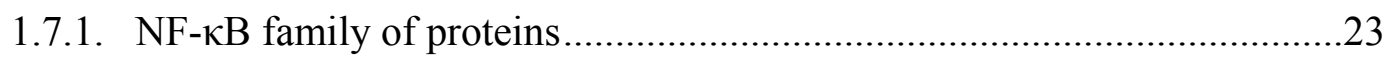

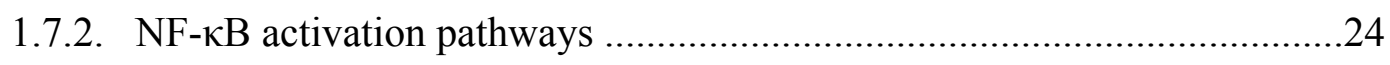

1.7.2.1. Classical/Canonical pathway ...................................................24

1.7.2.2. Alternative/Non-canonical pathway ……………………….......25

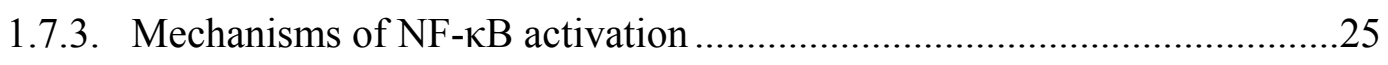

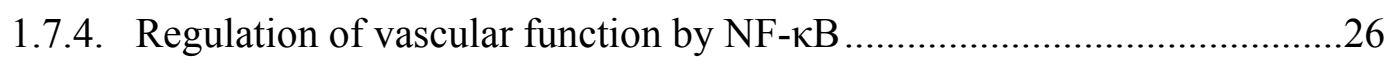

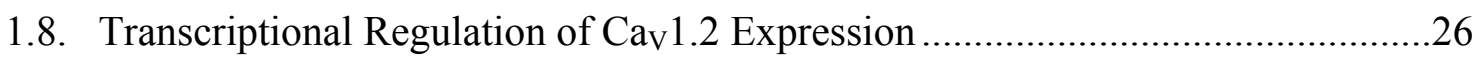

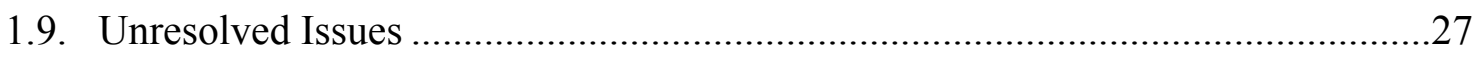

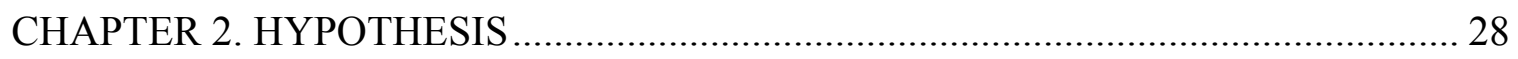

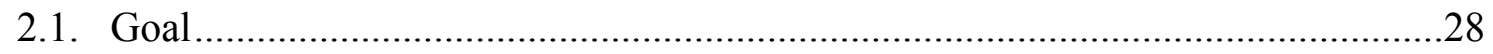

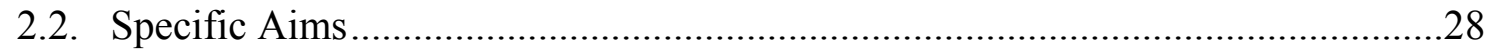

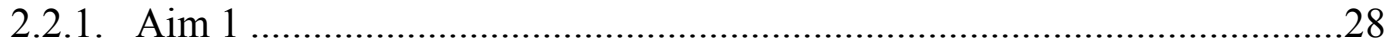

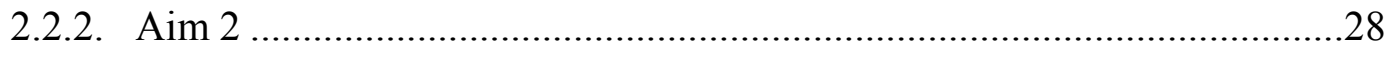

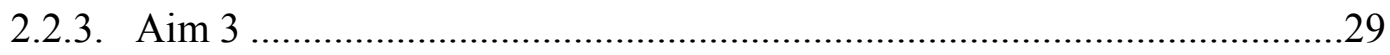

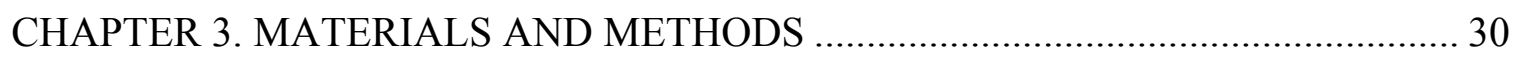

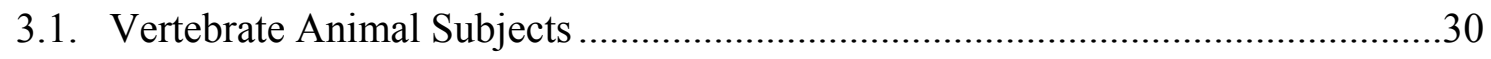

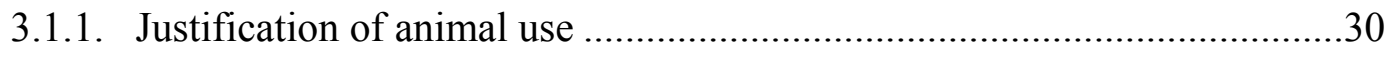

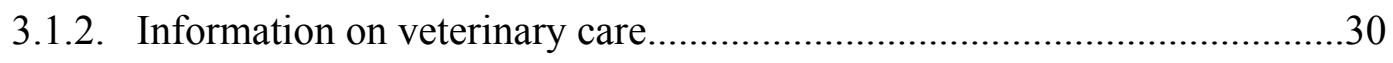

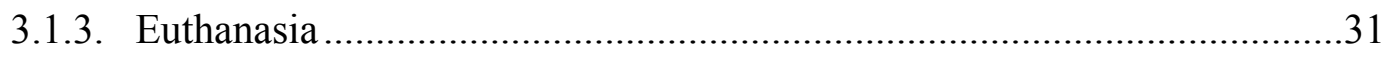

3.1.3.1. Procedure for limiting animal discomfort, distress, pain,

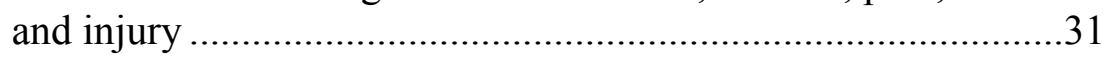

3.1.3.2. Method of euthanasia .................................................................. 


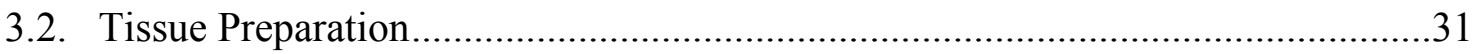

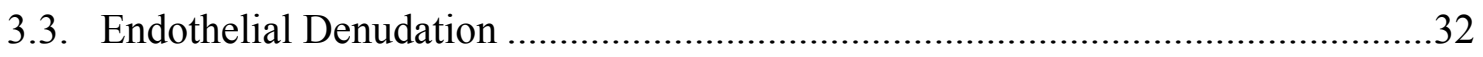

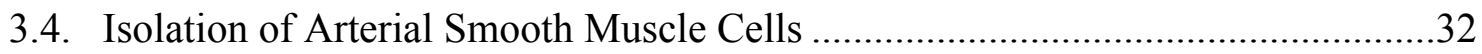

3.4.1. Preparation of solutions used for smooth muscle cell isolation..................32

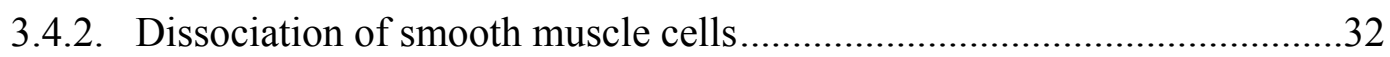

3.4.2.1. Freshly dissociated cerebral arteries ...........................................32

3.4.2.2. Reverse-permeabilized arteries .................................................33

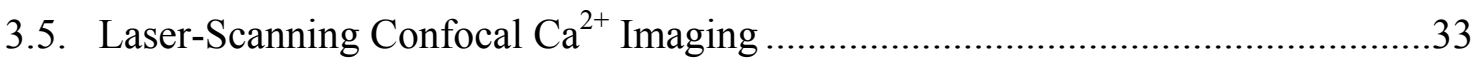

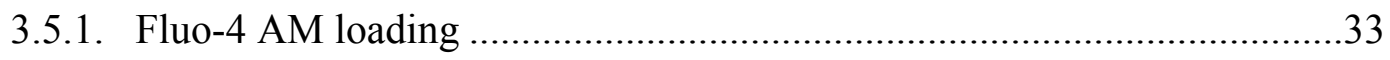

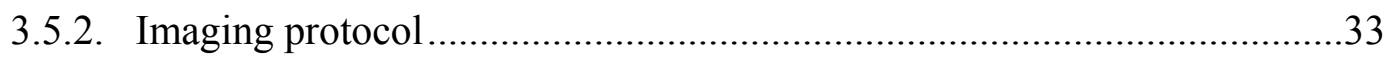

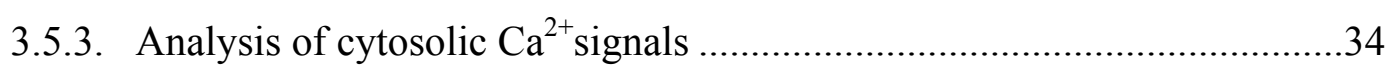

3.5.3.1. Detection of $\mathrm{Ca}^{2+}$ sparks and $\mathrm{Ca}^{2+}$ waves ...................................34

3.5.3.2. Calculation of $\mathrm{Ca}^{2+}$ spark and wave frequency, and global

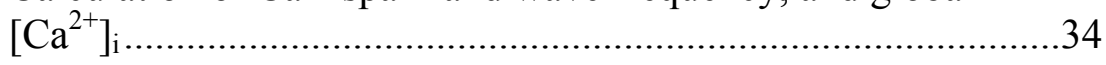

3.6. Genetically-Encoded Fluorescent Indicators ………..............................................

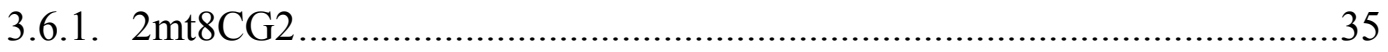

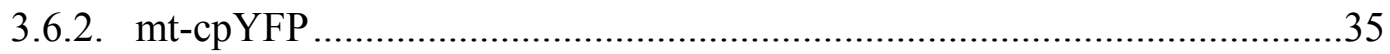

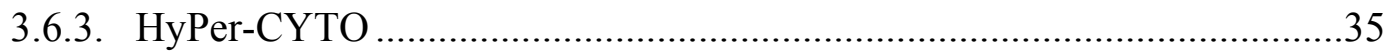

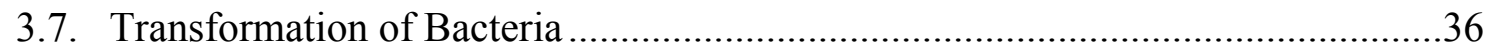

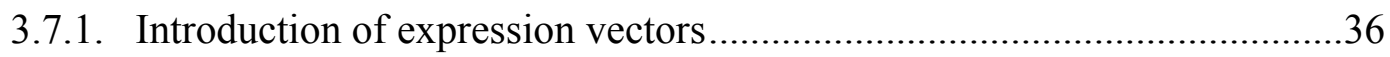

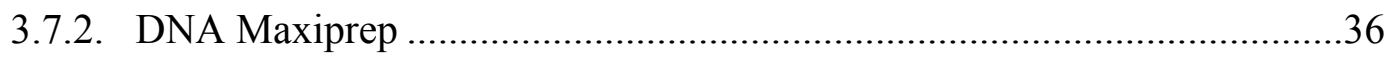

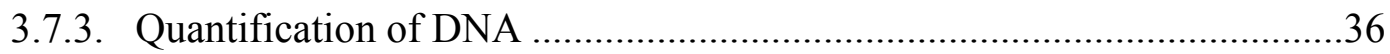

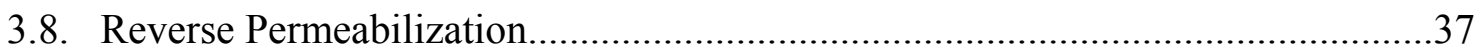

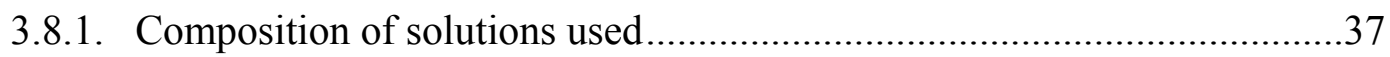

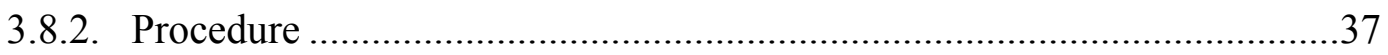

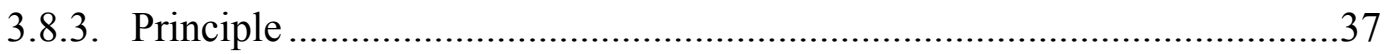

3.9. Confocal Imaging of Genetically-Encoded Fluorescent Indicators.........................39

3.9.1. Introduction of indicators into arterial smooth muscle cells.......................39

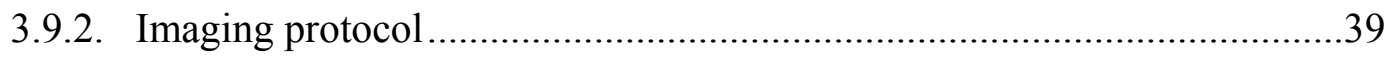

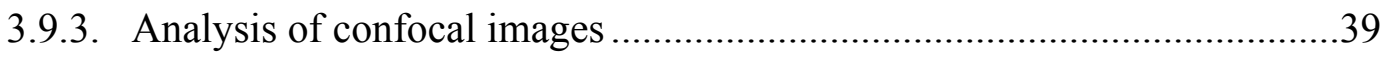

3.10. Localization of Mitochondria-Targeted Indicators ................................................40

3.10.1. Loading smooth muscle cells with MitoTracker .........................................40

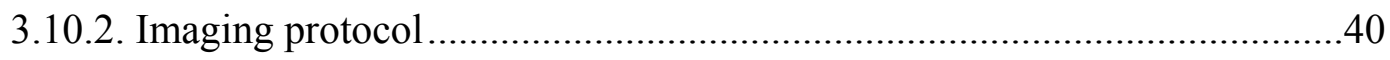

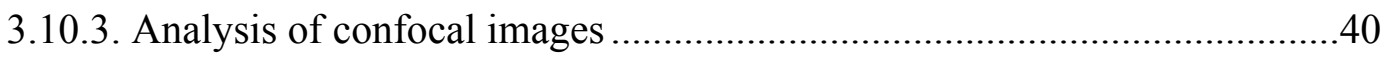

3.11. Imaging 2mt8CG2 in HEK293 Cells ............................................................ 
3.11.1. Transfection of HEK293 cells with 2mt8CG2 .......................................41

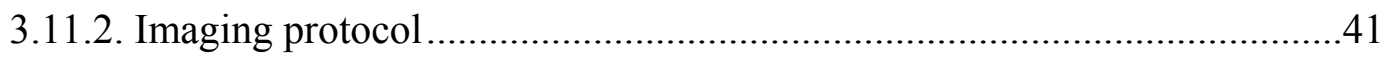

3.12. Tetramethylrhodamine, Methyl Ester Imaging for $\psi_{\mathrm{m}}$ Measurements ...................41

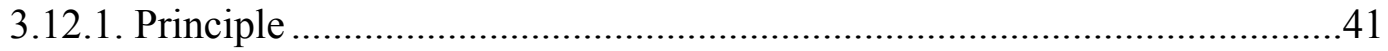

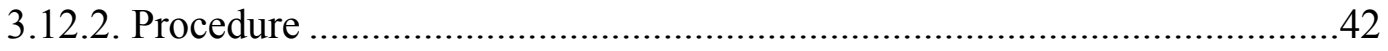

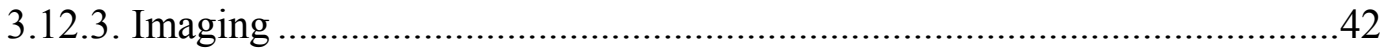

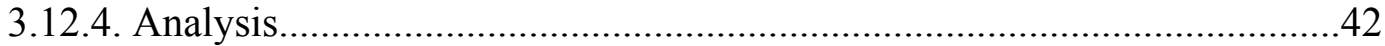

3.13. Dichlorofluorescein Imaging for ROS Measurements ..........................................42

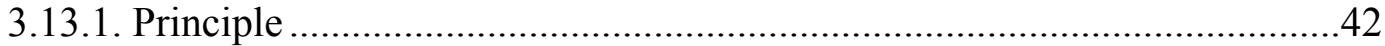

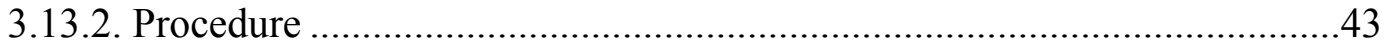

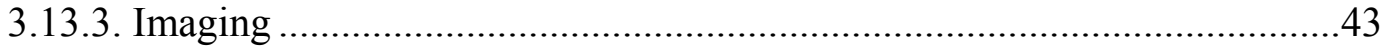

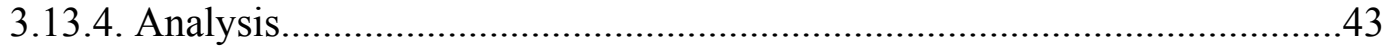

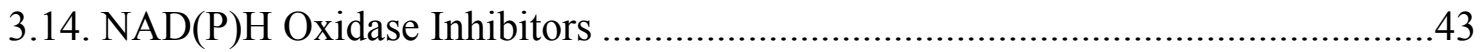

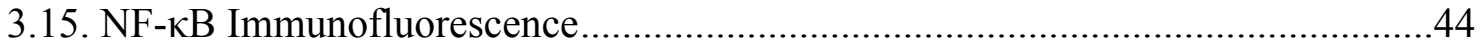

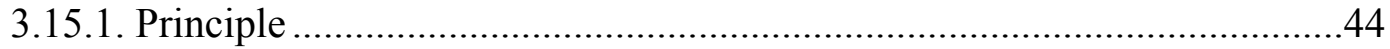

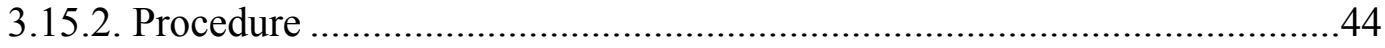

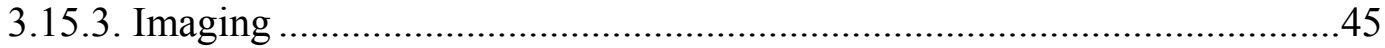

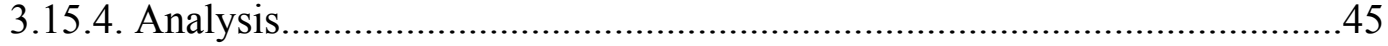

3.16. NF-кB-Dependent Luciferase Reporter Gene Activity ...........................................45

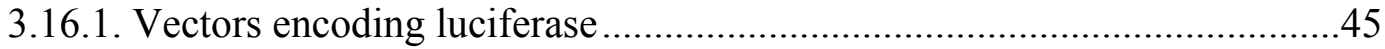

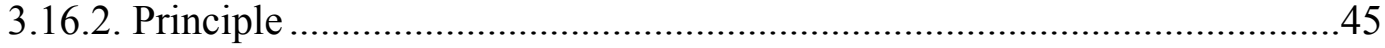

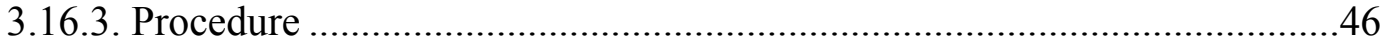

3.16.4. Measuring luciferase activity .................................................................

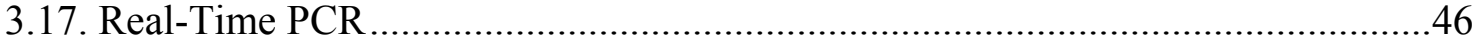

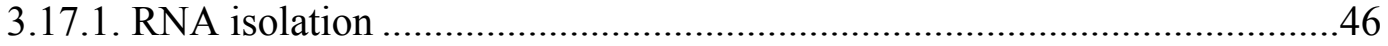

3.17.2. Quantification of RNA.......................................................................46

3.17.3. Reverse transcription ..........................................................................47

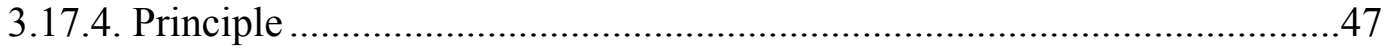

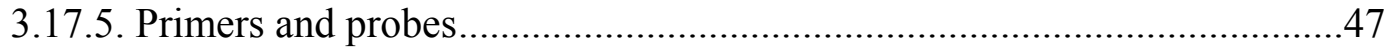

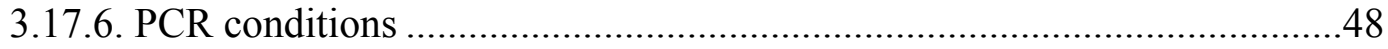

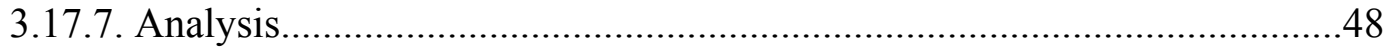

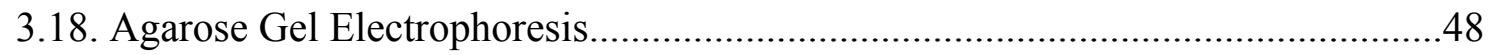

3.19. Protein Quantification and Estimation...............................................................

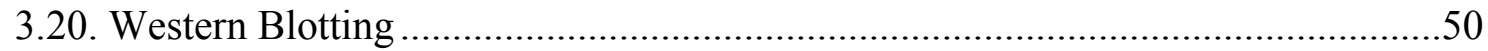


3.21. Densitometric Analysis of Western Blots..........................................................

3.22. NF-kB p105 Knockdown ............................................................................

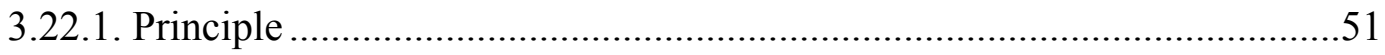

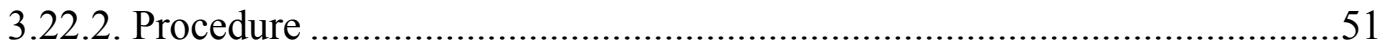

3.23. Pressurized Artery Diameter Measurements ...................................................51

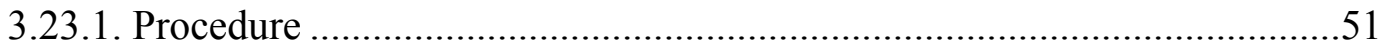

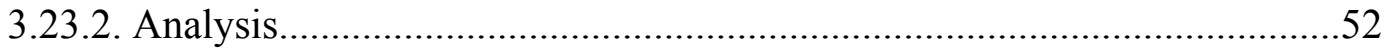

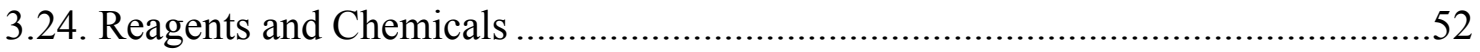

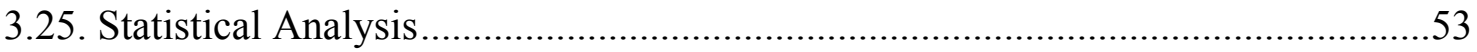

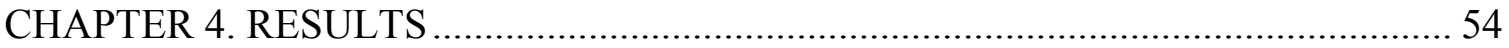

4.1. ET-1 Modifies Local and Global $\mathrm{Ca}^{2+}$ Signals in Cerebral Artery Smooth

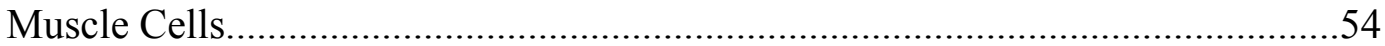

4.2. ET-1-Induced $\mathrm{IP}_{3} \mathrm{R}$-Mediated SR $\mathrm{Ca}^{2+}$ Release Elevates $\left[\mathrm{Ca}^{2+}\right]_{\text {mito }}$ in Cerebral Artery Smooth Muscle Cells ................................................................54

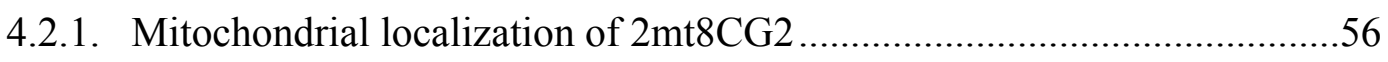

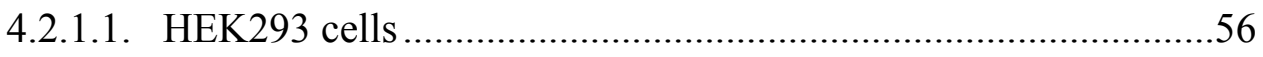

4.2.1.2. Cerebral artery smooth muscle cells ..........................................56

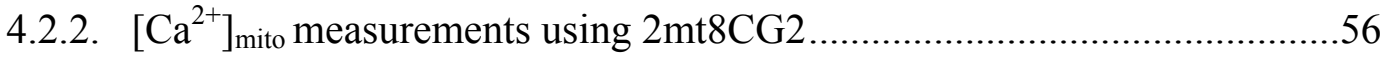

4.3. ET-1-Induced $\mathrm{IP}_{3} \mathrm{R}-$ Mediated $\mathrm{SR} \mathrm{Ca}^{2+}$ Release Depolarizes Mitochondria in Cerebral Artery Smooth Muscle Cells ............................................................59

4.4. ET-1-Induced $\mathrm{IP}_{3} \mathrm{R}$-Mediated $\mathrm{SR} \mathrm{Ca}^{2+}$ Release and $\left[\mathrm{Ca}^{2+}\right]_{\text {mito }}$ Elevation Stimulates MitoROS Generation .59

4.4.1. MitoROS measurements using mt-cpYFP .............................................59

4.4.1.1. Mitochondrial localization of mt-cpYFP ....................................59

4.4.1.2. ET-1 elevates mitoROS production .............................................59

4.4.2. ET-1-induced mitoROS generation elevates cytosolic ROS levels...........64

4.4.3. ROS measurements using DCF .............................................................64

4.4.3.1. ET-1 stimulates ROS generation ...............................................64

4.4.3.2. Source of ET-1-induced ROS elevation is mitochondria ............64

4.5. ET-1-Induced $\mathrm{IP}_{3} \mathrm{R}$-Mediated MitoROS Elevation Stimulates NF- $\mathrm{kB}$.................70

4.5.1. ET-1 stimulates nuclear translocation of NF- $\mathrm{kB}$ p50 ……........................70

4.5.2. ET-1 elevates NF-кB-dependent transcriptional activity ............................70

4.5.3. ROS measurements corresponding to transcriptional studies......................73

4.6. ET-1-Induced $\mathrm{IP}_{3} \mathrm{R}-$ Mediated $\mathrm{SR} \mathrm{Ca}^{2+}$ Release Stimulates $\mathrm{Ca}_{\mathrm{V}} 1.2$

Expression by MitoROS Elevation and NF-kB Activation 
4.6.1. ET-1 stimulates $\mathrm{Ca}_{\mathrm{V}} 1.2$ gene transcription

4.6.2. ET-1-induced $\mathrm{IP}_{3} \mathrm{R}$ activation and mitoROS elevation stimulate Cav1.2 expression .78

4.6.3. ET-1-induced NF- $\mathrm{BB}$ activation elevates $\mathrm{Ca}_{\mathrm{V}} 1.2$ expression .78

4.7. ET-1-Induced $\mathrm{IP}_{3} \mathrm{R}-\mathrm{Mediated} \mathrm{SR} \mathrm{Ca}^{2+}$ Release Also Stimulates p105 Expression. .78

4.8. ET-1-Induced NF- $\mathrm{B}$ Activation Does Not Stimulate p105 Expression. . .83

4.9. NF- $\kappa \mathrm{B}$ Stimulates Functional $\mathrm{Ca}_{\mathrm{V}} 1.2$ Expression in Cerebral Artery Smooth Muscle Cells .83

4.9.1. Myogenic tone development in arteries .83

4.9.2. ET-1-stimulates functional $\mathrm{Ca}_{\mathrm{V}} 1.2$ expression via $\mathrm{NF}-\kappa \mathrm{B}$ activation.

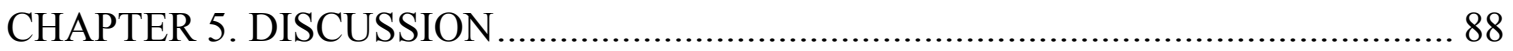

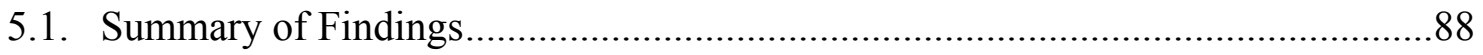

5.2. $\mathrm{Ca}^{2+}$ Signaling in Vascular Smooth Muscle Cells by PLC-Coupled Agonists .88

5.3. Regulation of $\left[\mathrm{Ca}^{2+}\right]_{\text {mito }}$ by Cytosolic $\mathrm{Ca}^{2+}$ Signals

5.4. $\mathrm{Ca}^{2+}$ Waves May Be the Cytosolic $\mathrm{Ca}^{2+}$ Signal Regulating Mitochondrial Events.

5.5. Regulation of MitoROS Generation by $\left[\mathrm{Ca}^{2+}\right]_{\text {mito }}$ and Mitochondrial Potential .93

5.6. Characterization of ET-1-Induced ROS Elevation . .94

5.7. ROS-Dependent and -Independent Pathways Which Activate NF- $\kappa B$ .94

5.8. Regulation of Basal and ET-1-Induced Elevation in $\mathrm{Ca}_{\mathrm{V}} 1.2$ Expression..............96

5.9. Regulation of $\mathrm{p} 105 / \mathrm{p} 50$ Expression by $\mathrm{IP}_{3} \mathrm{R}-\mathrm{Mediated} \mathrm{SR} \mathrm{Ca}^{2+}$ Release ............97

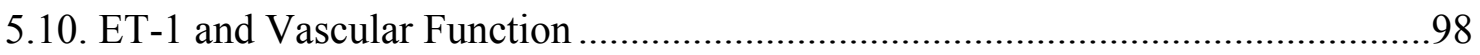

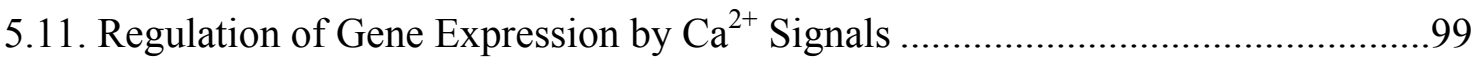

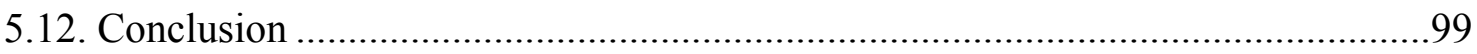

5.13. Restoration of Homeostasis - Possible Negative Feedback Mechanisms ...........100

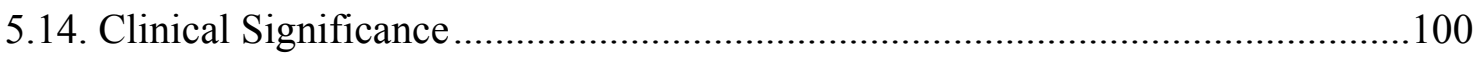

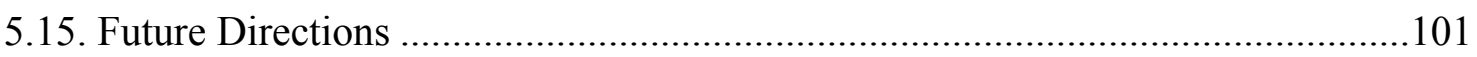

LIST OF REFERENCES 103

VITA 128 


\section{LIST OF FIGURES}

Figure 3-1. Reverse permeabilization of HyPer-CYTO in smooth muscle cells

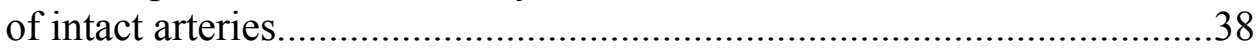

Figure 4-1. ET-1 regulates local and global $\mathrm{Ca}^{2+}$ signals in arterial smooth muscle cells

Figure 4-2. Mitochondrial localization of 2mt8CG2 in HEK293 cells and cerebral artery smooth muscle cells

Figure 4-3. ET-1-induced IP 3 R-mediated SR $\mathrm{Ca}^{2+}$ release elevates $\left[\mathrm{Ca}^{2+}\right]_{\text {mito }}$ in arterial smooth muscle cells.

Figure 4-4. ET-1-induced $\mathrm{IP}_{3} \mathrm{R}$-mediated $\mathrm{SR} \mathrm{Ca}^{2+}$ release depolarizes mitochondria in arterial smooth muscle cells

Figure 4-5. Mitochondrial localization of mt-cpYFP in cerebral artery smooth muscle cells

Figure 4-6. ET-1-induced $\mathrm{IP}_{3} \mathrm{R}$-mediated $\mathrm{SR} \mathrm{Ca}^{2+}$ release and mitochondrial $\mathrm{Ca}^{2+}$ uptake elevates mitoROS generation in arterial smooth muscle cells.

Figure 4-7. ET-1-induced IP ${ }_{3} \mathrm{R}$-mediated $\mathrm{SR} \mathrm{Ca}^{2+}$ release elevates cytosolic ROS in arterial smooth muscle cells

Figure 4-8. ET-1-induced $\mathrm{IP}_{3} \mathrm{R}$-mediated $\mathrm{SR} \mathrm{Ca}^{2+}$ release elevates DCF fluorescence in arterial smooth muscle cells

Figure 4-9. ET-1-induced mitoROS generation elevates DCF fluorescence in arterial smooth muscle cells.

Figure 4-10. ET-1 stimulates p50 nuclear translocation in arterial smooth muscle cells.

Figure 4-11. ET-1 stimulates NF-kB-dependent transcription through $\mathrm{IP}_{3} \mathrm{R}-$ mediated $\mathrm{SR} \mathrm{Ca}^{2+}$ release and mitoROS elevation in arterial smooth muscle cells

Figure 4-12. Mean changes in promoter-deficient (pGL3 Basic) luciferase activity .74

Figure 4-13. ROS measurements at time points used for transcriptional studies ...........75

Figure 4-14. ET-1 stimulates $\mathrm{Ca}_{\mathrm{V}} 1.2$ gene transcription in cerebral arteries .77

Figure 4-15. ET-1-induced $\mathrm{IP}_{3} \mathrm{R}$-mediated $\mathrm{SR} \mathrm{Ca}^{2+}$ release and mitoROS elevation stimulate $\mathrm{Ca}_{\mathrm{V}} 1.2$ protein expression in cerebral arteries

Figure 4-16. p105 knockdown in cerebral arteries

Figure 4-17. NF- $\mathrm{NB}$ controls basal and ET-1-induced elevation in functional $\mathrm{Ca}_{V} 1.2$ expression in cerebral arteries 
Figure 4-18. ET-1-induced $\mathrm{IP}_{3} \mathrm{R}$-mediated $\mathrm{SR} \mathrm{Ca}^{2+}$ release elevates p105/p50 expression via a mitochondria-, and ROS-independent mechanism in cerebral arteries....

Figure 4-19. ET-1 elevates p105/p50 expression via an NF- $\kappa B$-independent pathway in cerebral arteries .............................................................8 84

Figure 4-20. Myogenic tone development in cerebral arteries .....................................85

Figure 4-21. p105 knockdown reduces myogenic tone and attenuates ET-1induced elevation in myogenic tone in cerebral arteries.........................86

Figure 5-1. Proposed signaling pathways that control basal $\mathrm{Ca}_{\mathrm{V}} 1.2$ expression in smooth muscle cells of cerebral arteries

Figure 5-2. Proposed signaling pathways that control ET-1-induced $\mathrm{Ca}_{\mathrm{V}} 1.2$ expression in smooth muscle cells of cerebral arteries .90 


\section{LIST OF ABBREVIATIONS}

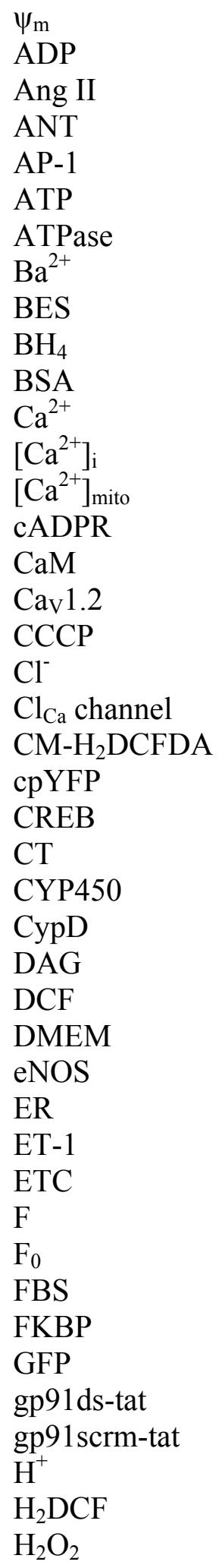

Mitochondrial membrane potential

Adenosine 5'-diphosphate

Angiotensin II

Adenine nucleotide translocase

Activator protein 1

Adenosine 5'-triphosphate

Adenosine 5'-triphosphatase

Barium

N,N-bis(2-hydroxyethyl)-2-aminoethanesulfonic acid

Tetrahydrobiopterin

Bovine serum albumin

Calcium

Intracellular $\mathrm{Ca}^{2+}$ concentration

Mitochondrial $\mathrm{Ca}^{2+}$ concentration

Cyclic ADP ribose

Calmodulin

L-type voltage-dependent $\mathrm{Ca}^{2+}$ channel

Carbonyl cyanide 3-chlorophenylhydrazone

Chloride

$\mathrm{Ca}^{2+}$-activated $\mathrm{Cl}^{-}$channel

5-(and-6)-chloromethyl-2',7'-dichlorodihydrofluorescein diacetate

Circularly permuted YFP

Cyclic AMP response element-binding protein

Fluorescence threshold

Cytochrome P450

Cyclophilin D

Diacylglycerol

Dichlorofluorescin

Dulbecco's modified eagle medium

Endothelial NOS

Endoplasmic reticulum

Endothelin-1

Electron transport chain

Fluorescence

Baseline fluorescence

Fetal bovine serum

FK-506 binding protein

Green fluorescent protein

gp91 ${ }^{\text {phox }}$ docking sequence peptide conjugated to tat

Scrambled gp91 ${ }^{\text {phox }}$ peptide conjugated to tat

Hydrogen

Dichlorodihydrofluorescein

Hydrogen peroxide 


\begin{tabular}{|c|c|}
\hline HEK293 cells & Human embryonic kidney 293 cells \\
\hline HGPRT & Hypoxanthine-guanine phosphoribosyltransferase \\
\hline HIF-1 $\alpha$ & Hypoxia-inducible factor- 1 alpha \\
\hline $\mathrm{HOCl}$ & Hypochlorous acid \\
\hline $\mathrm{I}_{\text {Cat }}$ & Non-selective cation current \\
\hline $\mathrm{I} \kappa \mathrm{B}$ & I kappa B \\
\hline IKK & IкB kinase \\
\hline $\mathrm{IL}$ & Interleukin \\
\hline iNOS & Inducible NOS \\
\hline $\mathrm{IP}_{3}$ & Inositol 1,4,5-triphosphate \\
\hline$\left[\mathrm{IP}_{3}\right]_{\mathrm{i}}$ & Intracellular $\mathrm{IP}_{3}$ concentration \\
\hline $\mathrm{IP}_{3} \mathrm{R}$ & $\mathrm{IP}_{3}$ receptor \\
\hline $\mathrm{K}^{+}$ & Potassium \\
\hline $\mathrm{K}_{\mathrm{Ca}}$ channel & Large conductance $\mathrm{Ca}^{2+}$-activated potassium channel \\
\hline $\mathrm{kDa}$ & Kilodalton \\
\hline MCP-1 & Monocyte chemoattractant protein-1 \\
\hline $\mathrm{MCU}$ & Mitochondrial $\mathrm{Ca}^{2+}$ uniporter \\
\hline $\mathrm{Mg}^{2+}$ & Magnesium \\
\hline mitoROS & Mitochondrial reactive oxygen species \\
\hline MLC20 & Myosin light chains \\
\hline $\mathrm{Mn}^{2+}$ & Manganese \\
\hline $\mathrm{mNCX}$ & Mitochondrial $\mathrm{Na}^{+} / \mathrm{Ca}^{2+}$ exchanger \\
\hline MnTMPyP & Manganese (III) tetrakis(1-methyl-4-pyridyl)porphyrin \\
\hline mPTP & Mitochondrial permeability transition pore \\
\hline $\mathrm{Na}^{+}$ & Sodium \\
\hline NAADP & Nicotinic acid adenine dinucleotide phosphate \\
\hline NADH & Nicotinamide adenine dinucleotide \\
\hline NCX & Plasma membrane $\mathrm{Na}^{+} / \mathrm{Ca}^{2+}$ exchanger \\
\hline NE & Norepinephrine \\
\hline NF-кB & Nuclear factor kappa B \\
\hline NF-кB-p-Luc & Firefly luciferase vectors under the control of an NF- $\mathrm{KB}$ promoter \\
\hline NFAT & Nuclear factor of activated $\mathrm{T}$ cell \\
\hline NLS & Nuclear localization signal \\
\hline NO & Nitric oxide \\
\hline NOS & NO synthase \\
\hline nNOS & Neuronal NOS \\
\hline $\mathrm{O}_{2}$ & Molecular oxygen \\
\hline $\mathrm{O}_{2}{ }^{-}$ & Superoxide \\
\hline $\mathrm{OH}^{\cdot}$ & Hydroxyl radical \\
\hline ONOO & Peroxynitrite \\
\hline p105 & NF-кB p105 subunit \\
\hline p105siRNA & siRNA directed against NF- $\mathrm{kB}$ p105 subunit \\
\hline p105scrm & Scrambled siRNA \\
\hline p50 & NF- $\kappa B$ p50 subunit \\
\hline PBS & Phosphate-buffered saline \\
\hline PDGF & Platelet-derived growth factor \\
\hline
\end{tabular}




\begin{tabular}{|c|c|}
\hline $\mathrm{Pi}$ & Inorganic phosphate \\
\hline $\mathrm{PIP}_{2}$ & Phosphatidylinositol 4,5-biphosphate \\
\hline PK & Protein kinase \\
\hline $\mathrm{PKC} \alpha$ & Protein kinase $\mathrm{C}$ alpha \\
\hline $\mathrm{PKC} \delta$ & Protein kinase $\mathrm{C}$ delta \\
\hline PLC & Phospholipase C \\
\hline PLN & Phospholamban \\
\hline PMCA & Plasma membrane $\mathrm{Ca}^{2+}$-ATPase \\
\hline PSS & Physiological salt solution \\
\hline $\mathrm{QH} \cdot$ & Ubisemiquinone radical intermediate \\
\hline RaM & Rapid uptake mode \\
\hline RNaseA & Ribonuclease A \\
\hline ROCC & Receptor-operated $\mathrm{Ca}^{2+}$ channel \\
\hline ROS & Reactive oxygen species \\
\hline Rps5 & Ribosomal protein subunit 5 \\
\hline RT-PCR & Real-time polymerase chain reaction \\
\hline RyR & Ryanodine-sensitive $\mathrm{Ca}^{2+}$ channel \\
\hline S1P & Sphingosine-1-phosphate \\
\hline SCaMPER & Sphingolipid $\mathrm{Ca}^{2+}$-release-mediating protein of ER \\
\hline SERCA & Sarcoplasmic/endoplasmic reticulum $\mathrm{Ca}^{2+}$ ATPase \\
\hline siRNA & Small interfering RNA \\
\hline SOCC & Store-operated $\mathrm{Ca}^{2+}$ channel \\
\hline SOD & Superoxide dismutase \\
\hline $\mathrm{Sr}^{2+}$ & Strontium \\
\hline SR & Sarcoplasmic reticulum \\
\hline STIM1 & Stromal interaction molecule 1 \\
\hline TBS & Tris-buffered solution \\
\hline TBS-T & TBS with $0.1 \%$ tween- 20 \\
\hline TMRM & Tetramethylrhodamine methyl ester \\
\hline TNF- $\alpha$ & Tumor necrosis factor-alpha \\
\hline TRP channel & Transient receptor potential channel \\
\hline UQ & Ubiquinone \\
\hline UTP & Uridine 5'-triphosphate \\
\hline VDAC & Voltage-dependent anion channel \\
\hline VDCC & Voltage-dependent $\mathrm{Ca}^{2+}$ channel \\
\hline VEGF & Vascular endothelial growth factor \\
\hline $\mathrm{XDH}$ & Xanthine dehydrogenase \\
\hline $\mathrm{XeC}$ & Xestospongin C. \\
\hline $\mathrm{XO}$ & Xanthine oxidase \\
\hline YFP & Yellow fluorescent protein \\
\hline${ }^{1} \mathrm{O}_{2}$ & Singlet oxygen \\
\hline 17-ODYA & 17-octadecynoic acid \\
\hline
\end{tabular}




\section{CHAPTER 1. INTRODUCTION*}

\section{1. $\quad \mathrm{Ca}^{2+}$ Signaling in Vascular Smooth Muscle Cells}

Calcium $\left(\mathrm{Ca}^{2+}\right)$ is a highly versatile signal transduction element in almost every cell type, controlling a wide variety of functions (Berridge, 2001; Bootman et al., 2001; Berridge, 2004). $\mathrm{Ca}^{2+}$ translates an array of extracellular stimuli, including hormones, neurotransmitters, and growth factors into distinct intracellular functions, varying from contraction to secretion, and from survival to differentiation. Under resting conditions, cytosolic $\mathrm{Ca}^{2+}$ concentration $\left(\left[\mathrm{Ca}^{2+}\right]_{\mathrm{i}}\right)$ is maintained at $\sim 100 \mathrm{nM}$, whereas the extracellular medium and intracellular stores contain more than $1 \mathrm{mM}$ (Rizzuto \& Pozzan, 2006). The difference in concentrations permits stimulation of rapid $\mathrm{Ca}^{2+}$ signals, to regulate various cellular responses. Under resting conditions, $\left[\mathrm{Ca}^{2+}\right]_{\mathrm{i}}$ is influenced by the regulation of several processes, which either introduce $\mathrm{Ca}^{2+}$ into or remove $\mathrm{Ca}^{2+}$ from the entire cytosol or a localized region of the cytosol (Bootman et al., 2001). Stimuli that elevate $\left[\mathrm{Ca}^{2+}\right]_{\mathrm{i}}$ cause $\mathrm{Ca}^{2+}$ influx from extracellular space and/or $\mathrm{Ca}^{2+}$ release from internal sources. Most of this $\mathrm{Ca}^{2+}$ is bound to buffers, whereas a small proportion of the $\mathrm{Ca}^{2+}$ binds to effector elements, leading to stimulation of numerous $\mathrm{Ca}^{2+}$-dependent processes (Berridge et al., 1998). Removal of $\mathrm{Ca}^{2+}$ from the cytosol occurs via various plasma membrane exchangers, which extrude $\mathrm{Ca}^{2+}$ into the extracellular space, or intracellular pumps, which recycle $\mathrm{Ca}^{2+}$ back into organelles (Berridge et al., 1998). Interplay between these opposing processes is responsible for the maintenance of $\left[\mathrm{Ca}^{2+}\right]_{\mathrm{i}}$ and modulation of $\mathrm{Ca}^{2+}$-dependent functions (Bootman et al., 2001).

To influence different cellular functions, $\mathrm{Ca}^{2+}$ signals are flexibly and precisely regulated with regard to space, time, and amplitude (Berridge et al., 1998). Spatial distribution of $\mathrm{Ca}^{2+}$ signals occur due to differences in $\mathrm{Ca}^{2+}$ sources, including $\mathrm{Ca}^{2+}$ entry from extracellular medium through plasma membrane ion channels, and $\mathrm{Ca}^{2+}$ release from internal stores (Berridge et al., 2003). Diffusion of $\mathrm{Ca}^{2+}$ from one cellular compartment to another, and localization of a $\mathrm{Ca}^{2+}$ signal to a specific cellular region also contribute to spatial heterogeneity. Temporal organization of $\mathrm{Ca}^{2+}$ signals occurs by modulation of the frequency of $\mathrm{Ca}^{2+}$ signals, leading to variations in intensity and nature of cellular process (Berridge et al., 2003). Changes in amplitude or concentration of $\mathrm{Ca}^{2+}$ also serve to differentially influence specific functions. The spatiotemporal organization of $\mathrm{Ca}^{2+}$ signals influences the diversity of $\mathrm{Ca}^{2+}$ signals, controls recruitment of different intracellular components, and regulation of specific cellular functions (Berridge, 2001; Bootman et al., 2001; Berridge, 2004).

* Portions of this chapter adapted with permission. Narayanan D, Xi Q, Pfeffer LM, \& Jaggar JH (2010). Mitochondria control functional $\mathrm{Ca}_{\mathrm{V}} 1.2$ expression in smooth muscle cells of cerebral arteries. Circ Res 107, 631-641. 


\section{2. $\mathrm{Ca}^{2+}$ Transport Mechanisms across Plasma Membrane}

$\mathrm{Ca}^{2+}$ entry from the extracellular medium occurs through plasma membrane ion channels in response to a wide variety of stimuli, including membrane depolarization, stretch, noxious stimuli, extracellular agonists, intracellular messengers, and the depletion of intracellular stores (Berridge et al., 2003). Under physiological conditions, the membrane potential of smooth muscle cells from resistance-size arteries is $\sim 45 \mathrm{mV}$ (Knot \& Nelson, 1998). The negative membrane potential, coupled with a high extracellular $\mathrm{Ca}^{2+}$ concentration creates a considerable electrochemical gradient across the plasma membrane, which drives $\mathrm{Ca}^{2+}$ entry through ion channels on the plasma membrane. Based on the mechanism of activation, several different types of $\mathrm{Ca}^{2+}$ influx channels have been found in vascular smooth muscle cells - voltage-dependent $\mathrm{Ca}^{2+}$ channels (VDCCs), receptor-operated $\mathrm{Ca}^{2+}$ channels (ROCCs), and store-operated $\mathrm{Ca}^{2+}$ channels (SOCCs) (Bootman et al., 2001). Two $\mathrm{Ca}^{2+}$ efflux mechanisms that exist are the plasma membrane $\mathrm{Ca}^{2+}$-adenosine 5'-triphosphatase (ATPase) (PMCA) and sodium $\left(\mathrm{Na}^{+}\right) / \mathrm{Ca}^{2+}$ exchanger (NCX).

\subsubsection{Voltage-dependent $\mathrm{Ca}^{2+}$ channels}

VDCCs open in response to membrane depolarization, permitting rapid $\mathrm{Ca}^{2+}$ entry to regulate numerous physiological functions, including excitation-contraction coupling, excitation-secretion coupling, neurotransmitter release, gene expression, and hormone secretion (Halling et al., 2005; Liao et al., 2005). VDCCs are hetero-oligomeric protein complexes, composed of an $\alpha_{1}$ subunit in association with auxiliary $\beta, \alpha_{2} \delta$, and $\gamma$ subunits (Liao et al., 2005). The 190-250 kilodalton $(\mathrm{kDa}) \alpha_{1}$ subunit is the autonomous poreforming subunit, comprising four membrane-spanning domains, with each domain consisting of six transmembrane segments (S1-S6) (Liao et al., 2005). The S4 segment contains three to five positively charged amino acids and serves as the voltage sensor of the channel (Liao et al., 2005). The $\alpha_{1}$ subunit also contains binding sites for dihydropyridines. An intracellular $\beta$ subunit, a transmembrane, disulfide-linked $\alpha_{2} \delta$ subunit, and a $\gamma$ subunit interact with the $\alpha_{1}$ subunit to regulate its expression and characteristics, such as activity and membrane trafficking of the channel (Liao et al., 2005). Based on the homology of their sequences, VDCCs are classified into three families - Cav1 (L-type), Cav2 (P/Q-, N-, and R-type), and Ca 3 (T-type) (Catterall, 2000; Ertel et al., 2000). VDCC $\alpha_{1}$ subunits are encoded by ten genes. Based on the $\alpha_{1}$ subunit, there are four types of $\mathrm{Ca}_{\mathrm{V}} 1$ channels. $\mathrm{Ca}_{\mathrm{V}} 1.1\left(\alpha_{1 \mathrm{~S}}\right)$ expressed in skeletal muscle cells, Cav1.2 $\left(\alpha_{1 C}\right)$ expressed in heart, vascular, and visceral smooth muscle cells, Cav1.3 $\left(\alpha_{1 \mathrm{D}}\right)$ expressed in brain, and $\mathrm{Ca}_{\mathrm{V}} 1.4\left(\alpha_{1 \mathrm{~F}}\right)$ expressed in the retina (Ertel et al., 2000).

$\mathrm{Ca}_{\mathrm{V}} 1.2$ channel is the major VDCC isoform and the primary $\mathrm{Ca}^{2+}$ entry pathway expressed in vascular smooth muscle cells (Gollasch \& Nelson, 1997). Molecular diversity of $\mathrm{Ca}_{\mathrm{V}} 1.2$ channels is achieved by alternative gene splicing and transcriptional regulation by different promoters in the 5' flanking regions of $\alpha_{1 \mathrm{C}}$ gene. This has given rise to exon $1 \mathrm{a}$, exon $1 \mathrm{~b}$, and exon $1 \mathrm{c}$ in the $\mathrm{N}$-terminus of $\alpha_{1 \mathrm{C}}$ subunit of $\mathrm{Ca}_{\mathrm{V}} 1.2$ in vascular smooth muscle cells (Cheng et al., 2007). The $\alpha_{1 \mathrm{C}}$ subunit of Cav1.2 is 
synthesized as a $\sim 240 \mathrm{kDa}$ protein which is proteolytically cleaved in its C-terminal domain by enzymes, including calpain to yield $\sim 190$ and $50 \mathrm{kDa}$ products (Gerhardstein et al., 2000). The $50 \mathrm{kDa}$ C-terminal product reassociates with the $190 \mathrm{kDa}$ channel to form the fully functional $\mathrm{Ca}_{\mathrm{v}} 1.2$ channel.

Activation of $\mathrm{Ca}_{\mathrm{v}} 1.2$ channels by membrane depolarization, leads to $\mathrm{Ca}^{2+}$ influx, $\left[\mathrm{Ca}^{2+}\right]_{\mathrm{i}}$ elevation, and vasoconstriction (Berridge, 2001; Cheng et al., 2007). $\mathrm{Ca}^{2+}$ influx also stimulates $\mathrm{Ca}^{2+}$ release from intracellular stores. In small, resistance-sized arteries and arterioles, $\mathrm{Ca}_{\mathrm{V}} 1.2$ channels are essential for myogenic tone development and blood pressure regulation (Cheng et al., 2007). Hypertension is associated with an elevation in arterial smooth muscle cell $\mathrm{Ca}_{v} 1.2$ expression, which leads to increased $\mathrm{Ca}^{2+}$ influx, $\left[\mathrm{Ca}^{2+}\right]_{\mathrm{i}}$ elevation, and vasoconstriction (Wang et al., 2006). L-type $\mathrm{Ca}^{2+}$ channel blockers are widely used to treat hypertension because of their ability to reduce arterial smooth muscle cell contractility (Triggle, 2006).

Vascular smooth muscle cells also express $\mathrm{Ca}_{\mathrm{v}} 1.3, \mathrm{Ca}_{\mathrm{v}} 2.1, \mathrm{Ca}_{\mathrm{v}} 3.1$, and $\mathrm{Ca}_{\mathrm{v}} 3.2$ channels. $\mathrm{Ca}^{2+}$ influx through these channels make a minor contribution to $\left[\mathrm{Ca}^{2+}\right]_{\mathrm{i}}$ in vascular smooth muscle cells.

\subsubsection{Store-operated $\mathrm{Ca}^{2+}$ channels}

SOCCs are plasma membrane, non-selective, cation channels that are activated in response to depletion of intracellular $\mathrm{Ca}^{2+}$ stores (Bootman et al., 2001). Although, the precise mechanisms are presently unclear, there exist two major theories which attempt to elucidate the activation mechanism of SOCCs. According to these schemes, SOCCs are activated by either a conformational coupling between $\mathrm{Ca}^{2+}$ channels on the SR and those on the plasma membrane, or $\mathrm{SR} \mathrm{Ca}^{2+}$ depletion stimulates a second messenger, which activates plasma membrane $\mathrm{Ca}^{2+}$ channels (Bootman et al., 2001).

The molecular identities of SOCCs are presently unclear. Many of the SOCCs are speculated to belong to the large transient receptor potential (TRP) channel family, which were first identified in Drosophila (Beech et al., 2004). The mammalian TRP channel superfamily that is subdivided into 7 families, is encoded by at least 28 different genes (Beech et al., 2004). Vascular smooth muscle cells express at least members of three TRP families, including TRPC (1, 3, 4, 5, 6, and 7), TRPM (2, 4, 7, and 8), and TRPV (2 and 4) (Earley \& Brayden, 2010). TRP channels, which are permeable to $\mathrm{Ca}^{2+}, \mathrm{Na}^{+}$, potassium $\left(\mathrm{K}^{+}\right)$, and magnesium $\left(\mathrm{Mg}^{2+}\right)$, regulate multiple functions in arterial smooth muscle cells, including membrane potential, $\left[\mathrm{Ca}^{2+}\right]_{\mathrm{i}}$, contractility, and proliferation (Beech et al., 2004; Adebiyi et al., 2010). Recent studies have identified two other proteins, including Orail and stromal interaction molecule (STIM)1 which regulate storeoperated $\mathrm{Ca}^{2+}$ entry in smooth muscle cells (Guibert et al., 2008). Orail is a plasma membrane protein which has been suggested to be the pore subunit of store-operated current (Guibert et al., 2008). STIM1 is primarily an endoplasmic reticulum (ER) membrane protein but it is also present in the plasma membrane (Guibert et al., 2008). Few studies have suggested that SOCCs comprise an assembly of proteins, including 
TRPC, STIM1 and Orai1 present in the plasma membrane (Guibert et al., 2008).

In smooth muscle cells, the regulation, ion selectivity, and conductance of storeoperated cation currents differ in anatomically diverse blood vessels (Xi et al., 2008). In rat cerebral artery smooth muscle cells, the preparation used in this study, there is very little evidence for SOCCs. $\mathrm{Ca}^{2+}$ depletion of sarcoplasmic reticulum (SR) by thapsigargin, an SR Ca ${ }^{2+}$ ATPase inhibitor (Lytton et al., 1991) resulted in vasoconstriction at $60 \mathrm{~mm} \mathrm{Hg}$ but not at $20 \mathrm{~mm} \mathrm{Hg}$ of intravascular pressure, indicating that $\mathrm{SR} \mathrm{Ca}^{2+}$ depletion-induced current is pressure-dependent (Xi et al., 2008). SR Ca ${ }^{2+}$ depletion has been suggested to constrict cerebral arteries by inhibiting $\mathrm{Ca}^{2+}$ sparks and large conductance $\mathrm{Ca}^{2+}$-activated $\mathrm{K}^{+}\left(\mathrm{K}_{\mathrm{Ca}}\right)$ channels, which are activated by an elevation in intravascular pressure (Xi et al., 2008).

\subsubsection{Receptor-operated $\mathrm{Ca}^{2+}$ channels}

ROCCs comprise a range of structurally and functionally diverse channels that exist in many cells, including vascular smooth muscle cells (Bootman et al., 2001). They are $\mathrm{Ca}^{2+}$-permeable, non-selective, cation channels activated by the binding of an agonist to the extracellular domain (Bootman et al., 2001). In vascular smooth muscle cells, a wide variety of agonists, including adenosine 5'-triphosphate (ATP), serotonin, norepinephrine (NE), acetylcholine, endothelin-1 (ET-1), vasopressin, glutamate, and angiotensin II (Ang II) activate ROCCs, and induce $\mathrm{Ca}^{2+}$ entry (Large, 2002). Apart from the P2X1 receptor, an ATP-gated cation channel, other receptor-operated currents are likely to be mediated via G-protein-coupled receptors, and some through tyrosine kinases (Large, 2002). In guinea pig aorta, $\mathrm{NE}$-induced $\mathrm{Ca}^{2+}$ influx was only partially blocked by $\mathrm{Ca}^{2+}$ channel blockers (Gouw et al., 1990). In rat cultured aortic smooth muscle cells, ATP, Ang II, and vasopressin cause ${ }^{45} \mathrm{Ca}^{2+}$ influx that is independent of membrane depolarization and unaffected by $\mathrm{Ca}^{2+}$ channel antagonists, but reduced by phospholipase C (PLC) inhibitors (Ruegg et al., 1989).

Several TRP channels, including TRPC4, TRPC5, and heteromultimeric complex of TRPC6 and TRPC7 can be activated by various stimuli, such as vasopressin (Plant \& Schaefer, 2003; Earley, 2006; Maruyama et al., 2006) suggesting that TRP channels could also act as ROCCs.

\subsubsection{Other $\mathrm{Ca}^{2+}$ entry channels}

Apart from VDCCs, SOCCs, and ROCCs, $\mathrm{Ca}^{2+}$ influx could occur through other pathways. One example is the stretch-activated cation channels which allow $\mathrm{Ca}^{2+}$ entry and regulate cell contractility (Bootman et al., 2001; Hill et al., 2001). In isolated vascular smooth muscle cells, longitudinal stretch activates a non-selective, inward cation conductance (Hill et al., 2001). Therefore, it is accepted that stretch activation contributes to membrane depolarization, leading to activation of VDCCs (Hill et al., 2001). Mechanical disturbance of cell membranes also releases factors that modulate the 
activity of stretch-activated channels (Hill et al., 2001). Second messengers, including fatty acids, arachidonic acid metabolites, diacylglycerol (DAG), and cyclic nucleotides have been suggested to activate channels by regulating ion channel gating (Hill et al., 2001).

\subsubsection{Plasma membrane $\mathrm{Ca}^{2+}$-ATPases}

PMCA extrude $\mathrm{Ca}^{2+}$ from cytosol to the extracellular compartment using energy derived from ATP hydrolysis to pump $\mathrm{Ca}^{2+}$ against the steep electrochemical gradient (Berridge, 2001). The C-terminus contains a calmodulin (CaM)-binding domain, which acts as an autoinhibitory domain and maintains the pump in an inactive state (Sanders, 2001). Binding of CaM removes the inhibition and stimulates pump activity (Sanders, 2001). Phosphorylation by protein kinases, including protein kinase A (PKA) and G (PKG) also reduces autoinhibition and facilitates $\mathrm{Ca}^{2+}$ transport (Sanders, 2001).

Four isoforms of PMCAs (1-4) are widely expressed (Bootman et al., 2001). Vascular smooth muscle cells express PMCA1 and PMCA4 (Abramowitz et al., 2000). PMCA4b inhibits neuronal nitric oxide synthase (nNOS), by binding of its C-terminus to the PDZ domain of nNOS (Schuh et al., 2001). Transgenic mice overexpressing PMCA4b in vascular smooth muscle cells are associated with elevated peripheral blood pressure due to inhibition of nNOS activity (Gros et al., 2003). Mesenteric arteries from these transgenic mice display more prominent myogenic response and elevated responses to vasoconstrictors, including phenylephrine and prostaglandin $\mathrm{F}_{2 \alpha}$ (Gros et al., 2003). PMCAs localize in caveolae of visceral smooth muscle cells, endothelial cells, and rat cardiomyocytes, but whether similar localization occurs in vascular smooth muscle cells is unclear.

\subsubsection{Plasma membrane $\mathrm{Na}^{+} / \mathrm{Ca}^{2+}$ exchanger}

$\mathrm{NCX}$ is an integral plasma membrane protein which counter-transports $\mathrm{Ca}^{2+}$ in exchange for $\mathrm{Na}^{+}$, utilizing the $\mathrm{Na}^{+}$gradient across the plasma membrane, generated by the $\mathrm{Na}^{+} / \mathrm{K}^{+}$-ATPase (NKA), as an energy source (Bootman et al., 2001). The mammalian NCX family comprises three isoforms NCX (1-3) with numerous splice variants.

Vascular smooth muscle cells predominantly expresses NCX1.3 and NCX1.7 (Quednau et al., 1997). NCXs function either to pump one molecule of $\mathrm{Ca}^{2+}$ out (forward mode) of cells, or into cells (reverse mode) in exchange for three molecules of $\mathrm{Na}^{+}$. NCX activity is regulated by membrane potential, ATP, and transmembrane gradients of $\mathrm{Na}^{+}$and $\mathrm{Ca}^{2+}$ (Iwamoto et al., 2005). In vascular smooth muscle cells, NCXs are colocalized with NKA on the plasma membrane near the SR, suggesting that NCX/NKA can functionally operate with SERCA (Ishida \& Paul, 2005). Under physiological conditions, high extracellular $\mathrm{Na}^{+}$concentration stimulates NCX to pump $\mathrm{Ca}^{2+}$ out of cells. Cardiovascular diseases, including hypertension are associated with improper functioning of NCX. High salt diet inhibits NKA, leading to elevated submembrane $\mathrm{Na}^{+}$levels, resulting in NCX functioning in the reverse mode. $\mathrm{Ca}^{2+}$ influx through NCX increases 
$\left[\mathrm{Ca}^{2+}\right]_{\mathrm{i}}$ and may contribute to salt-sensitive hypertension (Iwamoto et al., 2005). Aortic smooth muscle cells from spontaneously hypertensive rats are associated with elevated NCX1 expression and enhanced Ang II-induced $\mathrm{Ca}^{2+}$ efflux via NCX (Ishida \& Paul, 2005).

\subsection{Intracellular $\mathrm{Ca}^{2+}$ Stores}

Cytosol of smooth muscle cell is packed with myofilaments and intermediate filaments, occupying up to $90 \%$ of the cell volume with the intracellular organelles sharing the remaining space (Wray \& Burdyga, 2010). Intracellular stores contain a high $\mathrm{Ca}^{2+}$ concentration, and release $\mathrm{Ca}^{2+}$ into the cytosol upon stimulation and opening of $\mathrm{Ca}^{2+}$ channels on their membrane. SR, a rich reticular network, which occupies $\sim 5 \%$ of cell volume, is the major intracellular $\mathrm{Ca}^{2+}$ source (Wray \& Burdyga, 2010). Apart from the SR, mitochondria can store and release $\mathrm{Ca}^{2+}$.

\subsubsection{Sarcoplasmic reticulum}

In vascular smooth muscle cells, $\mathrm{Ca}^{2+}$ release from the SR occurs through inositol 1,4,5-triphosphate $\left(\mathrm{IP}_{3}\right)$ receptors $\left(\mathrm{IP}_{3} \mathrm{R}\right)$ and ryanodine-sensitive $\mathrm{Ca}^{2+}$ release (RyR) channels. $\mathrm{Ca}^{2+}$ release from these channels are regulated by a collection of messengers, including $\mathrm{Ca}^{2+}, \mathrm{IP}_{3}$, cyclic ADP ribose (cADPR), nicotinic acid adenine dinucleotide phosphate (NAADP), and sphingosine-1-phosphate (S1P), that operate on both the luminal and cytosolic surfaces of the channel (Berridge et al., 2003).

Sarcoplasmic/endoplasmic reticulum $\mathrm{Ca}^{2+}$ ATPase (SERCA), which is located on the SR membrane pumps $\mathrm{Ca}^{2+}$ from the cytosol into the SR (Inesi, 1987).

\subsubsection{Ryanodine-sensitive $\mathrm{Ca}^{2+}$ release channels}

RyR channels specifically bind the plant alkaloid ryanodine, which is the reason for its name (Jaggar et al., 2000). Three molecularly distinct RyR isoforms (1-3), encoded by distinct genes, are present in a variety of tissues (Jaggar et al., 2000). RyR1 is expressed primarily in skeletal muscle, whereas RyR2 and RyR3 are found in cardiac muscle and brain, respectively (Jaggar et al., 2000). All three RyR isoforms are expressed in smooth muscles of pulmonary and systemic vessels, with variations in the type and the relative proportion of each being tissue- and species-dependent (Wray \& Burdyga, 2010). In rat cerebral artery smooth muscle cells, RyR2 is the predominant isoform (Vaithianathan et al., 2010).

Each of these isoforms exists as a homotetramer with the subunits surrounding a central $\mathrm{Ca}^{2+}$ pore (Jaggar et al., 2000; Wray \& Burdyga, 2010). The subunits are associated with FK-506-binding protein (FKBP), a regulatory protein. The pore-forming, membrane-spanning regions are localized to the C-terminus (Wray \& Burdyga, 2010). The cytosolic N-terminus, which is the modulatory region, contains phosphorylation sites 
and binding sites for $\mathrm{Ca}^{2+}$, adenine nucleotides, CaM, and FKBP. RyRs are approximately twice as large as $\mathrm{IP}_{3} \mathrm{R}$ (Wray \& Burdyga, 2010). Because of their massive size, RyR is suitable for sudden and large release of SR Ca ${ }^{2+}$ (Wray \& Burdyga, 2010).

The principal endogenous modulator of RyR activity is $\mathrm{Ca}^{2+}$, which upon binding can activate or inhibit the channels. Low cytosolic $\mathrm{Ca}^{2+}$ concentrations (nM to $\mu \mathrm{M}$ ) activate RyR, whereas high cytosolic $\mathrm{Ca}^{2+}$ concentrations ( $\mu \mathrm{M}$ to $\mathrm{mM}$ ) inhibit RyRs (Bootman et al., 2001). Similarly, ryanodine at low concentrations (1-10 $\mu \mathrm{M})$ locks RyRs into a long-lived subconductance state, leading to $\mathrm{Ca}^{2+}$ release over a prolonged period of time and eventually SR $\mathrm{Ca}^{2+}$ depletion. At high concentrations $(\sim 100 \mu \mathrm{M})$, ryanodine irreversibly inhibits RyR channel opening. RyR channels have to be activated for ryanodine to bind to them (Bootman et al., 2001). Millimolar concentrations of caffeine activate RyRs by increasing the sensitivity of $\mathrm{RyRs}_{\mathrm{R}}$ to $\mathrm{Ca}^{2+}$, resulting in basal $\mathrm{Ca}^{2+}$ concentrations to become activatory and stimulate further $\mathrm{Ca}^{2+}$ release (Bootman et al., 2001). Changes in the SR luminal $\mathrm{Ca}^{2+}$ concentration, which is $\sim 1 \mathrm{mM}$ can activate RyRs (Bootman et al., 2001). Activation of SERCA, which is responsible for maintaining SR Ca ${ }^{2+}$ load, activates RyR by increasing luminal $\mathrm{Ca}^{2+}$ concentration (Bootman et al., 2001). cADPR is an endogenous cellular messenger that causes RyRmediated $\mathrm{SR} \mathrm{Ca}^{2+}$ release. The precise mechanism by which cADPR activates RyR is unclear. It has been suggested that cADPR binds to the inhibitory protein FKBP, resulting in increasing the open probability of RyR (Bootman et al., 2001). cADPR could also activate SERCA, leading to an increase in SR $\mathrm{Ca}^{2+}$ load, resulting in RyR activation (Lukyanenko et al., 2001). RyR channels can also be regulated by several protein kinases and phosphatases, including PKA, protein kinase $\mathrm{C}(\mathrm{PKC}), \mathrm{PKG}, \mathrm{CaM}$ kinase II, and protein phosphatase 1 (Jaggar et al., 2000; Bootman et al., 2001; Wray \& Burdyga, 2010).

\subsubsection{Inositol 1,4,5-triphosphate receptors}

Binding of ligands, including hormones, and growth factors to plasma membrane $\mathrm{G}_{\mathrm{q}}$ protein-coupled receptors activates PLC, leading to hydrolysis of phosphatidylinositol 4,5-biphosphate $\left(\mathrm{PIP}_{2}\right)$ to produce $\mathrm{IP}_{3}$ and DAG (Bootman et al., 2001). $\mathrm{IP}_{3}$ binds to $\mathrm{IP}_{3} \mathrm{R}$-gated $\mathrm{Ca}^{2+}$ channels on the $\mathrm{SR}$, leading to $\mathrm{Ca}^{2+}$ release. DAG serves as an intracellular messenger to activate PKC (Bootman et al., 2001).

Distinct genes encode each of the three $\mathrm{IP}_{3} \mathrm{R}$ isoforms (1-3) (Wray \& Burdyga, 2010). $\mathrm{IP}_{3} \mathrm{R}$ isoforms, which are structurally and functionally related, differ in their sensitivities to destruction by intracellular proteases, with $\mathrm{IP}_{3} \mathrm{R} 1$ and $\mathrm{IP}_{3} \mathrm{R} 3$ being more susceptible to breakdown than $\mathrm{IP}_{3} \mathrm{R} 2$ (Wray \& Burdyga, 2010). $\mathrm{IP}_{3} \mathrm{Rs}$ are extensively expressed in brain and other tissues including vascular smooth muscles. In vascular smooth muscles, $\mathrm{IP}_{3} \mathrm{R}$ density is $\sim 100$ times less than that in the brain, and the stoichiometric ratio of $\mathrm{IP}_{3}$ Rs to RyRs is 3-4:1 (Wray \& Burdyga, 2010). Smooth muscle cells express multiple $\mathrm{IP}_{3} \mathrm{R}$ isoforms (Zhao et al., 2008; Wray \& Burdyga, 2010). $\mathrm{IP}_{3} \mathrm{R} 1$ has been found in rat aorta, basilar, and mesenteric arteries, whereas $I_{3} R 2$ and $I_{3} R 3$ have been detected in basilar artery and a cell line derived from rat aorta, respectively 
(Wray \& Burdyga, 2010). $\mathrm{IP}_{3} \mathrm{R} 1$ is the predominant isoform expressed in smooth muscle cells of resistance-size cerebral arteries (Zhao et al., 2008).

$\mathrm{IP}_{3} \mathrm{Rs}$ are tetrameric, with a monomeric mass of $\sim 300 \mathrm{kDa}$, containing $\sim 2700$ amino acids (Wray \& Burdyga, 2010). $\mathrm{IP}_{3} \mathrm{Rs}$ can form either homo- or hetero-tetramer, although reports suggesting $\mathrm{IP}_{3} \mathrm{R}$ as a heterotetramer complex have been derived from cell lines (Patterson et al., 2004). The $\mathrm{IP}_{3} \mathrm{R}$ structure can be divided to two regions. The C-terminal end of $\mathrm{IP}_{3} \mathrm{R}$ contains the $\mathrm{Ca}^{2+}$ channel region, which shares sequence homology with that of the RyR (Patterson et al., 2004). The C-terminal region consists of six membrane-spanning helices with the C-terminus projecting into the cytosol (Patterson et al., 2004). The N-terminal region which also extends to the cytosol, contains the $\mathrm{IP}_{3}$-binding site (Patterson et al., 2004). The modulatory domain, which contains binding sites for $\mathrm{Ca}^{2+}$, nucleotides, $\mathrm{CaM}$, and protein kinases is located between the ligand-binding domain and the channel pore (Patterson et al., 2004).

The principal mechanism which results in $\mathrm{IP}_{3} \mathrm{R}$-mediated $\mathrm{SR} \mathrm{Ca}^{2+}$ release, is the interaction of $\mathrm{IP}_{3}$ with $\mathrm{IP}_{3} \mathrm{R}$ (Bootman et al., 2001). $\mathrm{IP}_{3}$ produced at the plasma membrane is highly mobile and diffuses in the cytosol to bind $\mathrm{IP}_{3} \mathrm{R}$ on the SR membrane (Bootman et al., 2001). Binding of $\mathrm{IP}_{3}$ induces a conformational change in $\mathrm{IP}_{3} \mathrm{R}$, resulting in channel opening and release of $\mathrm{Ca}^{2+}$, which is stored at high concentrations in the SR (Patterson et al., 2004). Although binding of $\mathrm{IP}_{3}$ is essential for $\mathrm{IP}_{3} \mathrm{R}$ activation, $\mathrm{Ca}^{2+}$ concentration at their cytosolic side also regulate $\mathrm{IP}_{3} \mathrm{R}$ activity, thereby permitting $\mathrm{IP}_{3} \mathrm{R}$-mediated $\mathrm{Ca}^{2+}$ release to regulate further $\mathrm{Ca}^{2+}$ release (Patterson et al., 2004). Binding of $\mathrm{IP}_{3}$ increases the $\mathrm{IP}_{3} \mathrm{R}$ sensitivity to $\mathrm{Ca}^{2+}$, which has a biphasic action (Patterson et al., 2004). At low $\mathrm{IP}_{3}$ levels $(<100 \mathrm{nM}), \mathrm{IP}_{3} \mathrm{Rs}$ are stimulated by $\mathrm{Ca}^{2+}$ concentrations between 100 and $300 \mathrm{nM}$, whereas inhibited by cytosolic $\mathrm{Ca}^{2+}$ concentrations $>1 \mu \mathrm{M}$ (Worley et al., 1987; Bootman et al., 2001). At high $\mathrm{IP}_{3}$ levels $(>100 \mathrm{nM})$, very high $\mathrm{Ca}^{2+}$ concentration is required to induce inhibition of $\mathrm{IP}_{3} \mathrm{R}$ (Berridge, 2001). $\mathrm{Ca}^{2+}$-dependence of $\mathrm{IP}_{3} \mathrm{R}$ activity is important for the generation of complex patterns of $\mathrm{Ca}^{2+}$ signals seen. SR luminal $\mathrm{Ca}^{2+}$ can also regulate $\mathrm{IP}_{3} \mathrm{R}$ activity, whereby a reduced $\mathrm{SR} \mathrm{Ca}^{2+}$ load, leads to a decrease in $\mathrm{IP}_{3}$-induced $\mathrm{Ca}^{2+}$ release (Patterson et al., 2004). In permeabilized hepatocytes, $\mathrm{IP}_{3} \mathrm{R}$ is inactivated by $\mathrm{IP}_{3}$, and this effect is enhanced by cytosolic $\mathrm{Ca}^{2+}$, suggesting that $\mathrm{IP}_{3}$ and $\mathrm{Ca}^{2+}$ inhibit $\mathrm{IP}_{3} \mathrm{R}$, resulting in limiting the $\mathrm{IP}_{3} \mathrm{R}$-mediated $\mathrm{SR} \mathrm{Ca}^{2+}$ release (Hajnoczky \& Thomas, 1994). Certain SR luminal proteins, including calreticulin and calnexin, which are $\mathrm{Ca}^{2+}$-binding proteins are also known to interact with $\mathrm{IP}_{3} \mathrm{R}$ and regulate their activity (Berridge, 2001). $\mathrm{IP}_{3} \mathrm{R}$ activity can also be modulated by other signaling pathways, including phosphorylation by PKA, PKC, PKG, and CaM kinase II (Bootman et al., 2001).

In smooth muscle cells of resistance-size cerebral arteries, $\mathrm{IP}_{3} \mathrm{R} 1$ activation also induces physical coupling of the $\mathrm{N}$-terminus of $\mathrm{IP}_{3} \mathrm{R} 1$ and the $\mathrm{C}$-terminus of plasma membrane TRPC3 channel, leading to non-selective cation current $\left(\mathrm{I}_{\text {Cat }}\right)$ activation. $\mathrm{IP}_{3} \mathrm{R}$ dependent $\mathrm{I}_{\mathrm{Cat}}$ activation produces membrane depolarization, $\mathrm{Ca}_{\mathrm{V}} 1.2$ channel activation, and global $\left[\mathrm{Ca}^{2+}\right]_{i}$ elevation (Xi et al., 2008; Zhao et al., 2008; Adebiyi et al., 2010). This is an additional mechanism by which $\mathrm{IP}_{3} \mathrm{R}$ activation contributes to global $\left[\mathrm{Ca}^{2+}\right]_{\mathrm{i}}$ elevation in arterial smooth muscle cells. 


\subsubsection{Sarcoplasmic/endoplasmic reticulum $\mathrm{Ca}^{2+}$ ATPases}

Three mammalian isoforms of SERCA (1-3) exist and splice variants have been reported in each of the isoforms (Rizzuto et al., 1993). SERCA2a, 2b, and 3 are the isoforms expressed in vascular smooth muscle cells, with SERCA2 $\mathrm{b}$ being the major isoform (Wu et al., 2001; Ishida \& Paul, 2005).

SERCA transports two molecules of $\mathrm{Ca}^{2+}$ into the SR using the energy from the hydrolysis of one molecule of ATP (Inesi, 1987). Counter-transport of two or three hydrogen $\left(\mathrm{H}^{+}\right)$ions into the cytosol ensures partial charge balancing (Levy et al., 1990). In smooth muscle cells, the locations of $\mathrm{Ca}^{2+}$ release and re-uptake by the SERCA on the SR membrane are spatially separated (Floyd \& Wray, 2007). $\mathrm{Ca}^{2+}$-binding proteins in the SR lumen regulate SERCA activity to attain a free $\mathrm{Ca}^{2+}$ concentration of $\sim 500 \mu \mathrm{M}$. In uterine smooth muscle cells, overloading the $\mathrm{SR}$ with $\mathrm{Ca}^{2+}$ did not alter, whereas reducing $\mathrm{SR} \mathrm{Ca}^{2+}$ load, inhibited $\mathrm{IP}_{3}$-induced $\mathrm{Ca}^{2+}$ signals, suggesting that the ability of SR to store $\mathrm{Ca}^{2+}$ is finite (Floyd \& Wray, 2007).

Phospholamban (PLN) endogenously inhibits SERCA through direct proteinprotein interactions by lowering its apparent $\mathrm{Ca}^{2+}$ affinity (Wray \& Burdyga, 2010). PLN is phosphorylated by PKA or CaM kinase, leading to removal of the inhibition, resulting in an increase in SERCA activity (Ishida \& Paul, 2005; Wray \& Burdyga, 2010). Sarcolipin, a PLN homolog, which inhibits SERCA by lowering its apparent $\mathrm{Ca}^{2+}$ affinity, is expressed in skeletal and cardiac muscles, but not in smooth muscle cells (Vangheluwe et al., 2005). SERCA activity is also controlled by regulators such as insulin-receptor substrate $1 / 2$, the $\mathrm{Ca}^{2+}$-binding protein $\mathrm{S} 100 \mathrm{~A} 1$, acylphosphatase, and the antiapoptotic protein Bc1-2 (Wray \& Burdyga, 2010).

\subsubsection{Mitochondria}

Intracellular $\mathrm{Ca}^{2+}$ signaling is also regulated by mitochondria which accumulate and retain $\mathrm{Ca}^{2+}$. Electron transport chain (ETC) complexes present on the inner mitochondrial membrane transfer electrons to molecular oxygen during oxidative phosphorylation. The electron transfer is coupled with translocation of protons into the intermembrane space, which creates and sustains the mitochondrial membrane potential $\left(\psi_{\mathrm{m}}\right)$ which is $\sim 150-200 \mathrm{mV}$ more negative than the cytosol (McCarron et al., 2006). This difference in potential between the cytosol and mitochondrial matrix, drives $\mathrm{Ca}^{2+}$ transport into the mitochondria (McCarron et al., 2006). Mitochondria act as a local, spatial buffering system, by regulating $\mathrm{Ca}^{2+}$ signals which arise from the SR or plasma membrane in many cells, including smooth muscle cells. Mitochondrial $\mathrm{Ca}^{2+}$ uptake occurs via the voltage-dependent anion channel (VDAC), mitochondrial $\mathrm{Ca}^{2+}$ uniporter (MCU), and rapid uptake mode (RaM) (Gunter et al., 2000). The mitochondrial permeability transition pore (mPTP) and the mitochondrial $\mathrm{Na}^{+} / \mathrm{Ca}^{2+}$ exchanger ( $\mathrm{mNCX}$ ) extrude $\mathrm{Ca}^{2+}$ from the mitochondrial matrix to the cytosol (Gunter et al., 2000). 


\subsubsection{Voltage-dependent anion channel}

$\mathrm{Ca}^{2+}$ transit through the outer mitochondrial membrane occurs through VDAC, the most abundant protein on the outer mitochondrial membrane. Mammals have three distinct VDAC isoforms (1-3). VDAC is an anion-selective channel, fully opened at low potential $(<20-30 \mathrm{mV})$, but switches to cation selectivity at higher potentials ("closed" state) (Colombini, 2004). In the resting condition, VDAC is closed and exhibits higher permeability to $\mathrm{Ca}^{2+}$, rather than in the opened state (Tan \& Colombini, 2007). In HeLa cells and skeletal myotubes, VDAC overexpression enhanced $\mathrm{Ca}^{2+}$ transport from SR into the mitochondrial matrix (Rapizzi et al., 2002). VDAC activity is regulated by several factors, including nicotinamide adenine dinucleotide (NADH), Bcl-2 proteins, chaperones, and cytoskeletal elements (Rizzuto et al., 2009).

\subsubsection{Mitochondrial $\mathrm{Ca}^{2+}$ uniporter}

MCU is a highly selective ion channel located on the inner mitochondrial membrane that transports $\mathrm{Ca}^{2+}$ from the cytosol into the mitochondrial matrix (Rizzuto et al., 2000). MCU has both an activation site as well as a transport site (Gunter \& Pfeiffer, 1990). MCU activation stimulates $\mathrm{Ca}^{2+}$ influx into the mitochondrial matrix due to the negative $\psi_{\mathrm{m}}$ (Rizzuto et al., 2000). MCU has low sensitivity to $\mathrm{Ca}^{2+}$ and is activated by $\mathrm{Ca}^{2+}$ concentrations $>3 \mu \mathrm{M}\left(\mathrm{K}_{\mathrm{m}} \sim 10 \mu \mathrm{M}\right)$ in the inter membrane space (Poburko et al., 2004). The velocity of $\mathrm{Ca}^{2+}$ uptake is near zero for external $\left[\mathrm{Ca}^{2+}\right]_{\mathrm{i}}<200-300 \mathrm{nM}$ (Poburko et al., 2004). $\left[\mathrm{Ca}^{2+}\right]_{\mathrm{i}}$ regulates MCU activity in a biphasic manner (Montero et al., 2004; Moreau et al., 2006). Studies in HeLa cells suggested that MCU activation by $\mathrm{Ca}^{2+}$ is mediated by the activation of $\mathrm{Ca}^{2+}$-dependent $\mathrm{CaM}$ and subsequently, CaM kinase II (Montero et al., 2004). Following activation, cytosolic $\mathrm{Ca}^{2+}$ elevation inactivates the MCU and limits mitochondrial $\mathrm{Ca}^{2+}$ uptake. This biphasic regulation of MCU activity by cytosolic $\mathrm{Ca}^{2+}$ occurs with MCU activation and $\mathrm{Ca}^{2+}$ uptake occurring with a time constant of $\sim 6$ seconds, while the $\mathrm{Ca}^{2+}$-dependent $\mathrm{MCU}$ inactivation occurs with a time constant of $\sim 17$ seconds. This mechanism permits oscillations in mitochondrial $\mathrm{Ca}^{2+}$ concentrations $\left(\left[\mathrm{Ca}^{2+}\right]_{\text {mito }}\right.$ ), but prevents excessive $\mathrm{Ca}^{2+}$ uptake when $\left[\mathrm{Ca}^{2+}\right]_{\mathrm{i}}$ elevation is prolonged (Moreau et al., 2006). Different PKC isoforms have been suggested to participate in the cytosolic $\mathrm{Ca}^{2+}$-mediated regulation of MCU activity (Rizzuto et al., 2009). Overexpression of uncoupling proteins, including UCP2 and UCP3 in an endothelial cell line enhanced mitochondrial $\mathrm{Ca}^{2+}$ uptake, and small interfering RNA (siRNA)-mediated knockdown decreased MCU activity and mitochondrial $\mathrm{Ca}^{2+}$ sequestration, suggesting that uncoupling proteins could be essential components of MCU (Trenker et al., 2007). MCU activity is inhibited by ruthenium red and its related compound Ru360, and adenine nucleotides (ATP>ADP>AMP) (Rizzuto et al., 2009).

\subsubsection{Rapid uptake mode}

$\mathrm{Ca}^{2+}$ pulses of physiological concentration $(\sim 400 \mathrm{nM})$ more effectively induce mitochondrial $\mathrm{Ca}^{2+}$ uptake compared to a steady $\left[\mathrm{Ca}^{2+}\right]_{\mathrm{i}}$ for the same overall time 
(Rizzuto et al., 2000; Rizzuto et al., 2009). RaM is a mechanism by which large amounts of $\mathrm{Ca}^{2+}$ are transported in short pulses at least 300 times faster than through the MCU (Rizzuto et al., 2000). The activity, identity, and regulation of RaM remains poorly understood. It is speculated that RaM transports $\mathrm{Ca}^{2+}$ only for a brief period during the initial part of the pulse, followed by inactivation induced by binding of $\mathrm{Ca}^{2+}$ to an external site (Rizzuto et al., 2009). RaM exhibits a high initial $\mathrm{Ca}^{2+}$ uptake velocity, and its steady-state uptake is inhibited at $\left[\mathrm{Ca}^{2+}\right]_{\mathrm{i}}>150-180 \mathrm{nM}$ (Gunter \& Gunter, 2001), suggesting that $\mathrm{RaM}$ functions in resting conditions to maintain basal $\left[\mathrm{Ca}^{2+}\right]_{\text {mito }}$ (Poburko et al., 2004).

\subsubsection{Mitochondrial permeability transition pore}

Mitochondria accumulate $\mathrm{Ca}^{2+}$ in the presence of adenine nucleotides. Depletion of adenine nucleotides in the presence of oxidants stimulates $\mathrm{Ca}^{2+}$ overload in the mitochondrial matrix. $\mathrm{Ca}^{2+}$ overload triggers opening of $\mathrm{mPTP}$, a high conductance, nonselective channel located in the inner-outer contact sites of the mitochondrial membranes (Rizzuto et al., 2000; Rizzuto et al., 2009). Several factors, including high $\left[\mathrm{Ca}^{2+}\right]_{\text {mito, }}$, mitochondrial depolarization, oxidative stress, adenine nucleotide depletion, and a high concentration of inorganic phosphate (Pi) stimulate mPTP opening (Duchen, 2000a; Rizzuto et al., 2009). mPTP opening is stimulated by $\mathrm{Ca}^{2+}$ influx into the mitochondrial matrix which binds to a site on the MPTP (Rizzuto et al., 2009). In the presence of high $\mathrm{Ca}^{2+}$ concentrations, cyclophilin $\mathrm{D}(\mathrm{CypD})$ binds to the inner mitochondrial membrane and to adenine nucleotide translocase (ANT), thus inhibiting ATP/adenosine 5'diphosphate (ADP) binding and inducing mPTP opening (Rizzuto et al., 2009). mPTP opening is inhibited by cyclosporine $\mathrm{A}$, and ions such as $\mathrm{Mg}^{2+}$, strontium $\left(\mathrm{Sr}^{2+}\right)$, and manganese $\left(\mathrm{Mn}^{2+}\right)$ (Rizzuto et al., 2009). The molecular identity of mPTP is unclear with studies speculating it to be a multi-protein complex comprising VDAC, ANT, and CypD, while others indicate that inhibiting one or more of these components does not affect mPTP activity (Duchen, 2000a; Rizzuto et al., 2009). Apoptosis which causes loss of mitochondrial components is associated with mPTP opening (Chang \& Yang, 2000; Rizzuto et al., 2009). Reversible mPTP openings have been observed both in individual isolated mitochondria (Huser et al., 1998) and in intact cells (Petronilli et al., 1999). However, it is unclear whether mPTP can function as a physiological mitochondrial $\mathrm{Ca}^{2+}$ release channel (Bernardi \& Petronilli, 1996).

\subsubsection{Mitochondrial $\mathrm{Na}^{+} / \mathrm{Ca}^{2+}$ exchanger}

mNCX mediates physiological $\mathrm{Ca}^{2+}$ cycling out of the mitochondrial matrix (Rizzuto et al., 2000). One molecule of $\mathrm{Ca}^{2+}$ is transported out of the mitochondria for every three molecules of $\mathrm{Na}^{+}$transported in (Rizzuto et al., 2000). Difference in $\mathrm{Na}^{+}$ concentration between the cytosol and mitochondria causes $\mathrm{Na}^{+}$influx into the mitochondrial matrix. $\mathrm{Na}^{+}$influx drives $\mathrm{Ca}^{2+}$ efflux out of the mitochondria into the cytosol. mNCX is inhibited by ions such as $\mathrm{Sr}^{2+}$, barium $\left(\mathrm{Ba}^{2+}\right), \mathrm{Mg}^{2+}$ or $\mathrm{Mn}^{2+}$, ruthenium red, and drugs, including antimycin A, amiloride, trifluoperazine, diltiazem, 
verapamil, clonazepam, bepridil and CGP37157 (Rizzuto et al., 2009). mNCX is inhibited by protonophores which disrupt $\psi_{\mathrm{m}}$, indicating that $\mathrm{mNCX}$ activity is regulated by the difference in potential between the cytosol and mitochondria (Rizzuto et al., 2000). Studies done in cultured vascular smooth muscle cells have found that CGP37157 , a selective $\mathrm{mNCX}$ inhibitor, increased resting $\left[\mathrm{Ca}^{2+}\right]_{\text {mito }}$ indicating that $\mathrm{mNCX}$ contributes to mitochondrial $\mathrm{Ca}^{2+}$ efflux in smooth muscle cells (Poburko et al., 2004).

\subsubsection{Other intracellular stores}

NAADP is formed from $\beta$-NADP ${ }^{+}$and $\beta-\mathrm{NAD}^{+}$by ADP ribosyl cyclases which also produce cADPR (Berridge, 2001). Unlike cADPR, NAADP does not activate RyR, but stimulates $\mathrm{Ca}^{2+}$ release from an internal store, which is distinct from the SR because $\mathrm{Ca}^{2+}$ depletion of SR does not affect NAADP-mediated $\mathrm{Ca}^{2+}$ release (Bootman et al., 2001). The mechanism(s) behind NAADP-mediated $\mathrm{Ca}^{2+}$ release and the channel identity remains unclear (Clapham, 1995).

Sphingolipids, including sphingosylphosphorylcholine and S1P stimulate $\mathrm{Ca}^{2+}$ release in several different cell types (Bootman et al., 2001). Sphingolipid-derived messengers are believed to be responsible for agonist-induced $\mathrm{SR} \mathrm{Ca}^{2+}$ signals that are generated independently of $\mathrm{IP}_{3} \mathrm{R}$ or RyR (Berridge et al., 2003). The exact mechanism for S1P-mediated $\mathrm{Ca}^{2+}$ release is unclear. The identity of the S1P receptor is believed to be the sphingolipid $\mathrm{Ca}^{2+}$-release-mediating protein of ER (SCaMPER), a $20 \mathrm{kDa}$ protein with a transmembrane domain (Bootman et al., 2001). In rat cerebral artery smooth muscle cells, plasma membrane S1P receptors activate PLC, leading to $\mathrm{IP}_{3} \mathrm{R}$ and RyR activation, resulting in $\mathrm{Ca}^{2+}$ release (Yatomi, 2006).

\subsection{Cytosolic $\mathrm{Ca}^{2+}$ Signals}

In arterial smooth muscle cells, four principal $\mathrm{Ca}^{2+}$ signaling modalities have been described: "Global intracellular $\mathrm{Ca}^{2+}$, " $\mathrm{Ca}^{2+}$ sparks", "Ca ${ }^{2+}$ sparklets", and " $\mathrm{Ca}^{2+}$ waves". These $\mathrm{Ca}^{2+}$ signals differ with respect to spatial localization, temporal kinetics, and amplitude properties (Jaggar et al., 2000; Lee et al., 2002; Wray et al., 2005). Several factors, including $\mathrm{Ca}^{2+}$ sensitivity and proximity to the source of a $\mathrm{Ca}^{2+}$ signal, influence whether proteins detect local or global $\mathrm{Ca}^{2+}$ signals (Jaggar, 2007).

\subsubsection{Global intracellular $\mathrm{Ca}^{2+}$}

Global $\left[\mathrm{Ca}^{2+}\right]_{\mathrm{i}}$ is the spatially averaged cytosolic $\left[\mathrm{Ca}^{2+}\right]_{\mathrm{i}}$. In arterial smooth muscle cells, an elevation in global $\left[\mathrm{Ca}^{2+}\right]_{\mathrm{i}}$ occurs because of $\mathrm{Ca}^{2+}$ influx through plasma membrane $\mathrm{Ca}^{2+}$ channels and $\mathrm{Ca}^{2+}$ release from the SR through $\mathrm{IP}_{3} \mathrm{R}$ channels (Jaggar $e t$ al., 2000; Zhao et al., 2008). Either of these events which produce an initial rise in global $\left[\mathrm{Ca}^{2+}\right]_{\mathrm{i}}$ can be further enhanced by RyR-mediated $\mathrm{Ca}^{2+}$ release via a $\mathrm{Ca}^{2+}$-induced $\mathrm{Ca}^{2+}$ release mechanism (Bolton et al., 2004). In addition to these mechanisms, $\mathrm{IP}_{3} \mathrm{R}$ 
activation induces $\mathrm{Ca}^{2+}$ influx through plasma membrane TRPC3 channels, resulting in a further elevation in global $\left[\mathrm{Ca}^{2+}\right]_{\mathrm{i}}$ (Adebiyi et al., 2010). A nanomolar elevation in global $\left[\mathrm{Ca}^{2+}\right]_{\mathrm{i}}$ regulates cell contractility by modulating $\mathrm{Ca}^{2+} / \mathrm{CaM}$-dependent myosin light chain (MLC) kinase activity (Nelson et al., 1988; Brayden \& Nelson, 1992; Endo, 2006). $\mathrm{Ca}^{2+}$ binds $\mathrm{CaM}$ and the $\mathrm{Ca}^{2+}-\mathrm{CaM}$ complex activates MLC kinase which phosphorylates MLC20. MLC20 is bound to the myosin head near the neck, and prevents it from interacting with actin. MLC20 phosphorylation by MLC kinase activates the myosin head, initiating contraction. A reduction in global $\left[\mathrm{Ca}^{2+}\right]_{\mathrm{i}}$ leads to MLC20 dephosphorylation by MLC phosphatase, resulting in vasodilation (Jaggar, 2001; Endo, 2006).

$\mathrm{Ca}^{2+}$ influx through $\mathrm{Ca}_{\mathrm{V}} 1.2$ channels is the major contributor to global $\left[\mathrm{Ca}^{2+}\right]_{\mathrm{i}}$ in arterial smooth muscle cells. Therefore, membrane potential, a key regulator of $\mathrm{Ca}_{\mathrm{V}} 1.2$ channel activation, influences global $\left[\mathrm{Ca}^{2+}\right]_{\mathrm{i}}$ (Knot \& Nelson, 1998). In cerebral artery smooth muscle cells under physiological conditions, the membrane potential is $\sim-45 \mathrm{mV}$, and global $\left[\mathrm{Ca}^{2+}\right]_{\mathrm{i}}$ is $193 \mathrm{nM}$ (Knot \& Nelson, 1998; Cheranov \& Jaggar, 2004; Zhao et al., 2008). Small changes in membrane potential result in significant changes to $\mathrm{Ca}^{2+}$ influx through $\mathrm{Ca}_{\mathrm{V}} 1.2$ channels, global $\left[\mathrm{Ca}^{2+}\right]_{\mathrm{i}}$, and arterial diameter. Membrane depolarization from $-45 \mathrm{mV}$ by $\sim 9 \mathrm{mV}$ elevates global $\left[\mathrm{Ca}^{2+}\right]_{\mathrm{i}}$ by $\sim 45 \mathrm{nM}$ and constricts the artery by about $25 \%$. In arterial smooth muscle cells, the entire range of global $\left[\mathrm{Ca}^{2+}\right]_{\mathrm{i}}$ which is from $\sim 120$ to $350 \mathrm{nM}$, and arterial diameter from fully dilated to maximally constricted state, is associated with membrane potentials from -65 to $-25 \mathrm{mV}$ (Knot \& Nelson, 1998).

\subsection{2. $\quad \mathrm{Ca}^{2+}$ sparks}

$\mathrm{Ca}^{2+}$ sparks are localized, intracellular $\mathrm{Ca}^{2+}$ transients that occur due to the activation of RyR channels on the SR (Cheng et al., 1993; Nelson et al., 1995; Jaggar et $a l ., 2000)$. In resting arterial smooth muscle cells, the $\mathrm{Ca}^{2+}$ spark frequency is very low ( $\sim 1 \mathrm{~Hz}$ in rat cerebral artery), and the spatial spread (full width at half maximal amplitude) is only $\sim 2-3 \mu \mathrm{m}$ (Jaggar et al., 2000). A single $\mathrm{Ca}^{2+}$ spark does not alter global $\left[\mathrm{Ca}^{2+}\right]_{\mathrm{i}}$ significantly in arterial smooth muscle cells (Wellman \& Nelson, 2003). However, $\mathrm{Ca}^{2+}$ sparks can produce a rapid, local elevation in $\left[\mathrm{Ca}^{2+}\right]_{\mathrm{i}}$ and activate $\mathrm{Ca}^{2+}$ sensitive proteins. One of the targets for $\mathrm{Ca}^{2+}$ sparks is the plasma membrane $\mathrm{K}_{\mathrm{Ca}}$ channel (Jaggar et al., 2000). $\mathrm{Ca}^{2+}$ sparks generate a micromolar $\left[\mathrm{Ca}^{2+}\right]_{\mathrm{i}}$ elevation near the release site, which activates many plasma membrane $\mathrm{K}_{\mathrm{Ca}}$ channels, causing a transient $\mathrm{K}_{\mathrm{Ca}}$ current (Jaggar et al., 2000; Perez et al., 2001; Zhuge et al., 2002). $\mathrm{K}_{\mathrm{Ca}}$ channel, which has a low $\mathrm{Ca}^{2+}$ affinity would not be activated by global $\left[\mathrm{Ca}^{2+}\right]_{\mathrm{i}}$ changes (Perez et al., 2001). $\mathrm{Ca}^{2+}$ spark-activated $\mathrm{K}_{\mathrm{Ca}}$ current induces membrane hyperpolarization, which reduces $\mathrm{Ca}_{\mathrm{V}} 1.2$ activity, causing global $\left[\mathrm{Ca}^{2+}\right]_{\mathrm{i}}$ reduction and vasodilation (Nelson et al., 1995; Jaggar et al., 2000). Therefore, in small resistance-size arteries, RyR, $\mathrm{K}_{\mathrm{Ca}}$, and $\mathrm{Ca}_{\mathrm{V}} 1.2$ channels form a functional unit that provides a negative feedback mechanism for the regulation of vascular tone and blood pressure (Jaggar et al., 2000).

RyR channels also form signaling complex with TRPV4 and $\mathrm{K}_{\mathrm{Ca}}$ channels in rat 
cerebral artery smooth muscle cells, and produce membrane hyperpolarization and vasodilation (Earley et al., 2005). In smooth muscle cells of pulmonary arteries and portal vein, $\mathrm{Ca}^{2+}$ sparks activate $\mathrm{Ca}^{2+}$-activated chloride $\left(\mathrm{Cl}_{\mathrm{Ca}}\right)$ channels, leading to chloride $\left(\mathrm{Cl}^{-}\right)$efflux and membrane depolarization (Wang et al., 1992; Hogg et al., 1993). Rat pulmonary artery smooth muscle cells express both $\mathrm{K}_{\mathrm{Ca}}$ and $\mathrm{Cl}_{\mathrm{Ca}}$ channels, giving rise to mixed $\mathrm{K}^{+}$and $\mathrm{Cl}^{-}$efflux.

\subsection{3. $\mathrm{Ca}^{2+}$ waves}

$\mathrm{Ca}^{2+}$ waves are intracellular $\mathrm{Ca}^{2+}$ transients that propagate across the whole cell along the longitudinal axis (Jaggar et al., 2000; Jaggar \& Nelson, 2000). $\mathrm{Ca}^{2+}$ wave generation requires: 1) a stimulus that activates $\mathrm{Ca}^{2+}$ channels, initiating $\mathrm{Ca}^{2+}$ release; 2) regenerative $\mathrm{Ca}^{2+}$ release propagating across the cell; 3) $\mathrm{Ca}^{2+}$ clearance from the cytosol; 4) refilling of intracellular $\mathrm{Ca}^{2+}$ stores; and 5) reactivation of $\mathrm{Ca}^{2+}$ release channels (Lee et al., 2005).

In resting arterial smooth muscle cells, $\mathrm{Ca}^{2+}$ wave frequency is low (Jaggar \& Nelson, 2000). Vasoconstrictors, including ET-1, NE, phenylephrine, uridine 5'triphosphate (UTP), and vasopressin stimulate $\mathrm{Ca}^{2+}$ waves in smooth muscle cells of rat tail artery, portal vein, mesenteric and cerebral arteries (Boittin et al., 1999; Jaggar \& Nelson, 2000; Mauban et al., 2001; Lamont \& Wier, 2004; Dai et al., 2007). Elevating the agonist concentration increases the frequency but not the amplitude of $\mathrm{Ca}^{2+}$ waves (Shimamura et al., 1999; Lee et al., 2002). Intravascular pressure elevation increases $\mathrm{Ca}^{2+}$ wave frequency via increasing $\mathrm{IP}_{3}$ synthesis and activating RyR channels (Jaggar, 2001). Blocking SERCA abolishes $\mathrm{Ca}^{2+}$ waves, suggesting the requirement of $\mathrm{Ca}^{2+}$ release from intracellular $\mathrm{Ca}^{2+}$ stores (Lee et al., 2002). $\mathrm{Ca}^{2+}$ waves could occur by activation of both RyR and $\mathrm{IP}_{3} \mathrm{Rs}$, with the relative involvement of each varying in different smooth muscle cells. In rat portal vein smooth muscle cells, an anti-IP ${ }_{3} R$ antibody blocked NE-induced $\mathrm{Ca}^{2+}$ waves (Boittin et al., 1999). Vasoconstrictor-induced $\mathrm{Ca}^{2+}$ waves are also abolished by ryanodine (Blatter \& Wier, 1992; Lamont \& Wier, 2004). In rat pulmonary artery smooth muscle cells, NAADP initiated $\mathrm{Ca}^{2+}$ waves, which were blocked by ryanodine but not by xestospongin $\mathrm{C}(\mathrm{XeC})$, an $\mathrm{IP}_{3} \mathrm{R}$ inhibitor (Gafni et al., 1997), suggesting that NAADP-mediated RyR activation results in $\mathrm{Ca}^{2+}$ waves (Boittin et al., 2002). During a $\mathrm{Ca}^{2+}$ wave, intracellular stores release $\mathrm{Ca}^{2+}$ and need to be refilled by extracellular $\mathrm{Ca}^{2+}$ influx to maintain the ongoing wave (Lee et al., 2005). In rat cerebral arteries, diltiazem, a $\mathrm{Ca}_{v} 1.2$ channel inhibitor blocked $\mathrm{Ca}^{2+}$ influx and reduced $\mathrm{Ca}^{2+}$ waves (Jaggar, 2001). The oscillatory feature of $\mathrm{Ca}^{2+}$ waves implicates repetitive $\left[\mathrm{Ca}^{2+}\right]_{\mathrm{i}}$ increase due to $\mathrm{Ca}^{2+}$ release from intracellular stores, and $\left[\mathrm{Ca}^{2+}\right]_{\mathrm{i}}$ decrease due to both a reduction in $\mathrm{Ca}^{2+}$ release and removal of cytosolic $\mathrm{Ca}^{2+}$ (Aalkjaer \& Nilsson, 2005).

Presently, the physiological function of $\mathrm{Ca}^{2+}$ waves is poorly understood. In rat mesenteric arteries, adrenergic stimulation using vasoconstrictors, including phenylephrine and NE elevated asynchronous propagating wave-like $\mathrm{Ca}^{2+}$ transients which induced vasoconstriction (Miriel et al., 1999; Mauban et al., 2001; Lamont \& 
Wier, 2004) and synchronous spatially uniform $\mathrm{Ca}^{2+}$ transients which caused oscillatory vasomotion (Mauban et al., 2001; Lamont \& Wier, 2004). In rat cerebral arteries, alkalinizing external $\mathrm{pH}$ (Heppner et al., 2002) or increasing intravascular pressure from 10 to $60 \mathrm{~mm} \mathrm{Hg}$ (Jaggar, 2001) elevated $\mathrm{Ca}^{2+}$ wave frequency, but $\mathrm{Ca}^{2+}$ waves do not appear to significantly contribute to the global $\left[\mathrm{Ca}^{2+}\right]_{\mathrm{i}}$ elevation required for vasoconstriction (Jaggar, 2001; Heppner et al., 2002). Therefore, it is unclear if $\mathrm{Ca}^{2+}$ waves influence vascular contractility with reports suggesting that activation of a large $\mathrm{Ca}^{2+}$ wave frequency can induce constriction, while others indicate that $\mathrm{Ca}^{2+}$ waves and oscillations do not contribute to contractile $\mathrm{Ca}^{2+}$ (Jaggar, 2007). Apart from contractility, $\mathrm{Ca}^{2+}$ waves have been suggested to regulate gene expression in cultured mouse cerebral artery segments (Wilkerson et al., 2006). $\mathrm{IP}_{3} \mathrm{R}$-mediated $\mathrm{Ca}^{2+}$ waves induced nuclear translocation of proliferating cell nuclear antigen, a transcriptional regulator resulting in smooth muscle cell proliferation (Wilkerson et al., 2006).

\subsection{4. $\quad \mathrm{Ca}^{2+}$ sparklets}

$\mathrm{Ca}^{2+}$ sparklets are intracellular subsarcolemmal $\mathrm{Ca}^{2+}$ transients generated by $\mathrm{Ca}^{2+}$ influx through one or several tightly clustered VDCCs, causing a local high $\left[\mathrm{Ca}^{2+}\right]_{\mathrm{i}}$ elevation near the $\mathrm{Ca}^{2+}$ channel (Amberg et al., 2007). In cerebral artery smooth muscle cells, $\mathrm{Ca}^{2+}$ sparklets occur due to the activation of $\mathrm{Ca}_{\mathrm{v}} 1.2$ channels (Navedo et al., 2005; Navedo et al., 2006). There are two modes of $\mathrm{Ca}^{2+}$ sparklet activity in arterial smooth muscle cells. Low activity $\mathrm{Ca}^{2+}$ sparklets occure due to random, brief openings of L-type $\mathrm{Ca}^{2+}$ channels (Navedo et al., 2006). Persistent $\mathrm{Ca}^{2+}$ sparklets occur due to small clusters of L-type $\mathrm{Ca}^{2+}$ channels operating in a high activity mode, generating sites of constant $\mathrm{Ca}^{2+}$ influx (Navedo et al., 2006). Persistent $\mathrm{Ca}^{2+}$ sparklets occur as a result of AKAP150, a scaffolding protein, which targets PKC alpha (PKC $\alpha)$ to specific regions of the plasma membrane, leading to $\mathrm{Ca}^{2+}$ channel activation, $\mathrm{Ca}^{2+}$ influx, and global $\left[\mathrm{Ca}^{2+}\right]_{\mathrm{i}}$ elevation (Navedo et al., 2008). Calcineurin, which is associated with AKAP150, inhibits PKC $\alpha$ and $\mathrm{Ca}^{2+}$ sparklets (Navedo et al., 2008). Membrane depolarization increases the occurrence of both modes of $\mathrm{Ca}^{2+}$ sparklets, resulting in an elevation in local and global $\left[\mathrm{Ca}^{2+}\right]_{\mathrm{i}}$ (Santana \& Navedo, 2009). $\mathrm{Ca}^{2+}$ sparklet activity is increased in arterial smooth muscle cells during hypertension, resulting in activation of the transcription factor nuclear factor of activated T cell (NFAT) c3 (Nieves-Cintron et al., 2008). $\mathrm{Ca}^{2+}$ sparklet activity is also elevated via a PKA-dependent pathway in cerebral artery smooth muscle cells during hyperglycemia (Navedo et al., 2010).

\subsection{Mitochondria in Vascular Smooth Muscle Cells}

\subsubsection{Electron transport chain and ATP synthesis}

Mitochondrial ETC consists of four proteins called Complexes I (NADHubiquinone oxidoreductase), II (succinate dehydrogenase), III (cytochrome bc c $_{1}$ ), and IV (cytochrome c oxidase) (Fernie et al., 2004). Electrons are transferred from the strongly 
reducing products (NADH, succinate) of the citric acid cycle through the ETC complexes to molecular oxygen $\left(\mathrm{O}_{2}\right)$ (Fernie et al., 2004). Coenzymes ubiquinone (UQ), which is in the lipid membrane and cytochrome $\mathrm{c}$, which is in the intermembrane space regulate the electron transfer between the ETC complexes (Fernie et al., 2004). Complex I transfers electrons from the Kreb's cycle product NADH to UQ, which also receives electrons from complex II (Fernie et al., 2004). UQ transfers electrons from Complexes I and II to III, and cytochrome c transfers electrons from Complex III to IV (Fernie et al., 2004). Complex IV uses the electrons to reduce $\mathrm{O}_{2}$ to water. Energy obtained as a result of electron transfer through the ETC complexes is coupled to pump protons from the mitochondrial matrix to the intermembrane space by complexes I and IV, and by UQ at complexes I, II, and III (Fernie et al., 2004). Proton pumping creates an electrochemical proton gradient across the inner mitochondrial membrane (Fernie et al., 2004). ATP synthase uses the $\mathrm{H}^{+}$flow down the gradient back into the matrix to stimulate ATP production from ADP and Pi (Fernie et al., 2004).

\subsubsection{Mitochondrial membrane potential}

The proton gradient that is physiologically generated across the inner mitochondrial membrane by the respiratory chain activity is responsible for the maintenance of $\psi_{\mathrm{m}}$ (Gunter et al., 2000). $\psi_{\mathrm{m}}$ is $\sim 150-180 \mathrm{mV}$ more negative compared to the cytosol (Gunter et al., 2000). Kinetics of ATP synthase follows a sigmoidal pattern in response to increase in $\psi_{\mathrm{m}}$, reaching a plateau phase when $\psi_{\mathrm{m}} \sim 50 \mathrm{mV}$ more negative compared to the cytosol, suggesting that ATP synthesis is regulated primarily by the availability of the substrates ADP and Pi and not by $\psi_{\mathrm{m}}$ in the physiological range (Brookes, 2005). $\psi_{\mathrm{m}}$ maintenance is essential for the normal functioning of mitochondria. Transport of ions and metabolites into and out of the mitochondria is regulated predominantly by $\psi_{\mathrm{m}}$ (Brookes, 2005). According to Nernst equation, equilibrium would be reached only if $\left[\mathrm{Ca}^{2+}\right]_{\text {mito }}$ is $10^{6}$ times that of $\left[\mathrm{Ca}^{2+}\right]_{\mathrm{i}}$ (Graier et al., 2007). Uncouplers, including carbonyl cyanide 3-chlorophenylhydrazone (CCCP), which disrupt the proton gradient across the inner mitochondrial membrane, reduce the driving force for $\mathrm{Ca}^{2+}$, resulting in strongly diminishing mitochondrial $\mathrm{Ca}^{2+}$ uptake (Graier et al., 2007).

\subsubsection{Spatial proximity between $S R$ and mitochondria}

To reconcile the low mitochondrial affinity for $\mathrm{Ca}^{2+}$ at physiological $\left[\mathrm{Ca}^{2+}\right]$, mitochondria may be exposed to $\mathrm{Ca}^{2+}$ microdomains, such as intracellular $\mathrm{Ca}^{2+}$ stores, permitting localized mitochondrial $\mathrm{Ca}^{2+}$ uptake to occur (Rizzuto et al., 2009). In HeLa cells, imaging green fluorescent protein (GFP) constructs targeted to the SR and mitochondria has revealed that $\sim 5-20 \%$ of the mitochondrial surface is in close apposition to the SR (Rizzuto et al., 2009). Conventional thin section transmission electron microscopy studies indicate that mitochondria are located in close proximity $(\sim 10-25 \mathrm{~nm})$ to the SR in many cell types, including arterial smooth muscle cells (Rizzuto et al., 1999; Duchen, 2000b; Szado et al., 2003; Rizzuto et al., 2009). 
To achieve effective local $\mathrm{Ca}^{2+}$ signaling between the SR and mitochondria, the $\mathrm{SR} \mathrm{Ca}^{2+}$ release sites and the mitochondrial $\mathrm{Ca}^{2+}$ uptake channels should be present at the interface area (Hajnoczky et al., 2000). Distribution of the $\mathrm{IP}_{3} \mathrm{Rs}$ and RyRs is not homogenous on the SR membrane (Hajnoczky et al., 2000). In cardiac muscle cells, $\sim 90 \%$ of the $\mathrm{SR} \mathrm{Ca}^{2+}$ release channels are located very close to mitochondria (Sharma et al., 2000). A high density of $\mathrm{IP}_{3} \mathrm{R} 1$ and $\mathrm{IP}_{3} \mathrm{R} 2$ exist on regions of the SR which face the mitochondria (Takei et al., 1992; Simpson et al., 1997). MCU is exclusively localized in the regions of contact between the mitochondria and ER (Hajnoczky et al., 2000).

In addition to being in close proximity to each other, SR and mitochondria may be physically tethered to one another to sustain local communication during continuous organelle movement and reorganization (Hajnoczky et al., 2000; Csordas \& Hajnoczky, 2009). The SR-mitochondria physical coupling is established via several anchoring proteins, including dynamin-like protein-1 (Pitts et al., 1999), glucose-regulated protein 75 (Szabadkai et al., 2006), sigma-1 receptor (Hayashi \& Su, 2007), and mitofusin-2 (De Brito \& Scorrano, 2008). Since both SR and mitochondria bind to microtubules/actin filaments, cytoskeletal proteins may also offer additional physical support to the SRmitochondria associations (Spat et al., 2008). Therefore, the spatial distribution of SR and mitochondria, and the physical coupling between them may provide a strong platform for efficient local communication.

Not all the mitochondria are in close proximity to the SR. Some mitochondria may be isolated or relatively far from the SR, resulting in them either not or poorly responding to $\mathrm{SR} \mathrm{Ca}^{2+}$ release (Hajnoczky et al., 2000). There may also exist substantial heterogeneity among different mitochondria in the efficacy of $\mathrm{Ca}^{2+}$ uptake with differences in MCU activation, driving force, rate, and peak of $\mathrm{Ca}^{2+}$ uptake (Rizzuto et al., 2004). Therefore, a sub-population of mitochondria may be exposed to $\left[\mathrm{Ca}^{2+}\right]_{\mathrm{i}}$ much higher than other mitochondria in the same cell (McCarron et al., 2006).

\subsubsection{Interplay between mitochondria and cytosolic $\mathrm{Ca}^{2+}$ signals}

$\mathrm{Ca}^{2+}$ transport pathways of the mitochondria consist of high velocity, $\psi_{\mathrm{m}}$-driven uptake mechanisms which are activated by local $\left[\mathrm{Ca}^{2+}\right]_{i}$ elevations, and slow, easily saturable, concentration-dependent efflux systems, which are only mildly stimulated by $\left[\mathrm{Ca}^{2+}\right]_{\text {mito }}$ elevations. Therefore, mitochondria accumulate $\mathrm{Ca}^{2+}$ during rapid, local $\left[\mathrm{Ca}^{2+}\right]_{\mathrm{i}}$ elevations and slowly release it back into the cytosol (Rizzuto et al., 2000). This permits the mitochondria to alter spatio-temporal patterns of global and local $\mathrm{Ca}^{2+}$ signaling (Rizzuto et al., 2000; Xi et al., 2005). The physiological range of arterial smooth muscle cell global $\left[\mathrm{Ca}^{2+}\right]_{\mathrm{i}}$ is $\sim 100-300 \mathrm{nM}$. Local $\mathrm{Ca}^{2+}$ signals elevate $\mathrm{Ca}^{2+}$ into the micromolar concentration range, which is sufficient for mitochondrial $\mathrm{Ca}^{2+}$ uptake because in vitro $\mathrm{K}_{\mathrm{d}}$ for $\mathrm{Ca}^{2+}$ of MCU is $\sim 10-20 \mu \mathrm{M}$ (Gunter \& Pfeiffer, 1990; Perez et al., 2001). SR Ca ${ }^{2+}$ release due to the activation of $\mathrm{IP}_{3} \mathrm{R}$-gated $\mathrm{Ca}^{2+}$-release channels caused a micromolar increase in the local cytosolic $\left[\mathrm{Ca}^{2+}\right]_{\mathrm{i}}$ and $\mathrm{Ca}^{2+}$ uptake by localized mitochondria (Rizzuto et al., 1993; Duchen et al., 1998; Hajnoczky et al., 2002). In rat pulmonary artery smooth muscle cells, cytosolic $\mathrm{Ca}^{2+}$ oscillations due to $\mathrm{SR} \mathrm{Ca}^{2+}$ release resulted in 
$\left[\mathrm{Ca}^{2+}\right]_{\text {mito }}$ oscillations (Drummond \& Tuft, 1999). In cardiac smooth muscle cells, local SR Ca ${ }^{2+}$ release via RyR channels elicited miniature $\left[\mathrm{Ca}^{2+}\right]_{\text {mito }}$ elevations termed " $\mathrm{Ca}^{2+}$ marks", and transient mitochondrial depolarizations termed "flickers" (Duchen et al., 1998; Pacher et al., 2002).

Vascular smooth muscle cell mitochondria can in turn feedback to alter the activity of $\mathrm{Ca}^{2+}$ channels which produce the local $\mathrm{Ca}^{2+}$ signals (Cheranov \& Jaggar, 2004; Poburko et al., 2004; Chalmers et al., 2007). In particular, mitochondria regulate $\mathrm{IP}_{3} \mathrm{R}$ and RyR channel activity, and in turn influence the propagation of $\mathrm{Ca}^{2+}$ waves and generation of $\mathrm{Ca}^{2+}$ sparks, respectively (Lee et al., 2002; Wellman \& Nelson, 2003). Mitochondria can regulate these SR $\mathrm{Ca}^{2+}$ release channels by buffering local $\left[\mathrm{Ca}^{2+}\right]$, controlling ATP synthesis, via reactive oxygen species (ROS) signaling, and cADPr metabolism (Poburko et al., 2004; Xi et al., 2005; Chalmers et al., 2007). RyR and IP ${ }_{3} \mathrm{R}$ are sensitive to cADPr and ATP, respectively (Bezprozvanny \& Ehrlich, 1995; Sitsapesan et al., 1995), and both channels have distinct $\mathrm{Ca}^{2+}$-sensitive stimulating and inhibiting sites. By influencing channel modulators and by buffering $\left[\mathrm{Ca}^{2+}\right]$, mitochondria can regulate both the $\mathrm{Ca}^{2+}$ sensitivity and the duration of opening of RyR and $\mathrm{IP}_{3} \mathrm{R}$. In various cell types, including vascular smooth muscle cells, mitochondria affect RyR channel activity and influence the frequency and amplitude of $\mathrm{Ca}^{2+}$ sparks (Pacher et al., 2002; Xi et al., 2005). In cerebral artery smooth muscle cells, mitochondrial depolarization-induced ROS elevation activated $\mathrm{Ca}^{2+}$ sparks, leading to $\mathrm{K}_{\mathrm{Ca}}$ channel stimulation, resulting in vasodilation (Xi et al., 2005). In pulmonary and mesenteric artery smooth muscle cells, mitochondria increased both $\mathrm{Ca}^{2+}$ spark frequency and amplitude, resulting in increased $\mathrm{Cl}_{\mathrm{Ca}}$ current (Wang et al., 2003). Mitochondrial regulation of $\mathrm{IP}_{3} \mathrm{R}$ activity has been reported in colonic and arterial smooth muscle cells (McCarron \& Muir, 1999; Sward et al., 2002). In rat tail artery smooth muscle cells, mitochondrial inhibitors increased the frequency and decreased the amplitude of $\mathrm{IP}_{3} \mathrm{R}$ mediated $\left[\mathrm{Ca}^{2+}\right]_{\mathrm{i}}$ oscillations (Sward et al., 2002). Mitochondria can also regulate SR $\mathrm{Ca}^{2+}$ refilling by controlling ATP synthesis and modulating $\mathrm{Ca}^{2+}$ efflux via mNCX (Landolfi et al., 1998; Arnaudeau et al., 2001). In vascular smooth muscle cells, mitochondria regulate the activity of several plasma membrane ion channels, including SOCCs, VDCCs, $\mathrm{K}_{\mathrm{Ca}}$, and $\mathrm{Cl}_{\mathrm{Ca}}$ channels (Poburko et al., 2004). Mitochondria influence plasma membrane channel activity by buffering local subplasmalemmal $\mathrm{Ca}^{2+}$ gradients, which activate or inhibit channels and also through regulation of $\mathrm{SR} \mathrm{Ca}^{2+}$ refilling, which dictates the activity of SOCCs (Poburko et al., 2004). Therefore, the activity of mitochondria may regulate and be influenced by $\mathrm{Ca}^{2+}$ signals in smooth muscle cells.

\subsubsection{Role of mitochondria in vascular smooth muscle cells}

In vascular smooth muscle cells, the physiological role of mitochondria apart from their energy-generating function is unclear. Mitochondria provide an efficient system for buffering cytosolic $\mathrm{Ca}^{2+}$ changes, thereby controlling a variety of mitochondrial events, including ATP synthesis, MPTP opening, and mitochondrial ROS (mitoROS) generation. However, the physiological consequences of these $\left[\mathrm{Ca}^{2+}\right]_{\text {mito }}$ elevation-mediated events are poorly understood. 
Mitochondrial dysfunction is associated with several pathological conditions of the vasculature, including apoptosis, migration, remodeling, and glycation (Lee et al., 2008; Birukov, 2009; Wang et al., 2009; Ahn et al., 2010). Few studies have examined the role of mitochondria in regulating physiological functions of vascular smooth muscle cells. In cerebral artery smooth muscle cells, mitoROS activate $\mathrm{Ca}^{2+}$ sparks and stimulate $\mathrm{K}_{\mathrm{Ca}}$ channels, resulting in vasodilation (Xi et al., 2005). Cold-induced constriction of cutaneous arteries is mediated through mitoROS generation (Bailey et al., 2005). During hypoxia, mitochondria in pulmonary artery smooth muscle cells act as oxygen sensors and stimulate redox-sensitive transcription factors (Schumacker, 2003; Sato et al., 2005). Therefore, there is very minimal information available about the role of mitochondria in mediating normal physiological processes other than ATP synthesis in vascular smooth muscle cells.

\subsection{Reactive Oxygen Species in Vascular Smooth Muscle Cells}

In physiological or pathological conditions, $\mathrm{O}_{2}$ is converted into highly reactive oxygen-derived molecules and free radicals, called reactive oxygen species (ROS) that interact with reducible compounds. There are different species of ROS, including hydrogen peroxide $\left(\mathrm{H}_{2} \mathrm{O}_{2}\right)$, superoxide anion $\left(\mathrm{O}^{2-} \cdot\right)$, hydroxyl radical $(\mathrm{OH} \cdot)$. nitric oxide (NO), peroxynitrite (ONOO-), hypochlorous acid $(\mathrm{HOCl})$, and singlet oxygen $\left({ }^{1} \mathrm{O}_{2}\right)$ (Mueller et al., 2005; Gloire et al., 2006). $\mathrm{O}^{2-}$. and $\mathrm{H}_{2} \mathrm{O}_{2}$ are the two major species of ROS produced in cells. $\mathrm{O}^{2-}$. through reaction with $\mathrm{NO}$ generates $\mathrm{ONOO} \cdot \mathrm{OH} \cdot$ is produced from $\mathrm{H}_{2} \mathrm{O}_{2}$ in a Fenton reaction (Turrens, 2003).

\subsubsection{Cellular sources of ROS}

Multiple sources generate ROS, including mitochondrial ETC complexes, NAD(P)H oxidase, cytochrome P450 (CYP450), xanthine oxidoreductase, NO synthase (NOS), cyclooxygenases, and lipoxygenases (Irani, 2000; Turrens, 2003; Wong et al., 2003; Mueller et al., 2005; Clempus \& Griendling, 2006). The major sources of ROS in vascular smooth muscle cells are mitochondrial ETC and $\mathrm{NAD}(\mathrm{P}) \mathrm{H}$ oxidase (Mueller et al., 2005).

\subsubsection{Mitochondrial ETC complexes}

Mitochondrial ETC is a major source of $\mathrm{O}^{2-} \cdot$ and $\mathrm{H}_{2} \mathrm{O}_{2}$ in most tissues, including vascular smooth muscle cells (Mueller et al., 2005; Clempus \& Griendling, 2006). Under normal metabolic conditions, electron leakage occurs during transfer between complexes, resulting in the incomplete reduction of $\sim 1-5 \%$ of total $\mathrm{O}_{2}$ consumed, to produce $\mathrm{O}^{2-}$. (Mueller et al., 2005). Mitochondrial $\mathrm{O}^{2-}$. production occurs primarily at ETC complexes I and III (Mueller et al., 2005). The main source of $\mathrm{O}^{2-} \cdot$ in mitochondria is the ubisemiquinone radical intermediate $(\mathrm{QH} \cdot)$, which is formed from UQ at complex III (Brookes et al., 2004). QH· formation occurs under two conditions: 1) an increase in 
$\mathrm{QH} \cdot$ concentration when ETC is inhibited distally, and 2) an increased rate of QH. production when ETC functions faster (Brookes et al., 2004). Therefore, both stimulation and inhibition of mitochondrial ETC elevate mitochondrial $\mathrm{O}^{2-} \cdot$ generation.

Mitochondrial superoxide dismutase converts $\mathrm{O}^{2-} \cdot$ to $\mathrm{H}_{2} \mathrm{O}_{2}($ Clempus \& Griendling, 2006). Since $\mathrm{O}^{2-} \cdot$ generation is non-enzymatic, the rate of mitoROS production is directly proportional to the rate of metabolism (Brookes, 2005). MitoROS generation is regulated primarily by the redox state of the ETC complexes, which is controlled by the $\psi_{\mathrm{m}}$ and the proton gradient (Brookes, 2005; Xi et al., 2005). Several other stimuli, including mitochondrial $\mathrm{Ca}^{2+}$ uptake (Wolin et al., 2005), and mPTP opening (Wang et al., 2008a) stimulate mitoROS production in cell types, including vascular smooth muscle cells. MitoROS regulates several physiological and pathological signaling pathways, including cell cycle, cell proliferation, apoptosis, metalloproteinase function, protein phosphorylation, dephosphorylation, $\mathrm{Ca}^{2+}$ signaling, vascular contractility, and transcription factors (Brookes et al., 2004; Xi et al., 2005).

\subsubsection{2. $\mathrm{NAD}(\mathrm{P}) \mathrm{H}$ oxidase}

$\mathrm{NAD}(\mathrm{P}) \mathrm{H}$ oxidases are multiprotein complexes consisting of the $\mathrm{p} 22^{\mathrm{phox}}$ subunit bound to the catalytic subunit Nox (known as gp91 ${ }^{\text {phox }}$ in phagocytes) (Touyz et al., 2002; Mueller et al., 2005; Paravicini \& Touyz, 2006; Parfenova \& Leffler, 2008; Basuroy et al., 2009). In addition to the membrane-bound Nox $/ \mathrm{p} 22^{\text {phox }}$ complex, there are three cytosolic subunits, including Rac1, p47 $7^{\text {phox }}$ and $\mathrm{p} 67^{\text {phox }}$, which are recruited to the membrane upon activation (Abo et al., 1991; Ambasta et al., 2004; Basuroy et al., 2009). The catalytic subunit in vascular smooth muscle cells is either Nox1, Nox2, or Nox4 (Mueller et al., 2005; Paravicini \& Touyz, 2006). Nox1 expression levels, which are low in vascular smooth muscle cells, can be induced by stimuli such as plateletderived growth factor (PDGF), Ang II, and serum (Lassegue \& Clempus, 2003). Nox2 is expressed in endothelial and adventitial cells of large arteries and in vascular smooth muscle cells of smaller resistance-size arteries (Wang et al., 1998; Gorlach et al., 2000; Touyz et al., 2002; Parfenova \& Leffler, 2008; Basuroy et al., 2009). Nox4 is constitutively expressed and active in vascular smooth muscle and endothelial cells (Ago et al., 2004; Hilenski et al., 2004; Basuroy et al., 2009).

Activation of $\mathrm{NAD}(\mathrm{P}) \mathrm{H}$ oxidase results in the assembly of the cytosolic and membrane-bound subunits to form an enzyme complex (Lassegue \& Clempus, 2003; Mueller et al., 2005). NAD(P)H oxidase produces $\mathrm{O}^{2-}$. by the transfer of two electrons from NAD $(\mathrm{P}) \mathrm{H}$ to $\mathrm{O}_{2}$ (Paravicini \& Touyz, 2006). Vasoactive hormones (Ang II), growth factors (PDGF), and mechanical stimuli (shear stress) activate NAD(P)H oxidase in vascular smooth muscle cells (Mueller et al., 2005). 


\subsubsection{Cytochrome P450}

Membrane-bound microsomal monooxygenase system is present in the SR of most tissues, including vascular smooth muscle cells (Zangar et al., 2004). It contains CYP450 enzymes which oxygenate exogenous and endogenous compounds. NAD(P)HCYP450 reductase transfers two electrons to CYP450 resulting in activation of $\mathrm{O}_{2}$, leading to monooxygenation of substrates (Zangar et al., 2004). The efficiency with which electrons are transferred from $\mathrm{NAD}(\mathrm{P}) \mathrm{H}$ to $\mathrm{CYP} 450$ for substrate oxygenation is not tightly regulated, resulting in ROS production (Gorsky et al., 1984; Blanck et al., 1991). Therefore, continuous generation of $\mathrm{O}^{2-}$. and $\mathrm{H}_{2} \mathrm{O}_{2}$ by CYP450, as a result of $\mathrm{NAD}(\mathrm{P}) \mathrm{H}$ consumption occurs both in the presence and absence of substrates (Kuthan \& Ullrich, 1982; Zangar et al., 2004).

\subsubsection{Xanthine oxidoreductase}

The xanthine oxidoreductase system exists as xanthine dehydrogenase (XDH) and xanthine oxidase (XO) (Mueller et al., 2005). XDH transfers electrons from hypoxanthine and xanthine to $\mathrm{NAD}^{+}$to produce NADH and uric acid (Harrison, 2002). $\mathrm{XO}$ forms $\mathrm{O}^{2-}$. and $\mathrm{H}_{2} \mathrm{O}_{2}$ by transferring electron from $\mathrm{NADH}$ and uric acid to $\mathrm{O}_{2}$ (Harrison, 2002). Therefore, the relative cellular amounts of XDH and XO determine the ROS produced (Mueller et al., 2005). Several stimuli, including tumor necrosis factor alpha (TNF- $\alpha$ ), and ONOO - convert XDH to XO, and thereby increase ROS production in vascular smooth muscle cells (Friedl et al., 1989; Sakuma et al., 1997).

\subsubsection{Nitric oxide synthases}

There are three NOS isoforms, namely endothelial NOS (eNOS) and nNOS, which are constituvely expressed, and inducible NOS (iNOS) (Kibbe et al., 1999). Under normal conditions, NOS transfers electrons to L-arginine in the presence of cofactor tetrahydrobiopterin $\left(\mathrm{BH}_{4}\right)$ to yield $\mathrm{NO}$ (Mueller et al., 2005).

eNOS activity is regulated by $\left[\mathrm{Ca}^{2+}\right]_{\mathrm{i}}$ between $\sim 100$ and $500 \mathrm{nM}$, which permits $\mathrm{CaM}$ binding and its activation (Forstermann et al., 1994). In pathological conditions, including hypertension, elevated levels of $\mathrm{O}^{2-}$. oxidize $\mathrm{BH}_{4}$, thereby uncoupling eNOS, which transfers electron to $\mathrm{O}_{2}$ instead of $\mathrm{L}$-arginine to produce additional $\mathrm{O}^{2-}$. (Mueller et al., 2005).

In addition to eNOS-derived NO production in endothelial cells, NO generation in vascular smooth muscle cells occurs via iNOS (Griendling \& FitzGerald, 2003). iNOS generates 100-1000-fold more NO than eNOS and nNOS (Kibbe et al., 1999). iNOS is expressed in conditions where smooth muscle cells change from a contractile to a proliferative phenotype in response to cellular stress, inflammatory states, and arterial injury (Kibbe et al., 1999; Griendling \& FitzGerald, 2003). 


\subsubsection{Cyclooxygenases and lipoxygenases}

Cyclooxygenases and lipoxygenases metabolize arachidonic acid. $\mathrm{O}^{2-}$. production occurs due to the hydroperoxidase activity of the enzymes via side-chain reactions that are dependent upon the presence of a suitable reducing substrate, either NADH or NAD(P)H (Wong et al., 2003). Like cyclooxygenases, lipoxygenases can produce $\mathrm{O}^{2-}$. in the presence of either NADH or NAD(P)H (Lotzer et al., 2005).

\subsubsection{Antioxidant mechanisms}

Cells have developed defensive antioxidant mechanisms to eliminate excess ROS from cell compartments and extracellularly. The antioxidant mechanisms include superoxide dismutase (SOD), catalase, thioredoxin, glutathione peroxidases and peroxiredoxins (Karihtala \& Soini, 2007). In human cells, three different types of SODs are expressed, including cytosolic copper-zinc SOD, mitochondrial manganese SOD and extracellular SOD (Karihtala \& Soini, 2007). All three SODs dismutate two $\mathrm{O}^{2-}$. anions to $\mathrm{H}_{2} \mathrm{O}_{2}$ and $\mathrm{O}_{2}$ (Karihtala \& Soini, 2007). Catalase, thioredoxin, glutathione peroxidases, and peroxiredoxins reduce $\mathrm{H}_{2} \mathrm{O}_{2}$ to water and $\mathrm{O}_{2}$ (Karihtala \& Soini, 2007). When cellular production of ROS overwhelms its antioxidant capacity, a state of oxidative stress is reached leading to serious cellular injuries and contributing to the pathogenesis of several diseases.

\subsubsection{ROS regulation of vascular smooth muscle cell functions}

When generated in optimal concentrations, ROS can act as second messengers in regulating signal transduction pathways, leading to regulation of cellular responses in a variety of cell types and conditions, including cytokine, growth factor and hormone treatments, ion transport, transcription, neuromodulation, and apoptosis (Lander, 1997; Hensley et al., 2000). Distinct properties of different species of ROS determine their capability of stimulating diverse signaling pathways, which may then lead to convergent or divergent consequences. $\mathrm{O}^{2-} \cdot$ and $\mathrm{OH} \cdot$ are very reactive, have short half-lives and therefore, are unlikely to mediate effects distant from where they are produced (Paravicini \& Touyz, 2006). The negative charge on $\mathrm{O}^{2-}$. prevents it from crossing cellular membranes, except through ion channels (Paravicini \& Touyz, 2006). $\mathrm{H}_{2} \mathrm{O}_{2}$ is comparatively more stable, has a greater diffusion radius than $\mathrm{O}^{2-} \cdot$ and $\mathrm{OH} \cdot$, and is able to diffuse across membranes and between cells (Paravicini \& Touyz, 2006). Therefore, different species of ROS are capable of regulating multiple signaling pathways, depending on their reactivity and stability (Paravicini \& Touyz, 2006).

In arterial smooth muscle cells, several ligands, including Ang II, ET-1, and PDGF, mechanical stress, and hypoxia increase ROS production (Griendling et al., 1994; Nishio \& Watanabe, 1997; Xi et al., 2005; Clempus \& Griendling, 2006; Paravicini \& Touyz, 2006). ROS exert their effects through interaction with and regulating the functions of multiple cellular components, including ion channels, protein kinases and 
phosphatases, transcription factors, and cell cycle proteins (Clempus \& Griendling, 2006; Paravicini \& Touyz, 2006).

In vascular smooth muscle cells, ROS regulate several processes, including contractility, hypertrophy, hyperplasia, migration, differentiation, secretion of inflammatory cytokines, gene expression, extracellular matrix protein deposition, activation of matrix metalloproteinases, and inflammation (Clempus \& Griendling, 2006; Paravicini \& Touyz, 2006). ROS stimulate smooth muscle cell hypertrophy and hyperplasia by regulating the activity of redox-sensitive kinases and phosphatases, which lead to c-Src activation (Clempus \& Griendling, 2006). Several vasoactive ligands, including PDGF, insulin-like growth factor-1, thrombin, vascular endothelial growth factor (VEGF), and monocyte chemoattractant protein-1 (MCP-1) induce redoxdependent migration of vascular smooth muscle cells (Clempus \& Griendling, 2006). ROS mediate smooth muscle cell differentiation from a native, contractile to an invasive, proliferative phenotype in response to arterial injury (Clempus \& Griendling, 2006). Arterial contractility is controlled by ROS by regulating functions of ion channels, including $\mathrm{K}_{\mathrm{Ca}}$ channels (Xi et al., 2005; Clempus \& Griendling, 2006; Paravicini \& Touyz, 2006). In addition, ROS also influence gene expression by activating redoxsensitive transcription factors.

ROS modulate the activity of redox-sensitive transcription factors, including activator protein (AP)-1, nuclear factor kappa B (NF- $\kappa \mathrm{B})$, cyclic AMP response elementbinding protein (CREB), hypoxia-inducible factor-1 alpha (HIF-1 $\alpha$ ), peroxisome proliferator-activated receptors, NF-E2-related factor-2 (Nrf2), Gax, and gut-enriched kruppel-like factor in vascular smooth muscle cells (Clempus \& Griendling, 2006; Gloire et al., 2006). ROS regulation of transcription factor activity occurs via direct and indirect mechanisms (Kunsch \& Medford, 1999). Direct mechanism involves oxidation of the transcription factor, leading to alteration of its activity (Kunsch \& Medford, 1999). ROS can also indirectly control transcription factor function by regulating its post-translational modifications (phosphorylation or dephosphorylation) via redox-sensitive kinases and phosphatases (Kunsch \& Medford, 1999). Both mechanisms alter several properties of transcription factors, including cellular localization, DNA binding, and recruitment of activators and/or repressors (Kunsch \& Medford, 1999). Vasoconstrictors, including Ang II induce expression of genes, including MCP-1 and interleukin (IL)-6 through ROSdependent NF- $\mathrm{BB}$ activation (Chen et al., 1998; Han et al., 1999). Therefore, ROS regulate both physiological and pathological functions in vascular smooth muscle cells.

\subsection{NF-אB in Vascular Smooth Muscle Cells}

\subsubsection{NF- $\mathrm{KB}$ family of proteins}

NF- $\mathrm{KB}$ proteins comprise structurally-related eukaryotic transcription factors that regulate gene expression and control a large number of cellular processes, including immune and inflammatory responses, cellular growth, and apoptosis. NF- $\mathrm{BB}$ proteins 
regulate gene expression by binding to cis-acting $\kappa \mathrm{B}$ sites in the promoter regions. In mammals, there are five NF- $\kappa \mathrm{B} / \mathrm{REL}$ genes, NF- $\kappa \mathrm{B} 1$, NF- $\kappa \mathrm{B} 2$, RELA, c-REL and RELB (Chen \& Greene, 2004; Hayden \& Ghosh, 2008). The NF- $\kappa$ B family of transcription

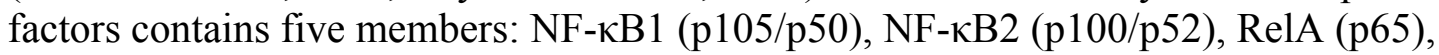
RelB, and c-Rel (Chen \& Greene, 2004; Hayden \& Ghosh, 2008). NF- $\kappa B$ proteins are related through the presence of a highly conserved Rel homology domain in their Nterminal region (Chen \& Greene, 2004; Hayden \& Ghosh, 2008). The Rel homology domain which contains a nuclear localization sequence is involved in DNA binding, dimerization with other NF- $\kappa \mathrm{B}$ proteins, and interaction with the inhibitory I kappa B (IкB) proteins (Chen \& Greene, 2004; Hayden \& Ghosh, 2008). p105 and p100 are processed to generate the DNA binding subunits p50 and p52, respectively. p105 and p100 proteins contain ankyrin repeats, as well as glycine-rich regions in their C-terminal regions. The glycine-rich regions are essential for co-translational processing of p105 to p50 and post-translational processing of p100 to p52 by the ubiquitin-proteasome pathway (Chen \& Greene, 2004; Hayden \& Ghosh, 2008). In addition to the Rel homology domain, p65, c-Rel, and RelB contain transactivation domains in their Cteminal region. Transactivation domains interact with various parts of the transcription apparatus to regulate gene expression (Chen \& Greene, 2004; Hayden \& Ghosh, 2008). p50 and p52 proteins contain the Rel homology domains but lack the transactivation domains. NF- $\kappa$ B proteins are expressed in a cell- and tissue-specific manner (Chen \& Greene, 2004; Hayden \& Ghosh, 2008). p50 and p65 are ubiquitously expressed, whereas NF- $\mathrm{kB} 2$, Rel-B, and c-Rel are specifically expressed in lymphoid tissues (Hayden \& Ghosh, 2008).

NF- $\kappa \mathrm{B}$ proteins dimerize to form homo- or hetero-dimers, which produce specific responses to different stimuli and diverse effects on transcription. The most often observed NF- $\kappa$ B complexes in cells are the p50-p65 and p52-RelB heterodimers (Sun \& Andersson, 2002). Homodimers of p50 and p52 act as transcriptional repressors (Sun \& Andersson, 2002). Presence of different NF- $\kappa$ B homo- and hetero-dimers determines which dimers control transcription. Therefore, depending on the dimer, transcriptional activity is either stimulated or inhibited (Sun \& Andersson, 2002).

\subsection{2. $\quad \mathrm{NF}-\kappa \mathrm{B}$ activation pathways}

There are two modes of signaling pathways, including the "classical/canonical" pathway and the "alternative/non-canonical" pathway, each of which lead to the translocation of NF- $\kappa \mathrm{B}$ dimers from the cytosol to the nucleus (Bonizzi \& Karin, 2004). $\mathrm{NF}-\kappa \mathrm{B}$ activated by each of these pathways regulate the transcription of distinct target genes (Bonizzi \& Karin, 2004; Chen \& Greene, 2004; Hayden \& Ghosh, 2008).

\subsubsection{Classical/Canonical pathway}

The prototypical NF- $\mathrm{kB}$ complex comprising the p50-p65 heterodimer is bound to $\mathrm{I} \kappa \mathrm{B}$ which masks the nuclear localization signal (NLS) of p65 and causes cytosolic 
retention of NF- $\kappa \mathrm{B}$ (Bonizzi \& Karin, 2004). Activation occurs when signalsome

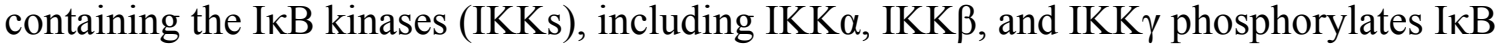
on serine residues 32 and 36 (Karin, 1999). IкB phosphorylation leads to I $\mathrm{B}$ dissociation from the inactive NF- $\kappa \mathrm{B} / \mathrm{I} \kappa \mathrm{B}$ complex (Karin, 1999). Dissociated $\mathrm{I} \kappa \mathrm{B}$ is ubiquitinated and degraded by the $26 \mathrm{~S}$ proteasome complex (Karin, 1999). ІкB degradation unmasks the NLS on p65, leading to nuclear translocation of activated NF$\kappa \mathrm{B}$ and DNA binding (Karin, 1999).

\subsubsection{Alternative/Non-canonical pathway}

Certain stimuli, including B-cell activating factor and CD40 activate NF- $\kappa \mathrm{B}-$ inducing kinase and IKK $\alpha$, leading to NF- $\mathrm{BB} 2$ (p100) phosphorylation (Senftleben et al., 2001). p100 phosphorylation leads to its ubiquitination, and is proteolytically processed by the 26S proteasome to yield p52 (Lin et al., 1998). This pathway principally involves the $\mathrm{p} 52$-RelB heterodimer as opposed to the p50-p65 heterodimer produced by the canonical pathway (Senftleben et al., 2001; Chen \& Greene, 2004).

Upon nuclear translocation, $\mathrm{NF}-\kappa \mathrm{B}$ regulates gene expression by recruiting additional transcriptional activators and/or repressors, which contain $\kappa \mathrm{B}$ consensus sequences (5'-GGGRNYYYCC-3', where $\mathrm{R}$ is a purine, $\mathrm{Y}$ is a pyrimidine, and $\mathrm{N}$ is any nucleic acid) (Chen \& Greene, 2004). One of the target genes that is always stimulated by NF- $\kappa \mathrm{B}$ is $\mathrm{I} \kappa \mathrm{B} \alpha$, which is depleted during the events of NF- $\kappa \mathrm{B}$ activation (Chen \& Greene, 2004). I $\kappa \mathrm{B} \alpha$ expression results in translocating the nuclear NF- $\kappa B$ back to the cytosol, thereby terminating the transcriptional regulation (Chen \& Greene, 2004).

\subsubsection{Mechanisms of NF- $\kappa B$ activation}

$\mathrm{NF}-\kappa \mathrm{B}$ is activated by a range of stimuli, including various pro-inflammatory cytokines, growth factors, DNA-damaging agents, and viral proteins. The cellular events underlying NF- $\kappa \mathrm{B}$ activation consists of IKK activation and $\mathrm{I} \kappa \mathrm{B} \alpha$ degradation (classical pathway) or the post-translational processing of p100 to p52 (alternative pathway) (Sun \& Andersson, 2002). With regard to vascular biology, various stimuli including TNF- $\alpha$, IL-1, advanced glycation end products, hyperglycemia, mechanical stress, ROS, and

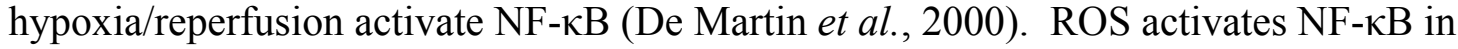
vascular smooth muscle cells and other cell types (Asehnoune et al., 2004; Bubici et al., 2006; Miller, Jr. et al., 2007). In addition, mitoROS activate NF- $\kappa B$ in several cell types, including in cultured vascular smooth muscle cells, skeletal muscle myotubes, and cultured macrophages (Li et al., 1999; Chandel et al., 2000; Lee et al., 2008). The mechanism through which ROS activate NF- $\kappa \mathrm{B}$ appears to involve the activity of IKKs, including IKK $\alpha$ and IKK $\beta$ (Gloire et al., 2006). 


\subsubsection{Regulation of vascular function by NF-кB}

$\mathrm{NF}-\kappa \mathrm{B}$ is constitutively activated and inactivated in arterial smooth muscle cells and is essential for the regulation of a variety of vascular functions, including smooth muscle cell proliferation, angiogenesis, and induction of cytokines (Asehnoune et al., 2004; Bubici et al., 2006; Clempus \& Griendling, 2006; Miller, Jr. et al., 2007). In arterial smooth muscle cells, NF- $\kappa \mathrm{B}$ regulates expression of genes, including vascular cell adhesion molecule-1, IL-1, and c-myc (Bourcier et al., 1997; Detmer et al., 2001). $\mathrm{NF}-\kappa \mathrm{B}$ also induces expression of anti-apoptotic genes, leading to protection during abnormal proliferation (De Martin et al., 2000). The physiological NF- $\kappa \mathrm{B}$-dependent gene expression may be exaggerated in pathological situations, resulting in damage to the vessel wall and impaired vascular cell function (De Martin et al., 2000). High levels of $\mathrm{NF}-\kappa \mathrm{B}$ are present in arterial smooth muscle cells of arteriosclerotic intimal lesions (De Martin et al., 2000).

Previous reports in cultured arterial smooth muscle cells have suggested that NF$\kappa \mathrm{B}$ plays an important role in regulating gene expression and proliferation (Landry et al., 1997). NF- $\kappa \mathrm{B}$ is also involved in regulating gene transcription of ion channels, including amiloride-sensitive $\mathrm{Na}^{+}$channel, small conductance $\mathrm{Ca}^{2+}$-activated $\mathrm{K}^{+}$channel, and TRPC1 channel (Baines et al., 2002; Paria et al., 2006; Kye et al., 2007) in several cell types, including cultured aortic smooth muscle cells. In pathological states, NF- $\kappa \mathrm{B}$ activation has been shown to upregulate $\mathrm{ET}_{\mathrm{B}}$ receptor expression in arterial smooth muscle cells, leading to enhanced contraction (Xu et al., 2008). However, the physiological functions and mechanisms of regulation of NF- $\kappa \mathrm{B}$ in contractile arterial smooth muscle cells are poorly understood. In this study, we have examined the

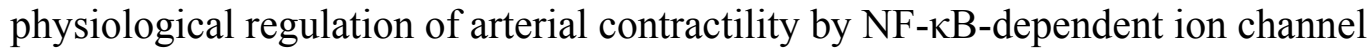
expression.

\subsection{Transcriptional Regulation of Cav1.2 Expression}

$\mathrm{Ca}_{\mathrm{V}} 1.2$ channels are expressed in heart, vascular, and visceral smooth muscle cells (Ertel et al., 2000). The $\alpha_{1 \mathrm{C}}$ subunit of human Cav1.2 is encoded by the CACNA1C gene, which is located in the distal region of chromosome 12 (Tang et al., 2004). CACNA1C contains 55 exons, of which 15 are subjected to alternative splicing, generating 40 reported splice variations, expressed in different tissues (Tang et al., 2004). In smooth muscle cells, alternatively splicing has been reported in exons 1, 8, and 9 in smooth muscle cells, and in exons 1, 8, 31, and 32 in cardiac muscle (Liao et al., 2005). CACNA1C transcription is regulated by different promoters in cardiac muscle and smooth muscle cells (Dai et al., 2002; Saada et al., 2003). CACNA1C transcription is driven by promoters upstream of exon $1 \mathrm{a}$ and $1 \mathrm{~b}$ in cardiac muscle and smooth muscle cells, respectively (Dai et al., 2002; Saada et al., 2003). The promoter driving $\alpha_{1 \mathrm{C}}$ expression in cardiac muscle has binding sites for several transcription factors, including myocyte enhancer factor-2, Nkx2.5, NFAT, and CREB (Dai et al., 2002). The promoter region of $\alpha_{1 C}$ in human colonic smooth muscle cells has 2 binding sites for CREB, which upregulates transcription, and 3 binding sites for NF- $\mathrm{kB}$ which represses transcription 
(Shi et al., 2005; Shi et al., 2007). The identity of the transcription factors which bind to the promoter region of $\alpha_{1 \mathrm{C}}$ in vascular smooth muscle cells are unknown. It is poorly understood if transcription factors regulating $\alpha_{1 \mathrm{C}}$ gene expression in visceral and vascular smooth muscle cells are similar or different. In rat renal arteries, global $\left[\mathrm{Ca}^{2+}\right]_{\mathrm{i}}$ elevation increased $\mathrm{Ca}_{V} 1.2$ protein expression (Pesic et al., 2004). In coronary artery smooth muscle cells, $\mathrm{PKC}$ delta ( $\mathrm{PKC} \delta$ ) increased $\mathrm{Ca}_{\mathrm{V}} 1.2$ protein levels (Maddali et al., 2005). Although these studies report an increase in $\mathrm{Ca}_{\mathrm{V}} 1.2$ protein levels, little is known about the transcriptional regulation of Cav $1.2 \alpha_{1 \mathrm{C}}$ gene in vascular smooth muscle cells.

\subsection{Unresolved Issues}

Smooth muscle cells from small, resistance-size arteries generate multiple types of local and global $\mathrm{Ca}^{2+}$ signals. Physiological functions of vasoconstrictor-induced $\mathrm{Ca}^{2+}$ signals, specifically $\mathrm{Ca}^{2+}$ waves in smooth muscle cells of resistance-size arteries are poorly understood (Miriel et al., 1999; Jaggar, 2001; Mauban et al., 2001; Heppner et al., 2002; Lamont \& Wier, 2004; Jaggar, 2007). Elevation in intracellular $\left[\mathrm{Ca}^{2+}\right]_{\mathrm{i}}$ induces mitochondrial $\mathrm{Ca}^{2+}$ uptake (Poburko et al., 2004; Chalmers et al., 2007), but identity of the intracellular $\mathrm{Ca}^{2+}$ signal(s) that regulate $\left[\mathrm{Ca}^{2+}\right]_{\text {mito }}$ in arterial smooth muscle cells is unclear. Physiological functions of changes in $\left[\mathrm{Ca}^{2+}\right]_{\text {mito }}$ and mitoROS in arterial smooth muscle cells are also poorly understood. Similarly, stimuli that cause mitochondrial depolarization and generate mitoROS in arterial smooth muscle cells are unclear (Rizzuto et al., 1999; Duchen, 2000b; Szado et al., 2003; Poburko et al., 2004). Also, little is known about the mechanisms that regulate NF- $\mathrm{KB}$ activity in contractile arterial smooth muscle cells. $\mathrm{Ca}_{\mathrm{v}} 1.2$ channels are the major $\mathrm{Ca}^{2+}$ entry pathway for smooth muscle cells of resistance-size arteries and are essential for myogenic tone development and blood pressure regulation (Cheng et al., 2007). However, the transcriptional regulation of $\mathrm{Ca}_{\mathrm{V}} 1.2$ gene expression in vascular smooth muscle cells is unclear.

This study aimed to determine the $\mathrm{Ca}^{2+}$ signaling mechanisms that regulate $\left[\mathrm{Ca}^{2+}\right]_{\text {mito }}$ and to investigate the physiological functions of changes in $\left[\mathrm{Ca}^{2+}\right]_{\text {mito }}$ in smooth muscle cells of resistance-size cerebral arteries in their native, contractile phenotype. 


\section{CHAPTER 2. HYPOTHESIS}

\subsection{Goal}

The unifying goal of this study was to test the hypothesis that ET-1-induced $\mathrm{IP}_{3} \mathrm{R}-$ mediated SR $\mathrm{Ca}^{2+}$ release elevates $\left[\mathrm{Ca}^{2+}\right]_{\text {mito }}$ and mitoROS generation, which activates $\mathrm{NF}-\mathrm{\kappa B}$, leading to transcription of $\mathrm{Ca}_{\mathrm{v}} 1.2$ channels and vasoconstriction.

\subsection{Specific Aims}

\subsubsection{Aim 1}

To test the hypothesis that ET-1-induced $\mathrm{IP}_{3} \mathrm{R}$-mediated $\mathrm{SR} \mathrm{Ca}^{2+}$ release elevates $\left[\mathrm{Ca}^{2+}\right]_{\text {mito }}$ leading to mitochondrial depolarization.

Regulation of local and global $\mathrm{Ca}^{2+}$ signals by ET-1 was studied. Mechanisms by which ET-1 regulate $\left[\mathrm{Ca}^{2+}\right]_{\text {mito }}$ and $\psi_{\mathrm{m}}$ were examined in arterial smooth muscle cells. ET-1 regulation of local and global $\mathrm{Ca}^{2+}$ signals was studied in intact arteries using fluo4 , a $\mathrm{Ca}^{2+}$-sensitive fluorescent dye and rapid confocal imaging. $\left[\mathrm{Ca}^{2+}\right]_{\text {mito }}$ was measured in smooth muscle cells of intact arteries using confocal imaging of 2 mt8CG2, a mitochondria-targeted, genetically-encoded $\mathrm{Ca}^{2+}$ indicator. $\psi_{\mathrm{m}}$ was studied by measuring TMRM fluorescence in isolated cerebral artery smooth muscle cells.

\subsection{2. $\quad$ Aim 2}

To investigate the hypothesis that ET-1-induced $\left[\mathrm{Ca}^{2+}\right]_{\text {mito }}$ elevation and mitochondrial depolarization elevate mitoROS production, which activates NF- $\kappa \mathrm{B}$.

The importance of ET-1-induced $\left[\mathrm{Ca}^{2+}\right]_{\text {mito }}$ elevation and mitochondrial depolarization in the mitoROS elevation was examined. The contributions of ET-1induced $\mathrm{IP}_{3} \mathrm{R}$-mediated $\mathrm{SR} \mathrm{Ca}^{2+}$ release and mitoROS elevation in mediating $\mathrm{NF}-\kappa \mathrm{B}$ activation in arterial smooth muscle cells were also studied. MitoROS and cytosolic ROS were measured in smooth muscle cells of intact arteries using genetically-encoded fluorescent ROS indicators targeted to the mitochondria and cytosol, respectively. ROS measurements obtained using genetically-encoded fluorescent ROS indicators were confirmed using 5-(and-6)-chloromethyl-2',7'-dichlorodihydrofluorescein diacetate, acetyl ester (CM- $\left.\mathrm{H}_{2} \mathrm{DCFDA}\right)$ and laser-scanning confocal microscopy. ET-1 regulation of endogenous NF- $\mathrm{BB}$ activity was evaluated by using immunofluorescence to study nuclear translocation of activated NF- $\mathrm{KB}$ in smooth muscle cells of intact arteries. Transcriptional activity of NF- $\kappa \mathrm{B}$ was measured by using luciferase reporter gene assays, which was also used to support results obtained in immmunofluorescence experiments. 


\subsection{3. $\quad$ Aim 3}

To explore the hypothesis that NF- $\kappa \mathrm{B}$, activated by ET-1-induced mitoROS elevation, stimulates $\mathrm{Ca}_{\mathrm{v}} 1.2$ transcription, leading to vasoconstriction.

Mechanisms by which ET-1 elevates Cav1.2 channel expression were investigated. The importance of ET-1-induced mitoROS elevation and NF- $\kappa \mathrm{B}$ activation in regulating $\mathrm{Ca}_{\mathrm{V}} 1.2$ expression in smooth muscle cells of cerebral arteries was studied. $\mathrm{Ca}_{\mathrm{V}} 1.2 \mathrm{mRNA}$ and protein levels were quantified by real-time polymerase chain reaction (RT-PCR) and Western blotting, respectively. Pressurized artery diameter measurements were used to assess the functional effects of the ET-1-induced elevation in Cav1.2 expression. 


\section{CHAPTER 3. MATERIALS AND METHODS*}

\subsection{Vertebrate Animal Subjects}

\subsubsection{Justification of animal use}

Male Sprague-Dawley rats (200-250 g body wt) (12-14 weeks of age) were purchased from Harlan-Teklad Laboratories (Ewing, IL). Rats were chosen for this study because diameter regulation by intravascular pressure, physiological functions of Cav1.2 channels, and vasoconstrictor-induced modulation of local and global $\mathrm{Ca}^{2+}$ signals are best described in rats. Therefore, rats were the most appropriate species in which to conduct this study. All experimental methodologies were carried out ex vivo on appropriate tissues collected from rats immediately following euthanasia. The number of animals used for a given experiment varied based on specific experimental design, variability of the measurements of the parameter in question, and the absolute difference among groups. For biochemical techniques such as Western blotting, it was usual for more than one rat to be used per experimental observation since the arteries used in this study gave smaller protein yields compared to other samples such as rat brain. For nonbiochemical techniques used herein, one rat was typically used per experimental number. In functional studies, more than one drug was tested in a single experiment, either alone, or in combination with other modulators, which increased the experimental observations obtained per animal.

\subsubsection{Information on veterinary care}

Research was conducted in accordance with the Guide for Care and Use of Laboratory Animals, and the provisions of the Animal Welfare Act (USDA) and all other applicable federal and state laws and regulations. Protocols were reviewed and approved by IACUC. The University of Tennessee maintains an AAALAC-accredited facility that is staffed by three full-time veterinarians, two of whom are board-certified in laboratory animal care. The Department of Comparative Medicine (DCM) was responsible for husbandry and veterinary care for all vertebrate animals on campus. Animals were housed by species and health status to minimize infectious disease problems.

* Portions of this chapter adapted with permission. Narayanan D, Xi Q, Pfeffer LM, \& Jaggar JH (2010). Mitochondria control functional $\mathrm{Ca}_{\mathrm{v}} 1.2$ expression in smooth muscle cells of cerebral arteries. Circ Res 107, 631-641. 


\subsubsection{Euthanasia}

3.1.3.1. Procedure for limiting animal discomfort, distress, pain, and injury

All experiments were performed using cerebral arteries isolated from rat brain after euthanization. Rats were rendered pliant (immobile but visibly breathing) with $\mathrm{CO}_{2}$ introduced directly into a specially designed housing chamber, prior to euthanasia by sodium pentobarbital injection. Care was taken at all times to minimize distress to rats during the euthanization process.

\subsubsection{Method of euthanasia}

Rats were euthanized by intraperitoneal injection of sodium pentobarbital solution $(150 \mathrm{mg} / \mathrm{kg}$ ) (Vortech Pharmaceuticals, Dearborn, MI). This method induces euthanasia smoothly and it is consistent with the recommendations of the American Veterinary Medical Association Panel on Euthanasia (American Veterinary Medical Association Panel on Euthanasia, 2001). Overdose of sodium pentobarbital causes rapid unconsciousness, followed by respiratory arrest through paralysis of the diaphragm and collapse of the lungs. The drug then suppresses cardiac activity, thus causing death. A new syringe and small needle was used with each animal to reduce injection trauma. Animal expiration was confirmed by cessation of spontaneous reflex movement to toe/skin pinch, absence of respiration, heartbeat, and corneal reflex. After confirmation of expiration, the rats were euthanized by decapitation and the brain removed, for dissection/removal of cerebral arteries.

\subsection{Tissue Preparation}

The brain was removed and placed into ice-cold $\left(4^{\circ} \mathrm{C}\right)$ HEPES-buffered physiological salt solution (PSS) containing (in $\mathrm{mM}$ ): $134 \mathrm{NaCl}, 6 \mathrm{KCl}, 2 \mathrm{CaCl}_{2}, 1$ $\mathrm{MgCl}_{2}, 10 \mathrm{HEPES}$, and 10 glucose (with $\mathrm{pH}$ adjusted to 7.4 with $\mathrm{NaOH}$ ). Posterior cerebral, middle cerebral, and cerebellar arteries $(\sim 50-200 \mu \mathrm{m}$ diameter) were removed from the brain. The arteries were cleaned of connective tissue. Care was taken while cleaning to avoid stretching and damage to the arteries. The cleaned arteries were placed in a petri dish containing $4^{\circ} \mathrm{C}$ HEPES-buffered PSS. Intact artery segments and enzymatically isolated smooth muscle cells were harvested on the day of experimentation. Enzymatically isolated smooth muscle cells were used for colocalization studies and $\psi_{\mathrm{m}}$ measurements. For all other experiments, intact artery segments were used. 


\subsection{Endothelial Denudation}

When appropriate, endothelial layer of the arterial wall was removed. Briefly, the artery segments (1-2 $\mathrm{mm}$ in length) were cannulated at one end in a perfusion chamber (Living Systems Instrumentation, Burlington, VT). Following cannulation at one end, an air bubble was gently introduced into the arterial lumen for 2 minutes. After 2 minutes, PSS was flushed through the lumen. This approach of endothelial denudation has been shown to be effective in previous studies (Xi et al., 2005; Adebiyi et al., 2008; Zhao et al., 2008).

\subsection{Isolation of Arterial Smooth Muscle Cells}

\subsubsection{Preparation of solutions used for smooth muscle cell isolation}

Isolated cerebral arteries were placed for 15 minutes in a $\mathrm{Ca}^{2+}$-free solution containing (in $\mathrm{mM}$ ): $55 \mathrm{NaCl}, 80$ sodium glutamate, $5.6 \mathrm{KCl}, 2 \mathrm{MgCl}_{2}, 10 \mathrm{HEPES}$, and 10 glucose (with $\mathrm{pH}$ adjusted to 7.4 with $\mathrm{NaOH}$ ). 3 glass vials were rinsed with $\mathrm{KOH}$ and washed thoroughly with distilled water. Papain $(0.7 \mathrm{mg} / \mathrm{ml})$ and dithioerythreitol (1 $\mathrm{mg} / \mathrm{ml})$ were dissolved in enzyme solution $\left(\mathrm{Ca}^{2+}\right.$-free solution containing bovine serum albumin (BSA) $(1 \mathrm{mg} / \mathrm{ml}))$. Collagenases $\mathrm{F}$ and $\mathrm{H}$ were added to enzyme solution supplemented with $\mathrm{CaCl}_{2}(100 \mu \mathrm{M})$ in a ratio of $2: 1(1 \mathrm{mg} / \mathrm{ml}$ total collagenase $)$. Vials containing papain and collagenase solutions were warmed to $37^{\circ} \mathrm{C}$ for 10 minutes prior to transferring arteries into them.

\subsubsection{Dissociation of smooth muscle cells}

\subsubsection{Freshly dissociated cerebral arteries}

Cerebral arteries were placed into vial containing prewarmed papain solution and incubated for 12 minutes at $37^{\circ} \mathrm{C}$. Then, the arteries were immediately transferred to a vial containing prewarmed collagenase solution and incubated for 9 minutes at $37^{\circ} \mathrm{C}$. Arteries were subsequently washed in three petri dishes containing ice-cold $\mathrm{Ca}^{2+}$-free solution for $10 \mathrm{~min}$, to remove the enzymes from the arteries. The rinsed arteries were transferred to a vial containing $\mathrm{Ca}^{2+}$-free solution and triturated gently using three polished glass pasteur pipettes of progressively decreasing diameter of their opening. The trituration process gently dissociates the smooth muscle cells from the arteries. Smooth muscle cells were used for experimentation within 8 hours of dissociation. 


\subsubsection{Reverse-permeabilized arteries}

To deliver expression vectors into smooth muscle cells of intact arteries, reverse permeabilization procedure (described in detail in section 3.8) was used. Reversepermeabilized arteries were then placed in Dulbecco's Modified Eagle Medium (DMEM)/F-12 culture medium (Cellgro, Manassas, VA) supplemented with penicillin/streptomycin (1\%) (Cellgro, Manassas, VA) and placed in a $74 \% \mathrm{~N}_{2} / 21 \%$ $\mathrm{O}_{2} / 5 \% \mathrm{CO}_{2}$ incubator at $37^{\circ} \mathrm{C}$ for 4 days prior to use to allow expression of the genes of interest. After 4 days, smooth muscle cells were isolated and used for colocalization experiments. The protocol for dissociation of smooth muscle cells from reversepermeabilized arteries was similar to that used for dissociating smooth muscle cells from freshly isolated arteries. The durations of papain and collagenase treatments were reduced to 9 and 7 minutes at $37^{\circ} \mathrm{C}$, respectively.

\subsection{Laser-Scanning Confocal $\mathrm{Ca}^{2+}$ Imaging}

\subsubsection{Fluo-4 AM loading}

Endothelium-denuded cerebral artery segments were cannulated on 10-15 mm length borosilicate rectangular tubing (external dimensions: $220 \times 40 \mu \mathrm{m}$ ) (internal dimensions: $200 \times 20 \mu \mathrm{m}$, wall thickness: $20 \mu \mathrm{m}$ ) (Friedrich \& Dimmock Inc., Millville, $\mathrm{NJ}$ ). Branches were removed from cerebral artery segments to provide a flat surface for imaging. Cannulated arteries were incubated in the dark in HEPES-buffered PSS containing fluo-4 AM $(10 \mu \mathrm{M})$ (Molecular Probes, Invitrogen, Eugene, OR) and 0.05\% Pluronic F-127 (Molecular Probes, Invitrogen, Eugene, OR) for 1 hour at room temperature. To allow indicator de-esterification, the cannulated arteries were then placed for 30 minutes at room temperature in $30 \mathrm{mM} \mathrm{K}^{+}$solution containing (in $\mathrm{mM}$ ): $110 \mathrm{NaCl}, 30 \mathrm{KCl}, 10 \mathrm{HEPES}, 2 \mathrm{CaCl}_{2}, 1 \mathrm{MgCl}_{2}$, and 10 glucose (with $\mathrm{pH}$ adjusted to 7.4 with $\mathrm{NaOH}$ ). $30 \mathrm{mM} \mathrm{K}^{+}$solution depolarizes smooth muscle cells to -40 mV, which is similar to the membrane potential of cerebral arteries pressurized to $60 \mathrm{mmHg}$ (Jaggar et al., 1998; Jaggar \& Nelson, 2000; Jaggar, 2001).

\subsubsection{Imaging protocol}

Intracellular $\mathrm{Ca}^{2+}$ signals in cerebral artery smooth muscle cells were imaged using a Noran Oz laser-scanning confocal microscope (Noran Instruments, Middleton, WI) with a $60 \mathrm{X}$ water-immersion objective (numerical aperture=1.2) attached to a Nikon TE300 microscope by illuminating with a krypton-argon laser at $488 \mathrm{~nm}$ and collecting emitted light $>500 \mathrm{~nm}$. Sequential planar images $(256 \times 240$ pixels, $56.3 \times 52.8 \mu \mathrm{m})$ of each region of the arterial wall containing $\sim 8-10$ smooth muscle cells were recorded every $16.6 \mathrm{~ms}(60 \mathrm{~Hz})$ for 10 seconds. In each artery, 2-3 different regions of smooth muscle cells were scanned for each condition. The same area of artery was scanned only once to avoid any laser-induced changes in $\mathrm{Ca}^{2+}$ signaling. $\mathrm{Ca}^{2+}$ spark frequency, $\mathrm{Ca}^{2+}$ 
wave frequency and global $\left[\mathrm{Ca}^{2+}\right]_{\mathrm{i}}$ were analyzed offline using custom software written with IDL 5.3 (Research Systems Inc., Boulder, CO) kindly provided by Dr. M. T. Nelson (University of Vermont, Burlington, VT). The full 10-second acquisition period of each image stack was analyzed to measure $\mathrm{Ca}^{2+}$ sparks, $\mathrm{Ca}^{2+}$ waves, and global $\left[\mathrm{Ca}^{2+}\right]_{\text {. }}$.

\subsubsection{Analysis of cytosolic $\mathrm{Ca}^{2+}$ signals}

\subsubsection{Detection of $\mathrm{Ca}^{2+}$ sparks and $\mathrm{Ca}^{2+}$ waves}

$\mathrm{Ca}^{2+}$ sparks were detected by dividing fluorescence $(\mathrm{F})$ in an area $1.54 \mu \mathrm{m} \times 1.54$ $\mu \mathrm{m}\left(7 \times 7\right.$ pixels, $\left.2.37 \mu \mathrm{m}^{2}\right)$ in individual smooth muscle cells in each image by a baseline fluorescence $\left(\mathrm{F}_{0}\right)$ that was determined by averaging 10 images without $\mathrm{Ca}^{2+}$ spark activity. The entire area of each image was analysed to detect $\mathrm{Ca}^{2+}$ sparks. $\mathrm{A} \mathrm{Ca}^{2+}$ spark was defined as a localized rapid increase in $\mathrm{F} / \mathrm{F}_{0}>1.2$ (Jaggar et al., 2000).

$\mathrm{Ca}^{2+}$ waves were detected by placing $2.2 \times 2.2 \mu \mathrm{m}\left(10 \times 10\right.$ pixel, $\left.4.84 \mu \mathrm{m}^{2}\right)$ boxes in individual smooth muscle cells, and refer to an elevation in $\mathrm{F} / \mathrm{F}_{0}>1.3$ that was monitored for $>200$ milliseconds and propagated for more than $20 \mu \mathrm{m}$.

\subsubsection{Calculation of $\mathrm{Ca}^{2+}$ spark and wave frequency, and global $\left[\mathrm{Ca}^{2+}\right]_{\mathrm{i}}$}

Changes in $\mathrm{Ca}^{2+}$ spark frequency, $\mathrm{Ca}^{2+}$ wave frequency, and global $\left[\mathrm{Ca}^{2+}\right]_{\mathrm{i}}$ in response to pharmacological manipulation were determined in paired arteries. For each condition, $\mathrm{Ca}^{2+}$ spark and wave frequency for a region was calculated by dividing the number of $\mathrm{Ca}^{2+}$ sparks or waves detected in that region by the time of acquisition. $\mathrm{Ca}^{2+}$ spark and wave frequency per cell was calculated by dividing the frequency for each region by the number of smooth muscle cells in that region. $\mathrm{Ca}^{2+}$ spark and $\mathrm{Ca}^{2+}$ wave frequency, and global $\left[\mathrm{Ca}^{2+}\right]_{i}$ that were obtained from smooth muscle cells of multiple regions of the same artery were averaged, giving data under each condition. Global F/ $\mathrm{F}_{0}$ for a given condition was calculated as the mean pixel value of 100 different images acquired over 10 seconds. Global $\left[\mathrm{Ca}^{2+}\right]_{\mathrm{i}}$ was calculated using the following equation: $\left[\mathrm{Ca}^{2+}\right]_{\mathrm{i}}=\mathrm{KR} /\left\{\mathrm{K} /\left(\left[\mathrm{Ca}^{2+}\right]_{\text {rest }}+1-\mathrm{R}\right)\right\}$, where $\mathrm{K}$ is the apparent affinity of fluo-4 AM for $\mathrm{Ca}^{2+}(770 \mathrm{nM})$ (Cheranov \& Jaggar, 2004), $\mathrm{R}$ is the fractional fluorescence increase $\left(\mathrm{F} / \mathrm{F}_{0}\right)$, and $\left[\mathrm{Ca}^{2+}\right]_{\text {rest }}$ is $\left[\mathrm{Ca}^{2+}\right]_{i}$ at $\mathrm{F}_{0}(193 \mathrm{nM})$ (Cheranov \& Jaggar, 2004). Changes in global $\left[\mathrm{Ca}^{2+}\right]_{\mathrm{i}}$ were calculated from a control value previously determined using fura-2 (Cheranov \& Jaggar, 2004). Arterial $\mathrm{Ca}^{2+}$ signal values were then averaged generating mean data. In results, $\mathrm{n}$ (experimental number) refers to the number of arteries from which data were obtained under each condition. 


\subsection{Genetically-Encoded Fluorescent Indicators}

\subsubsection{2mt8CG2}

pMITO-2mt8CG2 vector encoding 2mt8CG2, a genetically-encoded, mitochondria-targeted, fluorescent $\mathrm{Ca}^{2+}$ indicator (Griesbeck et al., 2001; Filippin et al., 2005) was a kind gift from Dr. Tullio Pozzan (University of Padua, Italy). pMITO2mt8CG2 was constructed as follows: firstly, CaM, the $\mathrm{Ca}^{2+}$ probe was inserted into the backbone of yellow fluorescent protein (YFP) in place of Tyr ${ }^{145}$ (Griesbeck et al., 2001). YFP-tagged CaM was then inserted in-frame with two copies of the first 36 amino acids of subunit VIII of human cytochrome c oxidase (ETC complex IV), a mitochondrial specific protein (Filippin et al., 2005). 2mt8CG2 targets to mitochondria via cytochrome c oxidase subunit expression (Filippin et al., 2005). Upon mitochondrial localization, $\mathrm{Ca}^{2+}$ in the mitochondrial matrix binds to CaM and causes a conformational change in YFP, leading to a change in fluorescence (Filippin et al., 2005). 2mt8CG2 has a $\mathrm{K}_{\mathrm{d}}$ for $\mathrm{Ca}^{2+}$ of $\sim 5.3 \mu \mathrm{M}$ (Griesbeck et al., 2001). Therefore, 2mt8CG2 is not capable of detecting changes in global $\left[\mathrm{Ca}^{2+}\right]_{\mathrm{i}}$, which is usually in the nanomolar range (Rizzuto \& Pozzan, 2006).

\subsection{2. mt-cpYFP}

pShuttle-CMV vector encoding mt-cpYFP, a genetically-encoded, mitochondriatargeted, fluorescent $\mathrm{O}_{2}{ }^{-} \cdot$ indicator was a kind gift from Dr. Heping Cheng (Peking University, China). mt-cpYFP comprises a circularly permuted YFP (cpYFP) that selectively detects $\mathrm{O}_{2}^{-}$, the major ROS generated by the mitochondrial ETC (Wang et al., 2008a). mt-cpYFP localizes to mitochondria using subunit IV of cytochrome C oxidase targeting sequence (Wang et al., 2008a). In vitro experiments have suggested that fluorescence changes of cpYFP are highly selective to $\mathrm{O}_{2}{ }^{-} \cdot$ levels since its fluorescence is unchanged by $\mathrm{H}_{2} \mathrm{O}_{2}$ and $\mathrm{ONOO} \cdot$, and is decreased by $\mathrm{OH}^{\cdot}$ and $\mathrm{NO}$ (Wang et al., 2008a).

\subsubsection{HyPer-CYTO}

pHyPer-Cyto vector encoding HyPer-CYTO, a genetically-encoded cytosolic fluorescent $\mathrm{H}_{2} \mathrm{O}_{2}$ indicator was purchased from Axxora, Evrogen (San Diego, CA). HyPer comprises a cpYFP inserted into the regulatory domain of Escherichia Coli OxyR, a prokaryotic $\mathrm{H}_{2} \mathrm{O}_{2}$-sensing protein (Belousov et al., 2006). Upon exposure to $\mathrm{H}_{2} \mathrm{O}_{2}$, the regulatory domain of OxyR undergoes a dramatic conformational change leading to an increase in cpYFP fluorescence (Belousov et al., 2006). HyPer demonstrates affinity to $\mathrm{H}_{2} \mathrm{O}_{2}$ but is insensitive to other oxidants including $\mathrm{O}^{2-}$, reactive nitrogen species, $\mathrm{NO}$, and ONOO· (Belousov et al., 2006). 


\subsection{Transformation of Bacteria}

\subsubsection{Introduction of expression vectors}

Ultracompetent GC10 bacterial cells (Sigma-Aldrich, St.Louis, MO) (transformation efficiency is $\sim 1 \times 10^{9}$ colony-forming units/ $\mu \mathrm{g}$ of plasmid DNA) were used for transformation. Vector ( $\sim 10 \mathrm{ng})$ was added to $\mathrm{GC} 10$ cells $(50 \mu \mathrm{l})$ and incubated at $4^{\circ} \mathrm{C}$ for 30 minutes. Cells were then heat shocked in a water bath at $42^{\circ} \mathrm{C}$ for 45 seconds. This heat shock step permeabilizes the membrane of the competent cells so that the expression vector can enter the cells. Following heat shock, GC10 cells were added to LB Broth $(950 \mu \mathrm{l})$ and incubated for 60 minutes at $37^{\circ} \mathrm{C}$. Incubation allows the cell membranes to recover from heat shock and permits cell replication to begin. Transformed bacteria were then plated onto LB agar plates. Ampicillin $(100 \mu \mathrm{g} / \mathrm{ml})$ resistant plates were used for pMITO-2mt8CG2 vector. Kanamycin $(50 \mu \mathrm{g} / \mathrm{ml})$-resistant plates were used for pShuttle-CMV and pHyPer-Cyto vectors, respectively. Agar plates were then incubated at $37^{\circ} \mathrm{C}$ for 16 to 20 hours. Following incubation, bacterial colonies which have taken up the expression vector and therefore resistant to the antibiotic added to the agar plate, appear on agar plates.

\subsubsection{DNA Maxiprep}

LB Broth $(3 \mathrm{ml})$ was supplemented with ampicillin $(100 \mu \mathrm{g} / \mathrm{ml})$ (for pMITO$2 \mathrm{mt} 8 \mathrm{CG} 2)$ or kanamycin $(50 \mu \mathrm{g} / \mathrm{ml})$ (for pShuttle-CMV and pHyPer-Cyto). LB Broth supplemented with antibodies was inoculated with a single bacterial colony and incubated at $37^{\circ} \mathrm{C}$ at $200 \mathrm{RPM}$ for 6 to 8 hours. This "starter culture" was then added to a large volume of LB Broth $(150 \mathrm{ml})$ supplemented with antibodies and incubated at $37^{\circ} \mathrm{C}$ for 16 to 20 hours or until the solution turns turbid. Incubation allows amplification of the bacteria which have taken up the expression vector. Plasmid cDNA was purified from the bacterial culture using Qiagen Maxiprep HiSpeed Plasmid Purification kit (Qiagen, Valencia, CA).

\subsubsection{Quantification of DNA}

Maxipreped DNA (1:80 dilution) was quantified by measuring the absorbance of UV light at $230 \mathrm{~nm}$ (A230), $260 \mathrm{~nm}$ (A260), and $280 \mathrm{~nm}$ (A280 nm) using a UV spectrophotometer. DNA concentration was calculated using the equation:

DNA concentration $(\mu \mathrm{g} / \mathrm{ml})=(\mathrm{A} 260-\mathrm{A} 230) \times$ dilution factor $\times 50 \mu \mathrm{g} / \mathrm{ml}$

Nucleic acid purity was estimated from A260/A280 and A260/A230 ratios. Ratios between 1.8 and 2.0 generally represent high-quality nucleic acid sample. Reduction of A260/A280 and A260/A230 ratios indicate contamination with protein and organic compounds, respectively. 


\subsection{Reverse Permeabilization}

\subsubsection{Composition of solutions used}

To deliver expression vectors into smooth muscle cells of intact arteries, reverse permeabilization was used (Lesh et al., 1995; Welsh et al., 2002). Compositions of the solutions used for reverse permeabilization are as follows. Solution 1 (in $\mathrm{mM}$ ): 10 EGTA, $120 \mathrm{KCl}, 5 \mathrm{ATP}, 2 \mathrm{MgCl}_{2}, 20 \mathrm{TES}$ (pH 6.8 at $4^{\circ} \mathrm{C}$ ); solution 2 (in $\mathrm{mM}$ ): $120 \mathrm{KCl}$, $5 \mathrm{ATP}, 2 \mathrm{MgCl}_{2}, 20$ TES (pH 6.8 at $4^{\circ} \mathrm{C}$ ); solution 3 (in $\mathrm{mM}$ ): $120 \mathrm{KCl}, 5 \mathrm{ATP}, 10$ $\mathrm{MgCl}_{2}, 20 \mathrm{TES}$ ( $\mathrm{pH} 6.8$ at $4^{\circ} \mathrm{C}$ ); solution 4 (in $\mathrm{mM}$ ): $140 \mathrm{NaCl}, 5 \mathrm{KCl}, 10 \mathrm{MgCl}_{2}, 5.6$ glucose, 2 MOPS (pH 7.1 at $22^{\circ} \mathrm{C}$ ).

\subsubsection{Procedure}

Freshly isolated and cleaned arteries were placed into the following solutions: solution 1 for 20 minutes at $4^{\circ} \mathrm{C}$, solution 2 containing expression vector $(10 \mu \mathrm{g} / \mathrm{ml})$ for 90 minutes at $4^{\circ} \mathrm{C}$, solution 3 containing expression vector $(10 \mu \mathrm{g} / \mathrm{ml})$ for 30 minutes at $4^{\circ} \mathrm{C}$, and solution 4 containing expression vector $(10 \mu \mathrm{g} / \mathrm{ml})$ for 30 minutes at room temperature. $\mathrm{Ca}^{2+}$ concentration in solution 4 was then increased incrementally to (in $\mathrm{mM}$ ): $0.01,0.1$ and 1.8 at 15-minute intervals. Arteries were then placed in DMEM/F-12 culture medium supplemented with penicillin/streptomycin (1\%) and placed in a $74 \%$ $\mathrm{N}_{2} / 21 \% \mathrm{O}_{2} / 5 \% \mathrm{CO}_{2}$ incubator at $37^{\circ} \mathrm{C}$ for 4 days prior to use. Fig. 3-1 illustrates HyPerCYTO expression in smooth muscle cells of intact arteries.

\subsubsection{Principle}

The mechanism of reversible permeabilization has been suggested to involve binding of $\mathrm{ATP}^{4-}$ to cell surface receptors and the removal of membrane-associated divalent cations when the arteries are in solutions 1, 2, and 3 (Lesh et al., 1995). The resulting increase in membrane permeability is responsible for the delivery of the expression vectors into the smooth muscle cells. The increase in membrane permeability is reversed in solution 4 by removal of extracellular ATP and addition of high $\left[\mathrm{Mg}^{2+}\right]$ followed by graded restoration of the physiological concentrations of extracellular $\mathrm{Ca}^{2+}$. Arteries are then placed in DMEM/F-12 culture medium supplemented with penicillin/streptomycin (1\%) for 4 days to allow expression of the genes of interest. Culture of arteries in serum-supplemented DMEM has been suggested to change the phenotype of smooth muscle cell from a contractile to an invasive proliferative one (Absher et al., 1989; Campbell et al., 1989; Eguchi et al., 1994). To prevent the phenotypic change of smooth muscle cells, the arteries are incubated in serum-free DMEM. Studies suggest that reverse permeabilization does not alter the ultrastructural features and contractile properties of smooth muscle cells (Lesh et al., 1995). 

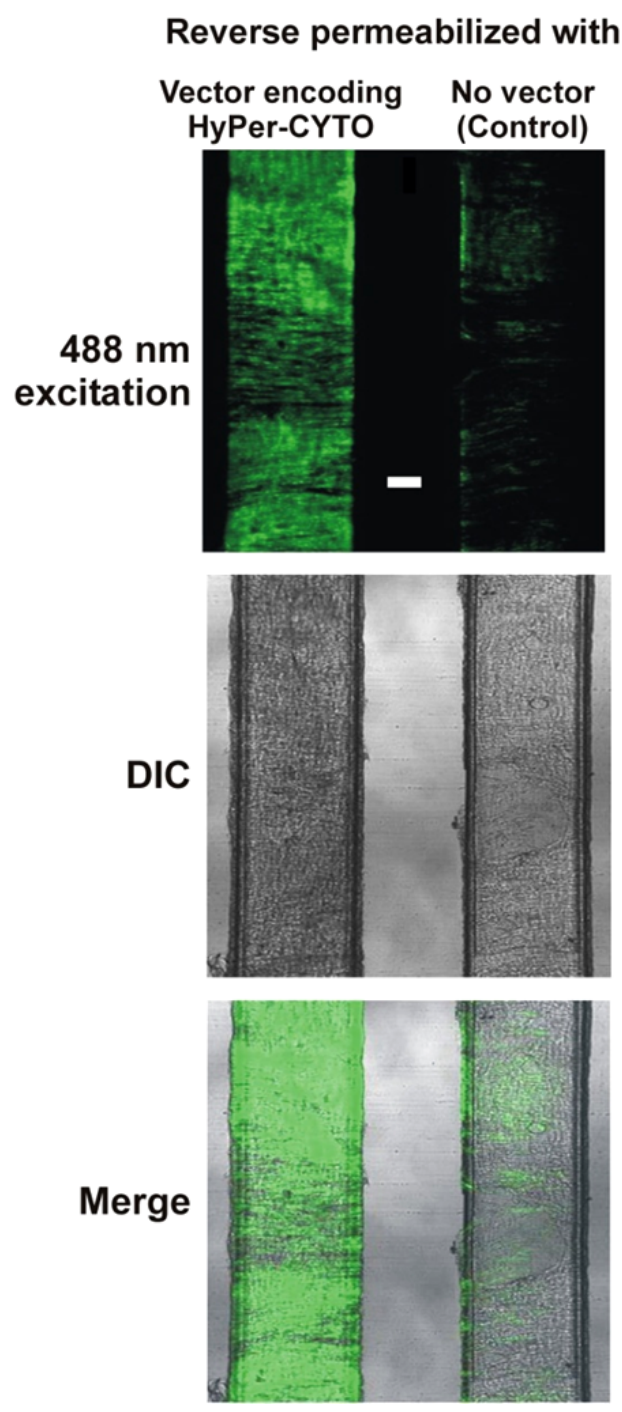

Figure 3-1. Reverse permeabilization of HyPer-CYTO in smooth muscle cells of intact arteries

Notes: Images comparing fluorescence in smooth muscle cells of intact arteries reverse permeabilized with either no vector or vectors encoding HyPer-CYTO. Rectangular glass cannula inserted intralumenally to provide a flat surface for imaging can be seen within each artery. Scale bar $=20 \mu \mathrm{m}$. 


\subsection{Confocal Imaging of Genetically-Encoded Fluorescent Indicators}

\subsubsection{Introduction of indicators into arterial smooth muscle cells}

pMITO-2mt8CG2, pShuttle-CMV, or pHyPer-Cyto vectors were inserted into smooth muscle cells of intact cerebral arteries using reverse permeabilization to express $2 \mathrm{mt} 8 \mathrm{CG} 2$, mt-cpYFP, or HyPer-CYTO, respectively. Following incubation for 4 days in serum-free DMEM, cerebral artery segments were cannulated on borosilicate rectangular tubing for confocal imaging.

\subsubsection{Imaging protocol}

Cannulated artery segment was placed in a No. 0 glass coverslip bottom petri dish (MatTek Corporation, Ashland, MA). 2mt8CG2, mt-cpYFP, or HyPer-CYTO were excited with $488 \mathrm{~nm}$ light and emitted light $>510 \mathrm{~nm}$ captured using a Zeiss LSM5 Pascal laser-scanning confocal microscope. In experiments where indicated, fluorescence was measured in smooth muscle cells of intact arteries. $2 \mathrm{mt} 8 \mathrm{CG} 2$ fluorescence was measured using a z-resolution of $\sim 4.5 \mu \mathrm{m}$, and mt-cpYFP and HyPer-CYTO fluorescence were measured using a z-resolution of $\sim 2.5 \mu \mathrm{m}$. Adjusting the z-plane, the field for image acquisition was chosen in a region containing exclusively of smooth muscle cells. Laser intensity was kept at a minimum while choosing the field to prevent laser-induced bleaching of the indicator fluorescence. Once the imaging field was chosen, the laser intensity was restored to original values. At the end of each experiment, smooth muscle cell viability was confirmed by application of CCCP, which uncouples the ETC and disrupts $\psi_{\mathrm{m}}$, leading to decrease in 2mt8CG2 and mt-cpYFP fluorescence. For experiments performed using HyPer-CYTO, cell viability at the end of each experiment was confirmed by an elevation in fluorescence to $\mathrm{H}_{2} \mathrm{O}_{2}$ application.

\subsubsection{Analysis of confocal images}

Mean intensity of smooth muscle cells in the imaging field was used as a measure of fluorescence. Cerebral arteries reverse permeabilized with no vector were used as controls. Background (autofluorescence) was measured from smooth muscle cells in these arteries with the same imaging parameters (laser intensity, detector gain, and zresolution) used to image smooth muscle cells of intact arteries expressing $2 \mathrm{mt} 8 \mathrm{CG} 2$, mtcpYFP, or HyPer-CYTO. Autofluorescence was then subtracted from all fluorescence measurements obtained from arteries expressing the fluorescent indicators. Following autofluorescence subtraction, changes in indicator fluorescence induced by pharmacological agents were calculated as a $\%$ of the initial pre-exposure fluorescence. Time control measurements were also obtained in arteries expressing the fluorescent indicators. Percentage changes in $2 \mathrm{mt} 8 \mathrm{CG} 2$, mt-cpYFP, or HyPer-CYTO were corrected for indicator bleaching using time control measurements. 


\subsection{Localization of Mitochondria-Targeted Indicators}

\subsubsection{Loading smooth muscle cells with MitoTracker}

To confirm targeting of $2 \mathrm{mt} 8 \mathrm{CG} 2$ and mt-cpYFP to the mitochondria, colocalization experiments were performed with MitoTracker Orange CMTMRos (Molecular Probes, Invitrogen, Eugene, OR), an organic mitochondria-selective dye. MitoTracker Orange CMTMRos is a cell permeant dye which upon entering the cells is sequestered to the mitochondria because of its mildly thiol-reactive chloromethyl moiety (Poot et al., 1996) (Molecular Probes, Invitrogen, Eugene, OR). Smooth muscle cells expressing $2 \mathrm{mt} 8 \mathrm{CG} 2$ or mt-cpYFP were isolated from intact arteries. Dissociated smooth muscle cells were allowed to adhere to glass coverslips for 15 minutes and then incubated with prewarmed $\left(37^{\circ} \mathrm{C}\right) \mathrm{DMEM} / \mathrm{F}-12$ culture medium supplemented with penicillin/streptomycin (1\%) containing MitoTracker Orange CMTMRos (100 nM) for 30 minutes at $37^{\circ} \mathrm{C}$ in a $74 \% \mathrm{~N}_{2} / 21 \% \mathrm{O}_{2} / 5 \% \mathrm{CO}_{2}$ incubator. Following wash with $\mathrm{DMEM} / \mathrm{F}-12$ culture medium for 10 minutes at $37^{\circ} \mathrm{C}$, cells were fixed with $4 \%$ paraformaldehyde in phosphate-buffered saline (PBS) for 15 minutes at room temperature and imaged using a Zeiss LSM5 Pascal laser-scanning confocal microscope.

\subsubsection{Imaging protocol}

MitoTracker and 2mt8CG2 or mt-cpYFP were imaged using an interleaved image acquisition protocol. Interleaved image acquisition requires sequential collection of fluorescence images from the same field for one channel followed immediately for another channel. MitoTracker was excited with $545 \mathrm{~nm}$ light and emitted light $>560 \mathrm{~nm}$ was captured. $2 \mathrm{mt} 8 \mathrm{CG} 2$ or mt-cpYFP was excited with $488 \mathrm{~nm}$ light and emitted light 505-530 nm captured. Bandpass emission filter of 505-530 nm collects fluorescence emitted within that range, and a long pass emission filter of $>510 \mathrm{~nm}$ collects all fluorescence emitted above $510 \mathrm{~nm}$. Bandpass emission filter of 505-530 nm was used to collect $2 \mathrm{mt} 8 \mathrm{CG} 2$ or mt-cpYFP fluorescence to prevent bleedthrough of MitoTracker fluorescence (which emits at wavelength $>560 \mathrm{~nm}$ ) into $2 \mathrm{mt} 8 \mathrm{CG} 2 \mathrm{or}$ mt-cpYFP emission. Isolated smooth muscle cells were imaged using a z-resolution of $\sim 1 \mu \mathrm{m}$ to visualize organelle distribution in the cytosol.

\subsubsection{Analysis of confocal images}

Data was analyzed using the Zeiss LSM5 Pascal colocalization module, which permits interactive analysis of fluorescence from two channels of an image. In a smooth muscle cell, colocalization would occur when fluorescence of $2 \mathrm{mt} 8 \mathrm{CG} 2$ or mt-cpYFP, and MitoTracker, a mitochondria-selective indicator are present in the same pixel. Therefore, weighted colocalization between 2mt8CG2 or mt-cpYFP and MitoTracker was used to quantify mitochondrial targeting of the fluorescent indicator. Weighted colocalization is determined as the sum of intensities of colocalizing pixels in $2 \mathrm{mt} 8 \mathrm{CG} 2$ 
or mt-cpYFP channel compared to sum of intensities of all 2mt8CG2 or mt-cpYFP pixels above threshold (background). The values for weighted colocalization range from 0 to $100 \%$, where 0 indicates no colocalization, and 100 indicates colocalization of all pixels. Threshold value was taken from a region in the imaging field where no cells are present.

\subsection{Imaging 2mt8CG2 in HEK293 Cells}

\subsubsection{Transfection of HEK293 cells with 2 mt8CG2}

Human Embryonic Kidney 293 (HEK293) cells (ATCC, Manassas, VA) were maintained in DMEM culture medium supplemented with $10 \%$ fetal bovine serum (FBS) (Cellgro, Manassas, VA) and penicillin-streptomycin (1\%) under standard tissue culture conditions $\left(74 \% \mathrm{~N}_{2} / 21 \% \mathrm{O}_{2} / 5 \% \mathrm{CO}_{2} ; 37^{\circ} \mathrm{C}\right)$. HEK 293 cells were grown on sterile glass coverslips placed in $35 \mathrm{~mm}$ petri dishes to achieve 20-50\% confluency and transfected using the $\mathrm{Ca}^{2+}$ phosphate method. Briefly, a reaction mixture containing $0.5 \mu \mathrm{g}$ of pMITO-2mt8CG2 and 0.125 $\mathrm{M} \mathrm{CaCl}_{2}$ in N,N-bis(2-hydroxyethyl)-2aminoethanesulfonic acid (BES)-buffered solution was added dropwise to HEK293 cells and placed at $37^{\circ} \mathrm{C}$ for 16 to 18 hours in a $74 \% \mathrm{~N}_{2} / 21 \% \mathrm{O}_{2} / 5 \% \mathrm{CO}_{2}$ incubator. Following aspiration of media, cells were washed with sterile PBS and incubated in DMEM for 24 hours at $37^{\circ} \mathrm{C}$ in a $74 \% \mathrm{~N}_{2} / 21 \% \mathrm{O}_{2} / 5 \% \mathrm{CO}_{2}$ incubator.

\subsubsection{Imaging protocol}

$2 \mathrm{mt} 8 \mathrm{CG} 2$ was excited with $488 \mathrm{~nm}$ light and emitted light $>510 \mathrm{~nm}$ captured using a Zeiss LSM5 Pascal laser-scanning confocal microscope using a z-resolution of $\sim 1 \mu \mathrm{m}$.

\subsection{Tetramethylrhodamine, Methyl Ester Imaging for $\psi_{m}$ Measurements}

\subsubsection{Principle}

$\psi_{\mathrm{m}}$ was studied using tetramethylrhodamine, methyl ester (TMRM) (Molecular Probes, Invitrogen, Eugene, OR), a membrane-permeant fluorescent potentiometric indicator (Scaduto, Jr. \& Grotyohann, 1999; Cheranov \& Jaggar, 2004; Xi et al., 2005). Following cell permeation, TMRM is cleaved by intracellular esterases to yield a cationic fluorescent probe. The mitochondrial matrix is negatively charged compared to the cytosol, thus enabling the uptake of the cationic TMRM into the mitochondrial matrix (Scaduto, Jr. \& Grotyohann, 1999). Mitochondrial depolarization makes the mitochondria more positively charged, thereby leading to extrusion of TMRM from the mitochondria into the cytosol, and eventually from the cell, leading to a decrease in TMRM fluorescence. 


\subsubsection{Procedure}

A small volume $(100 \mu \mathrm{l})$ of $\mathrm{Ca}^{2+}$-free solution containing freshly isolated arterial smooth muscle cells was placed on a No. 0 glass coverslip bottom petri dish. Cells were allowed to adhere to the coverslip for 15 minutes. Cells were subsequently incubated in HEPES-buffered PSS containing TMRM (100 nM) for 20 minutes, followed by a $15-$ minute wash in HEPES-buffered PSS. Solutions were perfused through the petri dish at room temperature. Perfusing solutions containing TMRM $(1 \mathrm{nM})$ in addition to the stimulus were used to maintain a steady extracellular TMRM concentration. This was found to facilitate TMRM reuptake into the mitochondria when the depolarizing stimulus was washed off and when $\psi_{\mathrm{m}}$ returned to its resting negative value. At the end of each experiment, cell viability was confirmed by application of CCCP, which uncouples the ETC and disrupts $\psi_{\mathrm{m}}$, leading to a decrease in TMRM fluorescence.

\subsubsection{Imaging}

In a region, every TMRM-loaded smooth muscle cell was chosen as a separate zone and fluorescence from every zone was collected. To measure temporal changes in TMRM intensity, smooth muscle cells were excited with $535 \mathrm{~nm}$ light, and background corrected fluorescence collected every 1 second at $610 \mathrm{~nm}$ using a Dage MTI iCCD camera and Ionwizard software (Ionoptix, Milton, MA). Background fluorescence was collected from a zone where no smooth muscle cells were present.

\subsubsection{Analysis}

Background-corrected TMRM fluorescence measurements for 2 minutes prior to addition of a stimulus were averaged to obtain the control fluorescence. TMRM fluorescence changes in response to stimuli were normalized to the pre-exposure control fluorescence.

\subsection{Dichlorofluorescein Imaging for ROS Measurements}

\subsubsection{Principle}

ROS measurements in isolated intact cerebral artery segments $(1-2 \mathrm{~mm})$ were performed using CM- $\mathrm{H}_{2}$ DCFDA (Molecular Probes, Invitrogen, Eugene, OR), a cellpermeant ROS indicator. CM- $\mathrm{H}_{2} \mathrm{DCFDA}$, which is an acetylated form of 2', $7^{\prime}-$ dichlorofluorescein (DCF) is hydrolyzed by intracellular esterases to remove the acetate groups yielding the nonfluorescent derivative dichlorodihydrofluorescein $\left(\mathrm{H}_{2} \mathrm{DCF}\right)$ (Jakubowski \& Bartosz, 2000). ROS oxidize the nonfluorescent $\mathrm{H}_{2} \mathrm{DCF}$ to fluorescent DCF (Jakubowski \& Bartosz, 2000; Cheranov \& Jaggar, 2006). Amount of DCF fluorescence is proportional to the amount of ROS present. DCF fluorescence changes 
can therefore be used to measure changes in ROS levels in arterial smooth muscle cells. The thiol-reactive chloromethyl group forms covalent bonds with intracellular components, permitting retention within the cell (Jakubowski \& Bartosz, 2000).

\subsubsection{Procedure}

Cerebral artery segments were cannulated on borosilicate rectangular tubing and incubated for 60 minutes at room temperature in HEPES-buffered PSS containing CM$\mathrm{H}_{2}$ DCFDA $(10 \mu \mathrm{M})$. The DCF-loaded arteries were washed with HEPES-buffered PSS for 15 minutes at room temperature. Following wash, the cannulated arteries were placed on a No. 0 glass coverslip bottom petri dish and imaged using a confocal microscope.

\subsubsection{Imaging}

DCF was excited with $488 \mathrm{~nm}$ light, and emitted light $>510 \mathrm{~nm}$ was collected using a Zeiss LSM5 Pascal laser-scanning confocal microscope using a z-resolution of $\sim 4.5 \mu \mathrm{m}$. Because the dye is susceptible to photo-oxidation, DCF fluorescence can increase spontaneously upon exposure to excitation light (Afzal et al., 2003; Cheranov \& Jaggar, 2006). To reduce the laser-induced photo-oxidation, each arterial region was scanned only once, and the laser intensity was set to minimize excitation.

\subsubsection{Analysis}

Mean intensity of DCF fluorescence from smooth muscle cells in the imaging field was subtracted from background (autofluorescence) to obtain the corrected fluorescence in a field. Autofluorescence was measured in control arteries that were not loaded with DCF but underwent the same imaging protocol (laser intensity, detector gain, and z-resolution). Following autofluorescence subtraction, changes in DCF fluorescence induced by pharmacological agents were calculated as a $\%$ of the initial pre-exposure fluorescence. \% changes in DCF fluorescence were then corrected for time-dependent photo-oxidation-induced elevation in DCF fluorescence. Time control measurements were obtained in smooth muscle cells of intact DCF-loaded arteries that underwent the same imaging protocol, but were not exposed to stimuli.

\subsection{NAD(P)H Oxidase Inhibitors}

gp9 $1^{\text {phox }}$ docking sequence represents the binding site of $\mathrm{p} 47^{\text {phox }}$ subunit of NAD(P)H oxidase (Rey et al., 2001). p47 ${ }^{\text {phox }}$ translocation to the smooth muscle cell membrane and anchoring with gp9 $1^{\text {phox }}$ is required for $\mathrm{NAD}(\mathrm{P}) \mathrm{H}$ oxidase activation (Rey et al., 2001). Therefore, to prevent association of NAD(P)H oxidase subunits and activation of $\mathrm{NAD}(\mathrm{P}) \mathrm{H}$ oxidase, peptides were used. 
gp91ds-tat peptide contains the gp91 ${ }^{\text {phox }}$ docking sequence $\left(\mathrm{NH}_{2}\right.$-LQRRIRTSC$\mathrm{COOH}$ (Rey et al., 2001) conjugated to the $\mathrm{N}$-terminus of a specific amino acid peptide $\left(\mathrm{NH}_{2}\right.$-RRRQRRKKR-COOH) of HIV viral coats (HIV-tat), which is known to be internalized by all cells (Fawell et al., 1994). gp91scrm-tat contains a scrambled gp91 peptide $\left(\mathrm{NH}_{2}\right.$-RSQRTIRLC-COOH) conjugated to N-terminus of HIV-tat (Rey et al., 2001). gp91ds-tat and gp91scrm-tat peptides were synthesized by Tufts University Core Facility (Boston, MA).

\subsection{NF-кB Immunofluorescence}

\subsubsection{Principle}

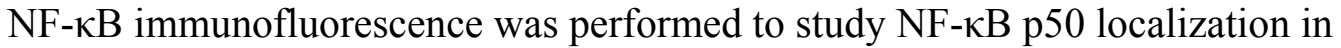
the smooth muscle cells of intact arteries. Following treatment, arteries were incubated with anti-p50 antibody and the corresponding fluorophore-conjugated secondary antibody. Nucleus was labeled using a dimeric cyanine nucleic acid stain. Upon nuclear translocation of p50, colocalization of fluorophore (attached to the secondary antibody) and nucleic acid stain was anticipated.

\subsubsection{Procedure}

Intact arteries were exposed to pharmacological agents in DMEM/F-12 culture medium supplemented with penicillin/streptomycin (1\%) and incubated in a $74 \% \mathrm{~N}_{2} / 21 \%$ $\mathrm{O}_{2} / 5 \% \mathrm{CO}_{2}$ incubator at $37^{\circ} \mathrm{C}$. Following treatment, arteries were fixed with $4 \%$ paraformaldehyde in PBS for 1 hour at room temperature, and washed three times for 5 minutes each with PBS. Permeabilization of cell membrane to facilitate passage of antibodies into cells to bind the protein(s) of interest was done using $0.5 \%$ TritonX-100 dissolved in PBS for 15 minutes at room temperature. After three washes with PBS, arteries were incubated in 5\% BSA in PBS for 1 hour at room temperature. Arteries were then incubated with mouse monoclonal anti-NF- $\mathrm{KB}$ p50 antibody (1:100 dilution; Santa Cruz Biotechnology Inc., Santa Cruz, CA) overnight at $4^{\circ} \mathrm{C}$. The epitope recognized by the anti-NF- $\mathrm{KB}$ p50 antibody is located in the N-terminus (amino acids 120-239) of NF$\kappa \mathrm{B}$ p50 of human origin. After five washes with PBS at room temperature, arteries were incubated with Cy3-conjugated goat anti-mouse IgG (1:100 dilution; Jackson ImmunoResearch, West Grove, PA) for 1 hour at $37^{\circ} \mathrm{C}$. After ten washes with PBS at room temperature, YOYO-1 iodide (1:10,000 dilution; Molecular Probes, Invitrogen, Eugene, OR), a fluorescent nucleic acid indicator and Ribonuclease A (RNase A) (250 $\mu \mathrm{g} / \mathrm{ml}$; Sigma-Aldrich, St.Louis, $\mathrm{MO}$ ) were added for 30 minutes at $37^{\circ} \mathrm{C}$ to counterstain smooth muscle cell nuclei. RNase A was added to destroy cellular RNA and thereby prevent YOYO-1 binding to RNA. A borosilicate rectangular tubing was then placed in the lumen of each fixed artery to provide a flat surface for imaging. The artery was then mounted on a glass slide and used for imaging. 


\subsubsection{Imaging}

NF- $\kappa \mathrm{B}$ localization in smooth muscle cells of intact arteries was examined using a Zeiss LSM 5 Pascal laser-scanning confocal microscope using a z-resolution of $\sim 0.8 \mu \mathrm{m}$. Cy3 was excited with $545 \mathrm{~nm}$ light, and emitted light $>560 \mathrm{~nm}$ was collected. YOYO-1 was excited with $488 \mathrm{~nm}$ light, and emitted light 505-530 nm was collected. YOYO-1 fluorescence was collected using bandpass emission filter $(505-530 \mathrm{~nm})$ instead of long pass emission filter $(>510 \mathrm{~nm})$ to prevent collection of $\mathrm{Cy} 3$ fluorescence into the YOYO1 channel.

\subsubsection{Analysis}

Data was analyzed using the Zeiss LSM5 Pascal colocalization module. Colocalization of p50 and YOYO-1 was determined using weighted colocalization, as previously described in section 3.10.3. Weighted colocalization of p50 pixels with YOYO-1 pixels in the field was used to quantify p50 nuclear translocation. Threshold value for each channel was taken from a region in the imaging field outside the artery.

\subsection{NF-кB-Dependent Luciferase Reporter Gene Activity}

\subsubsection{Vectors encoding luciferase}

NF- $\kappa$ B-p-Luc vector contains a luciferase reporter gene under the control of an $\mathrm{NF}-\kappa \mathrm{B}$ promoter $(\kappa \mathrm{B}$ sites in the promoter region of the immunoglobulin gene). Three $\kappa \mathrm{B}$ sites in the promoter regions are as follows: GGAAATTCCCC (-63 to -53$)$, AGGACTTTCC (-225 to -216), and GGGAAACCCC (-319 to -310) (Le Bail et al., 1993; Arsura et al., 2003; Kaur et al., 2005). pGL3 Basic control vector (Promega Corporation, Madison, WI) which contains the luciferase reporter gene but no promoter was used as a control.

\subsubsection{Principle}

$\mathrm{NF}-\kappa \mathrm{B}$-dependent transcriptional activity was studied using NF- $\mathrm{B}$-dependent luciferase reporter gene assay. NF- $\kappa \mathrm{B}$ binds to promoter of NF- $\kappa \mathrm{B}-\mathrm{p}-\mathrm{Luc}$, leading to transcription of luciferase reporter gene, resulting in luciferase protein expression and fluorescence. Stimuli which activate NF- $\kappa$ B increase the number of NF- $\kappa$ B proteins binding to the $\kappa \mathrm{B}$ sites in the promoter. Transcription of luciferase reporter gene is elevated, leading to an increase in luciferase protein expression and fluorescence. Therefore, fluorescence obtained from NF- $\kappa \mathrm{B}-\mathrm{p}-\mathrm{Luc}$ is proportional to NF- $\kappa \mathrm{B}$ activity.

pGL3 Basic vector contains a luciferase reporter gene but no promoter. Changes in NF- $\kappa \mathrm{B}$ activity would therefore not alter the luciferase expression and fluorescence. 


\subsubsection{Procedure}

NF- $\kappa$ B-p-Luc or pGL3 Basic vectors were inserted into smooth muscle cells of intact arteries using reverse permeabilization. The arteries were then placed for 3 days at $37^{\circ} \mathrm{C}$ in DMEM/F-12 culture medium supplemented with penicillin/streptomycin (1\%) in a $74 \% \mathrm{~N}_{2} / 21 \% \mathrm{O}_{2} / 5 \% \mathrm{CO}_{2}$ incubator. After 3 days, the arteries were exposed to stimuli for an additional 24 hours at $37^{\circ} \mathrm{C}$. Arterial protein lysates were then isolated and quantified (described in detail in section 3.19). Luciferase activity was determined using the Luciferase Assay System (Promega Corporation, Madison, WI).

\subsubsection{Measuring luciferase activity}

Protein lysate $(50 \mu \mathrm{g})$ was added to Luciferase Assay Reagent (100 $\mu \mathrm{l})$ and luciferase luminescence was measured using a TD-20/20 luminometer (Turner Designs, Sunnyvale, CA). As suggested by the vendor (Promega), the luminometer was programmed to perform a 2 -second measurement delay followed by a 10 -second measurement read for luciferase activity. Luminescence measurements were corrected for background luciferase luminescence, which was recorded from lysates of arteries that underwent the same reverse permeabilization, culture, and luminescence measurement protocol, but were not exposed to NF- $\kappa \mathrm{B}-\mathrm{p}-\mathrm{Luc}$ or pGL3 Basic vectors during the reverse permeabilization procedure.

\subsection{Real-Time PCR}

\subsubsection{RNA isolation}

Intact cerebral arteries were either untreated or treated with ET-1 $(10 \mathrm{nM})$ in DMEM/F-12 culture medium supplemented with penicillin/streptomycin (1\%) in a 74\% $\mathrm{N}_{2} / 21 \% \mathrm{O}_{2} / 5 \% \mathrm{CO}_{2}$ incubator for 6 hours at $37^{\circ} \mathrm{C}$. Following treatment, Trizol (Invitrogen, Eugene, OR) was added to arteries, homogenized, and incubated for 5 minutes at room temperature to completely dissociate cellular nucleoprotein complexes. Chloroform was added and centrifuged at $12000 \times \mathrm{g}$ for 15 minutes at $4{ }^{\circ} \mathrm{C}$ to separate the samples into a DNA-containing phenol, a DNA/protein-containing interphase, and an RNA-containing aqueous phase. RNA in the aqueous phase was precipitated by adding isopropyl alcohol and centrifuged at $12000 \times \mathrm{g}$ for 10 minutes at $4^{\circ} \mathrm{C}$. RNA precipitate which forms a gel-like pellet at the bottom of the tube was washed with $75 \%$ ethanol and reconstituted in RNase-free water.

\subsubsection{Quantification of RNA}

RNA concentration was quantified measuring the absorbance of UV light at 230 $\mathrm{nm}$ (A230), $260 \mathrm{~nm}$ (A260), and $280 \mathrm{~nm}$ (A280 nm) using a UV spectrophotometer. 
RNA concentration was calculated from the equation:

RNA concentration $(\mu \mathrm{g} / \mathrm{ml})=(\mathrm{A} 260-\mathrm{A} 230) \times$ dilution factor $\times 40 \mu \mathrm{g} / \mathrm{ml}$

Nucleic acid purity was estimated from A260/A280 and A260/A230 ratios. Ratios between 1.8 and 2.0 generally represent high-quality nucleic acid sample.

\subsubsection{Reverse transcription}

RNA ( $250 \mathrm{ng}$ ) from arteries for each condition was used in reverse transcription to obtain cDNA. The remaining RNA from each condition was used as template in negative control reactions for RT-PCR. cDNA was reverse transcribed from RNA using AffinityScript Multiple Temperature Reverse Transcriptase (Stratagene, Cedar Creek, TX). Briefly, RNA, random primers, and RNase-free water were added to a nucleasefree centrifuge tube and incubated at $65^{\circ} \mathrm{C}$ for 5 minutes. The mixture was slowly cooled to room temperature for 10 minutes, to allow annealing of primers to RNA. DTT (100 $\mathrm{mM})$, dNTP $(100 \mathrm{mM})$, buffer, and reverse transcriptase were added and the reaction incubated at $50^{\circ} \mathrm{C}$ for 1 hour. The reaction was stopped by heat inactivating the enzymes at $70^{\circ} \mathrm{C}$ for 15 minutes. Following reverse transcription, cDNA was used as template for RT-PCR.

\subsubsection{Principle}

TaqMan probes are designed to anneal to the DNA region which is amplified by a pair of primers. Probes consist of a fluorophore which is in close proximity to a quencher, which inhibits fluorescence from the fluorophore (Holland et al., 1991). Using the DNA template, Taq DNA polymerase synthesizes the nascent strand from the 3' end of the primer. TaqMan probe that is annealed to the DNA is degraded by the $5^{\prime}$ to $3^{\prime}$ exonuclease activity of the polymerase. Degradation of the probe releases the fluorophore from it, thereby preventing it from being in close proximity to the quencher, resulting in elevation of fluorescence. Presence of more DNA templates causes probe binding to more DNA, leading to elevated fluorescence. Therefore, fluorescence detected is directly proportional to the amount of DNA template present in the PCR. Since the DNA template used is reverse-transcribed from mRNA, the fluorescence detected is an indication of the cellular mRNA levels and hence, is used to quantify changes in gene expression.

\subsubsection{Primers and probes}

RT-PCR assays, hydrolysis probes, and gene specific primers that span long introns were designed to distinguish cDNA from genomic DNA using primer design online software Universal Probe Library available at http://www.roche-applied-science.com/sis/rtpcr/upl/index.jsp. Primers were ordered 
from Integrated DNA Techonologies (Coralville, IA). Hydrolysis probes were ordered from Molecular Resource Center, University of Tennessee Health Science Center (Memphis, TN). Primers and probes used for RT-PCR are listed in Table 3-1. Melting temperature of all the primers was between 59 and $60^{\circ} \mathrm{C}$.

\subsubsection{PCR conditions}

Quantitative TaqMan PCR reactions were performed using an LC480 light cycler (Roche Applied Science, Indianapolis, IN). Each PCR mixture (10 $\mu$ l) contained $5 \mu$ of Taqman LC480 Master Mix, $0.1 \mu 1$ of forward primer, $0.1 \mu 1$ of reverse primer, $0.1 \mu 1$ of hydrolysis probe, $2.7 \mu \mathrm{l}$ of RNase-free water, and $2 \mu \mathrm{l}$ of cDNA or mRNA template. Reaction was activated at $95^{\circ} \mathrm{C}$ for 5 minutes. Following activation, amplification was performed with 40 cycles of denaturation for 10 seconds at $95^{\circ} \mathrm{C}$, and annealing of primers for 30 seconds at $60^{\circ} \mathrm{C}$, and 1 cycle of extension for 10 seconds at $72^{\circ} \mathrm{C}$. Reaction was cooled to $40^{\circ} \mathrm{C}$ for 5 minutes. A negative control using RNA instead of cDNA was carried out in each experiment. Standard curves using four 10-fold dilution steps of cDNA samples were run for all probe and primer pairs to determine PCR efficiency. PCR efficiency, determined by the slope of standard curves for all primer and probe pairs were between $\sim 1.7$ and 2.3 .

\subsubsection{Analysis}

$\mathrm{Ca}_{\mathrm{v}} 1.2$ mRNA expression under each condition was calculated from the difference between $\mathrm{CT}$ values $(\Delta \mathrm{CT})$ of $\mathrm{Ca}_{\mathrm{V}} 1.2$ and ribosomal protein subunit 5 (Rps5), reference gene. $\Delta \Delta \mathrm{CT}$ was calculated from the difference between the $\Delta \mathrm{CT}$ values for control and ET-1 treatment. ET-1-induced elevation in $\mathrm{Ca}_{\mathrm{v}} 1.2 \mathrm{mRNA}$ levels was calculated using the formula $100 \times\left(2^{-\Delta \Delta \mathrm{CT}}\right)$ (Livak \& Schmittgen, 2001). All PCR reactions including standard curves were performed in triplicate.

\subsection{Agarose Gel Electrophoresis}

Products of RT-PCR were mixed with Green GoTaq Flexi Buffer (Promega Corporation, Madison, WI) and separated by electrophoresis using $2 \%$ agarose gel containing $0.01 \%$ ethidium bromide. Images of fluorescence from ethidium bromide bound to DNA within the gel were collected using the Kodak In-Vivo Imaging System (Carestream Health Inc., Woodbridge, CT) and the Kodak Molecular Imaging Software v4.5.1 (Carestream Health Inc., Woodbridge, CT).

\subsection{Protein Quantification and Estimation}

Cerebral arteries were homogenized in Laemmli sample buffer (2.5\% SDS, 10\% glycerol, $0.01 \%$ bromophenol blue, $5 \% \beta$-mercaptoethanol, and $100 \mathrm{mM}$ Tris- $\mathrm{HCl}, \mathrm{pH}$ 
Table 3-1. Primers and probes used in RT-PCR

\begin{tabular}{|c|c|c|c|}
\hline $\begin{array}{l}\text { Gene } \\
\text { (Accession number) }\end{array}$ & $\begin{array}{c}\text { Forward primer (5'sequence3') } \\
\text { (Position) }\end{array}$ & $\begin{array}{c}\text { Reverse primer (5'sequence3') } \\
\text { (Position) }\end{array}$ & $\begin{array}{l}\text { Hydrolysis probe } \\
\text { (Position) }\end{array}$ \\
\hline $\begin{array}{c}C a_{V} 1.2 \\
(\mathrm{DQ} 538522.1)\end{array}$ & $\begin{array}{c}\text { GAGAGCTTTCCGTGTGCTTC } \\
(727-746)\end{array}$ & $\begin{array}{c}\text { GTTCAGGACCACCTGGAGAC } \\
(777-796)\end{array}$ & $\begin{array}{l}\text { CTGGAGTC } \\
(765-772)\end{array}$ \\
\hline $\begin{array}{c}\text { Rps5 } \\
(\mathrm{NM}+001105722.1)\end{array}$ & $\begin{array}{c}\text { GACTGAGAAGCCCGGTTTG } \\
(70-88)\end{array}$ & $\begin{array}{c}\text { CTTGATGTCCGGGGTCTCT } \\
(134-152)\end{array}$ & $\begin{array}{l}\text { CAGCCACA } \\
(115-122)\end{array}$ \\
\hline $\begin{array}{c}\text { HGPRT } \\
(\text { ENSRNOT00000045153.2) }\end{array}$ & $\begin{array}{c}\text { TCAACGGGGGACATAAAAGT } \\
(394-413)\end{array}$ & $\begin{array}{l}\text { AGTGTCAATTATATCCAAACCCAAT } \\
(462-486)\end{array}$ & $\begin{array}{l}\text { TGGTGGAG } \\
(417-424)\end{array}$ \\
\hline $\begin{array}{c}\text { Cyclophilin B } \\
\text { (ENSRNOT00000022828.4) }\end{array}$ & $\begin{array}{c}\text { ACGTGGTTTTCGGCAAAGT } \\
(524-542)\end{array}$ & $\begin{array}{c}\text { CTTGGTGTTCTCCACCTTCC } \\
(566-585)\end{array}$ & $\begin{array}{l}\text { TGGAAGGC } \\
(545-552)\end{array}$ \\
\hline $\begin{array}{c}\beta \text { tubulin } \\
\text { (ENSRNOT00000023452.4) }\end{array}$ & $\begin{array}{c}\text { CAGAGCCATTCTGGTGGAC } \\
(239-257)\end{array}$ & $\begin{array}{c}\text { GCCAGCACCACTCTGACC } \\
(333-350)\end{array}$ & $\begin{array}{l}\text { GAGCCTGG } \\
(261-268)\end{array}$ \\
\hline $\begin{array}{c}\beta \text { actin } \\
(\text { ENSRNOT00000042459.1) }\end{array}$ & $\begin{array}{c}\text { CCCGCGAGTACAACCTTCT } \\
(17-35)\end{array}$ & $\begin{array}{c}\text { CGTCATCCATGGCGAACT } \\
(71-88)\end{array}$ & $\begin{array}{l}\text { CAGCTCCT } \\
(38-45)\end{array}$ \\
\hline
\end{tabular}


6.8). Tissue debris and nuclear fragments were removed by centrifugation at $6000 \times \mathrm{g}$ for 10 minutes at $4^{\circ} \mathrm{C}$. The whole cell lysate, obtained as a supernatant was transferred to a fresh tube and used for protein quantification and Western blotting. A $5 \mu 1$ aliquot of supernatant was placed on a nitrocellulose membrane, and following amido black staining, protein concentration was measured by spectrophotometric quantification at 630 nm.

\subsection{Western Blotting}

Protein extracts were heated for 3 minutes at $100^{\circ} \mathrm{C}$. Proteins (30 $\mu \mathrm{g}$ per lane) were separated by size on 7.5\% SDS-PAGE Tris-glycine gels. Prestained molecular weight markers (Bio-Rad, Hercules, CA) were used to monitor progress on the gel. Gel was run in MOPS-SDS Running Buffer (containing SDS and Tris-Glycine) at $200 \mathrm{~V}$ until the $37 \mathrm{kDa}$ marker reached the bottom of the gel. Following this, the gel was placed onto a PVDF membrane treated with methanol and placed between two sheets of filter paper between two sponges, all soaked in Transfer Buffer (Tris base, glycine, and methanol), into a binding cassette. Proteins were transferred for 2 hours at $100 \mathrm{~V}$ using a Mini Trans Blot Cell (Bio-Rad, Hercules, CA). The apparatus was placed on ice to manage heat exchange during the transfer.

Membranes were blocked in 5\% nonfat dry milk in Tris-buffered solution (TBS) with $0.1 \%$ Tween-20 (TBS-T) for 1 hour at room temperature. Membranes were then incubated with rabbit monoclonal anti-p105/p50 antibody (1:1000 dilution; Abcam Inc., Cambridge, MA), mouse monoclonal anti-Cav 1.2 antibody (1:200 dilution; UC Davis/NINDS/NIMH NeuroMab Facility), or mouse monoclonal anti-actin antibody (1:50,000 dilution; Millipore, Billerica, MA) overnight at $4^{\circ} \mathrm{C}$ in TBS-T and $5 \%$ nonfat dry milk. Anti-Cav 1.2 antibody was produced against intracellular C-terminus (amino acids 1507-1733) of rabbit $\mathrm{Ca}_{\mathrm{V}} 1.2$. Epitope recognized by the anti-actin antibody is located in the N-terminus (amino acids 50-70) of actin. Following overnight incubation with primary antibodies, membranes were washed three times with TBS-T for 5 minutes each, and incubated for 1-2 hours at room temperature with HRP-conjugated secondary antibody in TBS-T and 5\% nonfat dry milk. Membranes were then washed three times with TBS-T for 5 minutes each, and incubated with enhanced chemiluminiscence substrate (Amersham, Arlington heights, IL) for the HRP enzyme conjugated in the secondary antibody.

HRP-induced chemiluminescence from bound secondary antibodies was detected using a Kodak In-Vivo Imaging System and visualized using the Kodak Molecular Imaging Software v4.5.1. Membranes were developed multiple times using different exposure times, to optimize band intensity for densitometric analysis.

The PVDF membranes can be reprobed for other proteins after probing them for one. To achieve this, the membrane was stripped using a Stripping Buffer (Thermo Scientific, Rockford, IL) for 15 minutes at room temperature, washed with TBS-T, reblocked, and reprobed as explained above. 


\subsection{Densitometric Analysis of Western Blots}

Band intensity was quantified using digital densitometry using Quantity One software v4.6.9 (Bio-Rad, Hercules, CA). Briefly, background-subtracted band density was calculated by placing rectangular boxes of the same size around bands in each lane. Average band density was calculated from all images of the same blot acquired using different exposure times. Averaged band density for a protein was then normalized to the band density of actin for the corresponding sample. Actin was used to normalize data because pharmacological treatments used in this study did not alter its expression.

\subsection{NF-кB p105 Knockdown}

\subsubsection{Principle}

siRNA are long double-stranded RNA molecules that have a characteristic two nucleotide 3 ' overhang that allows them to be recognized by the enzymatic machinery of RNA interference. siRNA are separated into single strands which homology-dependently bind to target mRNA. siRNA-mRNA complex is eventually destroyed by the RNAinduced silencing complex, leading to target mRNA degradation. siRNA-mediated reduction in mRNA levels translate to a decrease in target protein levels.

\subsubsection{Procedure}

Two siRNAs directed against NF- $\mathrm{B}$ p105 subunit (p105siRNA1 and p105siRNA2) (10 $\mu \mathrm{g} / \mathrm{ml}$ each) (Qiagen, Valencia, CA) were used to inhibit p105 expression. p105siRNA1 and p105siRNA2 were directed against target sequences in regions 458-478 and 939-959, respectively of p105 sequence (XM_001075876). Scrambled siRNA (p105scrm) $(20 \mu \mathrm{g} / \mathrm{ml})$ (Qiagen, Valencia, CA) was used as a control. siRNAs were introduced into smooth muscle cells of intact cerebral arteries using reverse permeabilization (Lesh et al., 1995; Welsh et al., 2002). After 3 days in DMEM/F-12 culture medium supplemented with penicillin/streptomycin (1\%) in a $74 \% \mathrm{~N}_{2} / 21 \%$ $\mathrm{O}_{2} / 5 \% \mathrm{CO}_{2}$ incubator at $37^{\circ} \mathrm{C}$, arteries were exposed to stimuli for an additional 24 hours at $37^{\circ} \mathrm{C}$. Artery segments were then either used for pressurized artery diameter

measurements or protein lysates were isolated, quantified, and used for Western blotting.

\subsection{Pressurized Artery Diameter Measurements}

\subsubsection{Procedure}

Experiments were performed using PSS containing (in $\mathrm{mM}$ ): $112 \mathrm{NaCl}, 4.8 \mathrm{KCl}$, $26 \mathrm{NaHCO}_{3}, 1.8 \mathrm{CaCl}_{2}, 1.2 \mathrm{MgSO} 4,1.2 \mathrm{KH}_{2} \mathrm{PO}$, and 10 glucose (with $\mathrm{pH}$ adjusted to 
7.4 with $\mathrm{NaOH}$ ). Prior to use, PSS was oxygenated by bubbling with $74 \% \mathrm{~N}_{2} / 21 \%$ $\mathrm{O}_{2} / 5 \% \mathrm{CO}_{2}$. Endothelium-denuded artery segments $1-2 \mathrm{~mm}$ in length were cannulated at each end in a temperature-controlled perfusion chamber (Living Systems Instrumentation, Burlington, VT) containing PSS. Care was taken to cannulate artery segments that did not have a branch or tear in their wall. The chamber containing the cannulated artery was placed on the stage of a Nikon TS100-F microscope. Intravascular pressure was altered using a water-filled reservoir and monitored using a pressure transducer. Arterial wall diameter was measured at $1 \mathrm{~Hz}$ using a CCD camera attached to the Nikon TS100-F microscope and diameter changes measured in real time using the automatic edge-detection function of IonWizard software. Luminal flow was absent during experiments. Vessels were constantly superfused with PSS alone or containing pharmacological agent(s).

At the beginning of each experiment, the artery was allowed to equilibrate for 10 minutes at an intravascular pressure of $\sim 10 \mathrm{~mm} \mathrm{Hg}$. The artery dilated during this equilibration process because of its exposure to warm PSS. After the arterial diameter at $10 \mathrm{~mm} \mathrm{Hg}$ became stable for a period of 5 minutes, the intravascular pressure was elevated to $\sim 60 \mathrm{~mm} \mathrm{Hg}$. Elevation of intravascular pressure to $60 \mathrm{~mm} \mathrm{Hg}$ resulted in arterial dilation. The artery was allowed to sense the elevated intravascular pressure and develop pressure-induced vasoconstriction (myogenic tone). Pharmacological stimuli were perfused only after myogenic tone remained steady for a period of 15 minutes. After perfusion of the stimulus in PSS, stable diameter achieved for a period of 5 minutes was considered as active diameter. After a stimulus was washed off, time was given for the arterial diameter to return to its myogenic tone before addition of the next stimulus. Arterial diameter after perfusion of $\mathrm{Ca}^{2+}$-free solution containing EGTA $(10 \mathrm{mM})$ and nimodipine $(1 \mu \mathrm{M})$ was considered as passive diameter. Endothelial denudation was confirmed by the lack of response to carbachol $(1 \mu \mathrm{M})$, an endothelial-dependent vasodilator.

\subsubsection{Analysis}

Experimental traces were analyzed using IonWizard software. Measurements were obtained when the diameter remained stable. Myogenic tone (\%) was calculated as $100 \times(1$-active diameter/passive diameter $)$.

\subsection{Reagents and Chemicals}

$\mathrm{XeC}$ and 17-octadecynoic acid (17-ODYA) were purchased from Cayman Chemical Company (Ann Arbor, MI). Manganese (III) tetrakis (1-methyl-4-pyridyl) porphyrin (MnTMPyP) was purchased from AG Scientific Inc.(San Diego, CA). Apocynin and Ru360 were purchased from EMD Chemicals (Gibbstown, NJ). Recombinant rat TNF- $\alpha$ was purchased from BD Pharmingen (BD Biosciences, San Jose, $\mathrm{CA})$. All other reagents and chemicals were purchased either from Sigma-Aldrich Company (St.Louis, MO) or Fisher Scientific (Pittsburgh, PA), unless specified. 


\subsection{Statistical Analysis}

OriginLab and GraphPad InStat software were used for statistical analyses. Values are expressed as mean \pm SEM. Student's $t$-test with two-tail $p$ value was used for comparing paired and unpaired data from two populations. Ordinary one-way ANOVA followed by Student-Newman-Keuls post-hoc test were used for all multiple data comparisons. For ANOVA, the values were assumed to be sampled from a Gaussian distribution. Repeated measures ANOVA could not be performed since all the conditions to be compared were not paired and the sample numbers were not identical. Adjustments for multiple comparisons were made when necessary. $\mathrm{P}<0.05$ was considered statistically significant.

Power analysis was carried out where $\mathrm{P}>0.05$ to verify that sample size was sufficient to give a power value of $>0.8$. Power value, which is directly proportional to the sample size, is the probability of correctly rejecting the null hypothesis that there is no significant difference between the groups. The Type I error probability that the null hypothesis was falsely rejected was set to 0.05 . Power analysis was performed using PS Power and Sample Size Calculations software (Dupont \& Plummer, Jr., 1990). 


\section{CHAPTER 4. RESULTS*}

\subsection{ET-1 Modifies Local and Global $\mathrm{Ca}^{2+}$ Signals in Cerebral Artery Smooth Muscle Cells}

The regulation of local and global $\mathrm{Ca}^{2+}$ signals by ET-1, a PLC-coupled receptor agonist and vasoconstrictor, was studied in smooth muscle cells of endothelium-denuded cerebral artery segments using Noran Oz high-speed laser-scanning confocal imaging and fluo-4 AM. ET-1 elevated mean $\mathrm{Ca}^{2+}$ wave frequency from $\sim 0.34$ to $1.42 \mathrm{~Hz}(\sim 135 \%$ of control), reduced mean $\mathrm{Ca}^{2+}$ spark frequency from $\sim 1.06$ to $0.4 \mathrm{~Hz}(\sim 32 \%$ of control), and increased mean global $\left[\mathrm{Ca}^{2+}\right]_{\mathrm{i}}$ from $\sim 193$ to $253 \mathrm{nM}(\sim 127 \%$ of control) (Fig. 4-1). Pretreatment with $\mathrm{XeC}$, an $\mathrm{IP}_{3} \mathrm{R}$ inhibitor (Gafni et al., 1997) did not alter ET-1-induced $\mathrm{Ca}^{2+}$ spark inhibition but blocked ET-1-induced $\mathrm{Ca}^{2+}$ wave activation (Fig. 4-1D). In the presence of XeC, ET-1 elevated global $\left[\mathrm{Ca}^{2+}\right]_{\mathrm{i}}$ from $\sim 193$ to $225 \mathrm{nM}$ ( $\sim 113 \%$ of control) (Fig. 4-1D). Data indicate that ET-1-induced $\mathrm{IP}_{3} \mathrm{R}$ activation increases $\mathrm{Ca}^{2+}$ wave frequency and contributes to global $\left[\mathrm{Ca}^{2+}\right]_{\mathrm{i}}$ elevation but does not regulate ET-1-induced $\mathrm{Ca}^{2+}$ spark inhibition.

\subsection{ET-1-Induced $\mathrm{IP}_{3} \mathrm{R}-\mathrm{Mediated} \mathrm{SR} \mathrm{Ca} \mathrm{Ca}^{2+}$ Release Elevates $\left[\mathrm{Ca}^{2+}\right]_{\text {mito }}$ in Cerebral Artery Smooth Muscle Cells}

To study $\left[\mathrm{Ca}^{2+}\right]_{\text {mito }}$ in arterial smooth muscle cells, complex loading procedures have previously been used to enhance mitochondrial loading of synthetic, inorganic $\mathrm{Ca}^{2+}$ indicators such as Rhod-2 (Monteith \& Blaustein, 1999). Since inorganic $\mathrm{Ca}^{2+}$ indicators cannot be targeted to specific subcellular localizations, non-specific measurements of $\left[\mathrm{Ca}^{2+}\right]_{\text {mito }}$ were inevitably obtained (Hajnoczky et al., 1995; Monteith \& Blaustein, 1999; Kaftan et al., 2000; Trollinger et al., 2000; Collins et al., 2001; Gerasimenko \& Tepikin, 2005). To specifically measure $\left[\mathrm{Ca}^{2+}\right]_{\text {mito, }}$, genetically-encoded, targetable $\mathrm{Ca}^{2+}$ indicators have been developed (Griesbeck et al., 2001; Filippin et al., 2005). Regulation of $\left[\mathrm{Ca}^{2+}\right]_{\text {mito }}$ by ET-1-induced $\mathrm{Ca}^{2+}$ signals was measured in smooth muscle cells of intact arteries using $2 \mathrm{mt} 8 \mathrm{CG} 2$, a genetically-encoded, mitochondria-targeted, fluorescent $\mathrm{Ca}^{2+}$ indicator (Griesbeck et al., 2001; Filippin et al., 2005).

* Portions of this chapter adapted with permission. Narayanan D, Xi Q, Pfeffer LM, \& Jaggar JH (2010). Mitochondria control functional $\mathrm{Ca}_{\mathrm{V}} 1.2$ expression in smooth muscle cells of cerebral arteries. Circ Res 107, 631-641. 
A

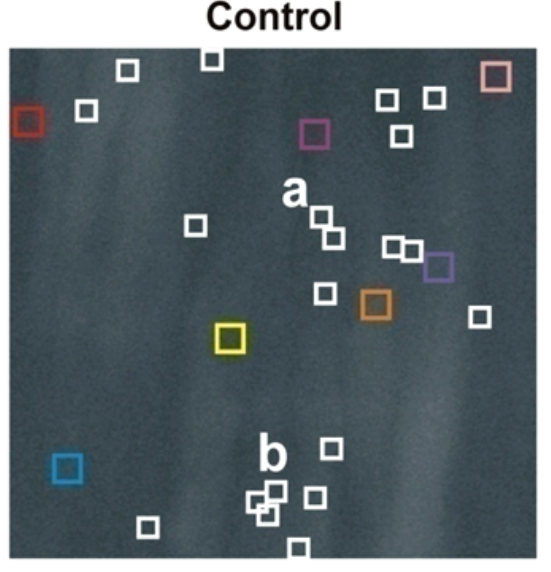

ET-1

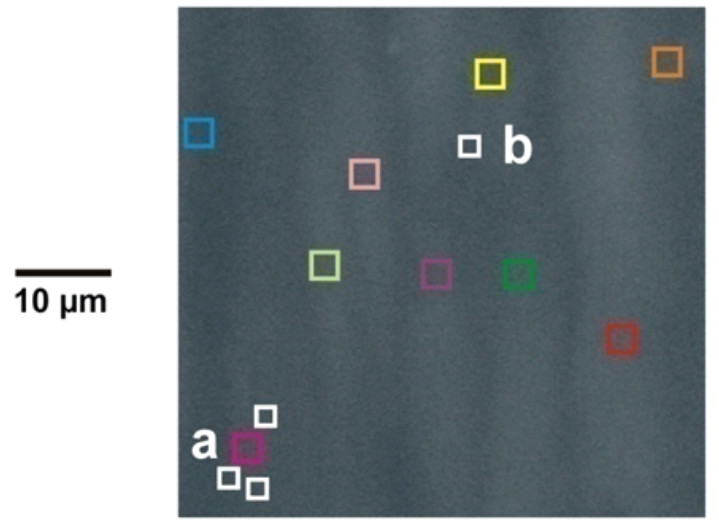

B

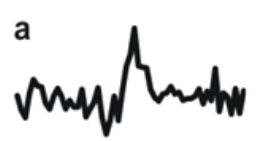
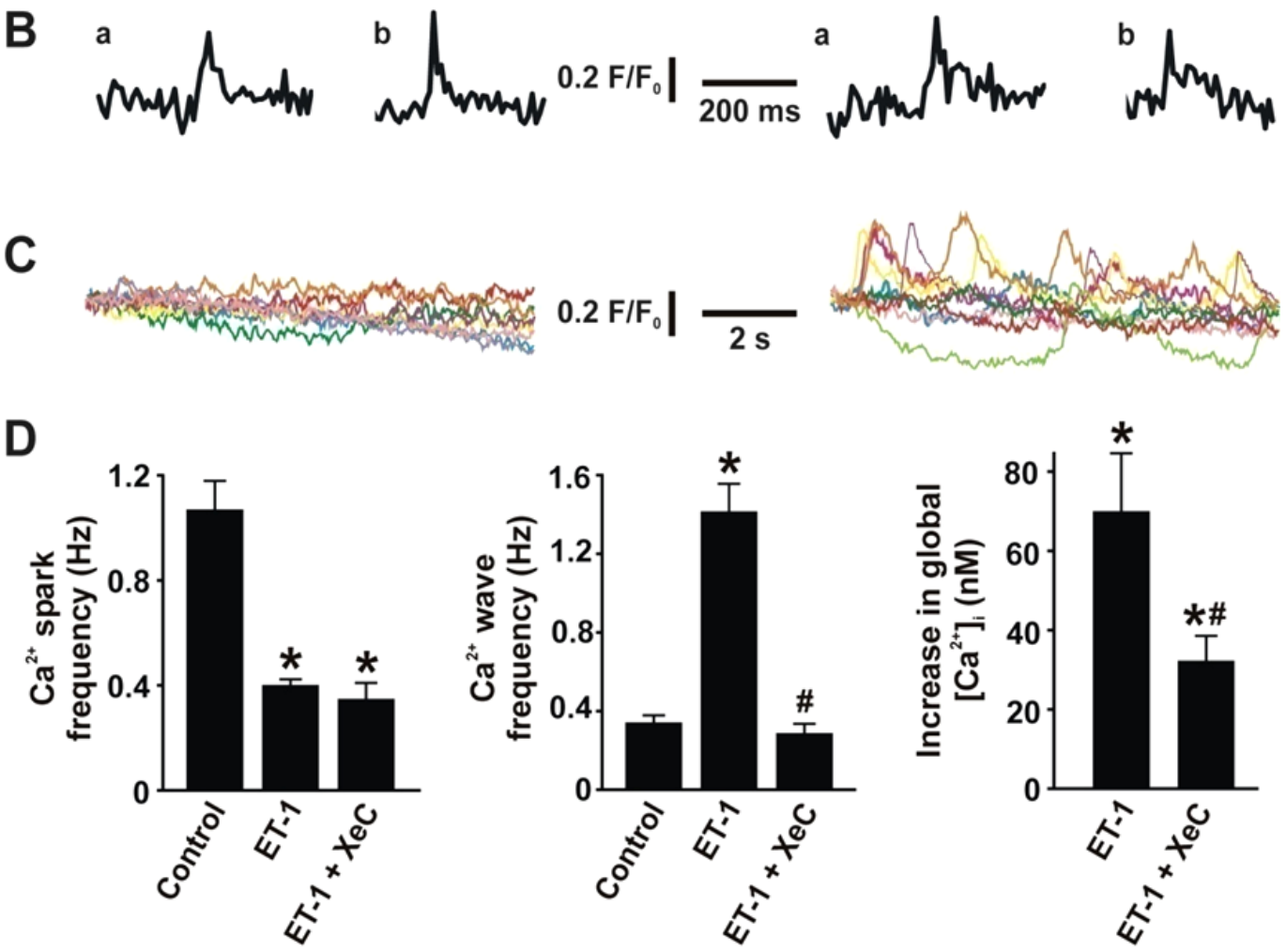

Figure 4-1. ET-1 regulates local and global $\mathrm{Ca}^{2+}$ signals in arterial smooth muscle cells

Notes: A, Confocal images illustrating average fluo-4 fluorescence in smooth muscle cells in the same artery in control and after ET-1 (10 nM). White boxes illustrate locations where $\mathrm{Ca}^{2+}$ sparks occurred during 10 seconds of imaging. Colored boxes illustrate locations from where normalized fluorescence $\left(\mathrm{F} / \mathrm{F}_{0}\right)$ over time traces shown in $\mathrm{C}$ were obtained. $\mathrm{B}$, Two representative $\mathrm{Ca}^{2+}$ sparks that occurred at locations labeled in A for each condition. $\mathrm{C}, \mathrm{F} / \mathrm{F}_{0}$ over time traces illustrate that $\mathrm{ET}-1$ elevates $\mathrm{Ca}^{2+}$ wave frequency. $\mathrm{D}$, Mean data ( $\mathrm{n}=7$ for each condition). Values are expressed as mean $\pm \mathrm{SEM}$. * indicates $\mathrm{P}<0.05$ compared to control. \# indicates $\mathrm{P}<0.05$ compared to ET-1. 


\subsubsection{Mitochondrial localization of $2 \mathrm{mt8CG} 2$}

\subsubsection{HEK293 cells}

2mt8CG2 expression in HeLa cells produces punctuate fluorescence when localized to mitochondria (Filippin et al., 2005). Here, transfection of HEK293 cells with the pMITO-2mt8CG2 vector by using $\mathrm{Ca}^{2+}$ phosphate, reproduced the punctuate fluorescence pattern when visualized using a Zeiss LSM 5 Pascal laser-scanning confocal microscope, suggesting mitochondrial localization of 2mt8CG2 (Fig. 4-2A).

\subsubsection{Cerebral artery smooth muscle cells}

pMITO-2mt8CG2 vector was inserted into smooth muscle cells of intact cerebral arteries using reverse permeabilization (Lesh et al., 1995; Welsh et al., 2002). Confocal imaging revealed punctate staining in smooth muscle cells, indicating mitochondrial localization of $2 \mathrm{mt} 8 \mathrm{CG} 2$ (Fig. 4-2B). To confirm mitochondrial targeting of $2 \mathrm{mt} 8 \mathrm{CG} 2$, colocalization studies were performed using MitoTracker Orange. 2mt8CG2 fluorescence exhibited $\sim 95 \%$ pixel colocalization with MitoTracker Orange, confirming mitochondrial localization (Fig. 4-2C).

\subsection{2. $\quad\left[\mathrm{Ca}^{2+}\right]_{\text {mito }}$ measurements using $2 \mathrm{mt8CG2}$}

In smooth muscle cells of intact arteries, ET-1 increased mean 2mt8CG2 fluorescence to $\sim 140 \%$ of control, and this elevation was blocked by thapsigargin and $\mathrm{XeC}$ (Fig. 4-3A,B), suggesting that ET-1 elevates $\left[\mathrm{Ca}^{2+}\right]_{\text {mito }}$ due to $\mathrm{IP}_{3} \mathrm{R}$-mediated SR $\mathrm{Ca}^{2+}$ release. Thapsigargin was applied 15 minutes prior to ET-1, a time course sufficient to deplete $\mathrm{SR} \mathrm{Ca}^{2+}$ load (Xi et al., 2008). Ionomycin, a $\mathrm{Ca}^{2+}$ ionophore (Liu \& Hermann, 1978), elevated mean $2 \mathrm{mt} 8 \mathrm{CG} 2$ fluorescence to $\sim 137 \%$ of control in smooth muscle cells of intact arteries (Fig. 4-3B), consistent with the fluorescence range of this indicator (Filippin et al., 2003; Filippin et al., 2005). Ru360, a MCU blocker (Matlib et al., 1998), also blocked the ET-1-induced elevation in 2mt8CG2 fluorescence (Fig. 4-3B), indicating that ET-1-induced mitochondrial $\mathrm{Ca}^{2+}$ uptake occurs through the MCU. Thapsigargin, $\mathrm{XeC}$, or Ru360 alone did not alter 2mt8CG2 fluorescence (Fig. 4-3B). Membrane depolarization $\left(60 \mathrm{mM} \mathrm{K}^{+}\right)$, which elevates global $\left[\mathrm{Ca}^{2+}\right]_{\mathrm{i}}$, did not alter $2 \mathrm{mt} 8 \mathrm{CG} 2$ fluorescence (Fig. 4-3B), suggesting that $\left[\mathrm{Ca}^{2+}\right]_{\text {mito }}$ elevation occurs due to local $\mathrm{Ca}^{2+}$ signals and not due to global $\left[\mathrm{Ca}^{2+}\right]_{\mathrm{i}}$ elevation. $\mathrm{CCCP}$, a protonophore that disrupts $\psi_{\mathrm{m}}$ by permeabilizing the inner mitochondrial membrane to $\mathrm{H}^{+}$(Goldsby \& Heytler, 1963; Heytler, 1963) and abolishes the driving force for mitochondrial $\mathrm{Ca}^{2+}$ uptake (McCarron \& Muir, 1999), reduced 2mt8CG2 fluorescence to $\sim 63 \%$ of control (Fig. 4-3B). Results with Ru360 and CCCP confirm the mitochondrial localization of $2 \mathrm{mt8CG} 2$. These data indicate that ET-1-induced $\mathrm{IP}_{3} \mathrm{R}$-mediated $\mathrm{SR} \mathrm{Ca}^{2+}$ release elevates $\left[\mathrm{Ca}^{2+}\right]_{\text {mito }}$ in arterial smooth muscle cells. 


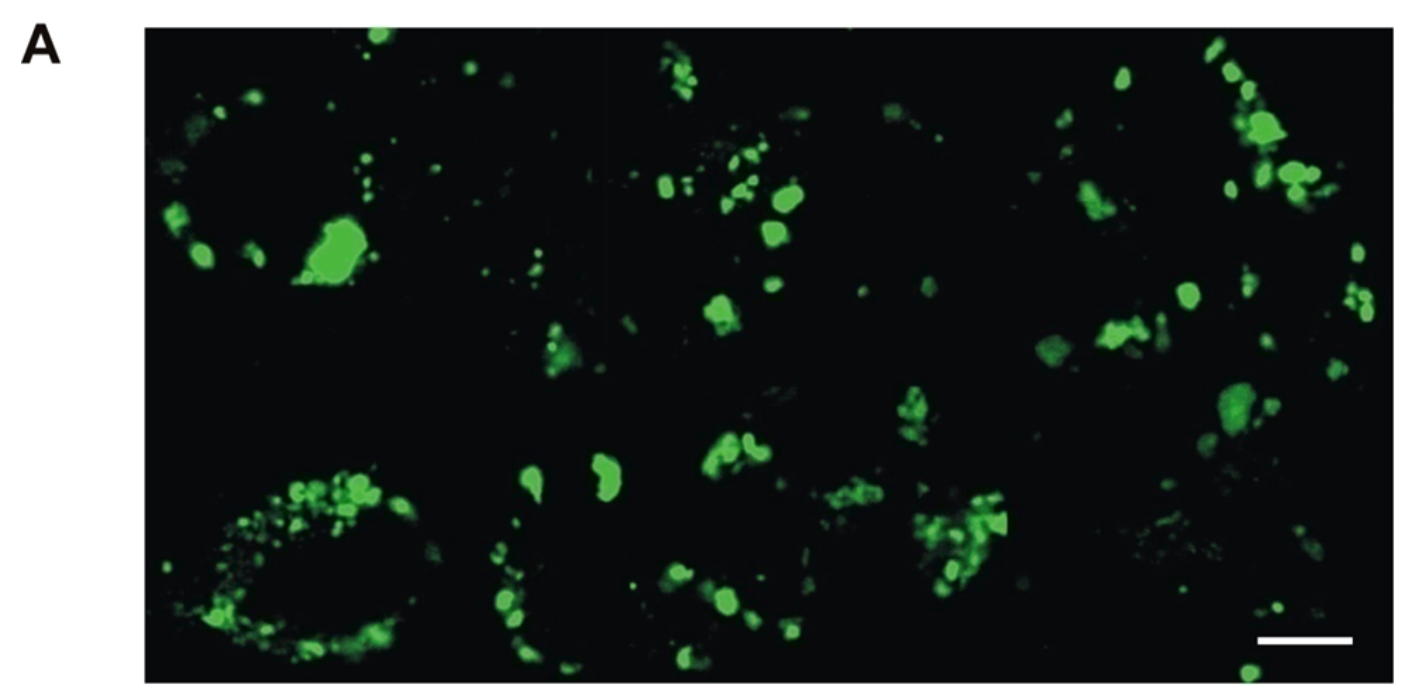

B

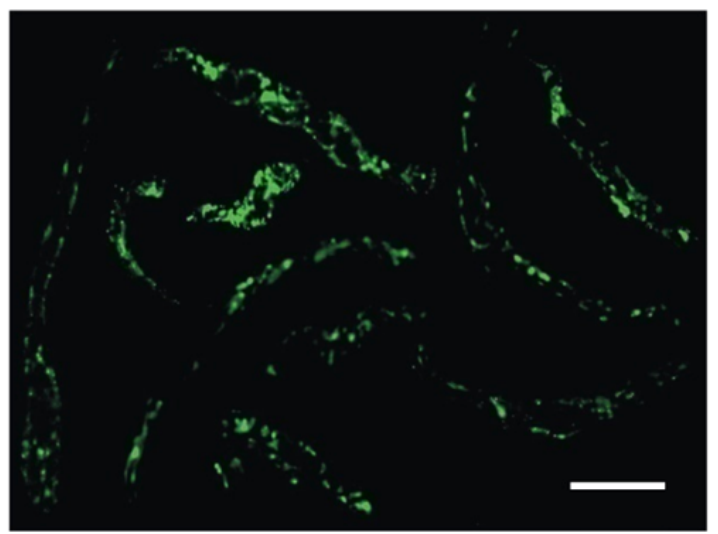

C
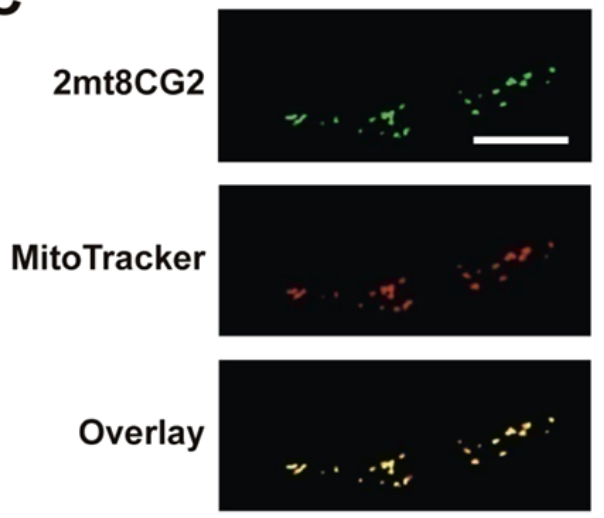

DIC

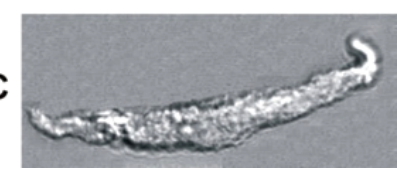

Figure 4-2. Mitochondrial localization of 2mt8CG2 in HEK293 cells and cerebral artery smooth muscle cells

Notes: A, Confocal image illustrates punctate fluorescence of 2mt8CG2 in HEK293 cells. B, Confocal image of smooth muscle cells dissociated from arteries reverse permeabilized with pMITO-2mt8CG2. Punctate pattern of fluorescence suggests mitochondrial targeting of $2 \mathrm{mt} 8 \mathrm{CG} 2$. C, Colocalization of punctate $2 \mathrm{mt} 8 \mathrm{CG} 2$ fluorescence with MitoTracker Orange in a smooth muscle cell. Colocalization quantified using weighted colocalization was $94.8 \pm 0.8 \%(n=10, p<0.001)$. Scale bar=10 $\mu \mathrm{m}$. 
A
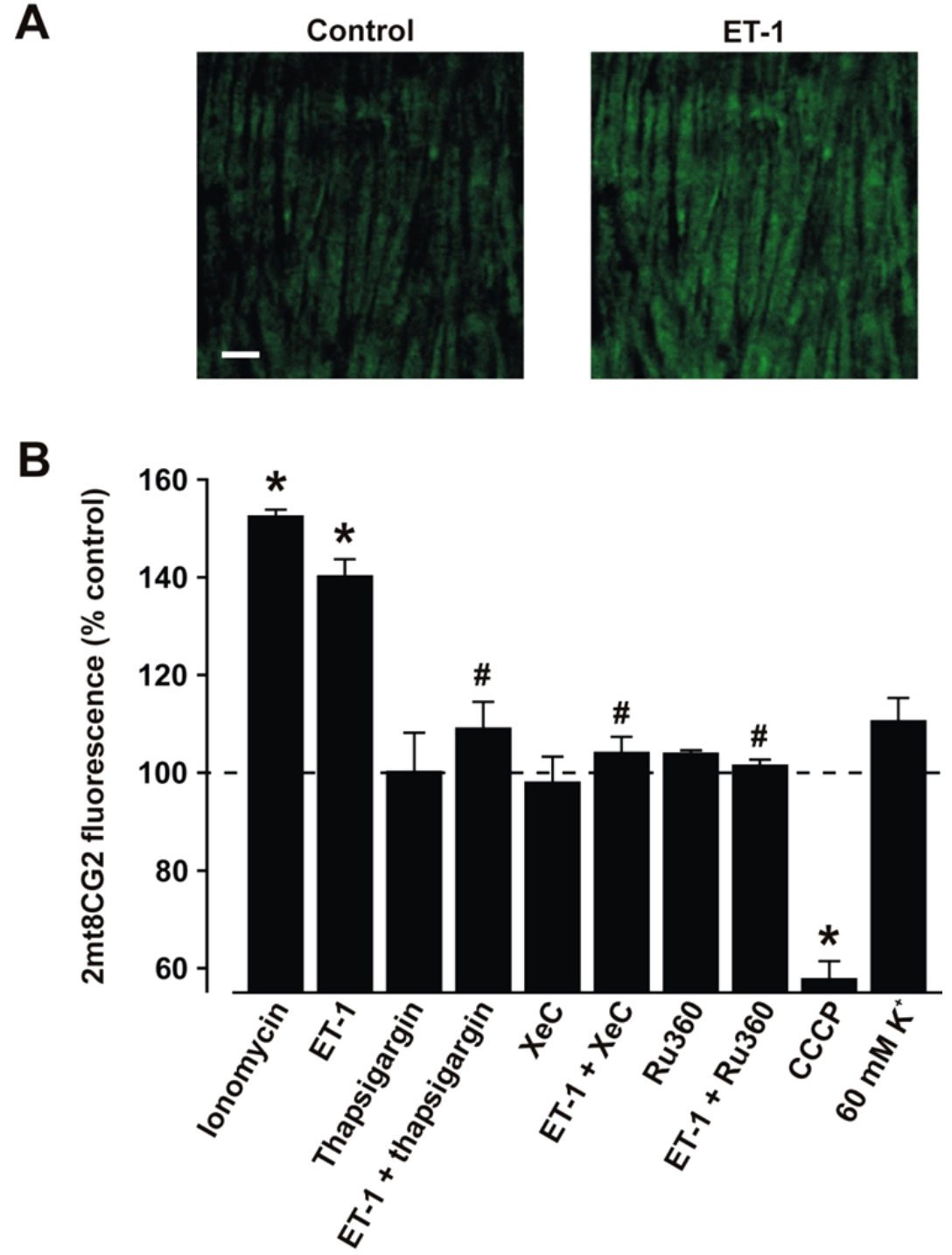

Figure 4-3. ET-1-induced $\mathrm{IP}_{3} \mathrm{R}$-mediated $\mathrm{SR} \mathrm{Ca}^{2+}$ release elevates $\left[\mathrm{Ca}^{2+}\right]_{\text {mito }}$ in arterial smooth muscle cells

Notes: A, Confocal images of $2 \mathrm{mt} 8 \mathrm{CG} 2$ fluorescence in smooth muscle cells in the same area of a cerebral artery in control and ET-1. Scale bar $=10 \mu \mathrm{m}$. B, Average changes in $2 \mathrm{mt} 8 \mathrm{CG} 2$ fluorescence for ionomycin $(10 \mu \mathrm{M}, \mathrm{n}=7)$, ET-1 $(\mathrm{n}=8)$, thapsigargin $(100 \mathrm{nM}$, $\mathrm{n}=5)$, ET-1+thapsigargin $(\mathrm{n}=6), \mathrm{XeC}(20 \mu \mathrm{M}, \mathrm{n}=5), \mathrm{ET}-1+\mathrm{XeC}(\mathrm{n}=6), \mathrm{Ru} 360(10 \mu \mathrm{M}$, $\mathrm{n}=4)$, ET-1+Ru360 $(\mathrm{n}=4)$, CCCP $(10 \mu \mathrm{M}, \mathrm{n}=4)$, and $60 \mathrm{mM} \mathrm{K}^{+}(\mathrm{n}=6)$. ET-1

concentration was $100 \mathrm{nM}$ in all experiments. Values are expressed as mean $\pm \mathrm{SEM}$. * indicates $\mathrm{P}<0.05$ compared to control. \# indicates $\mathrm{P}<0.05$ compared to ET-1. 


\subsection{ET-1-Induced $\mathrm{IP}_{3} \mathrm{R}-$ Mediated SR $\mathrm{Ca}^{2+}$ Release Depolarizes Mitochondria in Cerebral Artery Smooth Muscle Cells}

Regulation of mitochondria potential ET-1 was studied in isolated smooth muscle cells using TMRM. ET-1 $(30 \mathrm{nM})$ reversibly reduced TMRM fluorescence intensity to $\sim 67 \%$ of control (Fig. 4-4A-C). A second application of ET-1 (30 nM) produced a similar amplitude change in TMRM fluorescence ( $\sim 69 \%$ of control), indicating that the first ET-1 application did not desensitize the ET-1 receptors (Fig. 4-4A,B). ET-1 caused concentration-dependent reduction in TMRM fluorescence with an $\mathrm{EC}_{50}$ of $29 \mathrm{nM}$ (Fig. 4-4B). Thapsigargin and $\mathrm{XeC}$ abolished the ET-1-induced reduction in TMRM fluorescence, but did not alter TMRM fluorescence when applied alone (Fig. 4-4C). CCCP reduced TMRM fluorescence intensity to $\sim 34 \%$ of control, whereas $60 \mathrm{mM} \mathrm{K}^{+}$did not alter TMRM fluorescence (Fig. 4-4C). These data indicate that ET-1-induced IP $\mathrm{I}_{3} \mathrm{R}$ mediated SR $\mathrm{Ca}^{2+}$ release depolarizes mitochondria in arterial smooth muscle cells. In contrast, a global $\left[\mathrm{Ca}^{2+}\right]_{\mathrm{i}}$ elevation does not alter $\psi_{\mathrm{m}}$.

\subsection{ET-1-Induced $\mathrm{IP}_{3} \mathrm{R}$-Mediated SR $\mathrm{Ca}^{2+}$ Release and $\left[\mathrm{Ca}^{2+}\right]_{\text {mito }}$ Elevation Stimulates MitoROS Generation}

\subsubsection{MitoROS measurements using mt-cpYFP}

To examine physiological functions of $\left[\mathrm{Ca}^{2+}\right]_{\text {mito }}$, we tested the hypothesis that an elevation in $\left[\mathrm{Ca}^{2+}\right]_{\text {mito }}$ may alter mitoROS generation. MitoROS was measured using mtcpYFP, a genetically-encoded mitochondria-targeted fluorescent $\mathrm{O}_{2}{ }^{-} \cdot$ indicator (Wang et al., 2008a).

\subsubsection{Mitochondrial localization of mt-cpYFP}

Mitochondrial targeting of mt-cpYFP was studied by performing colocalization studies using MitoTracker Orange. mt-cpYFP fluorescence exhibited $\sim 95 \%$ pixel colocalization with MitoTracker Orange, indicating mitochondrial localization (Fig. 4-5).

\subsubsection{ET-1 elevates mitoROS production}

In smooth muscle cells of intact arteries, ET-1 elevated mt-cpYFP fluorescence to $\sim 199 \%$ of control, and this was blocked by XeC, Ru360, rotenone, a mitochondrial ETC complex I inhibitor (Fukami et al., 1967), and micromolar CCCP (Fig. 4-6A,B). When applied alone, rotenone and micromolar CCCP reduced mt-cpYFP fluorescence to $\sim 54$ and $64 \%$ of control, respectively (Fig. 4-6B). In contrast, Ru360, XeC, and $60 \mathrm{mM} \mathrm{K}^{+}$ did not alter mt-cpYFP fluorescence (Fig. 4-6B). In cerebral artery smooth muscle cells, $1 \mathrm{nM}$ CCCP reduced TMRM fluorescence to $\sim 87 \%$ of control, and elevated DCF fluorescence to $\sim 140 \%$ of control, suggesting that a low concentration of CCCP induces a 
Figure 4-4. ET-1-induced $\mathrm{IP}_{3} \mathrm{R}$-mediated $\mathrm{SR} \mathrm{Ca}^{2+}$ release depolarizes mitochondria in arterial smooth muscle cells

Notes: A, ET-1 caused reproducible mitochondrial depolarization in cerebral artery smooth muscle cells. ET-1-induced mitochondrial depolarization was blocked by pretreatment with $\mathrm{XeC}(20 \mu \mathrm{M})$. B, Concentration-dependent mitochondrial depolarization by ET-1 ( $n=4-7)$. C, Average changes in TMRM fluorescence for ET-1 $(n=37)$, second ET-1 application $(n=12)$, thapsigargin $(100 n M, n=18)$, ET$1+$ thapsigargin $(n=18), \operatorname{XeC}(20 \mu M, n=12), E T-1+X e C(n=12), 60 \mathrm{mM} \mathrm{K}^{+}(n=10)$, and CCCP $(10 \mu \mathrm{M}, \mathrm{n}=65)$. ET-1 concentration was $30 \mathrm{nM}$ in all experiments. Values are expressed as mean \pm SEM. * indicates $\mathrm{P}<0.05$ compared to control. \# indicates $\mathrm{P}<0.05$ compared to ET-1. 
A

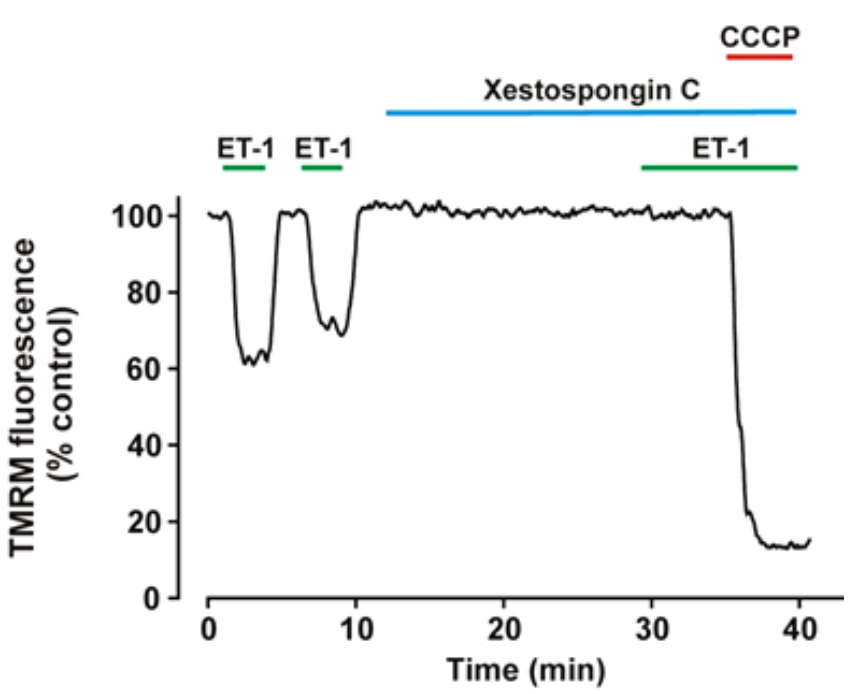

B

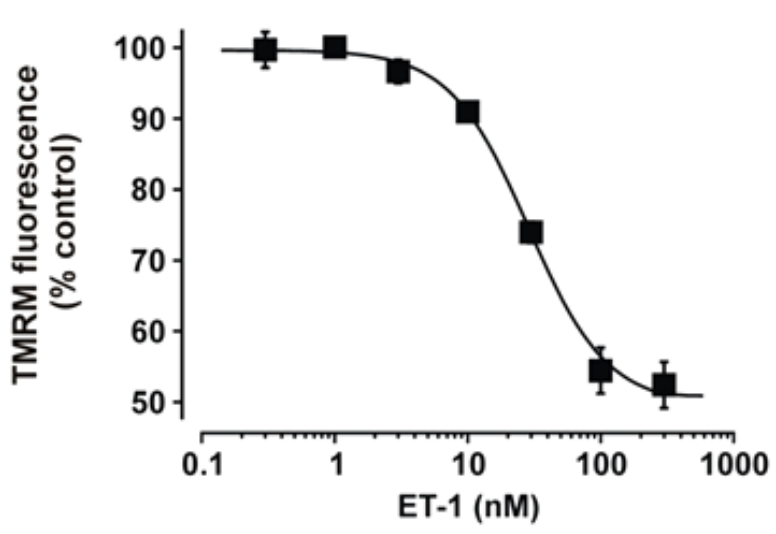

C

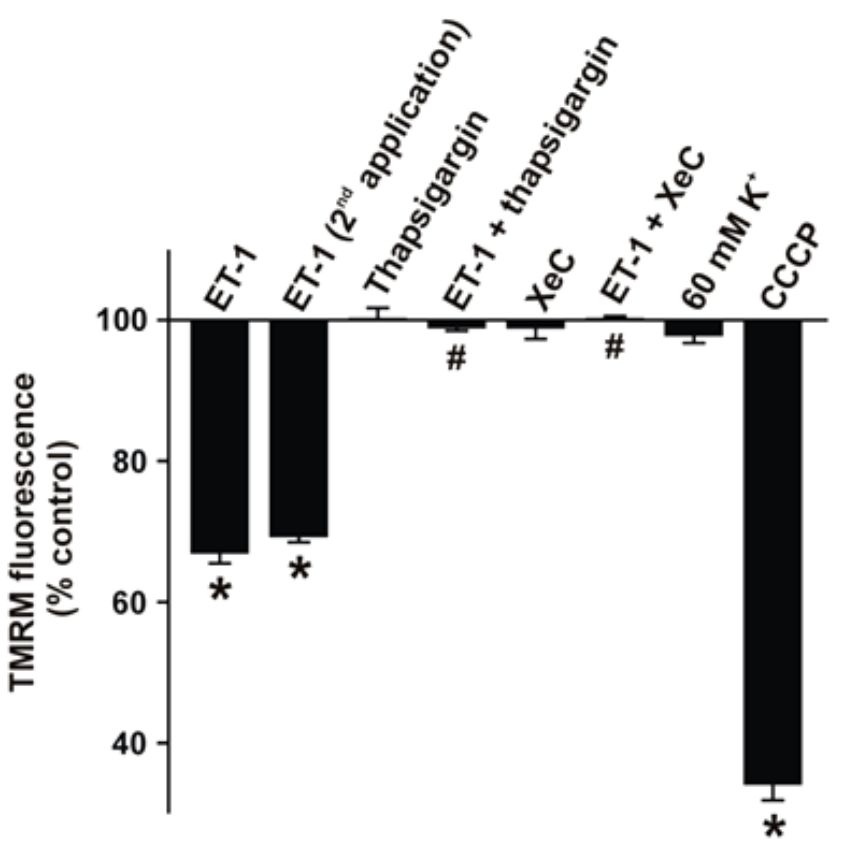



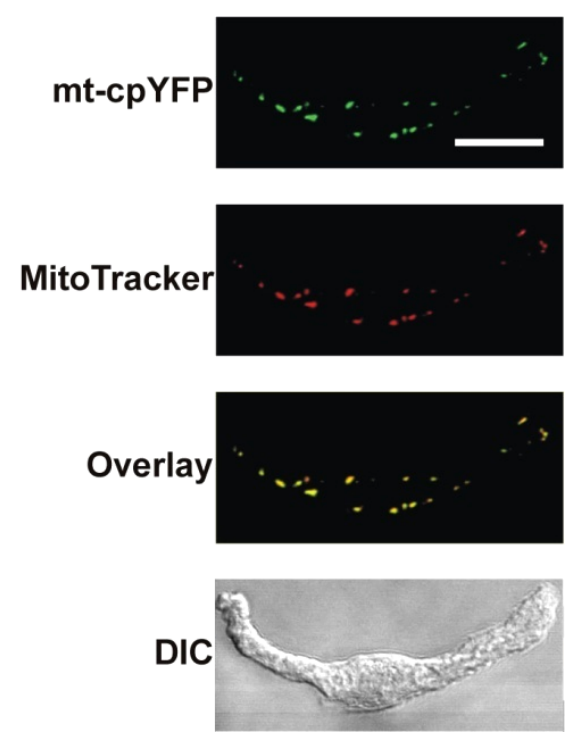

Figure 4-5. Mitochondrial localization of mt-cpYFP in cerebral artery smooth muscle cells

Notes: Confocal images illustrate colocalization of punctate mt-cpYFP fluorescence with MitoTracker Orange in a smooth muscle cell. Colocalization quantified using weighted colocalization was $94.7 \pm 1.2 \%(\mathrm{n}=10, \mathrm{p}<0.001)$. Scale bar $=10 \mu \mathrm{m}$. 
A
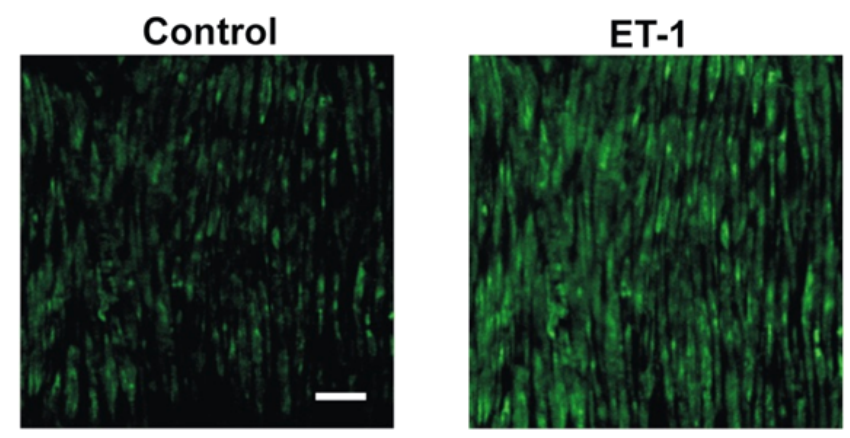

\section{B}

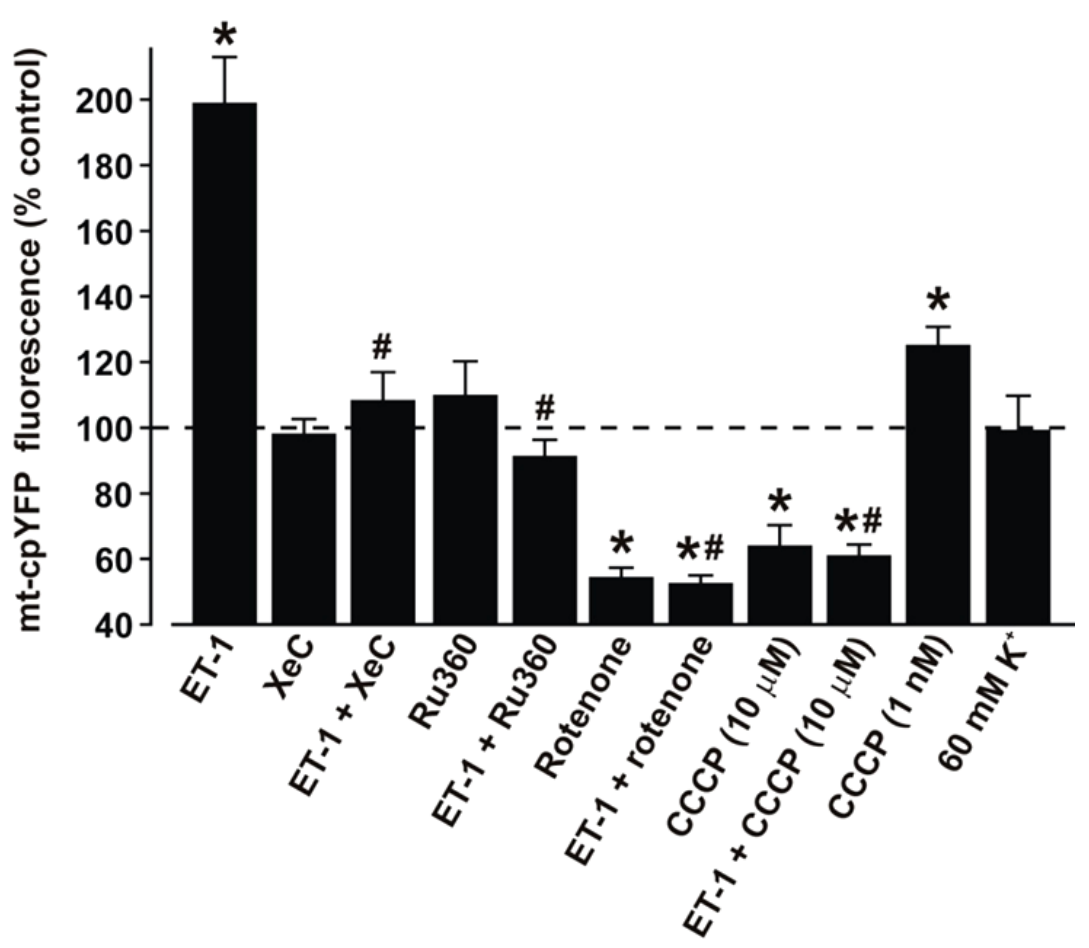

Figure 4-6. ET-1-induced $\mathrm{IP}_{3} \mathrm{R}$-mediated $\mathrm{SR} \mathrm{Ca}^{2+}$ release and mitochondrial $\mathrm{Ca}^{2+}$ uptake elevates mitoROS generation in arterial smooth muscle cells

Notes: A, Original images illustrating ET-1-induced elevation in mt-cpYFP fluorescence in smooth muscle cells of an intact artery. Scale bar $=20 \mu \mathrm{m}$. B, Average mt-cpYFP fluorescence changes in smooth muscle cells of intact arteries. ET-1, XeC $(20 \mu \mathrm{M})$, ET$1+\mathrm{XeC}$, Ru360 $(10 \mu \mathrm{M}), \mathrm{ET}-1+\mathrm{Ru} 360$, rotenone $(10 \mu \mathrm{M}), \mathrm{ET}-1+$ rotenone, CCCP $(10$ $\mu \mathrm{M})$, ET-1+CCCP, CCCP $(1 \mathrm{nM})$, and $60 \mathrm{mM} \mathrm{K}^{+}$. ET-1 concentration was $100 \mathrm{nM}$ in all experiments. $\mathrm{n}=5$ for each condition. Values are expressed as mean \pm SEM. * indicates $\mathrm{P}<0.05$ compared to control. \# indicates $\mathrm{P}<0.05$ compared to ET-1. 
small mitochondrial depolarization and increases mitoROS generation (Xi et al., 2005). Similarly, here $1 \mathrm{nM} \mathrm{CCCP}$ elevated mt-cpYFP fluorescence to $124 \%$ of control (Fig. 4-6B). These data indicate that mitochondria generate ROS in the absence of ET-1, and that ET-1-induced $\mathrm{IP}_{3} \mathrm{R}$-mediated SR $\mathrm{Ca}^{2+}$ release and $\left[\mathrm{Ca}^{2+}\right]_{\text {mito }}$ elevation stimulate mitoROS generation. Results with Ru360, rotenone, and micromolar CCCP confirm the mitochondrial localization of mt-cpYFP.

\subsubsection{ET-1-induced mitoROS generation elevates cytosolic ROS levels}

Cytosolic ROS was measured using HyPer-CYTO, a genetically-encoded fluorescent cytosolic $\mathrm{H}_{2} \mathrm{O}_{2}$ indicator (Fig. 3-1) (Belousov et al., 2006). Exogenous $\mathrm{H}_{2} \mathrm{O}_{2}$ elevated HyPer-CYTO fluorescence to $\sim 234 \%$ of control (Fig. 4-7A). ET-1 similarly increased HyPer-CYTO fluorescence in smooth muscle cells of endothelium-intact and denuded arteries to $\sim 158$ and $168 \%$ of control, respectively (Fig. 4-7B,C). When applied alone, rotenone and MnTMPyP, a SOD and catalase mimetic (Faulkner et al., 1994), reduced HyPer-CYTO fluorescence $\sim 75$ and $80 \%$ of control, respectively (Fig. 4-7C). Rotenone and MnTMPyP blocked the ET-1-induced elevations in HyPer-CYTO fluorescence (Fig. 4-7C). These data indicate that mitoROS production contributes to cytosolic ROS levels in the absence of ET-1 and that ET-1-induced mitoROS elevation leads to an increase in cytosolic ROS in cerebral artery smooth muscle cells.

\subsubsection{ROS measurements using DCF}

\subsubsection{ET-1 stimulates ROS generation}

To confirm measurements obtained using mt-cpYFP and HyPer-CYTO, ROS levels were studied in smooth muscle cells of cerebral arteries using CM- $\mathrm{H}_{2}$ DCFDA, an inorganic fluorescent ROS indicator. ET-1 increased mean DCF fluorescence in smooth muscle cells of endothelium-intact and -denuded arteries to $\sim 154$ and $151 \%$ of control, respectively (Fig. 4-8A,B). Exogenous $\mathrm{H}_{2} \mathrm{O}_{2}$ application elevated mean DCF fluorescence intensity to $\sim 219 \%$ of control (Fig. 4-8B). ET-1-induced DCF fluorescence elevations were blocked by thapsigargin, $\mathrm{XeC}$, and MnTMPyP (Fig. 4-8B). When applied alone, thapsigargin and $\mathrm{XeC}$ did not alter, but MnTMPyP reduced DCF fluorescence to $\sim 74 \%$ of control (Fig. 4-8B). $60 \mathrm{mM} \mathrm{K}^{+}$, which leads to global $\left[\mathrm{Ca}^{2+}\right]_{\mathrm{i}}$ elevation did not alter DCF fluorescence (Fig. 4-8B). These data confirm the finding that ET-1-induced $\mathrm{IP}_{3} \mathrm{R}$-mediated SR Ca ${ }^{2+}$ release stimulates ROS generation.

\subsubsection{Source of ET-1-induced ROS elevation is mitochondria}

ET-1-induced DCF fluorescence elevations were blocked by CCCP and rotenone (Fig. 4-9A). In the presence of oxypurinol, a xanthine oxidase inhibitor (Elion et al., 1968) and 17-ODYA, a cytochrome P450 blocker (Zou et al., 1994), ET-1 elevated DCF 
Figure 4-7. ET-1-induced $\mathrm{IP}_{3} \mathrm{R}$-mediated $\mathrm{SR} \mathrm{Ca}^{2+}$ release elevates cytosolic ROS in arterial smooth muscle cells

Notes: A,B, Confocal images illustrating that exogenous $\mathrm{H}_{2} \mathrm{O}_{2}$ (A) and ET-1 (B) elevates HyPer-CYTO fluorescence in arterial smooth muscle cells. C, Average changes in HyPer-CYTO fluorescence for $\mathrm{H}_{2} \mathrm{O}_{2}(100 \mu \mathrm{M})$, ET-1 (endothelium-intact), ET-1 (endothelium-denuded), rotenone $(10 \mu \mathrm{M})$, ET-1+rotenone, MnTMPyP $(10 \mu \mathrm{M})$, and ET-1+MnTMPyP. ET-1 concentration was $100 \mathrm{nM}$ in all experiments. $\mathrm{n}=5$ for each condition. Values are expressed as mean \pm SEM. * indicates $\mathrm{P}<0.05$ compared to control. \# indicates $\mathrm{P}<0.05$ compared to ET- 1 . 
A Control

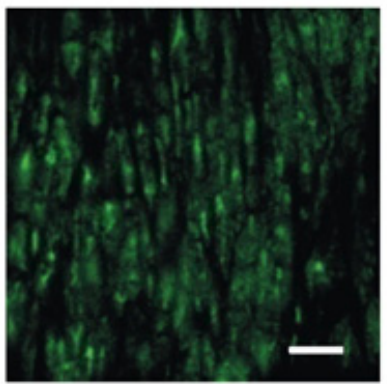

B

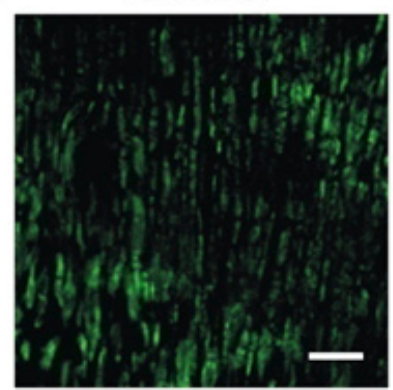

$\mathrm{H}_{2} \mathrm{O}_{2}$

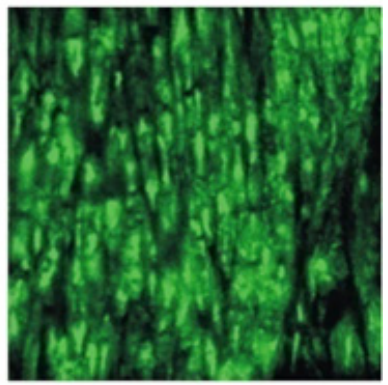

ET-1

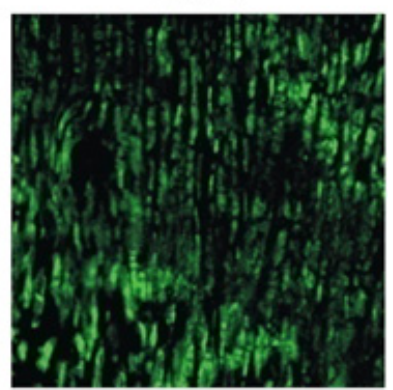

C

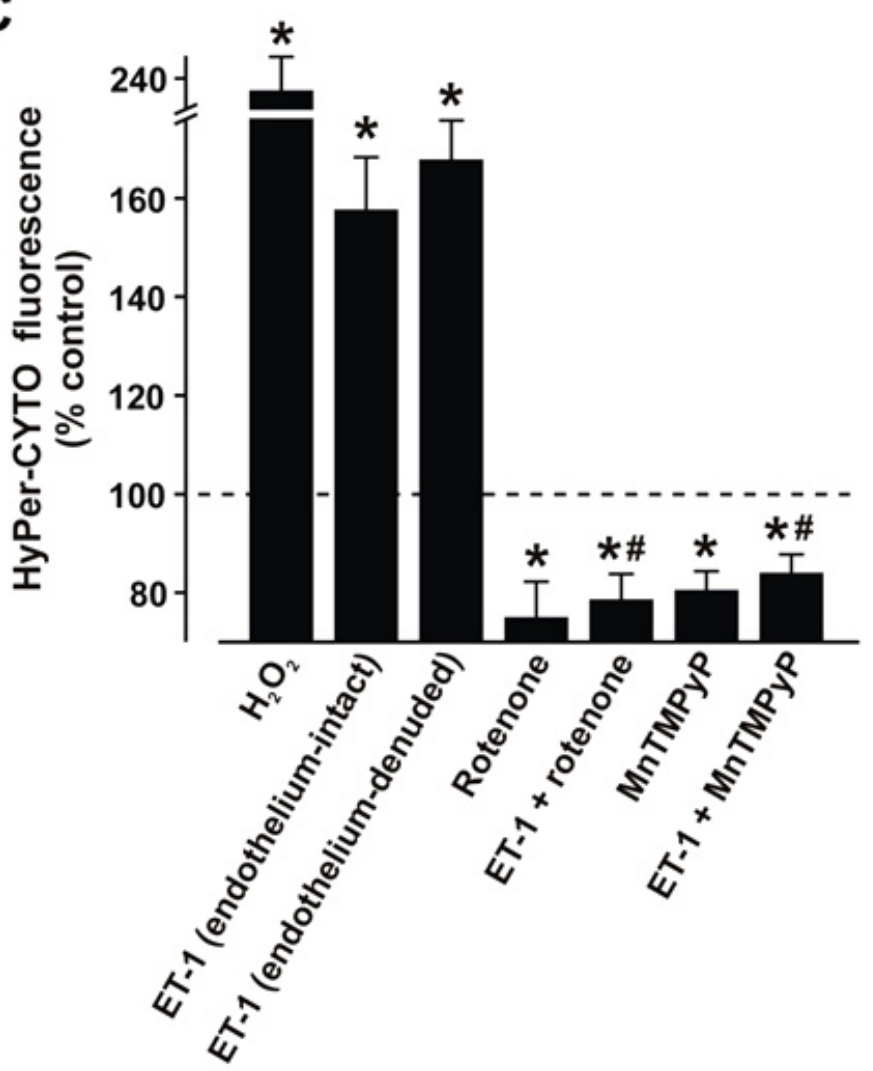



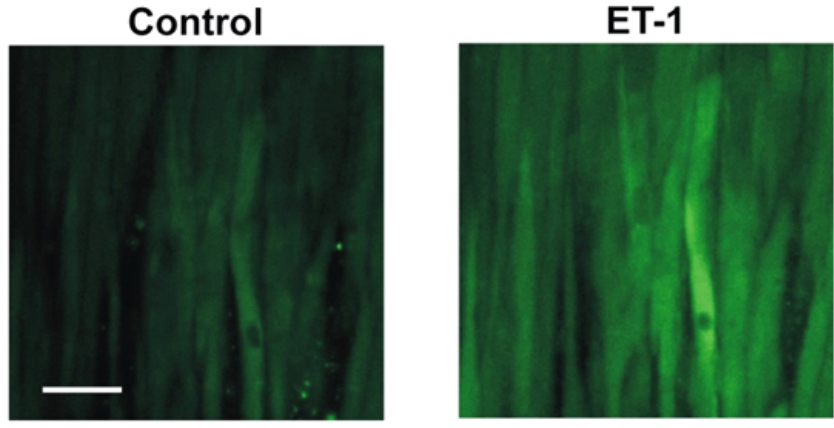

B

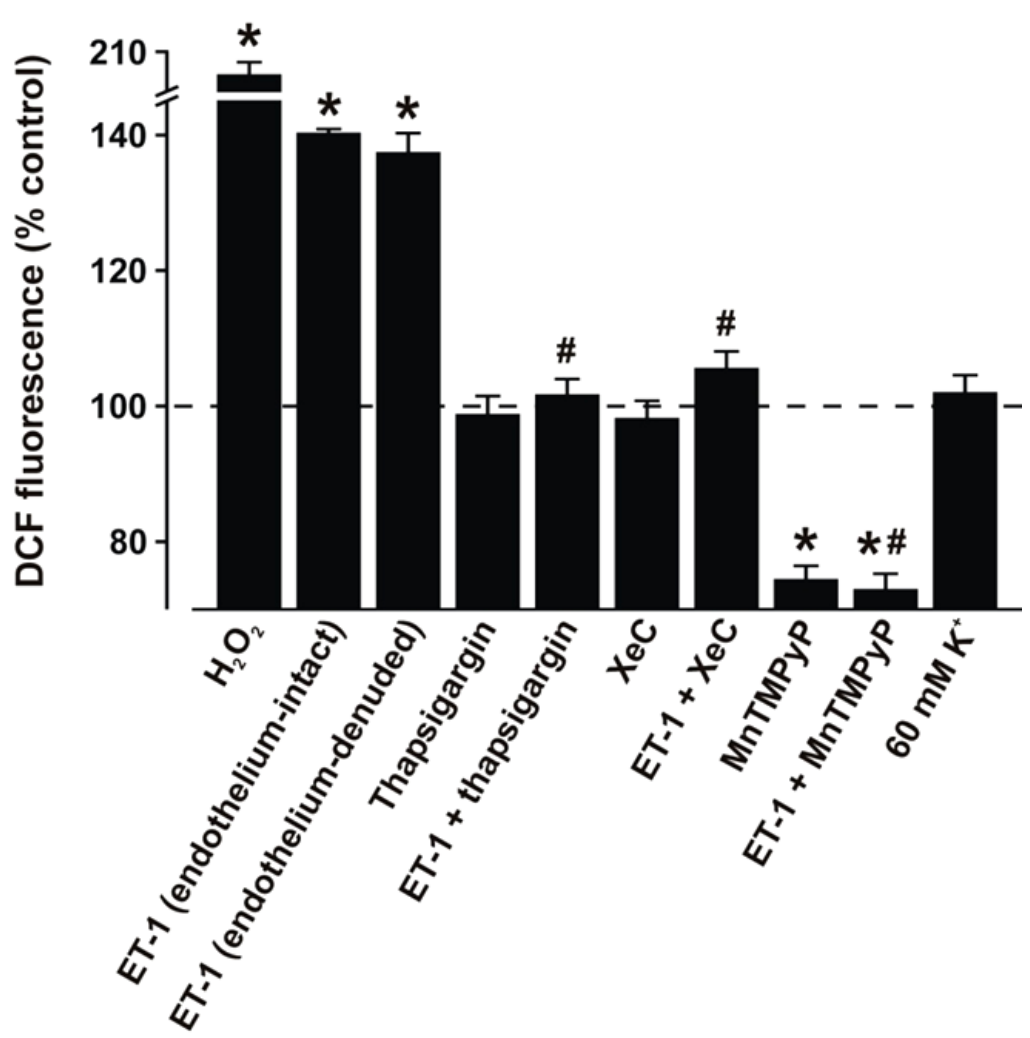

Figure 4-8. ET-1-induced $\mathrm{IP}_{3} \mathrm{R}$-mediated $\mathrm{SR} \mathrm{Ca}^{2+}$ release elevates DCF fluorescence in arterial smooth muscle cells

Notes: A, Confocal images of DCF fluorescence in smooth muscle cells of the same cerebral artery in control and ET-1. Scale bar $=20 \mu \mathrm{m}$. B, Mean DCF fluorescence changes in arterial smooth muscle cells. $\mathrm{H}_{2} \mathrm{O}_{2}(100 \mu \mathrm{M}, \mathrm{n}=6)$, ET-1 (endothelium-intact, $\mathrm{n}=10$ ), ET-1 (endothelium-denuded, $\mathrm{n}=6$ ), thapsigargin $(100 \mathrm{nM}, \mathrm{n}=5)$, ET-

$1+$ thapsigargin $(\mathrm{n}=10), \mathrm{XeC}(20 \mu \mathrm{M}, \mathrm{n}=5), \mathrm{ET}-1+\mathrm{XeC}(\mathrm{n}=6)$, MnTMPyP $(10 \mu \mathrm{M}, \mathrm{n}=5)$, ET-1+MnTMPyP $(\mathrm{n}=6)$, and $60 \mathrm{mM} \mathrm{K}^{+}(\mathrm{n}=6)$. Values are expressed as mean \pm SEM. * indicates $\mathrm{P}<0.05$ compared to control. \# indicates $\mathrm{P}<0.05$ compared to ET-1. 
Figure 4-9. ET-1-induced mitoROS generation elevates DCF fluorescence in arterial smooth muscle cells

Notes: A, Mean DCF fluorescence change for ET-1 (endothelium-intact, $\mathrm{n}=10$ ), rotenone $(10 \mu \mathrm{M}, \mathrm{n}=5), \mathrm{ET}-1+$ rotenone $(\mathrm{n}=10), \mathrm{CCCP}(10 \mu \mathrm{M}, \mathrm{n}=5), \mathrm{ET}-1+\mathrm{CCCP}(\mathrm{n}=10)$, gp91ds-tat $(50 \mu \mathrm{M}, \mathrm{n}=5)$, ET-1+gp91ds-tat $(\mathrm{n}=5)$, oxypurinol $(10 \mu \mathrm{M}, \mathrm{n}=5)$, ET1+oxypurinol $(\mathrm{n}=6), 17$-octadecynoic acid $(10 \mu \mathrm{M}, \mathrm{n}=5)$, and ET-1+17-octadecynoic acid $(\mathrm{n}=6)$. B, Mean DCF fluorescence change for TNF- $\alpha(100 \mathrm{ng} / \mathrm{ml}, \mathrm{n}=5)$, ET-1 (endothelium-intact, $\mathrm{n}=10)$, gp91scrm-tat $(50 \mu \mathrm{M}, \mathrm{n}=5)$, TNF- $\alpha+$ gp91scrm-tat $(\mathrm{n}=5)$, ET$1+$ gp91scrm-tat $(n=5)$, gp91ds-tat $(50 \mu \mathrm{M}, \mathrm{n}=5)$, TNF- $\alpha+$ gp91ds-tat $(\mathrm{n}=5)$, and ET$1+$ gp91ds-tat $(\mathrm{n}=5)$. ET-1 concentration was $100 \mathrm{nM}$ in all experiments. * indicates $\mathrm{P}<0.05$ compared to control. Values are expressed as mean \pm SEM. \# indicates $\mathrm{P}<0.05$ compared to ET-1. $\S$ indicates $\mathrm{P}<0.05$ compared to TNF- $\alpha$. 


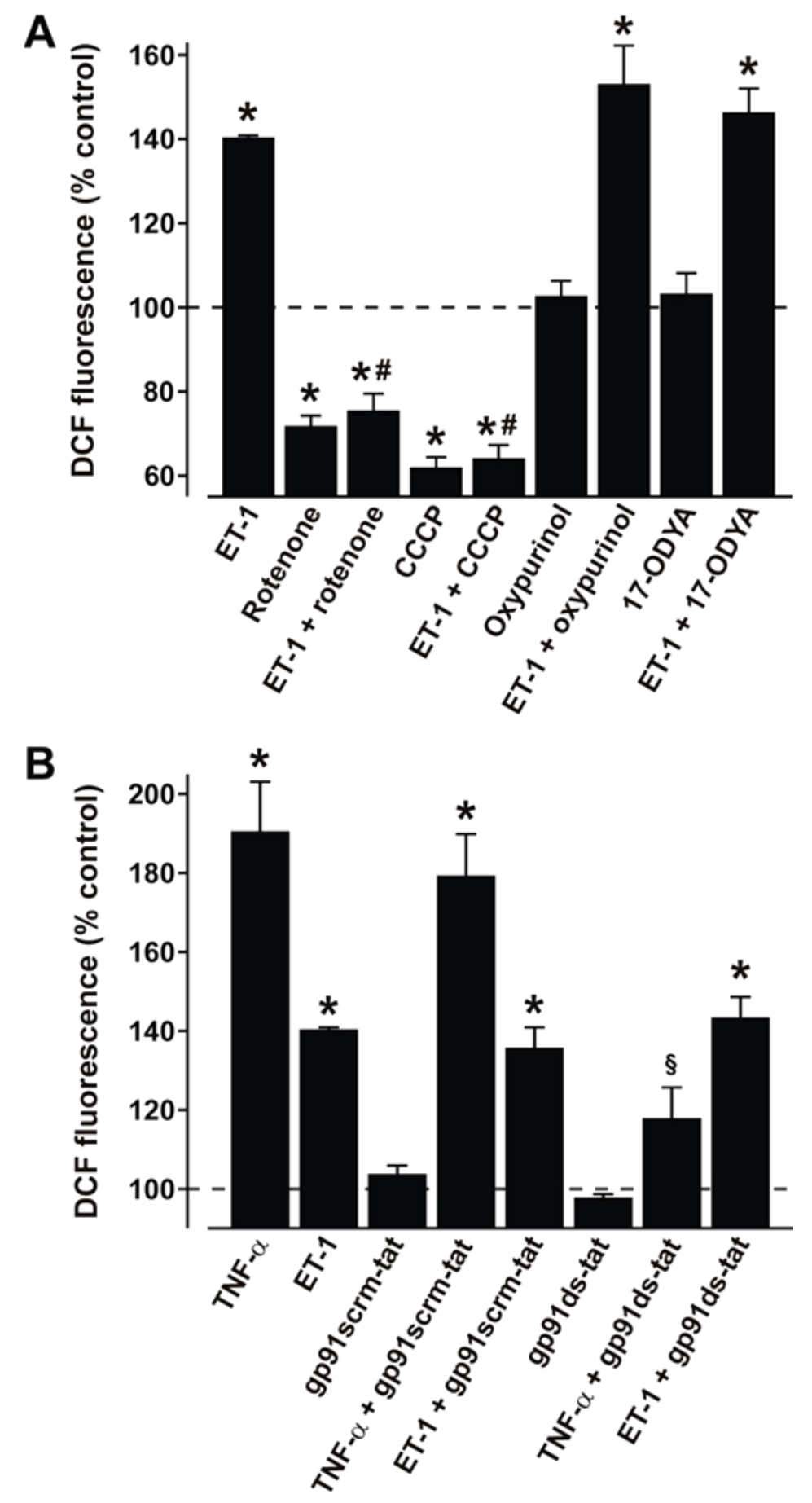


fluorescence to $\sim 153$ and $146 \%$ of control, respectively (Fig. 4-9A). Oxypurinol and 17ODYA did not alter baseline DCF fluorescence, whereas CCCP and rotenone alone decreased baseline DCF fluorescence to $\sim 62$ and $72 \%$ of control, respectively (Fig. 4-9A).

TNF- $\alpha$, which stimulates NAD(P)H oxidase-derived ROS in cerebral artery smooth muscle cells (Cheranov \& Jaggar, 2006), elevated DCF fluorescence to $\sim 190 \%$ of control (Fig. 4-9B). gp91ds-tat did not alter baseline DCF fluorescence, whereas blocked DCF fluorescence elevations induced by TNF- $\alpha$, suggesting that gp91ds-tat inhibits NAD(P)H oxidase (Fig. 4-9B). In the presence of gp91ds-tat, ET-1 increased DCF fluorescence to $\sim 143 \%$ of control (Fig. 4-9B). Scrambled gp91-tat did not alter baseline DCF fluorescence, or ET-1- or TNF- $\alpha$-induced DCF fluorescence elevations (Fig. 4-9B).

Data obtained using DCF confirm ROS measurements obtained using mt-cpYFP and HyPer-CYTO, that mitochondria generate ROS in the absence of ET-1, and that ET1 -induced $\mathrm{IP}_{3} \mathrm{R}$-mediated $\mathrm{SR} \mathrm{Ca}{ }^{2+}$ release and $\left[\mathrm{Ca}^{2+}\right]_{\text {mito }}$ elevation stimulate mitoROS generation, leading to an increase in cytosolic ROS in cerebral artery smooth muscle cells.

\subsection{ET-1-Induced IP ${ }_{3}$ R-Mediated MitoROS Elevation Stimulates NF-кB}

\subsection{1. $\quad$ ET-1 stimulates nuclear translocation of NF-кB p50}

To examine physiological functions of an $\mathrm{IP}_{3} \mathrm{R}$-mediated mitoROS elevation, we tested the hypothesis that mitochondria regulate the expression of genes that modulate smooth muscle cell contractility. Therefore, immunofluorescence was performed to study cellular localization of the $\mathrm{p} 50$ subunit of NF- $\kappa \mathrm{B}$, a ROS-sensitive transcription factor (Lee et al., 2008), in arterial smooth muscle cells. ET-1 increased mean pixel colocalization of p50 with YOYO-1 from $\sim 12$ to $22 \%$ (Fig. 4-10A-C), suggesting that ET-1 stimulates nuclear translocation of p50.

\subsection{2. $\quad$ ET-1 elevates NF-кB-dependent transcriptional activity}

To investigate the regulation of NF- $\mathrm{BB}$-dependent transcriptional activity, assays were performed using vectors that express firefly luciferase under the control of an NF$\kappa \mathrm{B}$ promoter. As a control, regulation of luciferase activity by TNF- $\alpha$, which activates NF- $\kappa \mathrm{B}$ (Li et al., 1999) was measured. TNF- $\alpha$ increased mean luciferase activity to $\sim 547 \%$ of control (Fig. 4-11). ET-1 increased luciferase activity to $\sim 372 \%$ of control, and this was blocked by thapsigargin and $\mathrm{XeC}$ (Fig. 4-11). Rotenone and MnTMPyP reduced the ET-1-induced elevation in luciferase activity to 152 and 109\% of control, respectively (Fig. 4-11). Exogenous $\mathrm{H}_{2} \mathrm{O}_{2}$ elevated luciferase activity to $\sim 252 \%$ of control, and this effect was not altered by rotenone, indicating that rotenone did not cause general inhibition of luciferase expression (Fig. 4-11). When applied alone, thapsigargin, 


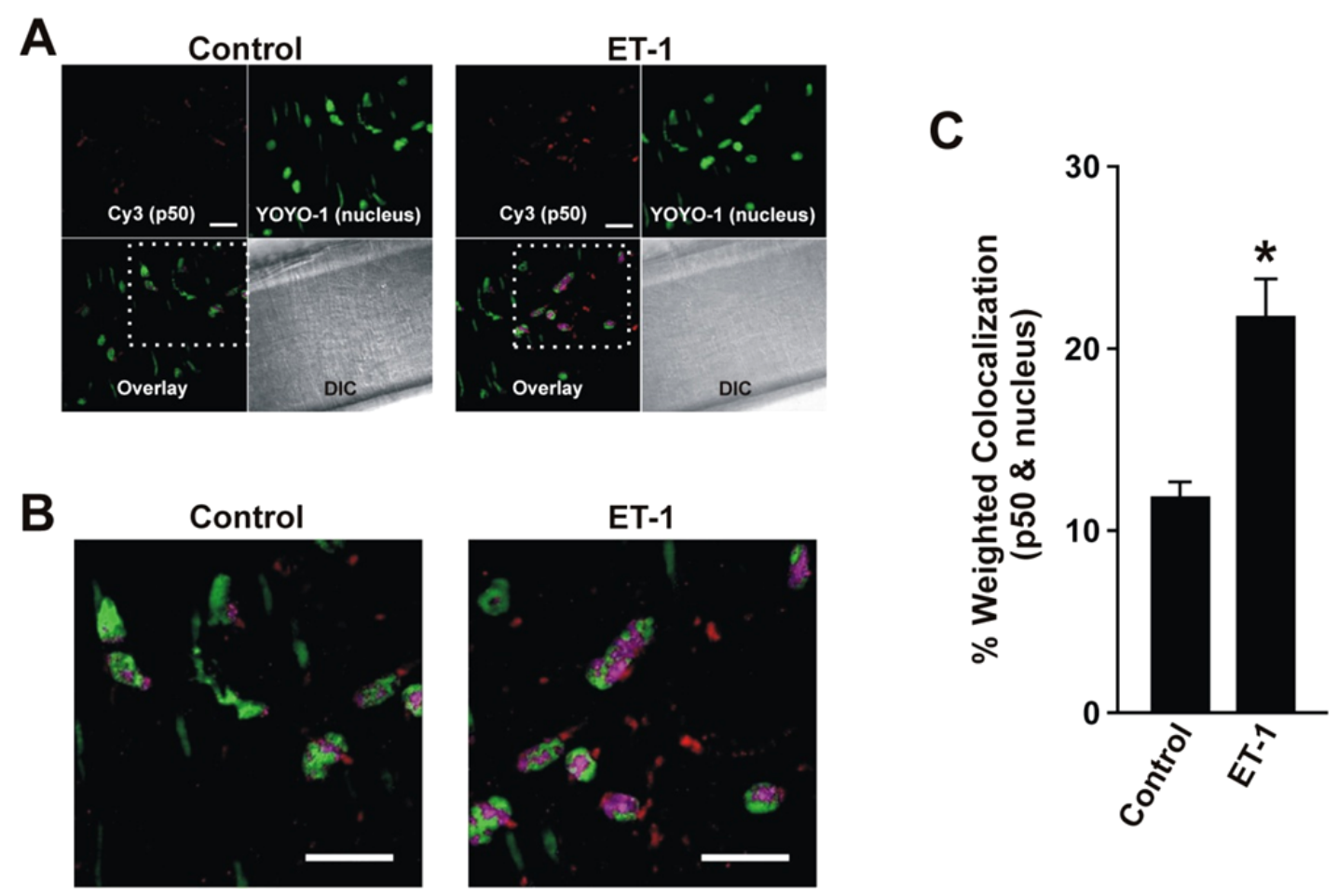

Figure 4-10. ET-1 stimulates p50 nuclear translocation in arterial smooth muscle cells

Notes: A, Immunofluorescence images of smooth muscle cells in arteries illustrating YOYO-1 (nuclear stain, green), p50 (red), overlay, and DIC (lumenally-inserted rectangular glass cannula can be seen). B, Enlarged images indicated by boxes in A illustrate ET-1-induced elevation in p50 and YOYO-1 pixel colocalization (purple). Scale bars $=20 \mu \mathrm{m}$. C, Mean data for weighted pixel colocalization ( $\mathrm{n}=10$ for each). Values are expressed as mean \pm SEM. * indicates $\mathrm{P}<0.05$ compared to control. 


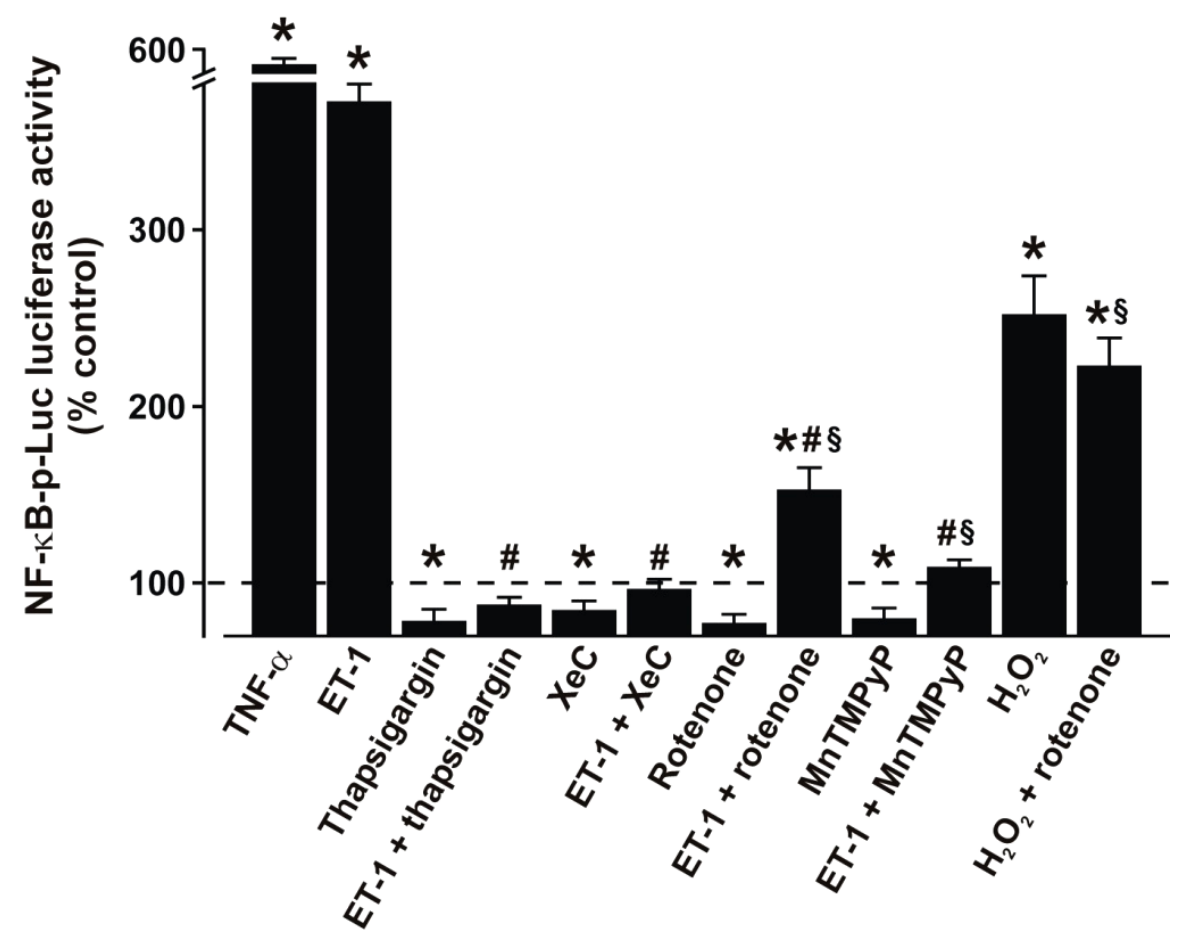

Figure 4-11. ET-1 stimulates NF- $\mathrm{BB}$-dependent transcription through $\mathrm{IP}_{3} \mathrm{R}$-mediated $\mathrm{SR} \mathrm{Ca}^{2+}$ release and mitoROS elevation in arterial smooth muscle cells

Notes: Average NF-кB-p-Luc luciferase activity with TNF- $\alpha(100 \mathrm{ng} / \mathrm{ml}, \mathrm{n}=4), \mathrm{ET}-1$ $(\mathrm{n}=5)$, thapsigargin $(100 \mathrm{nM}, \mathrm{n}=5), \mathrm{ET}-1+$ thapsigargin $(\mathrm{n}=5), \mathrm{XeC}(20 \mu \mathrm{M}, \mathrm{n}=5), \mathrm{ET}-$ $1+\mathrm{XeC}(\mathrm{n}=5)$, rotenone $(1 \mu \mathrm{M}, \mathrm{n}=5), \mathrm{ET}-1+$ rotenone $(\mathrm{n}=5), \operatorname{MnTMPyP}(10 \mu \mathrm{M}, \mathrm{n}=4)$, ET-1+MnTMPyP $(n=4), \mathrm{H}_{2} \mathrm{O}_{2}(100 \mu \mathrm{M}, \mathrm{n}=4)$, and $\mathrm{H}_{2} \mathrm{O}_{2}$ +rotenone $(\mathrm{n}=4)$. ET-1 concentration was $100 \mathrm{nM}$ in all experiments. Values are expressed as mean $\pm \mathrm{SEM}$. * indicates $\mathrm{P}<0.05$ compared to control. \# indicates $\mathrm{P}<0.05$ compared to ET- 1 . $\S$ indicates $\mathrm{P}<0.05$ compared to rotenone or MnTMPyP. 
$\mathrm{XeC}$, rotenone, and MnTMPyP reduced luciferase activity to $\sim 84,78,77$, and $80 \%$ of control, respectively (Fig. 4-11). TNF- $\alpha$, ET-1, thapsigargin, XeC, rotenone, MnTMPyP, and $\mathrm{H}_{2} \mathrm{O}_{2}$ did not alter luciferase activity in arteries in which a promoter-deficient control vector was inserted (Fig. 4-12). These data indicate that $\mathrm{IP}_{3} \mathrm{R}$-mediated $\mathrm{SR} \mathrm{Ca}^{2+}$ release stimulates NF- $\mathrm{\kappa B}$ primarily by elevating mitoROS generation, but also via a secondary mitochondria- and ROS-independent pathway in arterial smooth muscle cells.

\subsubsection{ROS measurements corresponding to transcriptional studies}

For transcriptional studies performed using luciferase reporter assays, arteries were exposed to stimuli for 24 hours. To determine if the inhibitors used, blocked the ET-1-induced ROS elevations which corresponded to the time points used in the above transcriptional studies, ROS levels were measured using DCF. After a 24-hour incubation in control, ET-1 elevated DCF fluorescence to $145 \%$ of control (Fig. 4-13). ET-1-induced DCF fluorescence elevations were blocked by 24-hour incubation in thapsigargin, $\mathrm{XeC}$, or rotenone (Fig. 4-13). These data indicate that the inhibitors used for a period of time in transcriptional studies blocked the ET-1-induced ROS elevations.

\subsection{ET-1-Induced $\mathrm{IP}_{3} \mathrm{R}-\mathrm{Mediated} \mathrm{SR} \mathrm{C \textrm {C } ^ { 2 + }}$ Release Stimulates Cav1.2 Expression by MitoROS Elevation and NF-кB Activation}

We sought to examine the functional significance of $\mathrm{IP}_{3} \mathrm{R}$-mediated, mitochondrial-dependent NF-kB activation. Cav1.2 channels are the principal $\mathrm{Ca}^{2+}$ influx pathway in smooth muscle cells of resistance-size arteries and are essential for contractility regulation by a wide variety of stimuli, including intravascular pressure and membrane potential (Cheng et al., 2007). However, mechanisms that regulate CACNA1C transcription in arterial smooth muscle cells are unclear. Three NF- $\kappa B$ binding motifs are located immediately upstream of the human Cav1.2 promoter (Shi et al., 2005). Therefore, we tested the hypothesis that ET-1-induced $\mathrm{IP}_{3} \mathrm{R}$-mediated, mitoROS-dependent NF- $\mathrm{kB}$ activation regulates $\mathrm{Ca}_{\mathrm{V}} 1.2$ expression in cerebral arteries.

\subsubsection{ET-1 stimulates Cav1.2 gene transcription}

To study ET-1 regulation of gene expression we performed RT-PCR. We sought to identify a reference gene whose transcription is not affected by ET-1 (6 hours). RTPCR reactions were performed for five genes, namely beta $(\beta)$ actin, beta $(\beta)$ tubulin, cyclophilin B, hypoxanthine-guanine phosphoribosyltransferase (HGPRT), and Rps5. $\mathrm{CT}$ values for the reference genes in control and ET-1 are shown in Table 4-1. Rps5 which had the least difference in average CT values between control and ET-1 treatment groups was chosen as the reference gene.

RT-PCR data indicated that in cerebral arteries, ET-1 increased Ca 1.2 channel mRNA expression to $\sim 244 \%$ of control, after normalization to Rps5 (Fig. 4-14D). 


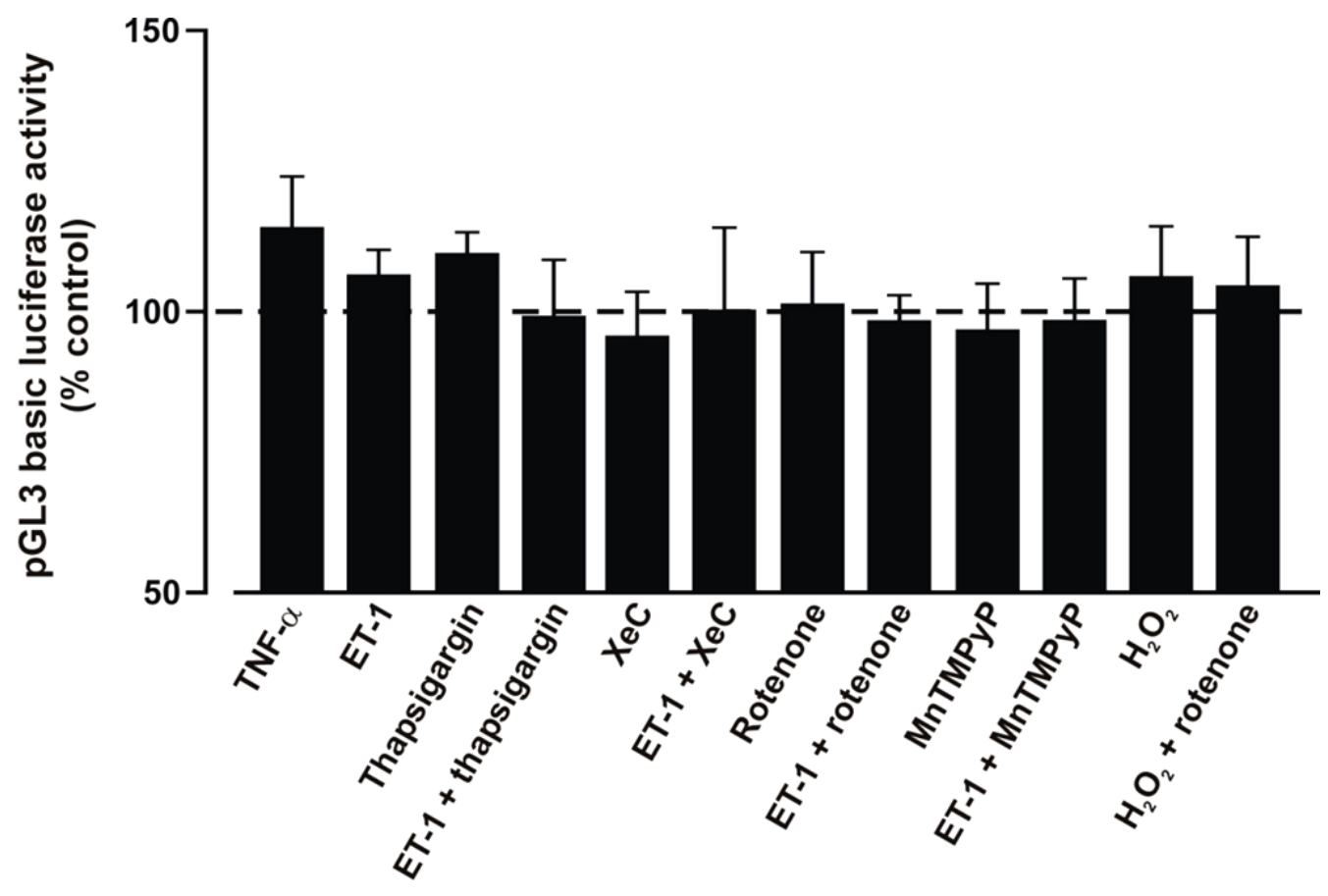

Figure 4-12. Mean changes in promoter-deficient (pGL3 Basic) luciferase activity

Notes: Mean data. TNF- $\alpha(100 \mathrm{ng} / \mathrm{ml}, \mathrm{n}=4), \mathrm{ET}-1(\mathrm{n}=5)$, thapsigargin $(100 \mathrm{nM}, \mathrm{n}=4)$, ET-1+thapsigargin $(\mathrm{n}=4), \mathrm{XeC}(20 \mu \mathrm{M}, \mathrm{n}=3), \mathrm{ET}-1+\mathrm{XeC}(\mathrm{n}=3)$, rotenone $(1 \mu \mathrm{M}, \mathrm{n}=4)$, ET-1+rotenone ( $\mathrm{n}=4), \operatorname{MnTMPyP}(10 \mu \mathrm{M}, \mathrm{n}=3), \mathrm{ET}-1+\mathrm{MnTMPyP}(\mathrm{n}=3), \mathrm{H}_{2} \mathrm{O}_{2}(100$ $\mu \mathrm{M}, \mathrm{n}=3$ ), and $\mathrm{H}_{2} \mathrm{O}_{2}+$ rotenone ( $\left.\mathrm{n}=3\right)$. ET- 1 concentration was $100 \mathrm{nM}$ in all experiments. Values are expressed as mean $\pm \mathrm{SEM}$. 


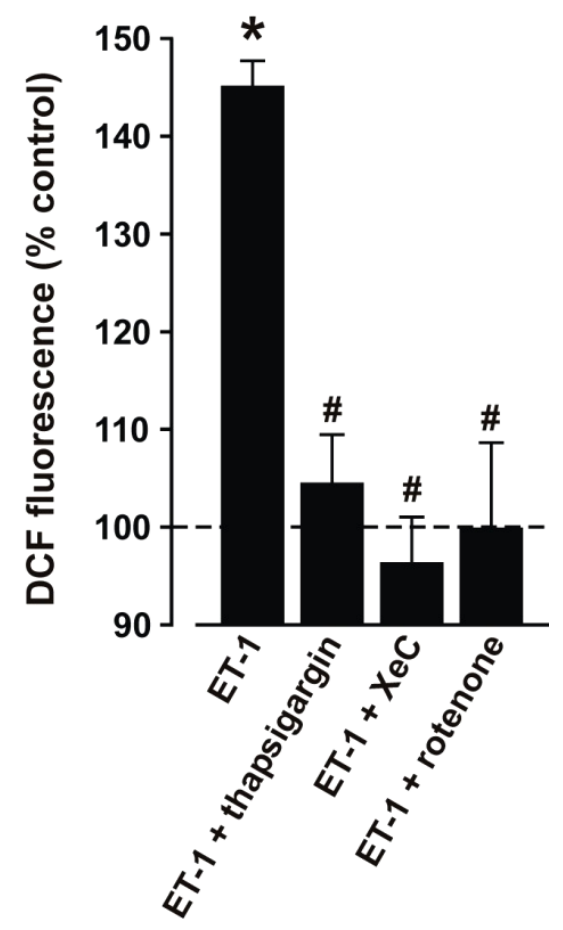

Figure 4-13. ROS measurements at time points used for transcriptional studies

Notes: Average change in DCF fluorescence with ET-1 (100 nM, n=5) after a 24 hour incubation in control, in the presence of thapsigargin $(100 \mathrm{nM}, \mathrm{n}=3), \mathrm{XeC}(20 \mu \mathrm{M}, \mathrm{n}=3)$, or rotenone $(1 \mu \mathrm{M}, \mathrm{n}=5)$. Values are expressed as mean $\pm \mathrm{SEM}$. * indicates $\mathrm{P}<0.05$ compared to control. \# indicates $\mathrm{P}<0.05$ compared to ET-1. 
Table 4-1. Identification of reference gene for RT-PCR

\begin{tabular}{cccc}
\hline Gene & CT $_{\text {control }}$ & CT $_{\text {ET-1 }}$ & CT $_{\text {control }}-\mathbf{C T}_{\text {ET-1 }}$ \\
\hline Rps5 & 25.43 & 24.83 & 0.60 \\
HGPRT & 31.90 & 31.21 & 0.69 \\
Cyclophilin B & 27.39 & 26.71 & 0.68 \\
$\beta$ tubulin & 32.81 & 32.12 & 0.69 \\
$\beta$ actin & 22.5 & 21.53 & 0.97 \\
\hline
\end{tabular}


A
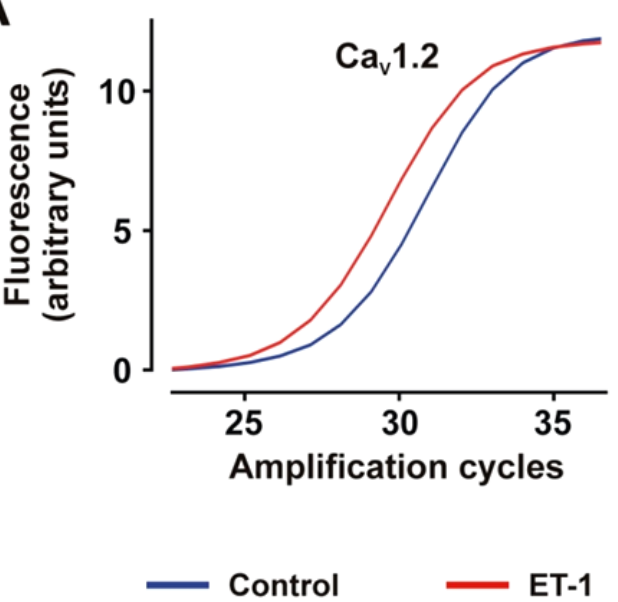

B

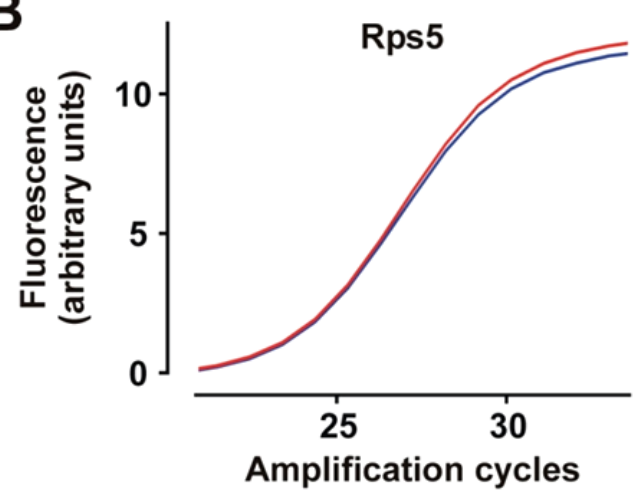

C

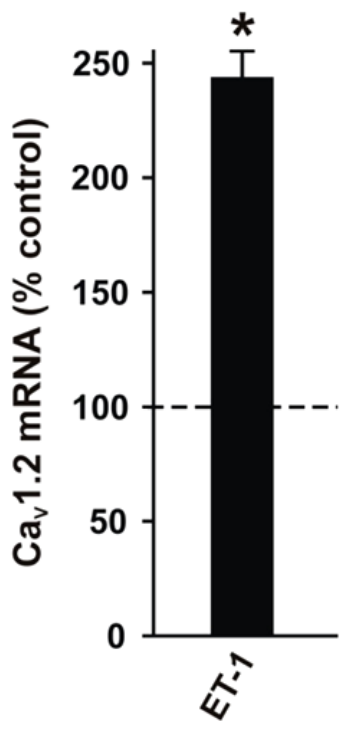

D

$\mathrm{Ca}_{\mathrm{v}} 1.2 \quad$ Rps5 NC-Ca 1.2

$100 \mathrm{bp}$

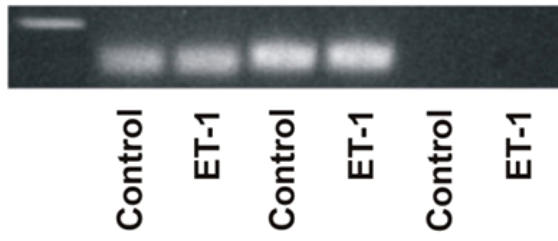

Figure 4-14. ET-1 stimulates $\mathrm{Ca}_{\vee} 1.2$ gene transcription in cerebral arteries

Notes: A,B, Representative amplification curves generated with probes and RT-PCR primers specific for $\mathrm{Ca}_{\mathrm{V}} 1.2$ (A) and Rps5 (B) genes in control (blue) and ET-1(10 nM)treated (red) arteries. The data points for the amplification curves shown were obtained by calculating the average of data points from triplicates for each condition. C, Application of ET-1 (10 nM) for 6 hours elevated mean Cav1.2 mRNA in cerebral arteries compared to control arteries ( $\mathrm{n}=7$ for each condition). Values are expressed as mean \pm SEM. * indicates $\mathrm{P}<0.05$ compared to control. D, Agarose gel illustrating transcripts amplified using RT-PCR primers for $\mathrm{Ca}_{\mathrm{V}} 1.2(70 \mathrm{bp})$ and Rps5 (83 bp) from cerebral arteries in control and ET-1 $(10 \mathrm{nM})$. NC, negative control using cerebral artery mRNA. 


\subsubsection{ET-1-induced $I P_{3} R$ activation and mitoROS elevation stimulate Cav1.2 expression}

Western blotting indicated that ET-1 (24 hrs) increased Cav1.2 channel (190 and $240 \mathrm{kD}$ bands) protein to $\sim 141 \%$ of control (Fig. 4-15A,B). XeC, rotenone, and MnTMPyP alone reduced basal $\mathrm{Ca}_{\mathrm{V}} 1.2$ expression to $\sim 87,89$, and $80 \%$ of control, respectively (Fig. 4-15A,B). XeC blocked the ET-1-induced elevation in $\mathrm{Ca}_{\mathrm{V}} 1.2$ expression (Fig. 4-15A,B). Rotenone and MnTMPyP reduced the ET-1-induced elevation in $\mathrm{Ca}_{\mathrm{V}} 1.2$ expression to $\sim 113$ and $90 \%$ of control, respectively (Fig. 4-15B). Exogenous $\mathrm{H}_{2} \mathrm{O}_{2}$ increased $\mathrm{Ca}_{V} 1.2$ expression to $\sim 128 \%$ of control, and this elevation was not altered by rotenone, indicating that rotenone did not induce non-specific inhibition of $\mathrm{Ca}_{V} 1.2$ expression (Fig. 4-15B). These data indicate that ET-1-induced $\mathrm{IP}_{3} \mathrm{R}$-mediated $\mathrm{SR} \mathrm{Ca}^{2+}$ release and mitoROS elevation stimulate $\mathrm{Ca}_{\mathrm{v}} 1.2$ expression in cerebral arteries.

\subsubsection{ET-1-induced NF- $\mathrm{kB}$ activation elevates Cav1.2 expression}

Two different siRNAs were used to knockdown expression of $\mathrm{p} 105$, the $\mathrm{p} 50$ precursor (Baeuerle \& Baltimore, 1996). p105siRNA1, p105siRNA2, and a combination of both siRNAs (p105siRNAs) reduced mean p105 protein to $\sim 73,80$, and $57 \%$, respectively, of that in arteries treated with scrambled siRNA (p105scrm) (Fig. 4-16A,B).

p105siRNAs reduced Ca 1.2 expression to $\sim 64 \%$ of p $105 \mathrm{scrm}$ (Fig. 4-17A,B), indicating that NF- $\mathrm{kB}$ controls basal $\mathrm{Ca}_{\mathrm{V}} 1.2$ expression. In $\mathrm{p} 105 \mathrm{scrm}$-treated arteries, ET-1 increased $\mathrm{Ca}_{V} 1.2$ protein to $\sim 136 \%$ of p105scrm (Fig. 4-17A,B). In p105siRNAstreated arteries, ET-1 increased $\mathrm{Ca}_{\mathrm{V}} 1.2$ protein from $\sim 64$ to $74 \%$ of $\mathrm{p} 105 \mathrm{scrm}(\sim 117 \%$ of p105siRNAs) (Fig. 4-17A,B). These data indicate that $\mathrm{IP}_{3} \mathrm{R}$-mediated $\mathrm{SR} \mathrm{Ca}^{2+}$ release stimulates $\mathrm{Ca}_{\mathrm{V}} 1.2$ expression via mitochondria-dependent $\mathrm{NF}-\mathrm{\kappa B}$ activation.

\subsection{ET-1-Induced $\mathrm{IP}_{3} \mathrm{R}$-Mediated SR $\mathrm{Ca}^{2+}$ Release Also Stimulates p105 Expression}

The p105 gene promoter contains an NF-kB-binding sequence, and p50 activation can elevate p105 expression (Ten et al., 1992). Therefore, mechanisms that regulate NF$\kappa \mathrm{B}$ subunit expression in cerebral arteries were investigated. Inhibiting $\mathrm{IP}_{3} \mathrm{R}$-mediated $\mathrm{SR} \mathrm{Ca}^{2+}$ release using $\mathrm{XeC}$ reduced basal p105 and p50 expression to $\sim 87$ and $90 \%$ of control, respectively (Fig. 4-18A,B). Inhibiting mitoROS production using rotenone or dismutating cellular ROS using MnTMPyP, did not alter basal p105 or p50 expression (Fig. 4-18B). ET-1 elevated p105 and p50 expression to 127 and $119 \%$ of control, respectively and $\mathrm{XeC}$ blocked this effect (Fig. 4-18B). In contrast, rotenone or MnTMPyP had no effect on the ET-1-induced elevation in p105 and p50 subunit expression (Fig. 4-18B). Exogenous $\mathrm{H}_{2} \mathrm{O}_{2}$ applied alone or in the presence of rotenone did not change p105 and p50 expression (Fig. 4-18B). 

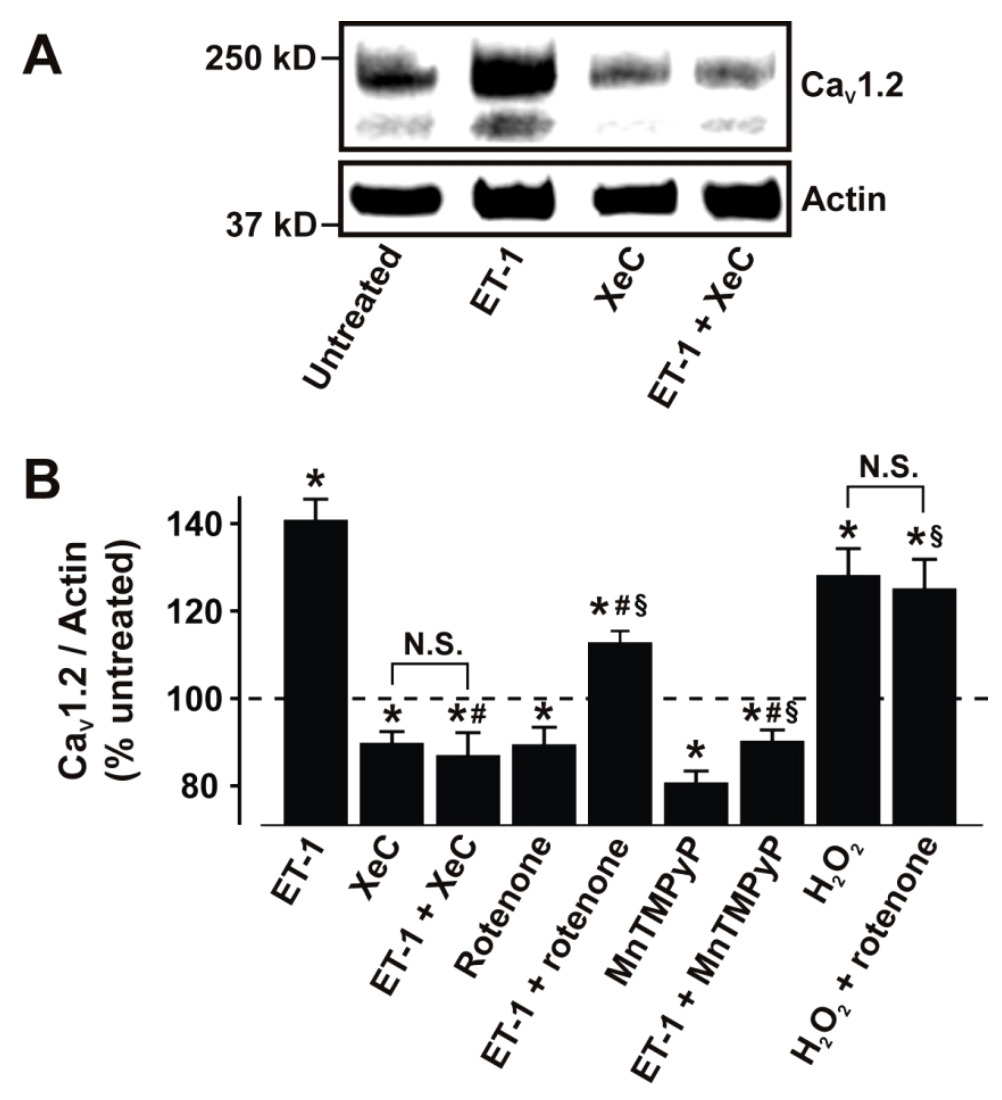

Figure 4-15. ET-1-induced $\mathrm{IP}_{3} \mathrm{R}$-mediated $\mathrm{SR} \mathrm{Ca}^{2+}$ release and mitoROS elevation stimulate $\mathrm{Ca}_{\mathrm{V}} 1.2$ protein expression in cerebral arteries

Notes: A, Western blot indicating that ET-1(10 nM) application for 24 hours elevated $\mathrm{Ca}_{\mathrm{V}} 1.2$ protein expression and $\mathrm{XeC}(20 \mu \mathrm{M})$ blocked the ET-1-induced elevation in Cav1.2 expression. B, Mean data for ET-1 ( $n=12), \operatorname{XeC}(20 \mu M, n=7), E T-1+\operatorname{XeC}(n=7)$, rotenone $(1 \mu \mathrm{M}, \mathrm{n}=6), \mathrm{ET}-1+$ rotenone $(\mathrm{n}=6), \operatorname{MnTMPyP}(10 \mu \mathrm{M}, \mathrm{n}=5), \mathrm{ET}-$ $1+\operatorname{MnTMPyP}(\mathrm{n}=5), \mathrm{H}_{2} \mathrm{O}_{2}(100 \mu \mathrm{M}, \mathrm{n}=5)$, and $\mathrm{H}_{2} \mathrm{O}_{2}+$ rotenone $(\mathrm{n}=5)$. ET-1 concentration was $10 \mathrm{nM}$ in all experiments. Values are expressed as mean $\pm \mathrm{SEM}$. * indicates $\mathrm{P}<0.05$ compared to control. \# indicates $\mathrm{P}<0.05$ compared to ET -1 . $\S$ indicates $\mathrm{P}<0.05$ compared to rotenone or MnTMPyP. 
A

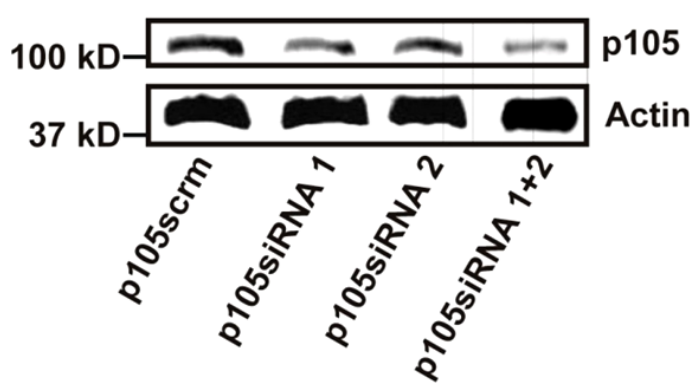

B

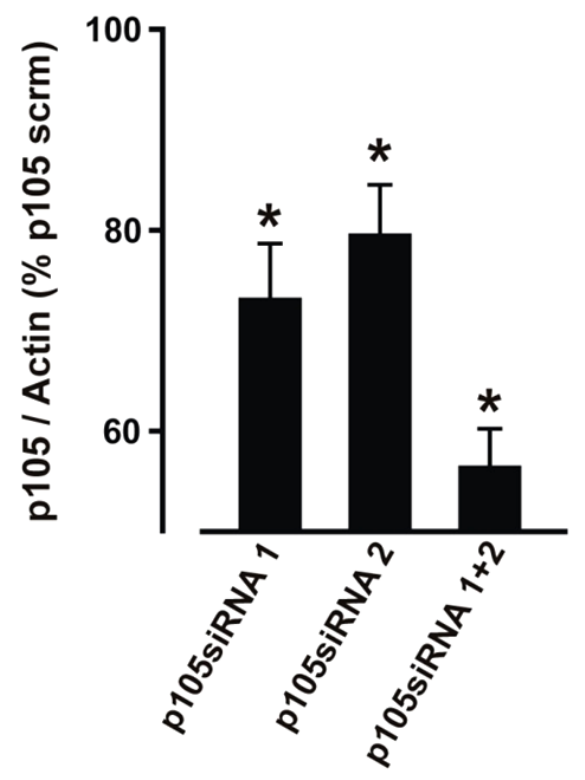

Figure 4-16. p105 knockdown in cerebral arteries

Notes: A, Western blot illustrating that p105siRNA1, p105siRNA2, and p105siRNA1+2 reduce $\mathrm{p} 105$ expression in cerebral arteries. B, Mean data. $\mathrm{n}=5$ for each. Values are expressed as mean \pm SEM. * indicates $\mathrm{P}<0.05$ compared to arteries reverse permeabilized with $\mathrm{p} 105 \mathrm{scrm}$. 
A

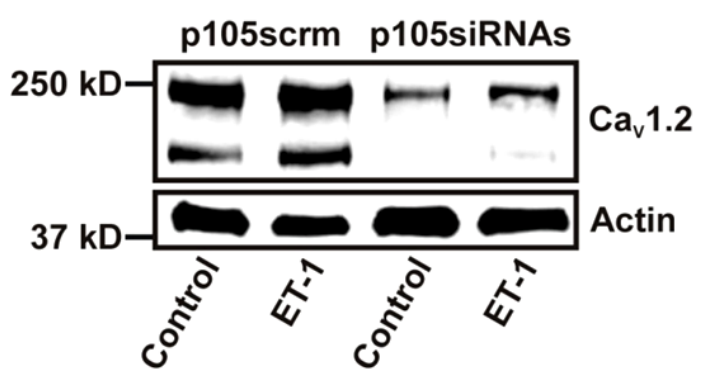

B

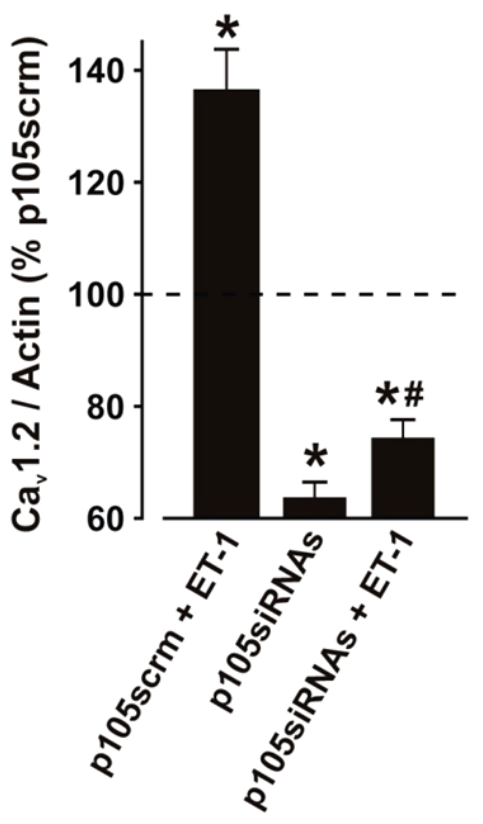

Figure 4-17. NF- $\kappa \mathrm{B}$ controls basal and ET-1-induced elevation in functional $\mathrm{Ca}_{\mathrm{V}} 1.2$ expression in cerebral arteries

Notes: A, Western blot illustrating effects of p105siRNAs $(10 \mu \mathrm{g} / \mathrm{ml}$ each $)$ on basal and ET-1-induced Cav1.2 expression. B, Mean data. $\mathrm{n}=5$ for each. Values are expressed as mean \pm SEM. * indicates $\mathrm{P}<0.05$ compared to arteries reverse permeabilized with p105scrm. \# indicates $\mathrm{P}<0.05$ compared to arteries reverse permeabilized with p105siRNAs. 
A

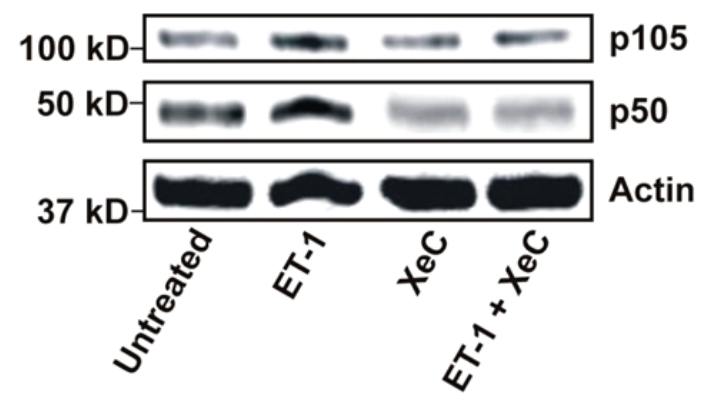

B

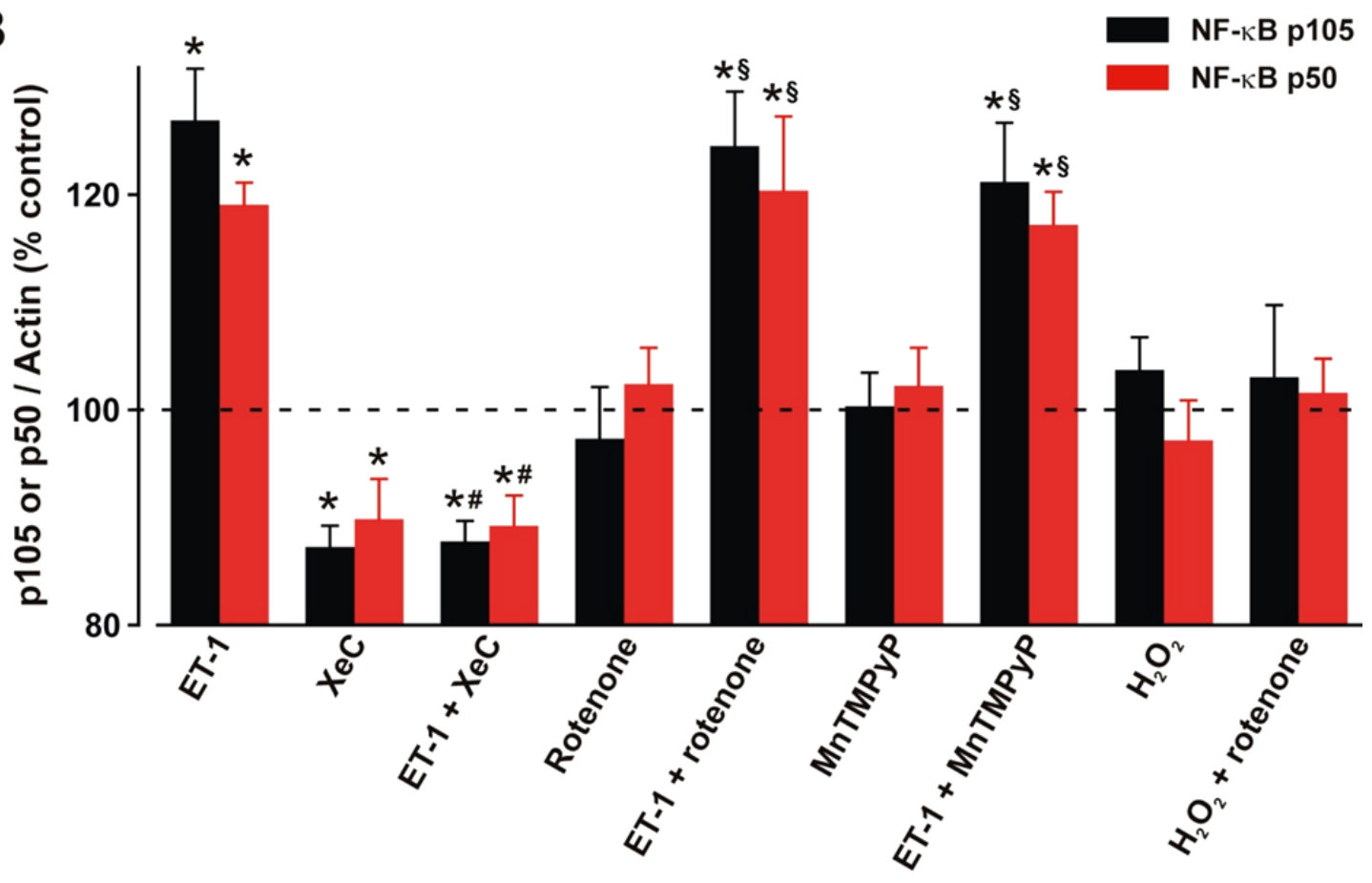

Figure 4-18. ET-1-induced $\mathrm{IP}_{3} \mathrm{R}$-mediated $\mathrm{SR} \mathrm{Ca}^{2+}$ release elevates $\mathrm{p} 105 / \mathrm{p} 50$ expression via a mitochondria-, and ROS-independent mechanism in cerebral arteries

Notes: A, Western blots indicating that $\mathrm{XeC}(20 \mu \mathrm{M})$ blocked an ET-1-induced elevation in p105 and p50 expression. B, Mean data for p105 (black) and p50 (red). p105 and p50 data were measured in the same blots, and thus experimental number is identical for each protein. ET-1 $(\mathrm{n}=8), \mathrm{XeC}(20 \mu \mathrm{M}, \mathrm{n}=6), \mathrm{ET}-1+\mathrm{XeC}(\mathrm{n}=6)$, rotenone $(1 \mu \mathrm{M}, \mathrm{n}=5), \mathrm{ET}-$ $1+$ rotenone $(\mathrm{n}=5), \operatorname{MnTMPyP}(10 \mu \mathrm{M}, \mathrm{n}=5), \mathrm{ET}-1+\operatorname{MnTMPyP}(\mathrm{n}=5), \mathrm{H}_{2} \mathrm{O}_{2}(100 \mu \mathrm{M}$, $\mathrm{n}=6)$, and $\mathrm{H}_{2} \mathrm{O}_{2}$ +rotenone $(\mathrm{n}=6)$. Values are expressed as mean \pm SEM. * indicates $\mathrm{P}<0.05$ compared to control. \# indicates $\mathrm{P}<0.05$ compared to ET- 1 . § indicates $\mathrm{P}<0.05$ compared to rotenone or MnTMPyP. 


\subsection{ET-1-Induced NF-кB Activation Does Not Stimulate p105 Expression}

p105siRNAs reduced p105 and p50 expression to $\sim 57$ and 53\% of p105scrm (Fig. 4-19A,B). ET-1 increased p105 expression in p105scrm-treated arteries to $\sim 123 \%$ of p105scrm, and in p105siRNAs-treated arteries from $\sim 57$ to $67 \%$ of $\mathrm{p} 105 \mathrm{scrm}(\sim 121 \%$ of p105siRNAs) (Fig. 4-19A,B). Similarly, ET-1 increased p50 expression in p105scrmtreated arteries to $\sim 118 \%$ of p $105 \mathrm{scrm}$, and in p105siRNAs-treated arteries from $\sim 53$ to $65 \%$ of p $105 \mathrm{scrm}(\sim 124 \%$ of p105siRNAs) (Fig. 4-19A,B). These data indicate that p105siRNAs did not alter the ET-1-induced relative increase in p105 and p50 expression (Fig. 4-19A,B).

Collectively, these data indicate that $\mathrm{IP}_{3} \mathrm{R}$-mediated $\mathrm{SR} \mathrm{Ca}^{2+}$ release activates p105/p50 expression via a mitochondria-, ROS-, and NF- $\mathrm{BB}-i n d e p e n d e n t$ pathway. Data also indicate that rotenone, MnTMPyP, and p105siRNAs do not cause general inhibition of gene transcription.

\subsection{NF-кB Stimulates Functional Cav1.2 Expression in Cerebral Artery Smooth Muscle Cells}

To investigate NF- $\kappa \mathrm{B}$ regulation of functional $\mathrm{Ca}_{\mathrm{V}} 1.2$ expression, diameter regulation of pressurized $(60 \mathrm{mmHg})$ endothelium-denuded arteries was studied.

\subsubsection{Myogenic tone development in arteries}

In resistance-size cerebral arteries, an elevation of intravascular pressure from 10 to $60 \mathrm{mmHg}$ stretches the smooth muscle cells of the arterial wall, leading to activation of mechanosensitive ion channels (Hill et al., 2001). Stimulation of stretch-activated cation channels induces a graded membrane depolarization of smooth muscle cells from $\sim-60$ to $-40 \mathrm{mV}$ (Jaggar, 2001), which increases the steady-state open probability of Cav 1.2 channels on smooth muscle cells (Knot \& Nelson, 1998). This leads to increased $\mathrm{Ca}^{2+}$ influx through $\mathrm{Ca}_{\mathrm{V}} 1.2$ channels to elevate steady-state arterial wall $\left[\mathrm{Ca}^{2+}\right]_{\mathrm{i}}$. Increased arterial wall $\left[\mathrm{Ca}^{2+}\right]_{\mathrm{i}}$ activates myosin light chain kinase, which leads to maintained constriction ('myogenic tone') (Fig. 4-20).

\subsubsection{ET-1-stimulates functional Cav1.2 expression via NF- $\mathrm{KB}$ activation}

Arteries were treated with either p105scrm or p105siRNAs and then exposed to either no further treatment or to ET-1 for 24 hours. At $60 \mathrm{~mm} \mathrm{Hg}$, control arteries (p105scrm) developed $\sim 21 \%$ myogenic tone and membrane depolarization with $60 \mathrm{mM}$ $\mathrm{K}^{+}$elevated tone to $\sim 45 \%$. p105 knockdown (p105siRNAs) reduced myogenic tone and depolarization-induced vasoconstriction to $\sim 14$ and 31\%, respectively (Fig. 4-21A,B). A 24-hour exposure to ET-1 elevated mean myogenic tone and depolarization-induced tone in control arteries to $\sim 32$ and 55\%, respectively (Fig. 4-21A,B). p105siRNAs attenuated 

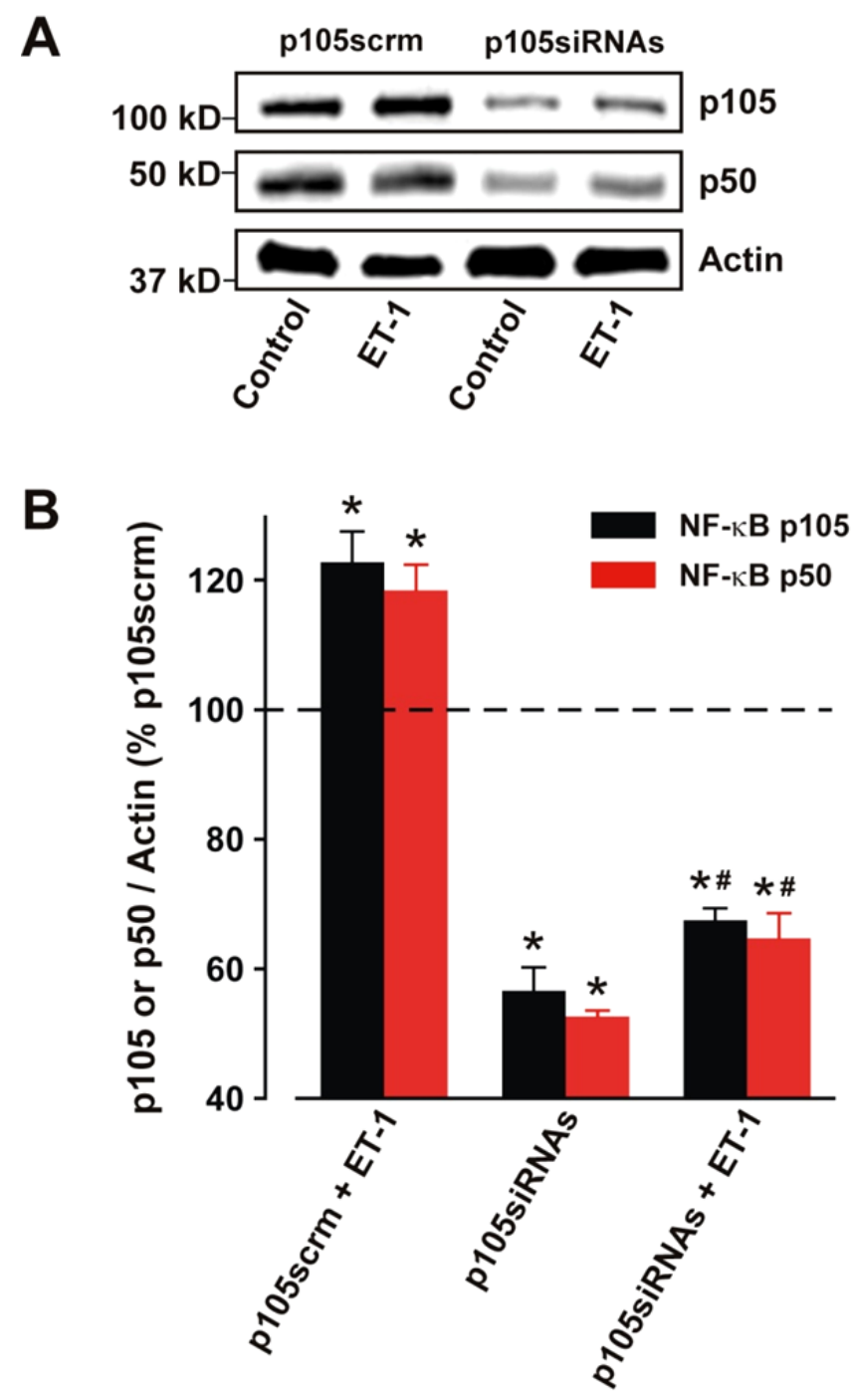

Figure 4-19. ET-1 elevates p105/p50 expression via an NF- $\mathrm{BB}$-independent pathway in cerebral arteries

Notes: A, Western blot illustrating effects of p105siRNAs $(10 \mu \mathrm{g} / \mathrm{ml}$ each $)$ on $\mathrm{p} 105$ and p50 expression and regulation by ET-1. B, Mean data for p105 (black) ( $\mathrm{n}=5$ for each) and p50 (red) expression ( $\mathrm{n}=4$ for each). ET-1 concentration was $10 \mathrm{nM}$ in all experiments. Values are expressed as mean \pm SEM. * indicates $\mathrm{P}<0.05$ compared to arteries reverse permeabilized with $\mathrm{p} 105 \mathrm{scrm}$. \# indicates $\mathrm{P}<0.05$ compared to arteries reverse permeabilized with p105siRNAs. 


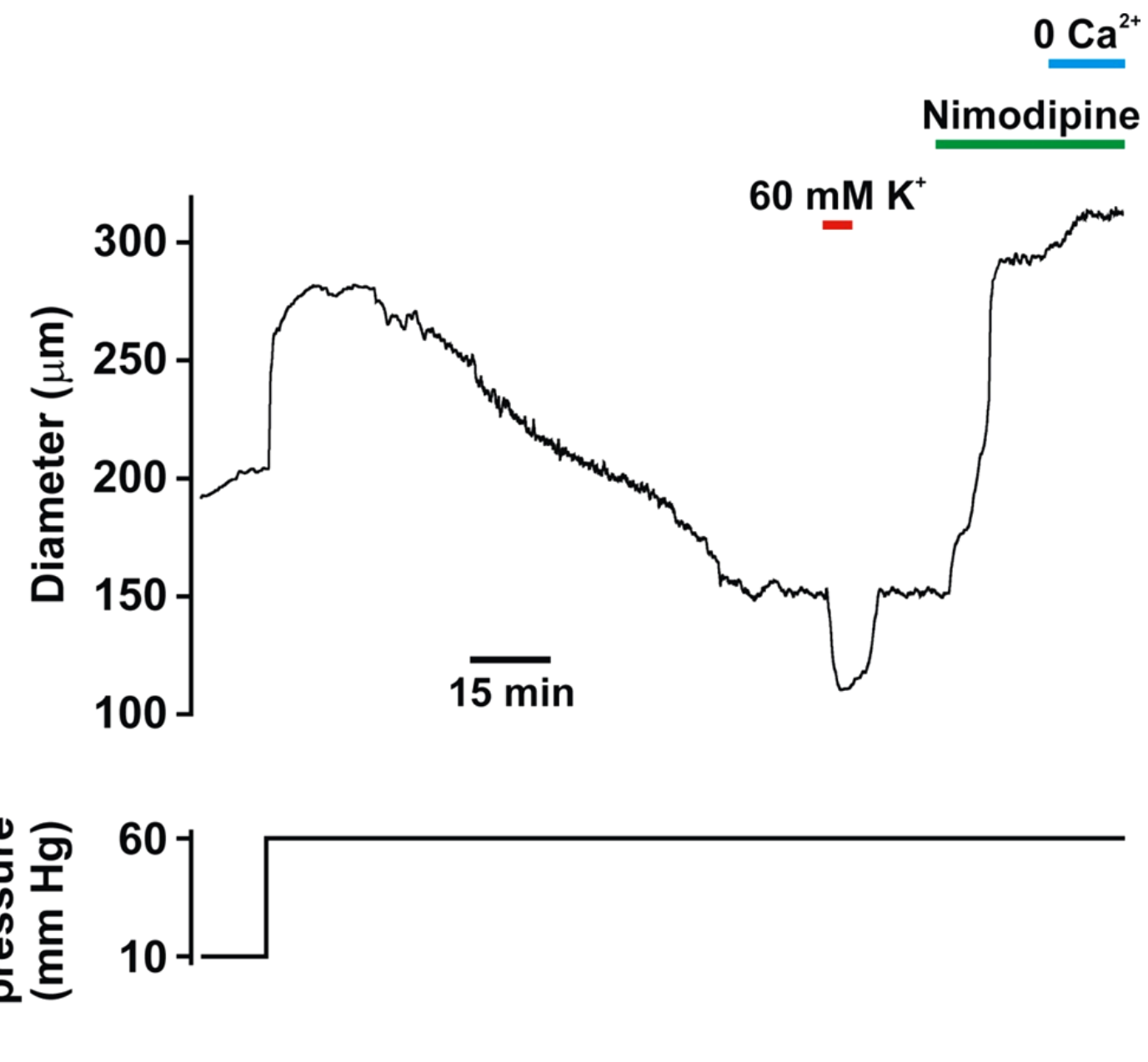

Figure 4-20. Myogenic tone development in cerebral arteries

Notes: Respresentative trace illustrating that an elevation of intravascular pressure from 10 to $60 \mathrm{~mm} \mathrm{Hg}$ induces nimodipine-sensitive myogenic tone in a cerebral artery.

Addition of $60 \mathrm{mM} \mathrm{K} \mathrm{K}^{+}$causes massive depolarization leading to further vasoconstriction. 
A

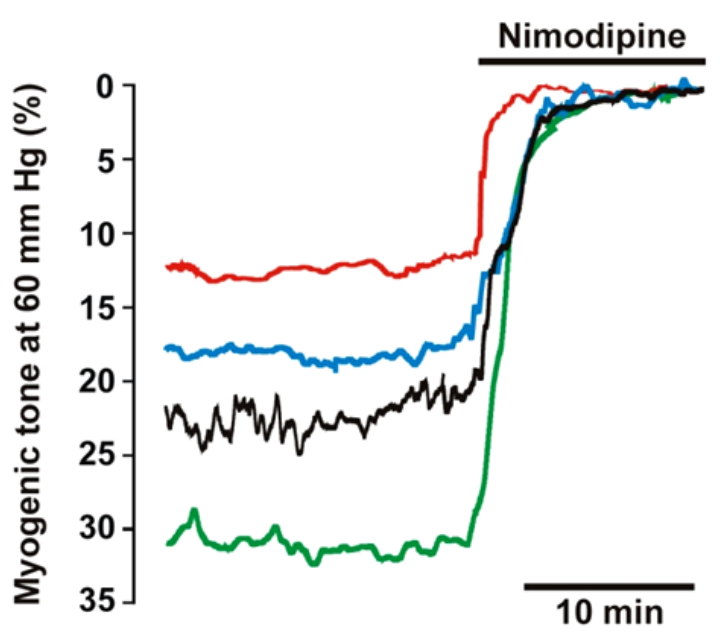

p105scrm p105scrm + ET-1 p105siRNA p105siRNAs + ET-1

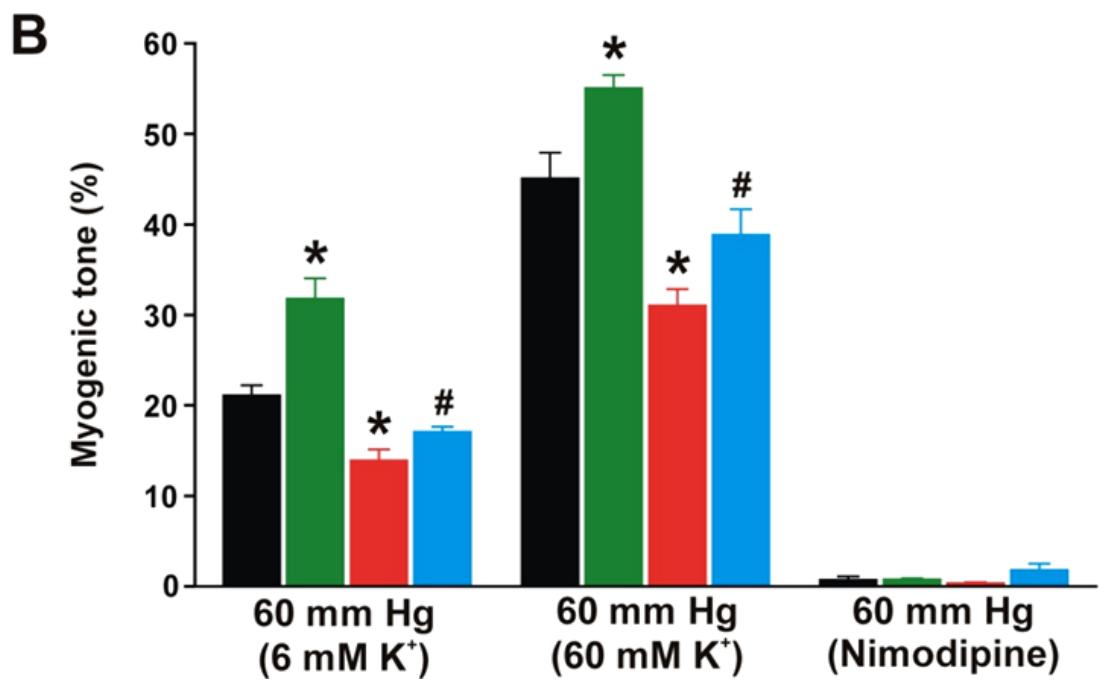

Figure 4-21. p105 knockdown reduces myogenic tone and attenuates ET-1-induced elevation in myogenic tone in cerebral arteries

Notes: A, Representative traces illustrating diameter in arteries pressurized to $60 \mathrm{~mm} \mathrm{Hg}$ $\left(6 \mathrm{mM} \mathrm{K}^{+}\right)$. Nimodipine $(1 \mu \mathrm{M})$ fully dilated p105scrm- and p105siRNAs-treated arteries. B, Mean myogenic tone at $60 \mathrm{~mm} \mathrm{Hg}(\mathrm{p} 105 \mathrm{scrm}, \mathrm{n}=5, \mathrm{p} 105 \mathrm{scrm}+\mathrm{ET}-1, \mathrm{n}=6$, p105siRNAs, $n=6, p 105 \mathrm{siRNAs}+\mathrm{ET}-1, \mathrm{n}=6)$, in $60 \mathrm{mM} \mathrm{K}^{+}$at $60 \mathrm{~mm} \mathrm{Hg}$ (p105scrm, $\mathrm{n}=5, \mathrm{p} 105 \mathrm{scrm}+\mathrm{ET}-1, \mathrm{n}=5, \mathrm{p} 105 \mathrm{siRNAs}, \mathrm{n}=5$, p105siRNAs + ET-1, $\mathrm{n}=5$ ), or nimodipine $(1 \mu \mathrm{M})$ at $60 \mathrm{~mm} \mathrm{Hg}(\mathrm{p} 105 \mathrm{scrm}, \mathrm{n}=5, \mathrm{p} 105 \mathrm{scrm}+\mathrm{ET}-1, \mathrm{n}=6, \mathrm{p} 105 \mathrm{siRNAs}$, $\mathrm{n}=5$, p105siRNAs + ET-1, $\mathrm{n}=5$ ). Values are expressed as mean \pm SEM. * indicates $\mathrm{P}<0.05$ compared to arteries reverse permeabilized with $\mathrm{p} 105 \mathrm{scrm}$. \# indicates $\mathrm{P}<0.05$ compared to arteries reverse permeabilized with p105siRNAs. 
the ET-1-induced elevation in myogenic tone and depolarization-induced vasoconstriction to $\sim 17$ and 39\%, respectively (Fig. 4-21A,B). Nimodipine fully dilated arteries regardless of treatment, indicating that vasoconstriction occurred due to $\mathrm{Ca}_{\mathrm{V}} 1.2$ channel activation (Fig. 4-21A,B). These data indicate that NF- $\mathrm{\kappa B}$ is essential for functional basal $\mathrm{Ca}_{V} 1.2$ expression in cerebral artery smooth muscle cells and that ET-1induced NF-kB activation elevates $\mathrm{Ca}_{\mathrm{V}} 1.2$ expression and vasoconstriction. 


\section{CHAPTER 5. DISCUSSION*}

\subsection{Summary of Findings}

Here, we investigated physiological signaling mechanisms that regulate $\left[\mathrm{Ca}^{2+}\right]_{\text {mito }}$, functional consequences of changes in $\left[\mathrm{Ca}^{2+}\right]_{\text {mito }}$, and mitochondrial regulation of ion channel gene expression in arterial smooth muscle cells. This study was performed using small, resistance-size cerebral arteries that regulate blood pressure and regional blood flow to the brain. In this study, we have used state-of-art techniques, including genetically-encoded fluorescent indicators and laser-scanning confocal microscopy to measure $\left[\mathrm{Ca}^{2+}\right]_{\text {mito }}$ and ROS, fluorescence imaging and luciferase reporter gene assays to examine NF- $\kappa \mathrm{B}$ activity, molecular biology and biochemical techniques to examine $\mathrm{Ca}_{\mathrm{V}} 1.2$ expression, and pressurized artery diameter measurements to study the functional significance of elevated $\mathrm{Ca}_{\mathrm{V}} 1.2$ channel expression.

A schematic diagram summarizing major findings of this study is provided in Figs. 5-1 and 5-2. Under resting conditions, basal levels of $\mathrm{IP}_{3}$ activate $\mathrm{IP}_{3} \mathrm{R}$, leading to $\mathrm{SR} \mathrm{Ca}{ }^{2+}$ release. $\mathrm{IP}_{3} \mathrm{R}-$ mediated $\mathrm{SR} \mathrm{Ca}{ }^{2+}$ release and constitutively produced mitoROS activate NF- $\kappa$ B. NF- $\kappa$ B controls basal Cav1.2 expression in cerebral artery smooth

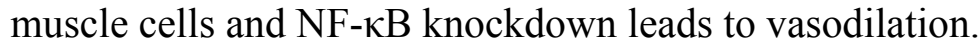

ET-1-induced $\mathrm{IP}_{3} \mathrm{R}$-mediated $\mathrm{SR} \mathrm{Ca}^{2+}$ release generates $\mathrm{Ca}^{2+}$ waves, elevates $\left[\mathrm{Ca}^{2+}\right]_{\text {mito, }}$, and depolarizes mitochondria, leading to an increase in mitoROS generation. ET-1-induced $\mathrm{IP}_{3}$ R-mediated mitoROS elevate cytosolic ROS that increase NF- $\kappa \mathrm{B}$ nuclear translocation and transcriptional activity. ET-1-induced NF- $\kappa \mathrm{B}$ activation stimulates $\mathrm{Ca}_{\mathrm{V}} 1.2$ expression, leading to an elevation in $\mathrm{Ca}_{\mathrm{V}} 1.2$-dependent pressure- and depolarization-induced vasoconstriction. ET-1-induced $\mathrm{IP}_{3} \mathrm{R}$-mediated $\mathrm{SR} \mathrm{Ca}{ }^{2+}$ release also elevates NF- $\mathrm{B}$ p105/p50 subunit expression via a mitochondria-, ROS-, and NF$\kappa \mathrm{B}$-independent pathway. Collectively, these data indicate that $\mathrm{IP}_{3} \mathrm{R}$-mediated $\mathrm{SR} \mathrm{Ca}^{2+}$ release elevates $\left[\mathrm{Ca}^{2+}\right]_{\text {mito }}$, stimulating mitoROS which activate NF- $\mathrm{BB}$-dependent $\mathrm{Ca} \mathrm{V}_{\mathrm{V}} 1.2$ channel expression. Thus, mitochondria sense $\mathrm{IP}_{3} \mathrm{R}$-mediated $\mathrm{SR} \mathrm{Ca}^{2+}$ release to control functional $\mathrm{Ca}_{\mathrm{V}} 1.2$ channel transcription in arterial smooth muscle cells, thereby regulating arterial contractility.

\section{2. $\mathrm{Ca}^{2+}$ Signaling in Vascular Smooth Muscle Cells by PLC-Coupled Agonists}

Several vasoconstrictors, including UTP, Ang II, and ET-1 activate PLC (Rosendorff, 1997; Ralevic \& Burnstock, 1998; Touyz \& Schiffrin, 2000; Zhang et al., 2003), leading to $\mathrm{PIP}_{2}$ hydrolysis and the generation of $\mathrm{IP}_{3}$ and DAG. $\mathrm{IP}_{3}$ stimulates

* Portions of this chapter adapted with permission. Narayanan D, Xi Q, Pfeffer LM, \& Jaggar JH (2010). Mitochondria control functional Cav 1.2 expression in smooth muscle cells of cerebral arteries. Circ Res 107, 631-641. 


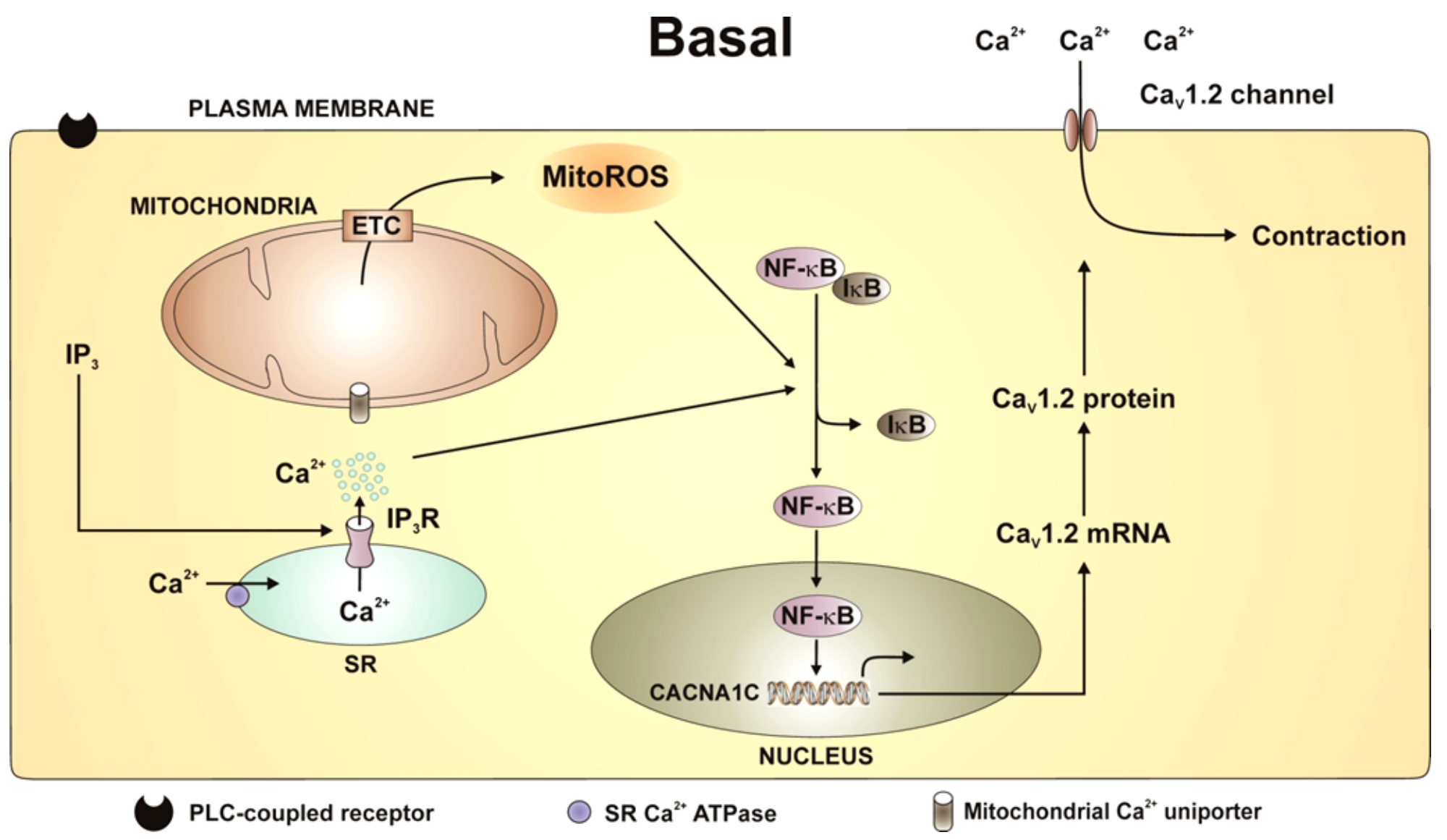

Figure 5-1. Proposed signaling pathways that control basal $\mathrm{Ca}_{\vee} 1.2$ expression in smooth muscle cells of cerebral arteries

Notes: Basal levels of $\mathrm{IP}_{3} \mathrm{R}-$-mediated $\mathrm{SR} \mathrm{Ca}^{2+}$ release and constitutively produced mitoROS activate NF- $\mathrm{kB}$ leading to Ca 1.2 expression. $\mathrm{IP}_{3}$ indicates inositol 1,4,5-trisphosphate, ETC indicates mitochondrial electron transport chain, and $\psi_{\mathrm{m}}$ indicates mitochondrial membrane potential. 


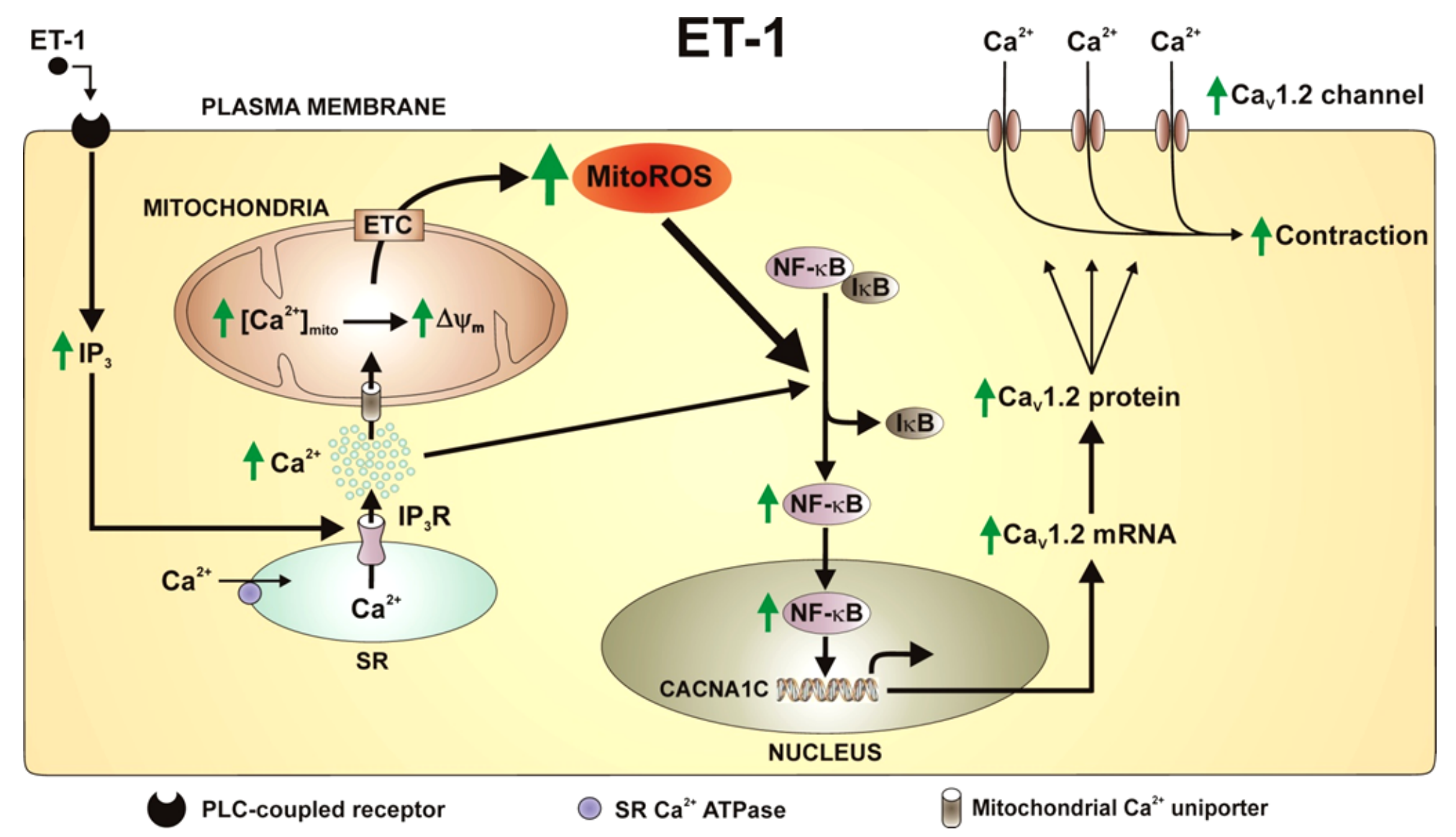

Figure 5-2. Proposed signaling pathways that control ET-1-induced $\mathrm{Ca}_{\mathrm{V}} 1.2$ expression in smooth muscle cells of cerebral arteries

Notes: ET-1-induced $\mathrm{IP}_{3} \mathrm{R}$-mediated $\mathrm{SR} \mathrm{Ca}^{2+}$ release activates NF- $\mathrm{KB}$ : (a) primarily by stimulating a mitochondrial ROS elevation and (b) via a secondary mitochondria-independent pathway, leading to $\mathrm{Ca}_{\mathrm{V}} 1.2$ expression. $\mathrm{IP}_{3}$ indicates inositol 1,4,5-trisphosphate, ETC indicates mitochondrial electron transport chain, and $\psi_{\mathrm{m}}$ indicates mitochondrial membrane potential. 
$\mathrm{IP}_{3} \mathrm{Rs}$, and DAG activates PKC. Activation of $\mathrm{IP}_{3} \mathrm{R} 1$, the major isoform expressed in smooth muscle cells of resistance-size cerebral arteries stimulates $\mathrm{SR} \mathrm{Ca}^{2+}$ release in the form of $\mathrm{Ca}^{2+}$ waves, which contribute to global $\left[\mathrm{Ca}^{2+}\right]_{\mathrm{i}}$ elevation (Jaggar \& Nelson, 2000; Zhao et al., 2008). IP ${ }_{3} \mathrm{R} 1$ activation also induces physical coupling of the N-terminus of $\mathrm{IP}_{3} \mathrm{R} 1$ and the $\mathrm{C}$-terminus of plasma membrane TRPC 3 channel, leading to $\mathrm{I}_{\mathrm{Cat}}$ activation. $\mathrm{IP}_{3} \mathrm{R}$-dependent $\mathrm{I}_{\mathrm{Cat}}$ activation produces membrane depolarization, $\mathrm{Ca}_{\mathrm{V}} 1.2$ channel activation, a global $\left[\mathrm{Ca}^{2+}\right]_{\mathrm{i}}$ elevation, and vasoconstriction (Xi et al., 2008; Zhao et al., 2008; Adebiyi et al., 2010). Therefore, vasoconstrictor-induced $\mathrm{IP}_{3} \mathrm{R}$ activation elevates $\left[\mathrm{Ca}^{2+}\right]_{\mathrm{i}}$ in cerebral artery smooth muscle cells via SR $\mathrm{Ca}^{2+}$ release-dependent and independent mechanisms. In contrast, vasoconstrictor-activated PKC inhibits $\mathrm{Ca}^{2+}$ sparks, which leads to membrane depolarization, $\mathrm{Ca}_{\mathrm{V}} 1.2$ channel activation, and a global $\left[\mathrm{Ca}^{2+}\right]_{\mathrm{i}}$ elevation (Jaggar \& Nelson, 2000).

\subsection{Regulation of $\left[\mathrm{Ca}^{2+}\right]_{\text {mito }}$ by Cytosolic $\mathrm{Ca}^{2+}$ Signals}

The regulation of arterial smooth muscle cell $\left[\mathrm{Ca}^{2+}\right]_{\text {mito }}$ by vasoconstrictorinduced intracellular $\mathrm{Ca}^{2+}$ signals is unclear. Electron microscopy studies indicate that mitochondria can be located in close proximity $(\sim 20 \mathrm{~nm})$ to the SR membrane in many cell types, including cultured arterial smooth muscle cells (Rizzuto et al., 1999; Duchen, 2000b; Szado et al., 2003; Pacher et al., 2008). Such localization should place mitochondria within the vicinity of $\mathrm{SR} \mathrm{Ca}^{2+}$ release channels that generate micromolar cytosolic $\mathrm{Ca}^{2+}$ elevations. Given that the MCU is sensitive to $\mathrm{Ca}^{2+}$ only within the micromolar concentration range (Gunter \& Pfeiffer, 1990), such structural orientation allows local signaling between $\mathrm{SR} \mathrm{Ca}^{2+}$ release channels and mitochondria. In cultured vascular smooth muscle cells, SR $\mathrm{Ca}^{2+}$ release elicited a $\left[\mathrm{Ca}^{2+}\right]_{\text {mito }}$ elevation (Pacher et al., 2008) and a delayed $\left[\mathrm{Ca}^{2+}\right]_{\text {mito }}$ elevation occurred when $\left[\mathrm{Ca}^{2+}\right]_{\mathrm{i}}$ increased $>1 \mu \mathrm{M}$, but not when the $\left[\mathrm{Ca}^{2+}\right]_{\mathrm{i}}$ elevation was $<500 \mathrm{nM}$ (Monteith \& Blaustein, 1999). $\mathrm{Ca}^{2+}$ influx via the plasma membrane $\mathrm{Na}^{+} / \mathrm{Ca}^{2+}$ exchanger also elevated $\left[\mathrm{Ca}^{2+}\right]_{\text {mito }}$ in cultured vascular smooth muscle cells (Poburko et al., 2009). In non-cultured, voltage-clamped colonic smooth muscle cells, uncaging $\mathrm{IP}_{3}$ leads to mitochondrial $\mathrm{Ca}^{2+}$ uptake that feeds back to regulate $\mathrm{IP}_{3} \mathrm{R}$ activity (Olson et al., 2010).

Previous studies have used inorganic $\mathrm{Ca}^{2+}$ indicators to measure $\left[\mathrm{Ca}^{2+}\right]_{\text {mito }}$ in cultured arterial smooth muscle cells (Monteith \& Blaustein, 1999; Pacher et al., 2008; Poburko et al., 2009). These fluorophores are not designed to target to specific cellular locations, which inevitably leads to non-specific $\mathrm{Ca}^{2+}$ measurements. To our knowledge, our study is the first to use a genetically-encoded, mitochondria-targeted, fluorescent indicator to measure $\left[\mathrm{Ca}^{2+}\right]_{\text {mito }}$ in contractile arterial smooth muscle cells. Furthermore, we studied cerebral artery smooth muscle cells in their native, contractile phenotype, while previous studies primarily used cultured, proliferating vascular smooth muscle cells. In vitro cultivation of vascular smooth muscle cells results in phenotypic alterations, characterized by changes in cell morphology, receptor expression, and contractile-cytoskeletal protein profiles, and switches arterial smooth muscle cell phenotype from a contractile state to an invasive, proliferative state (Absher et al., 1989; Campbell et al., 1989; Eguchi et al., 1994). Therefore, it is highly likely that 
physiological functions of mitochondria differ in these different cell phenotypes, particularly since spatial proximity to $\mathrm{Ca}^{2+}$ channels and transporters are critical for mitochondrial $\mathrm{Ca}^{2+}$ uptake.

Our data indicate that in contractile cerebral artery smooth muscle cells, thapsigargin, $\mathrm{XeC}$, and Ru360 did not alter resting $\left[\mathrm{Ca}^{2+}\right]_{\text {mito }}, \psi_{\mathrm{m}}$, or mitoROS. In contrast, mitochondrial inhibitors reduced basal $\left[\mathrm{Ca}^{2+}\right]_{\text {mito }}$, depolarized mitochondria, and reduced mitoROS levels. These data indicate that in resting arterial smooth muscle cells, mitochondria contain $\mathrm{Ca}^{2+}$ and generate low levels of ROS through mechanisms that are independent of $\mathrm{IP}_{3} \mathrm{R}$-mediated $\mathrm{SR} \mathrm{Ca}^{2+}$ release. Therefore, basal mitochondrial $\mathrm{Ca}^{2+}$ levels appear to be maintained by $\mathrm{Ca}^{2+}$ uptake through transporters other than the MCU, which is sensitive to micromolar $\mathrm{Ca}^{2+}$ as that produced by $\mathrm{SR} \mathrm{Ca}^{2+}$ release (Gunter \& Pfeiffer, 1990). Apart from the MCU, several mitochondrial pumps and exchangers, including RaM (Gunter et al., 2000) and reversal mode of mNCX (Griffiths et al., 1998) have been speculated to be responsible for mitochondrial $\mathrm{Ca}^{2+}$ uptake and the maintenance of resting $\left[\mathrm{Ca}^{2+}\right]_{\text {mito }}$ levels (Gunter et al., 2000).

ET-1-induced $\mathrm{IP}_{3} \mathrm{R}$-mediated $\mathrm{SR} \mathrm{Ca}{ }^{2+}$ release stimulated $\mathrm{Ca}^{2+}$ waves and elevated $\left[\mathrm{Ca}^{2+}\right]_{\text {mito, }}$, leading to mitochondrial depolarization and mitoROS generation. Here, thapsigargin and $\mathrm{XeC}$ blocked the ET-1-induced $\left[\mathrm{Ca}^{2+}\right]_{\text {mito }}$ elevation, mitochondrial depolarization, and mitoROS generation. In contrast, membrane depolarization, which elevates global $\left[\mathrm{Ca}^{2+}\right]_{\mathrm{i}}$, did not alter $\left[\mathrm{Ca}^{2+}\right]_{\text {mito }}, \psi_{\mathrm{m}}$, or mitoROS generation. These data are consistent with the hypothesis that $\mathrm{IP}_{3} \mathrm{R}$-mediated $\mathrm{SR} \mathrm{Ca}{ }^{2+}$ release stimulates mitochondrial $\mathrm{Ca}^{2+}$ uptake, leading to a $\left[\mathrm{Ca}^{2+}\right]_{\text {mito }}$ elevation, mitochondrial depolarization, and mitoROS generation.

\section{4. $\mathrm{Ca}^{2+}$ Waves May Be the Cytosolic $\mathrm{Ca}^{2+}$ Signal Regulating Mitochondrial Events}

Consistent with imaging data indicating that vasoconstrictor-induced $\mathrm{Ca}^{2+}$ waves occur due to $\mathrm{IP}_{3} \mathrm{R}$ activation in smooth muscle cells (Zhao et al., 2008), our data suggest that $\mathrm{Ca}^{2+}$ waves specifically regulate $\left[\mathrm{Ca}^{2+}\right]_{\text {mito }}$ and mitoROS generation in arterial smooth muscle cells. Given that $\mathrm{Ca}^{2+}$ waves are propagating $\mathrm{Ca}^{2+}$ signals, $\left[\mathrm{Ca}^{2+}\right]_{\text {mito }}$ and mitoROS may also oscillate. Here, $\left[\mathrm{Ca}^{2+}\right]_{\text {mito }}$ and mitoROS was measured within multiple smooth muscle cells in the arterial wall. $\left[\mathrm{Ca}^{2+}\right]_{\text {mito }}$ and mitoROS within individual mitochondria may oscillate. In our experiments, $2 \mathrm{mt} 8 \mathrm{CG} 2$ and mt-cpYFP fluorescence in each field was measured from mitochondria within $\sim 25$ smooth muscle cells within the arterial wall. Therefore, any asynchronous $\left[\mathrm{Ca}^{2+}\right]_{\text {mito }}$ or mitoROS oscillations within individual mitochondria would have been averaged out by the imaging protocol. This protocol was necessary to measure sufficient $2 \mathrm{mt} 8 \mathrm{CG} 2$ or mt-cpYFP fluorescence and to reduce the effects of indicator bleaching on measurements in cerebral artery smooth muscle cells. It would be interesting to study spatial and temporal relationships between ET-1-induced $\mathrm{Ca}^{2+}$ waves and $\left[\mathrm{Ca}^{2+}\right]_{\text {mito }}$ or mitoROS changes within individual mitochondria in arterial smooth muscle cells. However, such an examination of millisecond changes in $\left[\mathrm{Ca}^{2+}\right]_{\text {mito }}$ or mitoROS is more suitable for a future 
investigation, and may require the use of a different mitochondria-targeted $\mathrm{Ca}^{2+}$ or ROS indicator that better suits the type of experiment. Future studies should be designed to examine spatial and temporal relationships between $\mathrm{Ca}^{2+}$ waves and $\left[\mathrm{Ca}^{2+}\right]_{\text {mito }}$ or mitoROS signals within individual mitochondria in arterial smooth muscle cells.

\subsection{Regulation of MitoROS Generation by $\left[\mathrm{Ca}^{2+}\right]_{\text {mito }}$ and Mitochondrial Potential}

ET-1-induced mitoROS elevation was blocked by $\mathrm{XeC}, \mathrm{Ru} 360$, rotenone, and $\mathrm{CCCP}$, indicating that $\mathrm{IP}_{3} \mathrm{R}$-mediated $\mathrm{SR} \mathrm{Ca}^{2+}$ release, mitochondrial $\mathrm{Ca}^{2+}$ uptake, and mitochondrial depolarization stimulate mitoROS generation. The mechanism by which mitochondrial $\mathrm{Ca}^{2+}$ uptake induces mitochondrial depolarization and elevates ETCgenerated mitoROS was not determined. A $\left[\mathrm{Ca}^{2+}\right]_{\text {mito }}$ elevation may stimulate mitoROS generation at complexes I, III, and via $\mathrm{QH} \cdot$ generation through multiple mechanisms (Brookes et al., 2004): 1) stimulation of the tricarboxylic acid cycle enhancing electron flow through the ETC complexes; 2) inhibition of complex I; 3) dissociation and release cytochrome c from inner mitochondrial membrane; and 4) mPTP opening (Brookes et al., 2004).

Mitochondrial depolarization has been demonstrated to increase or decrease ROS in a variety of different cell types, including smooth muscle cells of anatomically diverse blood vessels (Brookes et al., 2004; Xi et al., 2005; Belousov et al., 2006; Wang et al., 2008a). $\psi_{\mathrm{m}}$ is another important regulator of mPTP opening. Mitochondrial depolarization can induce mPTP opening by shifting the threshold potential to higher levels (Petronilli et al., 1993; Bernardi, 1999). mPTP opening can in turn depolarize the mitochondria further, thereby enhancing the mitochondrial $\mathrm{Ca}^{2+}$ uptake-induced depolarization (Brookes et al., 2004; Wang et al., 2008a). Therefore, as suggested by a previous study, mitochondrial $\mathrm{Ca}^{2+}$ uptake may depolarize mitochondria due to (a) flow of $\mathrm{Ca}^{2+}$ ions into the mitochondrial matrix, and (b) mPTP opening (Duchen, 2004).

mPTP opening also elevates mitoROS generation via several pathways, including dissipation of chemical gradients across the mitochondrial membrane, and by changing

the fluidity and rigidity of the inner mitochondrial membrane, leading to diversion of electrons in the ETC to mitoROS generation (Wang et al., 2008a). Therefore, a $\left[\mathrm{Ca}^{2+}\right]_{\text {mito }}$ elevation and mitochondrial depolarization may stimulate mitoROS generation by opening the MPTP.

In the present study, a small mitochondrial depolarization increased mitoROS generation, whereas a large mitochondrial depolarization inhibited mitoROS production, consistent with an earlier report in cerebral artery smooth muscle cells (Xi et al., 2005). A small mitochondrial depolarization induced by nanomolar CCCP may increase mitoROS generation by shifting the MPTP threshold potential to higher levels (Petronilli et al., 1993; Bernardi, 1999). Micromolar CCCP, which causes massive uncoupling of ETC, and disrupts the regulation of $\psi_{\mathrm{m}}$, may severely affect electron transfer through the ETC complexes, resulting in a reduction in mitoROS generation. ETC uncoupling has 
been shown to decrease mitoROS generation in many cell types, including vascular smooth muscle cells (Okuda et al., 1992; Negre-Salvayre et al., 1997; Xi et al., 2005).

MitoROS production is also regulated by additional factors, including redox status of respiratory substrates, permeability of the inner mitochondrial membrane, and proton pumping by ETC complexes (Starkov \& Fiskum, 2003). Future investigations should examine the mechanisms by which a vasoconstrictor-induced $\left[\mathrm{Ca}^{2+}\right]_{\text {mito }}$ elevation and mitochondrial depolarization stimulate mitoROS generation.

\subsection{Characterization of ET-1-Induced ROS Elevation}

Endothelial denudation did not alter the ET-1-induced HyPer-CYTO and DCF fluorescence elevations, indicating that ROS were generated within smooth muscle cells and not by endothelial cells. This is in agreement with a previous study in pulmonary arteries suggesting that ET-1 elevates ROS in the arterial smooth muscle cells and not endothelial cells (Wedgwood et al., 2001). Our data with mt-cpYFP suggest that ET-1 elevates mitochondrial $\mathrm{O}_{2}^{-}$. production in arterial smooth muscle cells. Rotenone blocked the ET-1-induced elevations in mt-cpYFP and HyPer-CYTO fluorescence suggesting that ET-1-induced mitoROS elevation leads to an increase in cytosolic $\mathrm{H}_{2} \mathrm{O}_{2}$ levels. Dismutation of $\mathrm{O}_{2}{ }^{-} \cdot$ to $\mathrm{H}_{2} \mathrm{O}_{2}$ may occur both in the mitochondrial matrix and in the intermembrane space by mitochondrial SOD (Turrens, 2003; Li et al., 2005; Archer et al., 2010). Therefore, ET-1 elevates generation of mitochondrial $\mathrm{O}_{2}^{-} \cdot$ and cytosolic $\mathrm{H}_{2} \mathrm{O}_{2}$. However, ET-1-induced elevations in $\mathrm{O}^{2-}$. and $\mathrm{H}_{2} \mathrm{O}_{2}$ may also result in generation of $\mathrm{OH} \cdot \mathrm{NO}$, and $\mathrm{ONOO} \cdot$ through various pathways, including Fenton reaction (Turrens, 2003). ROS regulation of cellular signaling depends on the reactivity, and stability of the species. $\mathrm{H}_{2} \mathrm{O}_{2}$ which is more stable than $\mathrm{O}_{2}^{-}$, can diffuse for a longer distance allowing it to serve as a signaling molecule (Archer et al., 2010). $\mathrm{H}_{2} \mathrm{O}_{2}$ modulates the activity of several ROS-sensitive transcription factors such as HIF-1 $\alpha$ (Huang et al., 1996) and NFкB (Takada et al., 2003; Oliveira-Marques et al., 2009).

\subsection{ROS-Dependent and-Independent Pathways Which Activate NF-кB}

Physiological functions and mechanisms of regulation of NF- $\mathrm{KB}$ in contractile arterial smooth muscle cells are poorly understood. Our data indicate that thapsigargin, $\mathrm{XeC}$, rotenone, and MnTMPyP reduced basal NF- $\mathrm{kB}-$ dependent luciferase activity. Therefore, under basal conditions, NF- $\kappa B$ activation is regulated by both $\mathrm{IP}_{3} \mathrm{R}$-mediated $\mathrm{SR} \mathrm{Ca}^{2+}$ release and constitutively produced mitoROS. This is consistent with studies in neurons, indicating that $\mathrm{Ca}^{2+}$ influx through VDCCs and $\mathrm{IP}_{3} \mathrm{R}$-mediated $\mathrm{Ca}^{2+}$ release are responsible for the basal NF- $\mathrm{KB}$ activity (Lilienbaum \& Israel, 2003).

ET-1-induced NF- $\mathrm{\kappa B}$ activation was blocked by $\mathrm{XeC}$, and inhibited by rotenone and MnTMPyP. This indicates that ET-1-induced NF- $\mathrm{\kappa B}$ activation occurs primarily via $\mathrm{IP}_{3} \mathrm{R}$-mediated mitoROS generation in cerebral artery smooth muscle cells. MitoROS activate NF- $\mathrm{KB}$ in several cell types, including in cultured vascular smooth muscle cells 
(Lee et al., 2008). However, alternate ROS-mediated mechanisms have also been demonstrated to activate NF- $\mathrm{BB}$ in arterial smooth muscle cells. For example, following arterial balloon injury, ROS derived from $\mathrm{NO}$ and $\mathrm{NAD}(\mathrm{P}) \mathrm{H}$ oxidase are primarily responsible for the elevated NF- $\mathrm{kB}$ activity in arterial smooth muscle cells (Souza et al., 2000; Ialenti et al., 2001). The mechanisms by which ROS activate NF- $\kappa B$ are unclear, with reports suggesting that ROS stimulate IKK, leading to serine phosphorylation and proteasomal degradation of I $\mathrm{KB}$ (Gloire et al., 2006). Studies also indicate that ROS activate other kinases, such as tyrosine kinase to cause ІкB tyrosine phosphorylation rather than the classical serine phosphorylation (Takada et al., 2003; Brzoska \& Szumiel, 2009). Additional studies will be necessary to identify the specific mechanisms by which ROS activate NF- $\mathrm{KB}$ in contractile arterial smooth muscle cells.

Rotenone and MnTMPyP abolished the ET-1-induced mitoROS elevation, but did not completely block ET-1-induced NF-kB activation. Therefore, ET-1-induced IP ${ }_{3}$ Rmediated SR $\mathrm{Ca}^{2+}$ release may activate NF- $\mathrm{\kappa B}$ via a secondary mitoROS-independent pathway. $\mathrm{Ca}^{2+}$-dependent, redox-independent NF- $\mathrm{kB}$ activation mechanisms may be mediated by calcineurin, PI3K/Akt, and/or PKC, as demonstrated in neurons (Lilienbaum $\&$ Israel, 2003). Calcineurin activation occurs due to $\mathrm{Ca}^{2+}$ binding to $\mathrm{CaM}$, leading to the dissociation of the two proteins, allowing the catalytic site of calcineurin to become accessible (Lilienbaum \& Israel, 2003). In addition to $\mathrm{CaM}, \mathrm{Ca}^{2+}$ activate $\mathrm{NF}-\mathrm{\kappa B}$ via $\mathrm{Ca}^{2+}$-sensitive PKC isoforms, including PKC $\alpha$ and PKC $\beta 1$, and PI3K/Akt (Lilienbaum \& Israel, 2003). Supporting bi-modal activation, $\mathrm{ER} \mathrm{Ca}^{2+}$ release activates NF- $\mathrm{kB}$ through both calcineurin- and redox-dependent mechanisms in U937 cells (Shatrov et al., 1997). In addition to ET-1, Ang II, another PLC-coupled receptor agonist activates transcription factors, including NF- $\mathrm{KB}$ through ROS-dependent and -independent mechanisms (Iadecola \& Gorelick, 2004). Binding of Ang II to AT1 receptors leads to PLC activation, $\left[\mathrm{Ca}^{2+}\right]_{\mathrm{i}}$ elevation, and PKC activation (Iadecola \& Gorelick, 2004). PKCmediated phosphorylation of $\mathrm{p} 47^{\text {phox }}$ stimulates ROS generation via NAD(P)H oxidase (Iadecola \& Gorelick, 2004). Activated PKC could also stimulate cellular effectors in a ROS-independent manner (Iadecola \& Gorelick, 2004).

In whole artery immunofluorescence experiments to study NF- $\mathrm{kB}$ localization, it is interesting to note that p50 nuclear translocation occurred in nuclei of some smooth muscle cells but not others. These experiments were performed on fixed arteries after 1 hour of ET-1 treatment, therefore, representing a snapshot of the cellular events occurring in the arterial smooth muscle cells at that time point. NF-kB activation and nuclear translocation may not occur at the same time in all smooth muscle cells of the artery due to a variety of reasons. The time taken for ET-1 to reach individual smooth muscle cells and stimulate its receptors will depend upon the location of the smooth muscle cell in the arterial wall. ET-1 will stimulate receptors of smooth muscle cells located on the periphery of the arterial wall prior to activating those cells in deeper layers. In some cells, ET-1 may have stimulated SR $\mathrm{Ca}^{2+}$ release but there may not be mitochondria in close proximity to the SR to stimulate mitoROS elevation and NF- $\mathrm{kB}$ activation. It is also possible that NF- $\mathrm{KB}$ nuclear translocation and activation of transcription may have already taken place and NF- $\mathrm{KB}$ may have recycled back to the cytosol within 1 hour. Nevertheless, our data suggests that ET-1 increases p50 nuclear translocation, thereby 
activating NF- $\kappa \mathrm{B}$ in cerebral artery smooth muscle cells. Transcriptional studies performed using NF- $\kappa \mathrm{B}-$ dependent luciferase constructs confirm the finding that ET-1 activates NF- $\mathrm{NB}$.

\subsection{Regulation of Basal and ET-1-Induced Elevation in Cav1.2 Expression}

Cav1.2 channels are the principal functional $\mathrm{Ca}^{2+}$ influx pathway in smooth muscle cells of resistance-size arteries (Jaggar et al., 2000; Jaggar, 2001; Cheng et al., 2007). Cav1.2 channels regulate multiple physiological functions in arterial smooth muscle cells, including contractility and gene expression, but signaling mechanisms and transcription factors that regulate their expression in these cells are unclear.

Our data indicate that $\mathrm{IP}_{3} \mathrm{R}-$-mediated NF- $\kappa \mathrm{B}$ activity controls basal $\mathrm{Ca}_{\mathrm{V}} 1.2$ expression through both mitoROS generation and via a mitochondria-independent pathway. XeC, rotenone, and MnTMPyP slightly reduced basal $\mathrm{Ca}_{\mathrm{V}} 1.2$ expression. In the absence of PLC-coupled receptor ligands, $\left[\mathrm{IP}_{3}\right]_{i}$ and thus, $\mathrm{IP}_{3} \mathrm{R}$ activity should be low. However, in the intact artery preparation studied here, basal release of receptor ligands, including ET-1, by endothelial cells may generate low levels of $\left[\mathrm{IP}_{3}\right]_{\mathrm{i}}$ in smooth muscle cells. Even though this basal $\mathrm{IP}_{3} \mathrm{R}$-mediated $\mathrm{SR} \mathrm{Ca}^{2+}$ release was insufficient to elevate $\left[\mathrm{Ca}^{2+}\right]_{\text {mito }}$, depolarize mitochondria, or stimulate mitoROS and cytosolic ROS, it was sufficient to activate $\mathrm{NF}-\kappa \mathrm{B}$ and stimulate $\mathrm{Ca}_{\mathrm{V}} 1.2$ expression. $\mathrm{IP}_{3} \mathrm{R}$-independent basal mitoROS generation also activates NF- $\mathrm{B}$, leading to stimulation of basal $\mathrm{Ca}_{\mathrm{V}} 1.2$ expression. Thus, $\mathrm{IP}_{3} \mathrm{Rs}$ contribute to basal $\mathrm{Ca}_{\mathrm{V}} 1.2$ expression through mitochondriadependent and -independent NF- $\kappa \mathrm{B}$ activation. In our experiments, the degree of $\mathrm{p} 105$ knockdown and the reduction in basal $\mathrm{Ca}_{\mathrm{V}} 1.2$ expression were similar, indicating that $\mathrm{NF}-\kappa \mathrm{B}$ is a major transcriptional factor regulating $\mathrm{Ca}_{\mathrm{V}} 1.2$ gene expression in arterial smooth muscle cells.

Data indicate that ET-1-induced $\mathrm{IP}_{3} \mathrm{R}$-mediated $\mathrm{Ca}^{2+}$ release stimulates $\mathrm{Ca}_{V} 1.2$ expression by causing a $\left[\mathrm{Ca}^{2+}\right]_{\text {mito }}$ elevation, leading to mitoROS generation that activate $\mathrm{NF}-\kappa \mathrm{B}$. Consistent with effects on NF- $\kappa \mathrm{B}$ transcriptional activity, rotenone and MnTMPyP did not fully block the ET-1-induced elevation in $\mathrm{Ca}_{\mathrm{V}} 1.2$ expression. Thus, $\mathrm{IP}_{3} \mathrm{R}$ activation may also stimulate $\mathrm{Ca}_{\mathrm{V}} 1.2$ expression via a secondary mitochondria- and ROS-independent pathway that also involves NF- $\kappa$ B. Therefore, ET-1-induced $\mathrm{IP}_{3} \mathrm{R}$ activation stimulates NF- $\mathrm{KB}$-dependent elevation in $\mathrm{Ca}_{\mathrm{V}} 1.2$ expression primarily via a mitoROS-dependent pathway and through a secondary mitochondria- and ROSindependent pathway. Consistent with our finding that NF- $\kappa \mathrm{B}$ controls $\mathrm{Ca}_{\mathrm{V}} 1.2$ expression, TNF- $\alpha$-induced NF- $\kappa \mathrm{B}$ activation elevated L-type $\mathrm{Ca}^{2+}$ current in cultured rat hippocampal neurons (Furukawa \& Mattson, 1998). In contrast, in human colonic smooth muscle cells NF-kB p50 and p65 subunit activation reduced Cav1.2 channel expression (Shi et al., 2005). Opposing regulation of Cav1.2 transcription by $\mathrm{NF}-\kappa \mathrm{B}$ in these different smooth muscle cell types may occur through interaction with different $\kappa \mathrm{B}$ binding motifs, of which there are several upstream of the Ca 1.2 gene (Shi et al., 2005). Furthermore, the presence or absence of additional transcriptional activators and/or repressors may explain differential regulation of $\mathrm{Ca}_{\mathrm{V}} 1.2$ expression by $\mathrm{NF}-\kappa \mathrm{B}$. 
Ang II, a vasoconstrictor caused an endothelium-dependent increase in Cav1.2 expression in primary culture of rat mesenteric artery smooth muscle cells although it is unclear if depolarization of the smooth muscle cells is involved in this upregulation (Wang et al., 2008b). Ang II has been shown to stimulate endothelial cells and induces ET-1 gene expression and secretion (Dohi et al., 1992; Morey et al., 1998). Therefore, the Ang II-induced ET-1 elevation may stimulate the pathway described here, resulting in an elevation in $\mathrm{Ca}_{\mathrm{V}} 1.2$ expression in mesenteric artery smooth muscle cells. In cultured ventricular myocytes, global $\left[\mathrm{Ca}^{2+}\right]_{\mathrm{i}}$ elevation stimulated transcription of $\mathrm{Ca}_{\mathrm{V}} 1.2 \alpha_{1}$ subunit (Davidoff et al., 1997). In rat renal arteries, membrane depolarization which elevates global $\left[\mathrm{Ca}^{2+}\right]_{\mathrm{i}}$, increased Cav1.2 protein (Pesic et al., 2004). Here, $\mathrm{IP}_{3} \mathrm{R}$ mediated SR $\mathrm{Ca}^{2+}$ release stimulated $\mathrm{Ca}_{\mathrm{V}} 1.2$ expression. Data from these studies raise several possibilities, including that local and global $\mathrm{Ca}^{2+}$ signals regulate $\mathrm{Ca}_{\mathrm{V}} 1.2$ expression by different mechanisms in cerebral and renal artery smooth muscle cells and ventricular myocytes. Conceivably, this could occur at many levels in the pathway described here, including that global $\left[\mathrm{Ca}^{2+}\right]_{\mathrm{i}}$ may elevate $\left[\mathrm{Ca}^{2+}\right]_{\text {mito }}$ in renal artery smooth muscle cells and ventricular myocytes, leading to mitoROS generation and NF- $\kappa \mathrm{B}$ activation.

\subsection{Regulation of $\mathrm{p} 105 / \mathrm{p50}$ Expression by $\mathrm{IP}_{3} \mathrm{R}$-Mediated $\mathrm{SR} \mathrm{Ca}^{2+}$ Release}

Factors that regulate p105 gene expression in arterial smooth muscle cells are poorly understood. Our data indicate that $\mathrm{XeC}$ reduced the basal $\mathrm{p} 105 / \mathrm{p} 50$ expression and blocked the ET-1-induced elevation in p105/p50 expression. However, rotenone and MnTMPyP did not affect the basal and ET-1-induced elevation in p105/p50 expression. In addition, p105 knockdown did not alter the ET-1-induced relative increase in p105/p50 expression. These data indicate that ET-1-induced $\mathrm{IP}_{3} \mathrm{R}$-mediated $\mathrm{SR} \mathrm{Ca}^{2+}$ release stimulated p105/p50 subunit expression via a mitochondria-, ROS-, and p105/p50independent pathway. This is in contrast to the mitoROS- and p105/p50-dependence of $\mathrm{Ca}_{V} 1.2$ expression. Thus, ET-1-induced $\mathrm{IP}_{3} \mathrm{R}$-mediated SR $\mathrm{Ca}^{2+}$ release regulates $\mathrm{Ca}_{V} 1.2$ and NF- $\kappa$ B subunit expression through mitoROS- and p105/p50-dependent and independent pathways, respectively.

The p105 promoter has binding sites for several transcription factors, including NF-кB, Sp1, Egr-1, and PEA3 (Cogswell et al., 1993). In our study, using siRNA we specifically suppressed expression of only one NF- $\mathrm{KB}$ protein, namely $\mathrm{p} 105$, and its product $\mathrm{p} 50$. Expression of other NF- $\mathrm{KB}$ proteins, including $\mathrm{p} 100 / \mathrm{p} 52$, p65, RelB, and cRel were not studied. Our data indicate that $\mathrm{IP}_{3} \mathrm{R}$-mediated $\mathrm{SR} \mathrm{Ca}{ }^{2+}$ release regulates p105 expression through a p105/p50-independent pathway. p105 gene transcription could be regulated by other members of the NF- $\kappa \mathrm{B}$ family, as previously shown (Cogswell et al., 1993). In addition, other $\mathrm{Ca}^{2+}$-activated transcription factors, including Spl (Santini et al., 2001) and Egr-1 (Thiel et al., 2010) may also regulate p105 expression in the cerebral artery smooth muscle cells.

ET-1-induced $\mathrm{IP}_{3} \mathrm{R}$-mediated $\mathrm{SR} \mathrm{Ca}^{2+}$ release activates $\mathrm{NF}-\kappa \mathrm{B}$ and also elevates $\mathrm{NF}-\kappa \mathrm{B}$ subunit expression. It is interesting to determine the relative contribution of each 
of these signaling events in the ET-1-induced NF- $\mathrm{BB}$-dependent elevation in $\mathrm{Ca}_{\mathrm{V}} 1.2$ expression. Our data indicate that rotenone and MnTMPyP reduced the ET-1-induced elevation in NF- $\mathrm{BB}$-dependent luciferase activity and $\mathrm{Ca}_{\mathrm{V}} 1.2$ expression but did not affect the ET-1-induced elevation in $\mathrm{p} 105 / \mathrm{p} 50$ expression. This suggests that ET-1 regulation of $\mathrm{Ca}_{\mathrm{V}} 1.2$ expression is dependent on NF- $\mathrm{KB}$ activation and not an elevation in $\mathrm{p} 105$ expression. However, the ET-1-induced elevation in NF- $\kappa \mathrm{B}$ subunit expression may amplify the elevation in $\mathrm{NF}-\kappa \mathrm{B}-d e p e n d e n t \mathrm{Ca}_{\mathrm{V}} 1.2$ transcription.

\subsection{ET-1 and Vascular Function}

ET-1 belongs to the endothelin (ET) peptide family, which have three more isoforms (Masaki, 2004). ET synthesis begins with production of preproET, which is cleaved by peptidases to yield big-ET, a biologically inactive intermediate (Masaki, 2004). Big-ET undergoes further cleavage by ET converting enzymes to produce ET (Masaki, 2004). Endothelial cell is the major source of ET-1 produced. In addition to endothelial cells, ET-1 is also produced by airway epithelial cells, macrophages, fibroblasts, cardiomyocytes, and neurons (Kedzierski \& Yanagisawa, 2001). ET-1 released from the endothelial cells acts in a paracrine and autocrine manner by interacting with receptors on vascular smooth muscle cells and endothelial cells, respectively, and thereby modifying vascular contractility, growth, and proliferation (Kedzierski \& Yanagisawa, 2001). Arterial smooth muscle cells express $\mathrm{ET}_{\mathrm{A}}$ and $\mathrm{ET}_{\mathrm{B} 2}$ receptors (Masaki, 2004; Dammanahalli \& Sun, 2008a), and endothelial cells express ET $_{\mathrm{B} 1}$ receptors (Dammanahalli \& Sun, 2008a). Stimulation of $\mathrm{ET}_{\mathrm{A}}$ and $\mathrm{ET}_{\mathrm{B} 2}$ receptor activation stimulates $\mathrm{Ca}^{2+}$ waves, increases global $\left[\mathrm{Ca}^{2+}\right]_{\mathrm{i}}$, and vasoconstriction. $\mathrm{ET}_{\mathrm{B} 1}$ receptor activation leads to endothelial release of $\mathrm{NO}$ and prostaglandins, resulting in arterial vasodilation (Dammanahalli \& Sun, 2008b).

ET-1 was used in this study to elicit local and global $\mathrm{Ca}^{2+}$ signals in cerebral artery smooth muscle cells. ET-1 plasma levels in rats and normal human subjects is $\sim 20$ $\mathrm{pg} / \mathrm{ml}(8 \mathrm{pM})$ and $3.6 \mathrm{pg} / \mathrm{ml}(1.44 \mathrm{pM})$, respectively (Loffler et al., 1993; Parlapiano et al., 1999). Circulating levels of ET-1 in the plasma represent merely the "spillover" by endothelial cells (Zhu et al., 1994; Maeda et al., 1998). Vascular smooth muscle cells are exposed to ET-1 concentrations which are much higher than its plasma level (Zhu et al., 1994; Maeda et al., 1998). In this study, concentrations of ET-1 used for different experiments ranged from 10-100 $\mathrm{nM}$ based on the experimental preparations and conditions. Experiments designed to study mRNA and protein levels, required exposure of arteries to ET-1 over a long period of time. In these experiments, smooth muscle cell ET-1 receptors were intact and using higher concentrations over a long period of time could have desensitized the receptors. Therefore, a low concentration of ET-1 (10 nM) was used. $\psi_{\mathrm{m}}$ measurements were performed using isolated smooth muscle cells. The enzymes and trituration procedure used during the dissociation process could also result in damaging a few ET-1 receptors on the surface of arterial smooth muscle cells, resulting in a reduction of healthy ET-1 receptors. Therefore, a moderately high concentration of ET-1 (30 nM) was used. $\left[\mathrm{Ca}^{2+}\right]_{\text {mito, }}$, mitoROS, and cytosolic ROS measurements were obtained using moderately expressed amounts of genetically-encoded 
fluorescent indicators. Therefore, a higher concentration of ET-1 $(100 \mathrm{nM})$ was used for these experiments to elicit fluorescence changes from these indicators. $\psi_{\mathrm{m}}$ measurements using TMRM suggested that the different concentrations of ET-1 (10, 30, and $100 \mathrm{nM})$ used are within the slope of the sigmoidal curve. This indicates that the ET-1 concentrations used in this study neither understimulated nor saturated the receptors.

\subsection{Regulation of Gene Expression by $\mathrm{Ca}^{2+}$ Signals}

Vasoconstrictors, including purinergic and adrenergic receptor agonists modulate local and global $\mathrm{Ca}^{2+}$ signals similarly to ET-1 in smooth muscle cells of cerebral and systemic resistance-size arteries (Jaggar \& Nelson, 2000; Mauban et al., 2001).

Therefore, $\mathrm{IP}_{3} \mathrm{R}$ regulation of $\mathrm{Ca}^{2+}$ waves, $\left[\mathrm{Ca}^{2+}\right]_{\text {mito, }}$, and mitoROS generation may be a common mechanism by which vasoconstrictors regulate smooth muscle cell NF- $\mathrm{KB}$ activity, and thus control functional $\mathrm{Ca}_{\mathrm{v}} 1.2$ expression and arterial contractility. Identification of this transcriptional pathway expands knowledge of $\mathrm{Ca}^{2+}$ signaling mechanisms regulating ion channel expression in vascular smooth muscle cells. Local and global $\mathrm{Ca}^{2+}$ signals have been shown to activate transcription factors and regulate ion channel gene expression in arterial smooth muscle cells. $\mathrm{IP}_{3} \mathrm{R}$-mediated $\mathrm{SR} \mathrm{Ca}^{2+}$ release and local $\mathrm{Ca}^{2+}$ influx through $\mathrm{Ca}_{\mathrm{V}} 1.2$ channels also stimulates calcineurin-dependent nuclear translocation of NFATc3 in cerebral artery smooth muscle cells (Gomez et al., 2002; Nieves-Cintron et al., 2008). However, $\mathrm{Ca}^{2+}$ sparks suppress calcineurindependent NFATc3 activation (Gomez et al., 2002). NFATc3 activation downregulates expression of the $\mathrm{K}_{\mathrm{Ca}}$ channel $\beta 1$ subunit and $\mathrm{Kv} 2.1$, leading to hypertension (Amberg et al., 2004; Nieves-Cintron et al., 2007). In arterial smooth muscle cells, voltagedependent $\mathrm{Ca}^{2+}$ influx and $\mathrm{Ca}^{2+}$ spark inhibition activate CREB leading to an increase in c-fos expression (Cartin et al., 2000). Our data not only demonstrate that mitochondria are essential for mediating $\mathrm{Ca}^{2+}$-dependent gene expression in arterial smooth muscle cells, but indicate that these organelles do so by sensing $\mathrm{IP}_{3} \mathrm{R}$-mediated $\mathrm{Ca}^{2+}$ release.

\subsection{Conclusion}

In native cerebral artery smooth muscle cells, $\mathrm{SR} \mathrm{Ca}^{2+}$ release through $\mathrm{IP}_{3} \mathrm{R}$-gated $\mathrm{Ca}^{2+}$ channels elevates $\left[\mathrm{Ca}^{2+}\right]_{\text {mito }}$, leading to mitochondrial depolarization and mitoROS generation. An IP 3 R-mediated elevation in mitoROS generation activates NF- $\kappa \mathrm{B}$, leading to an elevation in $\mathrm{Ca}_{\mathrm{v}} 1.2$ expression and vasoconstriction. In summary, this study indicates that mitochondria sense $\mathrm{IP}_{3} \mathrm{R}$-mediated $\mathrm{SR} \mathrm{Ca}^{2+}$ release to control NF- $\mathrm{kB}$ activity, and thereby, functional $\mathrm{Ca}_{\mathrm{V}} 1.2$ expression in cerebral artery smooth muscle cells.

A previous study has shown that mitochondria are involved in acute regulation of arterial contractility by activating $\mathrm{Ca}^{2+}$ sparks (Xi et al., 2005). This study identifies another physiological function for mitochondria in arterial smooth muscle cells and shows that mitochondria can control ion channel gene expression and regulate arterial contractility on a more long-term basis. This study also highlights an important signaling 
cascade wherein intracellular local $\mathrm{Ca}^{2+}$ signals modulate functional expression of plasma membrane $\mathrm{Ca}^{2+}$ channels and thereby regulate $\mathrm{Ca}^{2+}$ influx and arterial contractility.

\subsection{Restoration of Homeostasis - Possible Negative Feedback Mechanisms}

The pathway studied here begins with ET-1 binding to its receptors on arterial smooth muscle cells, and eventually results in elevated $\mathrm{Ca}_{V} 1.2$ expression and enhanced arterial contractility. Under normal conditions, various negative feedback mechanisms could regulate individual signaling events in the pathway described here leading to restoration of homeostasis. 1) ET-1 binding to endothelial $\mathrm{ET}_{\mathrm{B}}$ receptors decreases the circulating ET-1 available to bind smooth muscle cell receptors thereby buffering the circulating ET-1 levels (Sanchez et al., 2002), preventing overstimulation of smooth muscle cell receptors. 2) Increased ET-1 secretion can exert a negative feedback on ET-1 gene transcription in endothelial cells, through activation of $\mathrm{ET}_{\mathrm{B}}$ receptors and internalization of the ET-1/ET B receptor complex, as previously demonstrated in cultured porcine aortic endothelial cells (Sanchez et al., 2002). Inhibition of ET-1 gene transcription would result in decreased ET-1 synthesis and therefore, result in a reduction in ET-1 secretion. 3) ET-1-induced $\left[\mathrm{IP}_{3}\right]_{\mathrm{i}}$ elevation stimulates $\mathrm{IP}_{3} \mathrm{R}$-mediated $\mathrm{SR} \mathrm{Ca}{ }^{2+}$ release. $\mathrm{IP}_{3}$ and $\mathrm{Ca}^{2+}$ have been suggested to inhibit $\mathrm{IP}_{3} \mathrm{R}$ (Hajnoczky \& Thomas, 1994), thereby maintaining cytosolic $\mathrm{IP}_{3} \mathrm{R}$-mediated $\mathrm{Ca}^{2+}$ elevations. 4) Mitochondrial depolarization which occurs due to $\left[\mathrm{Ca}^{2+}\right]_{\text {mito }}$ elevation, reduces the driving force for further mitochondrial $\mathrm{Ca}^{2+}$ uptake (Gunter et al., 2000) and therefore could limit $\left[\mathrm{Ca}^{2+}\right]_{\text {mito }}$ and mitoROS elevation. 5) NF- $\mathrm{BB}$ activation leads to nuclear translocation and stimulation of gene transcription. One of the mechanisms by which NF- $\kappa \mathrm{B}$ autoregulates its activity is by stimulating transcription of $\mathrm{I} \kappa \mathrm{B} \alpha$, which causes cytosolic retention of NF- $\kappa \mathrm{B}$ and reduces its activation (Chen \& Greene, 2004). 6) As previously reported in cultured neurons, an elevation in $\left[\mathrm{Ca}^{2+}\right]_{i}$, can internalize $\mathrm{Ca}_{\mathrm{V}} 1.2$ channels reducing $\mathrm{Ca}^{2+}$ influx and $\left[\mathrm{Ca}^{2+}\right]_{\mathrm{i}}$ elevation.

Presence of these negative feedback loops may be essential for normal vascular physiology. Deregulation of these regulatory mechanisms could contribute to the development and maintenance of cardiovascular diseases.

\subsection{Clinical Significance}

Functional integrity of the endothelium is responsible for $\mathrm{Ca}^{2+}$ channel availability in vascular smooth muscle cells (Simard \& Li, 2000). Dysfunctional endothelium is associated with a variety of diseases including hypertension and atherosclerosis (Ogita \& Liao, 2004; Ray \& Shah, 2005). Cardiovascular diseases, including systemic (Shichiri et al., 1990) and pulmonary hypertension (Stewart et al., 1991b) are associated with an elevation in circulating vasoconstrictors, including ET-1 (Ishikawa et al., 1995; Abdel-Sayed et al., 2003). Hypertension is also associated with an increase in vascular ROS, NF- $\mathrm{BB}$ activity, $\mathrm{Ca}_{\mathrm{V}} 1.2$ protein, and $\mathrm{Ca}^{2+}$ currents (Wang et al., 2006; Sawada et al., 2007; Touyz \& Schiffrin, 2008). These disease-associated 
alterations may occur through activation of the $\mathrm{IP}_{3} \mathrm{R} / \mathrm{mitoROS} / \mathrm{NF}-\kappa \mathrm{B} / \mathrm{Ca} \mathrm{a}_{\mathrm{V}} 1.2$ pathway.

Apart from hypertension, circulating plasma levels of ET-1 are elevated in other cardiovascular diseases, including cardiogenic shock (Cernacek \& Stewart, 1989), myocardial infarction (Stewart et al., 1991a), atherosclerosis (Luscher \& Barton, 2000), and ischemic stroke (Estrada et al., 1994). In addition, TNF- $\alpha$, interferon- $\gamma$, Ang II, and thrombin increase ET-1 release from endothelial cells (Delerive et al., 1999). Elevated levels of ET-1 receptors on arterial smooth muscle cells are observed in cardiovascular diseases, including pulmonary hypertension (Masaki, 2004), ischemic heart disease (Wackenfors et al., 2004), and atherosclerosis (Pernow et al., 2000). Enhancement of the ET-1-induced signaling pathways in arterial smooth muscle cells may occur due to endothelial injury resulting in increased ET-1 secretion, elevated ET-1 plasma levels, and/or enhanced ET-1 receptor expression levels. Pathological changes related to increased activation of ET-1 receptors may occur due to triggering of the $\mathrm{IP}_{3} \mathrm{R} / \mathrm{mitoROS} / \mathrm{NF}-\kappa \mathrm{B}$ activation pathway. Therefore, targeting this pathway may provide a better understanding of the disease-related pathological changes and could be beneficial in developing therapeutic strategies to treat cardiovascular diseases.

\subsection{Future Directions}

This study shows that mitochondria control functional ion channel expression in native contractile cerebral artery smooth muscle cells. Future studies could be performed in several parts of the proposed signaling cascade to better characterize the individual events in the pathway. Potential investigations could be designed to explore:

1. The spatial and temporal relationships between $\mathrm{Ca}^{2+}$ waves and $\left[\mathrm{Ca}^{2+}\right]_{\text {mito }}$ or mitoROS signals within individual mitochondria in arterial smooth muscle cells to determine if $\left[\mathrm{Ca}^{2+}\right]_{\text {mito }}$ and mitoROS oscillate within individual mitochondria. It would also be interesting to examine whether propagation of $\mathrm{Ca}^{2+}$ waves induces waves of $\left[\mathrm{Ca}^{2+}\right]_{\text {mito }}$ and mitoROS originating from mitochondria located along the path of propagation of the $\mathrm{Ca}^{2+}$ wave.

2. The precise mechanisms by which a $\left[\mathrm{Ca}^{2+}\right]_{\text {mito }}$ elevation and mitochondrial depolarization stimulate mitoROS generation.

3. The pathways by which mitoROS and $\mathrm{IP}_{3} \mathrm{R}$-mediated $\mathrm{SR} \mathrm{Ca}^{2+}$ release activate $\mathrm{NF}-\kappa \mathrm{B}$ in arterial smooth muscle cells.

4. The involvement of other members of the NF- $\mathrm{B}$ f family, including p52, p65, c-Rel, and RelB in regulating $\mathrm{Ca}_{\mathrm{V}} 1.2$ expression.

5. The role(s) played by additional ROS-sensitive transcription factors, including AP-1, CREB, and Kruppel-like factor transcription factor(s) in the regulation of $\mathrm{Ca}_{\mathrm{V}} 1.2$ gene expression. 
6. If the proposed pathway is common to most $\mathrm{G}_{\mathrm{q}}$-protein coupled receptor agonists, including UTP and Ang II.

7. The regulation of expression of $\alpha_{2} \delta, \beta$, and $\gamma$ subunits of $\mathrm{Ca}_{\vee} 1.2$, and other NF- $\kappa \mathrm{B}$ proteins, including $\mathrm{p} 52$, p65, c-Rel, and RelB by $\mathrm{IP}_{3} \mathrm{R}$-mediated $\mathrm{SR} \mathrm{Ca}^{2+}$ release, mitoROS, and NF- $\kappa$ B.

8. The importance and relevance of this pathway in the maintenance of hypertension by administration of pharmacological inhibitors of NF- $\kappa$ B and smooth muscle cell ET-1 receptors to hypertensive rodent models, followed by monitoring the blood pressure. 


\section{LIST OF REFERENCES}

Aalkjaer C \& Nilsson H (2005). Vasomotion: cellular background for the oscillator and for the synchronization of smooth muscle cells. Br J Pharmacol 144, 605-616.

Abdel-Sayed S, Nussberger J, Aubert JF, Gohlke P, Brunner HR, \& Brakch N (2003). Measurement of plasma endothelin-1 in experimental hypertension and in healthy subjects. Am J Hypertens 16, 515-521.

Abo A, Pick E, Hall A, Totty N, Teahan CG, \& Segal AW (1991). Activation of the $\mathrm{NAD}(\mathrm{P}) \mathrm{H}$ oxidase involves the small GTP-binding protein $\mathrm{p} 21$ rac1. Nature 353, 668670.

Abramowitz J, Aydemir-Koksoy A, Helgason T, Jemelka S, Odebunmi T, Seidel CL, \& Allen JC (2000). Expression of plasma membrane calcium ATPases in phenotypically distinct canine vascular smooth muscle cells. J Mol Cell Cardiol 32, 777-789.

Absher M, Woodcock-Mitchell J, Mitchell J, Baldor L, Low R, \& Warshaw D (1989). Characterization of vascular smooth muscle cell phenotype in long-term culture. In Vitro Cell Dev Biol 25, 183-192.

Adebiyi A, McNally EM, \& Jaggar JH (2008). Sulfonylurea receptor-dependent and independent pathways mediate vasodilation induced by ATP-sensitive $\mathrm{K}^{+}$channel openers. Mol Pharmacol 74, 736-743.

Adebiyi A, Zhao G, Narayanan D, Thomas-Gatewood CM, Bannister JP, \& Jaggar JH (2010). Isoform-selective physical coupling of TRPC3 channels to $\mathrm{IP}_{3}$ receptors in smooth muscle cells regulates arterial contractility. Circ Res 106, 1603-1612.

Afzal M, Matsugo S, Sasai M, Xu B, Aoyama K, \& Takeuchi T (2003). Method to overcome photoreaction, a serious drawback to the use of dichlorofluorescin in evaluation of reactive oxygen species. Biochem Biophys Res Commun 304, 619-624.

Ago T, Kitazono T, Ooboshi H, Iyama T, Han YH, Takada J, Wakisaka M, Ibayashi S, Utsumi H, \& Iida M (2004). Nox4 as the major catalytic component of an endothelial NAD(P)H oxidase. Circulation 109, 227-233.

Ahn SY, Choi YS, Koo HJ, Jeong JH, Park WH, Kim M, Piao Y, \& Pak YK (2010). Mitochondrial dysfunction enhances the migration of vascular smooth muscles cells via suppression of Akt phosphorylation. Biochim Biophys Acta 1800, 275-281.

Ambasta RK, Kumar P, Griendling KK, Schmidt HH, Busse R, \& Brandes RP (2004). Direct interaction of the novel Nox proteins with $\mathrm{p} 22^{\text {phox }}$ is required for the formation of a functionally active NAD(P)H oxidase. J Biol Chem 279, 45935-45941. 
Amberg GC, Navedo MF, Nieves-Cintron M, Molkentin JD, \& Santana LF (2007). Calcium sparklets regulate local and global calcium in murine arterial smooth muscle. $J$ Physiol 579, 187-201.

Amberg GC, Rossow CF, Navedo MF, \& Santana LF (2004). NFATc3 regulates Kv2.1 expression in arterial smooth muscle. $J$ Biol Chem 279, 47326-47334.

American Veterinary Medical Association Panel on Euthanasia (2001). 2000 Report of the AVMA Panel on Euthanasia. J Am Vet Med Assoc 218, 669-696.

Archer SL, Marsboom G, Kim GH, Zhang HJ, Toth PT, Svensson EC, Dyck JR, Gomberg-Maitland M, Thebaud B, Husain AN, Cipriani N, \& Rehman J (2010). Epigenetic attenuation of mitochondrial superoxide dismutase 2 in pulmonary arterial hypertension: a basis for excessive cell proliferation and a new therapeutic target. Circulation 121, 2661-2671.

Arnaudeau S, Kelley WL, Walsh JV, Jr., \& Demaurex N (2001). Mitochondria recycle $\mathrm{Ca}^{2+}$ to the endoplasmic reticulum and prevent the depletion of neighboring endoplasmic reticulum regions. J Biol Chem 276, 29430-29439.

Arsura M, Panta GR, Bilyeu JD, Cavin LG, Sovak MA, Oliver AA, Factor V, Heuchel R, Mercurio F, Thorgeirsson SS, \& Sonenshein GE (2003). Transient activation of NF- $\kappa$ B through a TAK1/IKK kinase pathway by TGF- $\beta 1$ inhibits AP-1/SMAD signaling and apoptosis: implications in liver tumor formation. Oncogene 22, 412-425.

Asehnoune K, Strassheim D, Mitra S, Kim JY, \& Abraham E (2004). Involvement of reactive oxygen species in Toll-like receptor 4-dependent activation of NF-кB. $J$ Immunol 172, 2522-2529.

Baeuerle PA \& Baltimore D (1996). NF-кB: ten years after. Cell 87, 13-20.

Bailey SR, Mitra S, Flavahan S, \& Flavahan NA (2005). Reactive oxygen species from smooth muscle mitochondria initiate cold-induced constriction of cutaneous arteries. $\mathrm{Am}$ J Physiol Heart Circ Physiol 289, H243-H250.

Baines DL, Janes M, Newman DJ, \& Best OG (2002). Oxygen-evoked changes in transcriptional activity of the 5'-flanking region of the human amiloride-sensitive sodium channel $(\alpha \mathrm{ENaC})$ gene: role of nuclear factor $\kappa \mathrm{B}$. Biochem J 364, 537-545.

Basuroy S, Bhattacharya S, Leffler CW, \& Parfenova H (2009). Nox4 NAD(P)H oxidase mediates oxidative stress and apoptosis caused by TNF- $\alpha$ in cerebral vascular endothelial cells. Am J Physiol Cell Physiol 296, C422-C432.

Beech DJ, Muraki K, \& Flemming R (2004). Non-selective cationic channels of smooth muscle and the mammalian homologues of Drosophila TRP. J Physiol 559, 685-706. 
Belousov VV, Fradkov AF, Lukyanov KA, Staroverov DB, Shakhbazov KS, Terskikh AV, \& Lukyanov S (2006). Genetically encoded fluorescent indicator for intracellular hydrogen peroxide. Nat Methods 3, 281-286.

Bernardi P (1999). Mitochondrial transport of cations: channels, exchangers, and permeability transition. Physiol Rev 79, 1127-1155.

Bernardi P \& Petronilli V (1996). The permeability transition pore as a mitochondrial calcium release channel: a critical appraisal. J Bioenerg Biomembr 28, 131-138.

Berridge MJ (2001). The versatility and complexity of calcium signalling. Novartis Found Symp 239, 52-64.

Berridge MJ (2004). Calcium signal transduction and cellular control mechanisms. Biochim Biophys Acta 1742, 3-7.

Berridge MJ, Bootman MD, \& Lipp P (1998). Calcium - a life and death signal. Nature 395, 645-648.

Berridge MJ, Bootman MD, \& Roderick HL (2003). Calcium signalling: dynamics, homeostasis and remodelling. Nat Rev Mol Cell Biol 4, 517-529.

Bezprozvanny I \& Ehrlich BE (1995). The inositol 1,4,5-trisphosphate ( $\left.\mathrm{InsP}_{3}\right)$ receptor. $J$ Membr Biol 145, 205-216.

Birukov KG (2009). Cyclic stretch, reactive oxygen species, and vascular remodeling. Antioxid Redox Signal 11, 1651-1667.

Blanck J, Ristau O, Zhukov AA, Archakov AI, Rein H, \& Ruckpaul K (1991). Cytochrome P-450 spin state and leakiness of the monooxygenase pathway. Xenobiotica 21, 121-135.

Blatter LA \& Wier WG (1992). Agonist-induced $\left[\mathrm{Ca}^{2+}\right]_{\mathrm{i}}$ waves and $\mathrm{Ca}^{2+}$-induced $\mathrm{Ca}^{2+}$ release in mammalian vascular smooth muscle cells. Am J Physiol 263, H576-H586.

Boittin FX, Galione A, \& Evans AM (2002). Nicotinic acid adenine dinucleotide phosphate mediates $\mathrm{Ca}^{2+}$ signals and contraction in arterial smooth muscle via a two-pool mechanism. Circ Res 91, 1168-1175.

Boittin FX, Macrez N, Halet G, \& Mironneau J (1999). Norepinephrine-induced $\mathrm{Ca}^{2+}$ waves depend on $\mathrm{InsP}_{3}$ and ryanodine receptor activation in vascular myocytes. $\mathrm{Am} \mathrm{J}$ Physiol 277, C139-C151.

Bolton TB, Gordienko DV, Povstyan OV, Harhun MI, \& Pucovsky V (2004). Smooth muscle cells and interstitial cells of blood vessels. Cell Calcium 35, 643-657.

Bonizzi G \& Karin M (2004). The two $\mathrm{NF}_{-\mathrm{k}} \mathrm{B}$ activation pathways and their role in innate and adaptive immunity. Trends Immunol 25, 280-288. 
Bootman MD, Collins TJ, Peppiatt CM, Prothero LS, MacKenzie L, De Smet P, Travers M, Tovey SC, Seo JT, Berridge MJ, Ciccolini F, \& Lipp P (2001). Calcium signalling an overview. Semin Cell Dev Biol 12, 3-10.

Bourcier T, Sukhova G, \& Libby P (1997). The nuclear factor $\kappa-B$ signaling pathway participates in dysregulation of vascular smooth muscle cells in vitro and in human atherosclerosis. J Biol Chem 272, 15817-15824.

Brayden JE \& Nelson MT (1992). Regulation of arterial tone by activation of calciumdependent potassium channels. Science 256, 532-535.

Brookes PS (2005). Mitochondrial $\mathrm{H}^{+}$leak and ROS generation: an odd couple. Free Radic Biol Med 38, 12-23.

Brookes PS, Yoon Y, Robotham JL, Anders MW, \& Sheu SS (2004). Calcium, ATP, and ROS: a mitochondrial love-hate triangle. Am J Physiol 287, C817-C833.

Brzoska K \& Szumiel I (2009). Signalling loops and linear pathways: NF-кB activation in response to genotoxic stress. Mutagenesis 24, 1-8.

Bubici C, Papa S, Dean K, \& Franzoso G (2006). Mutual cross-talk between reactive oxygen species and nuclear factor-kappa B: molecular basis and biological significance. Oncogene 25, 6731-6748.

Campbell JH, Kocher O, Skalli O, Gabbiani G, \& Campbell GR (1989). Cytodifferentiation and expression of alpha-smooth muscle actin mRNA and protein during primary culture of aortic smooth muscle cells. Correlation with cell density and proliferative state. Arteriosclerosis 9, 633-643.

Cartin L, Lounsbury KM, \& Nelson MT (2000). Coupling of $\mathrm{Ca}^{2+}$ to CREB activation and gene expression in intact cerebral arteries from mouse: roles of ryanodine receptors and voltage- dependent $\mathrm{Ca}^{2+}$ channels. Circ Res 86, 760-767.

Catterall WA (2000). Structure and regulation of voltage-gated $\mathrm{Ca}^{2+}$ channels. Annu Rev Cell Dev Biol 16, 521-555.

Cernacek P \& Stewart DJ (1989). Immunoreactive endothelin in human plasma: marked elevations in patients in cardiogenic shock. Biochem Biophys Res Commun 161, 562-567.

Chalmers S, Olson ML, MacMillan D, Rainbow RD, \& McCarron JG (2007). Ion channels in smooth muscle: regulation by the sarcoplasmic reticulum and mitochondria. Cell Calcium 42, 447-466.

Chandel NS, Trzyna WC, McClintock DS, \& Schumacker PT (2000). Role of oxidants in NF- $\kappa \mathrm{B}$ activation and TNF- $\alpha$ gene transcription induced by hypoxia and endotoxin. $J$ Immunol 165, 1013-1021. 
Chang HY \& Yang X (2000). Proteases for cell suicide: functions and regulation of caspases. Microbiol Mol Biol Rev 64, 821-846.

Chen LF \& Greene WC (2004). Shaping the nuclear action of NF-kappaB. Nat Rev Mol Cell Biol 5, 392-401.

Chen XL, Tummala PE, Olbrych MT, Alexander RW, \& Medford RM (1998). Angiotensin II induces monocyte chemoattractant protein-1 gene expression in rat vascular smooth muscle cells. Circ Res 83, 952-959.

Cheng H, Lederer WJ, \& Cannell MB (1993). Calcium sparks: elementary events underlying excitation-contraction coupling in heart muscle. Science 262, 740-744.

Cheng X, Liu J, Asuncion-Chin M, Blaskova E, Bannister JP, Dopico AM, \& Jaggar JH (2007). A novel Ca $1.2 \mathrm{~N}$ terminus expressed in smooth muscle cells of resistance size arteries modifies channel regulation by auxiliary subunits. J Biol Chem 282, 2921129221.

Cheranov SY \& Jaggar JH (2004). Mitochondrial modulation of $\mathrm{Ca}^{2+}$ sparks and transient $\mathrm{K}_{\mathrm{Ca}}$ currents in smooth muscle cells of rat cerebral arteries. $J$ Physiol 556, 755-771.

Cheranov SY \& Jaggar JH (2006). TNF- $\alpha$ dilates cerebral arteries via NAD(P)H oxidasedependent $\mathrm{Ca}^{2+}$ spark activation. Am J Physiol Cell Physiol 290, C964-C971.

Clapham DE (1995). Calcium signaling. Cell 80, 259-268.

Clempus RE \& Griendling KK (2006). Reactive oxygen species signaling in vascular smooth muscle cells. Cardiovasc Res 71, 216-225.

Cogswell PC, Scheinman RI, \& Baldwin AS, Jr. (1993). Promoter of the human NF-kB p50/p105 gene. Regulation by NF-кB subunits and by c-REL. J Immunol 150, 27942804.

Collins TJ, Lipp P, Berridge MJ, \& Bootman MD (2001). Mitochondrial $\mathrm{Ca}^{2+}$ uptake depends on the spatial and temporal profile of cytosolic $\mathrm{Ca}^{2+}$ signals. $J$ Biol Chem 276, 26411-26420.

Colombini M (2004). VDAC: the channel at the interface between mitochondria and the cytosol. Mol Cell Biochem 256-257, 107-115.

Csordas G \& Hajnoczky G (2009). SR/ER-mitochondrial local communication: calcium and ROS. Biochim Biophys Acta 1787, 1352-1362.

Dai B, Saada N, Echetebu C, Dettbarn C, \& Palade P (2002). A new promoter for $\alpha_{1 C}$ subunit of human L-type cardiac calcium channel Cav1.2. Biochem Biophys Res Commun 296, 429-433. 
Dai J, Lee CH, Poburko D, Szado T, Kuo KH, \& van Breemen C (2007). Endothelin-1mediated wave-like $\left[\mathrm{Ca}^{2+}\right]_{\mathrm{i}}$ oscillations in intact rabbit inferior vena cava. J Vasc Res 44, 495-503.

Dammanahalli JK \& Sun Z (2008a). Endothelin (ET)-1 inhibits nicotinamide adenine dinucleotide phosphate oxidase activity in human abdominal aortic endothelial cells: a novel function of $\mathrm{ET}_{\mathrm{B} 1}$ receptors. Endocrinology 149, 4979-4987.

Dammanahalli KJ \& Sun Z (2008b). Endothelins and NAD(P)H oxidases in the cardiovascular system. Clin Exp Pharmacol Physiol 35, 2-6.

Davidoff AJ, Maki TM, Ellingsen O, \& Marsh JD (1997). Expression of calcium channels in adult cardiac myocytes is regulated by calcium. J Mol Cell Cardiol 29, 17911803.

De Brito OM \& Scorrano L (2008). Mitofusin 2 tethers endoplasmic reticulum to mitochondria. Nature 456, 605-610.

De Martin R, Hoeth M, Hofer-Warbinek R, \& Schmid JA (2000). The transcription factor $\mathrm{NF}-\kappa \mathrm{B}$ and the regulation of vascular cell function. Arterioscler Thromb Vasc Biol 20, E83-E88.

Delerive P, Martin-Nizard F, Chinetti G, Trottein F, Fruchart JC, Najib J, Duriez P, \& Staels B (1999). Peroxisome proliferator-activated receptor activators inhibit thrombininduced endothelin-1 production in human vascular endothelial cells by inhibiting the activator protein-1 signaling pathway. Circ Res 85, 394-402.

Detmer K, Wang Z, Warejcka D, Leeper-Woodford SK, \& Newman WH (2001). Endotoxin stimulated cytokine production in rat vascular smooth muscle cells. Am J Physiol Heart Circ Physiol 281, H661-H668.

Dohi Y, Hahn AW, Boulanger CM, Buhler FR, \& Luscher TF (1992). Endothelin stimulated by angiotensin II augments contractility of spontaneously hypertensive rat resistance arteries. Hypertension 19, 131-137.

Drummond RM \& Tuft RA (1999). Release of $\mathrm{Ca}^{2+}$ from the sarcoplasmic reticulum increases mitochondrial $\left[\mathrm{Ca}^{2+}\right]$ in rat pulmonary artery smooth muscle cells. J Physiol 516 Pt 1, 139-147.

Duchen MR (2000a). Mitochondria and $\mathrm{Ca}^{2+}$ in cell physiology and pathophysiology. Cell Calcium 28, 339-348.

Duchen MR (2000b). Mitochondria and calcium: from cell signalling to cell death. $J$ Physiol 529 Pt 1, 57-68.

Duchen MR (2004). Roles of mitochondria in health and disease. Diabetes 53 Suppl 1, S96-S102. 
Duchen MR, Leyssens A, \& Crompton M (1998). Transient mitochondrial depolarizations reflect focal sarcoplasmic reticular calcium release in single rat cardiomyocytes. J Cell Biol 142, 975-988.

Dupont WD \& Plummer WD, Jr. (1990). Power and sample size calculations. A review and computer program. Control Clin Trials 11, 116-128.

Earley S (2006). Molecular diversity of receptor operated channels in vascular smooth muscle: a role for heteromultimeric TRP channels? Circ Res 98, 1462-1464.

Earley S \& Brayden JE (2010). Transient receptor potential channels and vascular function. Clin Sci (Lond) 119, 19-36.

Earley S, Heppner TJ, Nelson MT, \& Brayden JE (2005). TRPV4 forms a novel $\mathrm{Ca}^{2+}$ signaling complex with ryanodine receptors and $\mathrm{BK}_{\mathrm{Ca}}$ channels. Circ Res 97, 1270-1279.

Eguchi S, Hirata Y, Imai T, Kanno K, \& Marumo F (1994). Phenotypic change of endothelin receptor subtype in cultured rat vascular smooth muscle cells. Endocrinology 134, 222-228.

Elion GB, Yu TF, Gutman AB, \& Hitchings GH (1968). Renal clearance of oxipurinol, the chief metabolite of allopurinol. Am J Med 45, 69-77.

Endo M (2006). Calcium ion as a second messenger with special reference to excitationcontraction coupling. J Pharmacol Sci 100, 519-524.

Ertel EA, Campbell KP, Harpold MM, Hofmann F, Mori Y, Perez-Reyes E, Schwartz A, Snutch TP, Tanabe T, Birnbaumer L, Tsien RW, \& Catterall WA (2000). Nomenclature of voltage-gated calcium channels. Neuron 25, 533-535.

Estrada V, Tellez MJ, Moya J, Fernandez-Durango R, Egido J, \& Fernandez Cruz AF (1994). High plasma levels of endothelin-1 and atrial natriuretic peptide in patients with acute ischemic stroke. Am J Hypertens 7, 1085-1089.

Faulkner KM, Liochev SI, \& Fridovich I (1994). Stable Mn(III) porphyrins mimic superoxide dismutase in vitro and substitute for it in vivo. J Biol Chem 269, 2347123476.

Fawell S, Seery J, Daikh Y, Moore C, Chen LL, Pepinsky B, \& Barsoum J (1994). Tatmediated delivery of heterologous proteins into cells. Proc Natl Acad Sci USA 91, 664668.

Fernie AR, Carrari F, \& Sweetlove LJ (2004). Respiratory metabolism: glycolysis, the TCA cycle and mitochondrial electron transport. Curr Opin Plant Biol 7, 254-261.

Filippin L, Abad MC, Gastaldello S, Magalhaes PJ, Sandona D, \& Pozzan T (2005). Improved strategies for the delivery of GFP-based $\mathrm{Ca}^{2+}$ sensors into the mitochondrial matrix. Cell Calcium 37, 129-136. 
Filippin L, Magalhaes PJ, Di BG, Colella M, \& Pozzan T (2003). Stable interactions between mitochondria and endoplasmic reticulum allow rapid accumulation of calcium in a subpopulation of mitochondria. J Biol Chem 278, 39224-39234.

Floyd R \& Wray S (2007). Calcium transporters and signalling in smooth muscles. Cell Calcium 42, 467-476.

Forstermann U, Closs EI, Pollock JS, Nakane M, Schwarz P, Gath I, \& Kleinert H (1994). Nitric oxide synthase isozymes. Characterization, purification, molecular cloning, and functions. Hypertension 23, 1121-1131.

Friedl HP, Till GO, Ryan US, \& Ward PA (1989). Mediator-induced activation of xanthine oxidase in endothelial cells. FASEB J 3, 2512-2518.

Fukami JI, Yamamoto I, \& Casida JE (1967). Metabolism of rotenone in vitro by tissue homogenates from mammals and insects. Science 155, 713-716.

Furukawa K \& Mattson MP (1998). The transcription factor NF- $\kappa B$ mediates increases in calcium currents and decreases in NMDA- and AMPA/kainate-induced currents induced by tumor necrosis factor- $\alpha$ in hippocampal neurons. $J$ Neurochem 70, 1876-1886.

Gafni J, Munsch JA, Lam TH, Catlin MC, Costa LG, Molinski TF, \& Pessah IN (1997). Xestospongins: potent membrane permeable blockers of the inositol 1,4,5-trisphosphate receptor. Neuron 19, 723-733.

Gerasimenko O \& Tepikin A (2005). How to measure $\mathrm{Ca}^{2+}$ in cellular organelles? Cell Calcium 38, 201-211.

Gerhardstein BL, Gao T, Bunemann M, Puri TS, Adair A, Ma H, \& Hosey MM (2000). Proteolytic processing of the $\mathrm{C}$ terminus of the $\alpha_{1 \mathrm{C}}$ subunit of L-type calcium channels and the role of a proline-rich domain in membrane tethering of proteolytic fragments. $J$ Biol Chem 275, 8556-8563.

Gloire G, Legrand-Poels S, \& Piette J (2006). NF- $\kappa$ B activation by reactive oxygen species: fifteen years later. Biochem Pharmacol 72, 1493-1505.

Goldsby RA \& Heytler PG (1963). Uncoupling of oxidative phosphorylation by carbonyl cyanide phenylhydrazones. II. Effects of carbonyl cyanide m-chlorophenylhydrazone on mitochondrial respiration. Biochemistry 2, 1142-1147.

Gollasch M \& Nelson MT (1997). Voltage-dependent $\mathrm{Ca}^{2+}$ channels in arterial smooth muscle cells. Kidney Blood Press Res 20, 355-371.

Gomez MF, Stevenson AS, Bonev AD, Hill-Eubanks DC, \& Nelson MT (2002).

Opposing actions of inositol 1,4,5-trisphosphate and ryanodine receptors on nuclear factor of activated T-cells regulation in smooth muscle. J Biol Chem 277, 37756-37764. 
Gorlach A, Brandes RP, Nguyen K, Amidi M, Dehghani F, \& Busse R (2000). A gp9 $1^{\text {phox }}$ containing NAD(P)H oxidase selectively expressed in endothelial cells is a major source of oxygen radical generation in the arterial wall. Circ Res 87, 26-32.

Gorsky LD, Koop DR, \& Coon MJ (1984). On the stoichiometry of the oxidase and monooxygenase reactions catalyzed by liver microsomal cytochrome P-450. Products of oxygen reduction. J Biol Chem 259, 6812-6817.

Gouw MA, Wilffert B, Wermelskirchen D, \& van Zwieten PA (1990). Ca ${ }^{2+}$ influx insensitive to organic $\mathrm{Ca}^{2+}$ entry blockers contributes to noradrenaline-induced contractions of the isolated guinea pig aorta. Pharmacology 40, 277-287.

Graier WF, Frieden M, \& Malli R (2007). Mitochondria and $\mathrm{Ca}^{2+}$ signaling: old guests, new functions. Pflugers Arch 455, 375-396.

Griendling KK \& FitzGerald GA (2003). Oxidative stress and cardiovascular injury: Part I: basic mechanisms and in vivo monitoring of ROS. Circulation 108, 1912-1916.

Griendling KK, Minieri CA, Ollerenshaw JD, \& Alexander RW (1994). Angiotensin II stimulates NADH and NAD(P)H oxidase activity in cultured vascular smooth muscle cells. Circ Res 74, 1141-1148.

Griesbeck O, Baird GS, Campbell RE, Zacharias DA, \& Tsien RY (2001). Reducing the environmental sensitivity of yellow fluorescent protein. Mechanism and applications. $J$ Biol Chem 276, 29188-29194.

Griffiths EJ, Ocampo CJ, Savage JS, Rutter GA, Hansford RG, Stern MD, \& Silverman HS (1998). Mitochondrial calcium transporting pathways during hypoxia and reoxygenation in single rat cardiomyocytes. Cardiovasc Res 39, 423-433.

Gros R, Afroze T, You XM, Kabir G, Van WR, Kalair W, Hoque AE, Mungrue IN, \& Husain M (2003). Plasma membrane calcium ATPase overexpression in arterial smooth muscle increases vasomotor responsiveness and blood pressure. Circ Res 93, 614-621.

Guibert C, Ducret T, \& Savineau JP (2008). Voltage-independent calcium influx in smooth muscle. Prog Biophys Mol Biol 98, 10-23.

Gunter TE, Buntinas L, Sparagna G, Eliseev R, \& Gunter K (2000). Mitochondrial calcium transport: mechanisms and functions. Cell Calcium 28, 285-296.

Gunter TE \& Gunter KK (2001). Uptake of calcium by mitochondria: transport and possible function. IUBMB Life 52, 197-204.

Gunter TE \& Pfeiffer DR (1990). Mechanisms by which mitochondria transport calcium. Am J Physiol 258, C755-C786. 
Hajnoczky G, Csordas G, Madesh M, \& Pacher P (2000). The machinery of local $\mathrm{Ca}^{2+}$ signalling between sarco-endoplasmic reticulum and mitochondria. J Physiol 529 Pt 1, $69-81$.

Hajnoczky G, Csordas G, \& Yi M (2002). Old players in a new role: mitochondriaassociated membranes, VDAC, and ryanodine receptors as contributors to calcium signal propagation from endoplasmic reticulum to the mitochondria. Cell Calcium 32, 363-377.

Hajnoczky G, Robb-Gaspers LD, Seitz MB, \& Thomas AP (1995). Decoding of cytosolic calcium oscillations in the mitochondria. Cell 82, 415-424.

Hajnoczky G \& Thomas AP (1994). The inositol trisphosphate calcium channel is inactivated by inositol trisphosphate. Nature 370, 474-477.

Halling DB, Aracena-Parks P, \& Hamilton SL (2005). Regulation of voltage-gated $\mathrm{Ca}^{2+}$ channels by calmodulin. Sci STKE 2005, re15.

Han Y, Runge MS, \& Brasier AR (1999). Angiotensin II induces interleukin-6 transcription in vascular smooth muscle cells through pleiotropic activation of nuclear factor- $\kappa \mathrm{B}$ transcription factors. Circ Res 84, 695-703.

Harrison R (2002). Structure and function of xanthine oxidoreductase: where are we now? Free Radic Biol Med 33, 774-797.

Hayashi T \& Su TP (2007). Sigma-1 receptor chaperones at the ER-mitochondrion interface regulate $\mathrm{Ca}^{2+}$ signaling and cell survival. Cell 131, 596-610.

Hayden MS \& Ghosh S (2008). Shared principles in NF-кB signaling. Cell 132, 344-362.

Hensley K, Robinson KA, Gabbita SP, Salsman S, \& Floyd RA (2000). Reactive oxygen species, cell signaling, and cell injury. Free Radic Biol Med 28, 1456-1462.

Heppner TJ, Bonev AD, Santana LF, \& Nelson MT (2002). Alkaline pH shifts $\mathrm{Ca}^{2+}$ sparks to $\mathrm{Ca}^{2+}$ waves in smooth muscle cells of pressurized cerebral arteries. Am J Physiol Heart Circ Physiol 283, H2169-H2176.

Heytler PG (1963). Uncoupling of oxidative phosphorylation by carbonyl cyanide phenylhydrazones. I. Some characteristics of m-Cl-CCP action on mitochondria and chloroplasts. Biochemistry 2, 357-361.

Hilenski LL, Clempus RE, Quinn MT, Lambeth JD, \& Griendling KK (2004). Distinct subcellular localizations of Nox 1 and Nox 4 in vascular smooth muscle cells. Arterioscler Thromb Vasc Biol 24, 677-683.

Hill MA, Zou H, Potocnik SJ, Meininger GA, \& Davis MJ (2001). Invited review: arteriolar smooth muscle mechanotransduction: $\mathrm{Ca}^{2+}$ signaling pathways underlying myogenic reactivity. $J$ Appl Physiol 91, 973-983. 
Hogg RC, Wang Q, Helliwell RM, \& Large WA (1993). Properties of spontaneous inward currents in rabbit pulmonary artery smooth muscle cells. Pflugers Arch 425, 233240.

Holland PM, Abramson RD, Watson R, \& Gelfand DH (1991). Detection of specific polymerase chain reaction product by utilizing the 5 ' $->3$ ' exonuclease activity of Thermus aquaticus DNA polymerase. Proc Natl Acad Sci USA 88, 7276-7280.

Huang LE, Arany Z, Livingston DM, \& Bunn HF (1996). Activation of hypoxiainducible transcription factor depends primarily upon redox-sensitive stabilization of its a subunit. J Biol Chem 271, 32253-32259.

Huser J, Rechenmacher CE, \& Blatter LA (1998). Imaging the permeability pore transition in single mitochondria. Biophys J 74, 2129-2137.

Iadecola C \& Gorelick PB (2004). Hypertension, angiotensin, and stroke: beyond blood pressure. Stroke 35, 348-350.

Ialenti A, Ianaro A, Maffia P, Carnuccio R, D'Acquisto F, Maiello FM, \& Di RM (2001). Role of nuclear factor- $\mathrm{KB}$ in a rat model of vascular injury. Naunyn Schmiedebergs Arch Pharmacol 364, 343-350.

Inesi $\mathrm{G}$ (1987). Sequential mechanism of calcium binding and translocation in sarcoplasmic reticulum adenosine triphosphatase. J Biol Chem 262, 16338-16342.

Irani K (2000). Oxidant signaling in vascular cell growth, death, and survival: a review of the roles of reactive oxygen species in smooth muscle and endothelial cell mitogenic and apoptotic signaling. Circ Res 87, 179-183.

Ishida Y \& Paul RJ (2005). $\mathrm{Ca}^{2+}$ clearance in smooth muscle: lessons from gene-altered mice. J Smooth Muscle Res 41, 235-245.

Ishikawa S, Miyauchi T, Sakai S, Ushinohama H, Sagawa K, Fusazaki N, Kado H, Sunagawa H, Honda S, Ueno H, Yamaguchi I, Sugishita Y, \& Goto K (1995). Elevated levels of plasma endothelin-1 in young patients with pulmonary hypertension caused by congenital heart disease are decreased after successful surgical repair. J Thorac Cardiovasc Surg 110, 271-273.

Iwamoto T, Kita S, \& Katsuragi T (2005). Salt-sensitive hypertension, $\mathrm{Na}^{+} / \mathrm{Ca}^{2+}$ exchanger, and vascular smooth muscle. Trends Cardiovasc Med 15, 273-277.

Jaggar JH (2001). Intravascular pressure regulates local and global $\mathrm{Ca}^{2+}$ signaling in cerebral artery smooth muscle cells. Am J Physiol Cell Physiol 281, C439-C448.

Jaggar JH (2007). Smooth muscle sparklet $\mathrm{Ca}_{\mathrm{V}}$ channels defined: 1.2 is the number. Am J Physiol Heart Circ Physiol 293, H1317-H1319. 
Jaggar JH \& Nelson MT (2000). Differential regulation of $\mathrm{Ca}^{2+}$ sparks and $\mathrm{Ca}^{2+}$ waves by UTP in rat cerebral artery smooth muscle cells. Am J Physiol Cell Physiol 279, C1528C1539.

Jaggar JH, Porter VA, Lederer WJ, \& Nelson MT (2000). Calcium sparks in smooth muscle. Am J Physiol Cell Physiol 278, C235-C256.

Jaggar JH, Stevenson AS, \& Nelson MT (1998). Voltage dependence of $\mathrm{Ca}^{2+}$ sparks in intact cerebral arteries. Am J Physiol 274, C1755-C1761.

Jakubowski W \& Bartosz G (2000). 2,7-dichlorofluorescin oxidation and reactive oxygen species: what does it measure? Cell Biol Int 24, 757-760.

Kaftan EJ, Xu T, Abercrombie RF, \& Hille B (2000). Mitochondria shape hormonally induced cytoplasmic calcium oscillations and modulate exocytosis. J Biol Chem 275, 25465-25470.

Karihtala P \& Soini Y (2007). Reactive oxygen species and antioxidant mechanisms in human tissues and their relation to malignancies. APMIS 115, 81-103.

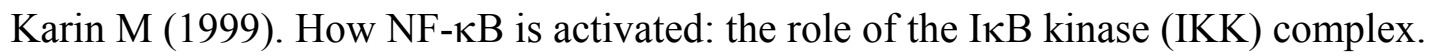
Oncogene 18, 6867-6874.

Kaur S, Wang F, Venkatraman M, \& Arsura M (2005). X-linked inhibitor of apoptosis (XIAP) inhibits c-Jun N-terminal kinase 1 (JNK1) activation by transforming growth factor $\beta 1$ (TGF- $\beta 1$ ) through ubiquitin-mediated proteosomal degradation of the TGF- $\beta 1$ activated kinase 1 (TAK1). J Biol Chem 280, 38599-38608.

Kedzierski RM \& Yanagisawa M (2001). Endothelin system: the double-edged sword in health and disease. Annu Rev Pharmacol Toxicol 41, 851-876.

Kibbe M, Billiar T, \& Tzeng E (1999). Inducible nitric oxide synthase and vascular injury. Cardiovasc Res 43, 650-657.

Knot HJ \& Nelson MT (1998). Regulation of arterial diameter and wall $\left[\mathrm{Ca}^{2+}\right]$ in cerebral arteries of rat by membrane potential and intravascular pressure. J Physiol 508 Pt 1, 199209.

Kunsch C \& Medford RM (1999). Oxidative stress as a regulator of gene expression in the vasculature. Circ Res 85, 753-766.

Kuthan H \& Ullrich V (1982). Oxidase and oxygenase function of the microsomal cytochrome P450 monooxygenase system. Eur J Biochem 126, 583-588.

Kye MJ, Spiess J, \& Blank T (2007). Transcriptional regulation of intronic calciumactivated potassium channel SK2 promoters by nuclear factor- $\kappa \mathrm{B}$ and glucocorticoids. Mol Cell Biochem 300, 9-17. 
Lamont C \& Wier WG (2004). Different roles of ryanodine receptors and inositol $(1,4,5)-$ trisphosphate receptors in adrenergically stimulated contractions of small arteries. $\mathrm{Am} \mathrm{J}$ Physiol Heart Circ Physiol 287, H617-H625.

Lander HM (1997). An essential role for free radicals and derived species in signal transduction. FASEB J 11, 118-124.

Landolfi B, Curci S, Debellis L, Pozzan T, \& Hofer AM (1998). $\mathrm{Ca}^{2+}$ homeostasis in the agonist-sensitive internal store: functional interactions between mitochondria and the ER measured In situ in intact cells. J Cell Biol 142, 1235-1243.

Landry DB, Couper LL, Bryant SR, \& Lindner V (1997). Activation of the NF- $\kappa$ B and $\mathrm{I} \kappa \mathrm{B}$ system in smooth muscle cells after rat arterial injury. Induction of vascular cell adhesion molecule-1 and monocyte chemoattractant protein-1. Am J Pathol 151, 10851095.

Large WA (2002). Receptor-operated $\mathrm{Ca}^{2+}$-permeable nonselective cation channels in vascular smooth muscle: a physiologic perspective. J Cardiovasc Electrophysiol 13, 493501.

Lassegue B \& Clempus RE (2003). Vascular NAD(P)H oxidases: specific features, expression, and regulation. Am J Physiol Regul Integr Comp Physiol 285, R277-R297.

Le Bail O, Schmidt-Ullrich R, \& Israel A (1993). Promoter analysis of the gene encoding the I $\kappa \mathrm{B}-\alpha / \mathrm{MAD} 3$ inhibitor of $\mathrm{NF}-\kappa \mathrm{B}$ : positive regulation by members of the rel/NF- $\kappa \mathrm{B}$ family. $E M B O J$ 12, 5043-5049.

Lee $\mathrm{CH}$, Kuo KH, Dai J, \& van Breemen C (2005). Asynchronous calcium waves in smooth muscle cells. Can J Physiol Pharmacol 83, 733-741.

Lee CH, Poburko D, Kuo KH, Seow CY, \& van Breemen C (2002). $\mathrm{Ca}^{2+}$ oscillations, gradients, and homeostasis in vascular smooth muscle. Am J Physiol Heart Circ Physiol 282, H1571-H1583.

Lee SJ, Seo KW, Yun MR, Bae SS, Lee WS, Hong KW, \& Kim CD (2008). 4Hydroxynonenal enhances MMP-2 production in vascular smooth muscle cells via mitochondrial ROS-mediated activation of the Akt/NF- $\mathrm{kB}$ signaling pathways. Free Radic Biol Med 45, 1487-1492.

Lesh RE, Somlyo AP, Owens GK, \& Somlyo AV (1995). Reversible permeabilization. A novel technique for the intracellular introduction of antisense oligodeoxynucleotides into intact smooth muscle. Circ Res 77, 220-230.

Levy D, Seigneuret M, Bluzat A, \& Rigaud JL (1990). Evidence for proton countertransport by the sarcoplasmic reticulum $\mathrm{Ca}^{2+}$-ATPase during calcium transport in reconstituted proteoliposomes with low ionic permeability. J Biol Chem 265, 1952419534. 
Li L, Mamputu JC, Wiernsperger N, \& Renier G (2005). Signaling pathways involved in human vascular smooth muscle cell proliferation and matrix metalloproteinase-2 expression induced by leptin: inhibitory effect of metformin. Diabetes 54, 2227-2234.

Li YP, Atkins CM, Sweatt JD, \& Reid MB (1999). Mitochondria mediate tumor necrosis factor- $\alpha / \mathrm{NF}-\kappa \mathrm{B}$ signaling in skeletal muscle myotubes. Antioxid Redox Signal 1, 97-104.

Liao P, Yong TF, Liang MC, Yue DT, \& Soong TW (2005). Splicing for alternative structures of $\mathrm{Ca}_{\mathrm{v}} 1.2 \mathrm{Ca}^{2+}$ channels in cardiac and smooth muscles. Cardiovasc Res $\mathbf{6 8}$, 197-203.

Lilienbaum A \& Israel A (2003). From calcium to NF- $\kappa B$ signaling pathways in neurons. Mol Cell Biol 23, 2680-2698.

Lin L, DeMartino GN, \& Greene WC (1998). Cotranslational biogenesis of NF- $\kappa B$ p50 by the $26 \mathrm{~S}$ proteasome. Cell 92, 819-828.

Liu C \& Hermann TE (1978). Characterization of ionomycin as a calcium ionophore. $J$ Biol Chem 253, 5892-5894.

Livak KJ \& Schmittgen TD (2001). Analysis of relative gene expression data using realtime quantitative PCR and the $2^{-\Delta \Delta \mathrm{CT}}$ Method. Methods 25, 402-408.

Loffler BM, Breu V, \& Clozel M (1993). Effect of different endothelin receptor antagonists and of the novel non-peptide antagonist Ro 46-2005 on endothelin levels in rat plasma. FEBS Lett 333, 108-110.

Lotzer K, Funk CD, \& Habenicht AJ (2005). The 5-lipoxygenase pathway in arterial wall biology and atherosclerosis. Biochim Biophys Acta 1736, 30-37.

Lukyanenko V, Gyorke I, Wiesner TF, \& Gyorke S (2001). Potentiation of $\mathrm{Ca}^{2+}$ release by cADP-ribose in the heart is mediated by enhanced SR $\mathrm{Ca}^{2+}$ uptake into the sarcoplasmic reticulum. Circ Res 89, 614-622.

Luscher TF \& Barton M (2000). Endothelins and endothelin receptor antagonists: therapeutic considerations for a novel class of cardiovascular drugs. Circulation 102, 2434-2440.

Lytton J, Westlin M, \& Hanley MR (1991). Thapsigargin inhibits the sarcoplasmic or endoplasmic reticulum Ca-ATPase family of calcium pumps. $J$ Biol Chem 266, 1706717071.

Maddali KK, Korzick DH, Tharp DL, \& Bowles DK (2005). PKC $\delta$ mediates testosterone-induced increases in coronary smooth muscle Cav1.2. J Biol Chem 280, 43024-43029. 
Maeda S, Miyauchi T, Kobayashi T, Goto K, \& Matsuda M (1998). Exercise causes tissue-specific enhancement of endothelin-1 mRNA expression in internal organs. J Appl Physiol 85, 425-431.

Maruyama Y, Nakanishi Y, Walsh EJ, Wilson DP, Welsh DG, \& Cole WC (2006). Heteromultimeric TRPC6-TRPC7 channels contribute to arginine vasopressin-induced cation current of A7r5 vascular smooth muscle cells. Circ Res 98, 1520-1527.

Masaki T (2004). Historical review: Endothelin. Trends Pharmacol Sci 25, 219-224.

Matlib MA, Zhou Z, Knight S, Ahmed S, Choi KM, Krause-Bauer J, Phillips R, Altschuld R, Katsube Y, Sperelakis N, \& Bers DM (1998). Oxygen-bridged dinuclear ruthenium amine complex specifically inhibits $\mathrm{Ca}^{2+}$ uptake into mitochondria in vitro and in situ in single cardiac myocytes. J Biol Chem 273, 10223-10231.

Mauban JR, Lamont C, Balke CW, \& Wier WG (2001). Adrenergic stimulation of rat resistance arteries affects $\mathrm{Ca}^{2+}$ sparks, $\mathrm{Ca}^{2+}$ waves, and $\mathrm{Ca}^{2+}$ oscillations. Am J Physiol Heart Circ Physiol 280, H2399-H2405.

McCarron JG, Chalmers S, Bradley KN, MacMillan D, \& Muir TC (2006). $\mathrm{Ca}^{2+}$ microdomains in smooth muscle. Cell Calcium 40, 461-493.

McCarron JG \& Muir TC (1999). Mitochondrial regulation of the cytosolic $\mathrm{Ca}^{2+}$ concentration and the $\mathrm{InsP}_{3}$-sensitive $\mathrm{Ca}^{2+}$ store in guinea-pig colonic smooth muscle. $J$ Physiol 516 Pt 1, 149-161.

Miller FJ, Jr., Filali M, Huss GJ, Stanic B, Chamseddine A, Barna TJ, \& Lamb FS (2007). Cytokine activation of nuclear factor $\kappa \mathrm{B}$ in vascular smooth muscle cells requires signaling endosomes containing Nox1 and ClC-3. Circ Res 101, 663-671.

Miriel VA, Mauban JR, Blaustein MP, \& Wier WG (1999). Local and cellular $\mathrm{Ca}^{2+}$ transients in smooth muscle of pressurized rat resistance arteries during myogenic and agonist stimulation. $J$ Physiol 518, 815-824.

Monteith GR \& Blaustein MP (1999). Heterogeneity of mitochondrial matrix free $\mathrm{Ca}^{2+}$ : resolution of $\mathrm{Ca}^{2+}$ dynamics in individual mitochondria in situ. Am J Physiol 276, C1193C1204.

Montero M, Lobaton CD, Hernandez-Sanmiguel E, Santodomingo J, Vay L, Moreno A, \& Alvarez J (2004). Direct activation of the mitochondrial calcium uniporter by natural plant flavonoids. Biochem J 384, 19-24.

Moreau B, Nelson C, \& Parekh AB (2006). Biphasic regulation of mitochondrial $\mathrm{Ca}^{2+}$ uptake by cytosolic $\mathrm{Ca}^{2+}$ concentration. Curr Biol 16, 1672-1677.

Morey AK, Razandi M, Pedram A, Hu RM, Prins BA, \& Levin ER (1998). Oestrogen and progesterone inhibit the stimulated production of endothelin-1. Biochem J $330 \mathbf{P t} \mathbf{3}$, 1097-1105. 
Mueller CF, Laude K, McNally JS, \& Harrison DG (2005). ATVB in focus: redox mechanisms in blood vessels. Arterioscler Thromb Vasc Biol 25, 274-278.

Narayanan D, Xi Q, Pfeffer LM, \& Jaggar JH (2010). Mitochondria control functional Cav1.2 expression in smooth muscle cells of cerebral arteries. Circ Res 107, 631-641.

Navedo MF, Amberg GC, Nieves M, Molkentin JD, \& Santana LF (2006). Mechanisms underlying heterogeneous $\mathrm{Ca}^{2+}$ sparklet activity in arterial smooth muscle. J Gen Physiol 127, 611-622.

Navedo MF, Amberg GC, Votaw VS, \& Santana LF (2005). Constitutively active L-type $\mathrm{Ca}^{2+}$ channels. Proc Natl Acad Sci USA 102, 11112-11117.

Navedo MF, Nieves-Cintron M, Amberg GC, Yuan C, Votaw VS, Lederer WJ, McKnight GS, \& Santana LF (2008). AKAP150 is required for stuttering persistent $\mathrm{Ca}^{2+}$ sparklets and angiotensin II-induced hypertension. Circ Res 102, E1-E11.

Navedo MF, Takeda Y, Nieves-Cintron M, Molkentin JD, \& Santana LF (2010). Elevated $\mathrm{Ca}^{2+}$ sparklet activity during acute hyperglycemia and diabetes in cerebral arterial smooth muscle cells. Am J Physiol Cell Physiol 298, C211-C220.

Negre-Salvayre A, Hirtz C, Carrera G, Cazenave R, Troly M, Salvayre R, Penicaud L, \& Casteilla L (1997). A role for uncoupling protein-2 as a regulator of mitochondrial hydrogen peroxide generation. FASEB J11, 809-815.

Nelson MT, Cheng H, Rubart M, Santana LF, Bonev AD, Knot HJ, \& Lederer WJ (1995). Relaxation of arterial smooth muscle by calcium sparks. Science 270, 633-637.

Nelson MT, Standen NB, Brayden JE, \& Worley JF, III (1988). Noradrenaline contracts arteries by activating voltage-dependent calcium channels. Nature 336, 382-385.

Nieves-Cintron M, Amberg GC, Navedo MF, Molkentin JD, \& Santana LF (2008). The control of $\mathrm{Ca}^{2+}$ influx and NFATc3 signaling in arterial smooth muscle during hypertension. Proc Natl Acad Sci USA 105, 15623-15628.

Nieves-Cintron M, Amberg GC, Nichols CB, Molkentin JD, \& Santana LF (2007). Activation of NFATc3 down-regulates the $\beta 1$ subunit of large conductance, calciumactivated $\mathrm{K}^{+}$channels in arterial smooth muscle and contributes to hypertension. J Biol Chem 282, 3231-3240.

Nishio E \& Watanabe Y (1997). The involvement of reactive oxygen species and arachidonic acid in alpha 1-adrenoceptor-induced smooth muscle cell proliferation and migration. Br J Pharmacol 121, 665-670.

Ogita H \& Liao J (2004). Endothelial function and oxidative stress. Endothelium 11, 123132. 
Okuda M, Lee HC, Kumar C, \& Chance B (1992). Comparison of the effect of a mitochondrial uncoupler, 2,4-dinitrophenol and adrenaline on oxygen radical production in the isolated perfused rat liver. Acta Physiol Scand 145, 159-168.

Oliveira-Marques V, Marinho HS, Cyrne L, \& Antunes F (2009). Role of hydrogen peroxide in NF- $\kappa \mathrm{B}$ activation: from inducer to modulator. Antioxid Redox Signal 11, 2223-2243.

Olson ML, Chalmers S, \& McCarron JG (2010). Mitochondrial $\mathrm{Ca}^{2+}$ uptake increases $\mathrm{Ca}^{2+}$ release from inositol 1,4,5-trisphosphate receptor clusters in smooth muscle cells. $J$ Biol Chem 285, 2040-2050.

Pacher P, Sharma K, Csordas G, Zhu Y, \& Hajnoczky G (2008). Uncoupling of ERmitochondrial calcium communication by transforming growth factor- $\beta$. Am J Physiol Renal Physiol 295, F1303-F1312.

Pacher P, Thomas AP, \& Hajnoczky G (2002). $\mathrm{Ca}^{2+}$ marks: miniature calcium signals in single mitochondria driven by ryanodine receptors. Proc Natl Acad Sci USA 99, 23802385 .

Paravicini TM \& Touyz RM (2006). Redox signaling in hypertension. Cardiovasc Res 71, 247-258.

Parfenova H \& Leffler CW (2008). Cerebroprotective functions of HO-2. Curr Pharm Des 14, 443-453.

Paria BC, Bair AM, Xue J, Yu Y, Malik AB, \& Tiruppathi C (2006). $\mathrm{Ca}^{2+}$ influx induced by protease-activated receptor-1 activates a feed-forward mechanism of TRPC1 expression via nuclear factor- $\kappa \mathrm{B}$ activation in endothelial cells. J Biol Chem 281, 2071520727.

Parlapiano C, Paoletti V, Campana E, Giovanniello T, Pantone P, Labbadia G, Califano F, Donnarumma L, \& Musca A (1999). CGRP and ET-1 plasma levels in normal subjects. Eur Rev Med Pharmacol Sci 3, 139-141.

Patterson RL, Boehning D, \& Snyder SH (2004). Inositol 1,4,5-trisphosphate receptors as signal integrators. Annu Rev Biochem 73, 437-465.

Perez GJ, Bonev AD, \& Nelson MT (2001). Micromolar $\mathrm{Ca}^{2+}$ from sparks activates $\mathrm{Ca}^{2+}$ sensitive $\mathrm{K}^{+}$channels in rat cerebral artery smooth muscle. Am J Physiol Cell Physiol 281, C1769-C1775.

Pernow J, Bohm F, Johansson BL, Hedin U, \& Ryden L (2000). Enhanced vasoconstrictor response to endothelin-B-receptor stimulation in patients with atherosclerosis. J Cardiovasc Pharmacol 36, S418-S420. 
Pesic A, Madden JA, Pesic M, \& Rusch NJ (2004). High blood pressure upregulates arterial L-type $\mathrm{Ca}^{2+}$ channels: is membrane depolarization the signal? Circ Res 94, E97E104.

Petronilli V, Cola C, Massari S, Colonna R, \& Bernardi P (1993). Physiological effectors modify voltage sensing by the cyclosporin A-sensitive permeability transition pore of mitochondria. J Biol Chem 268, 21939-21945.

Petronilli V, Miotto G, Canton M, Brini M, Colonna R, Bernardi P, \& Di LF (1999). Transient and long-lasting openings of the mitochondrial permeability transition pore can be monitored directly in intact cells by changes in mitochondrial calcein fluorescence. Biophys J 76, 725-734.

Pitts KR, Yoon Y, Krueger EW, \& McNiven MA (1999). The dynamin-like protein DLP1 is essential for normal distribution and morphology of the endoplasmic reticulum and mitochondria in mammalian cells. Mol Biol Cell 10, 4403-4417.

Plant TD \& Schaefer M (2003). TRPC4 and TRPC5: receptor-operated $\mathrm{Ca}^{2+}$-permeable nonselective cation channels. Cell Calcium 33, 441-450.

Poburko D, Lee CH, \& van Breemen C (2004). Vascular smooth muscle mitochondria at the cross roads of $\mathrm{Ca}^{2+}$ regulation. Cell Calcium 35, 509-521.

Poburko D, Liao CH, van Breemen C, \& Demaurex N (2009). Mitochondrial regulation of sarcoplasmic reticulum $\mathrm{Ca}^{2+}$ content in vascular smooth muscle cells. Circ Res 104, 104-112.

Poot M, Zhang YZ, Kramer JA, Wells KS, Jones LJ, Hanzel DK, Lugade AG, Singer VL, \& Haugland RP (1996). Analysis of mitochondrial morphology and function with novel fixable fluorescent stains. J Histochem Cytochem 44, 1363-1372.

Quednau BD, Nicoll DA, \& Philipson KD (1997). Tissue specificity and alternative splicing of the $\mathrm{Na}^{+} / \mathrm{Ca}^{2+}$ exchanger isoforms NCX1, NCX2, and NCX3 in rat. Am $J$ Physiol 272, C1250-C1261.

Ralevic V \& Burnstock G (1998). Receptors for purines and pyrimidines. Pharmacol Rev 50, 413-492.

Rapizzi E, Pinton P, Szabadkai G, Wieckowski MR, Vandecasteele G, Baird G, Tuft RA, Fogarty KE, \& Rizzuto R (2002). Recombinant expression of the voltage-dependent anion channel enhances the transfer of $\mathrm{Ca}^{2+}$ microdomains to mitochondria. $J$ Cell Biol 159, 613-624.

Ray R \& Shah AM (2005). NAD(P)H oxidase and endothelial cell function. Clin Sci (Lond) 109, 217-226. 
Rey FE, Cifuentes ME, Kiarash A, Quinn MT, \& Pagano PJ (2001). Novel competitive inhibitor of NAD(P)H oxidase assembly attenuates vascular $\mathrm{O}^{2-}$ and systolic blood pressure in mice. Circ Res 89, 408-414.

Rizzuto R, Bernardi P, \& Pozzan T (2000). Mitochondria as all-round players of the calcium game. J Physiol 529 Pt 1, 37-47.

Rizzuto R, Brini M, Murgia M, \& Pozzan T (1993). Microdomains with high $\mathrm{Ca}^{2+}$ close to $\mathrm{IP}_{3}$-sensitive channels that are sensed by neighboring mitochondria. Science 262, 744747.

Rizzuto R, Duchen MR, \& Pozzan T (2004). Flirting in little space: the ER/mitochondria $\mathrm{Ca}^{2+}$ liaison. Sci STKE 2004, re1.

Rizzuto R, Marchi S, Bonora M, Aguiari P, Bononi A, De Stefani D, Giorgi C, Leo S, Rimessi A, Siviero R, Zecchini E, \& Pinton P (2009). $\mathrm{Ca}^{2+}$ transfer from the ER to mitochondria: when, how and why. Biochim Biophys Acta 1787, 1342-1351.

Rizzuto R, Pinton P, Brini M, Chiesa A, Filippin L, \& Pozzan T (1999). Mitochondria as biosensors of calcium microdomains. Cell Calcium 26, 193-199.

Rizzuto R \& Pozzan T (2006). Microdomains of intracellular $\mathrm{Ca}^{2+}$ : molecular determinants and functional consequences. Physiol Rev 86, 369-408.

Rosendorff C (1997). Endothelin, vascular hypertrophy, and hypertension. Cardiovasc Drugs Ther 10, 795-802.

Ruegg UT, Wallnofer A, Weir S, \& Cauvin C (1989). Receptor-operated calciumpermeable channels in vascular smooth muscle. J Cardiovasc Pharmacol 14 Suppl 6, S49-S58.

Saada N, Dai B, Echetebu C, Sarna SK, \& Palade P (2003). Smooth muscle uses another promoter to express primarily a form of human $\mathrm{Ca}_{\mathrm{V}} 1.2 \mathrm{~L}$-type calcium channel different from the principal heart form. Biochem Biophys Res Commun 302, 23-28.

Sakuma S, Fujimoto Y, Sakamoto Y, Uchiyama T, Yoshioka K, Nishida H, \& Fujita T (1997). Peroxynitrite induces the conversion of xanthine dehydrogenase to oxidase in rabbit liver. Biochem Biophys Res Commun 230, 476-479.

Sanchez R, MacKenzie A, Farhat N, Nguyen TD, Stewart DJ, Mercier I, Calderone A, \& Thorin E (2002). Endothelin B receptor-mediated regulation of endothelin-1 content and release in cultured porcine aorta endothelial cell. J Cardiovasc Pharmacol 39, 652-659.

Sanders KM (2001). Invited review: mechanisms of calcium handling in smooth muscles. J Appl Physiol 91, 1438-1449.

Santana LF \& Navedo MF (2009). Molecular and biophysical mechanisms of $\mathrm{Ca}^{2+}$ sparklets in smooth muscle. J Mol Cell Cardiol 47, 436-444. 
Santini MP, Talora C, Seki T, Bolgan L, \& Dotto GP (2001). Cross talk among calcineurin, Sp1/Sp3, and NFAT in control of p21 ${ }^{\mathrm{WAF} 1 / \mathrm{CIP} 1}$ expression in keratinocyte differentiation. Proc Natl Acad Sci USA 98, 9575-9580.

Sato H, Sato M, Kanai H, Uchiyama T, Iso T, Ohyama Y, Sakamoto H, Tamura J, Nagai R, \& Kurabayashi M (2005). Mitochondrial reactive oxygen species and c-Src play a critical role in hypoxic response in vascular smooth muscle cells. Cardiovasc Res 67, 714-722.

Sawada H, Mitani Y, Maruyama J, Jiang BH, Ikeyama Y, Dida FA, Yamamoto H, Imanaka-Yoshida K, Shimpo H, Mizoguchi A, Maruyama K, \& Komada Y (2007). A nuclear factor- $\kappa \mathrm{B}$ inhibitor pyrrolidine dithiocarbamate ameliorates pulmonary hypertension in rats. Chest 132, 1265-1274.

Scaduto RC, Jr. \& Grotyohann LW (1999). Measurement of mitochondrial membrane potential using fluorescent rhodamine derivatives. Biophys $J$ 76, 469-477.

Schuh K, Uldrijan S, Telkamp M, Rothlein N, \& Neyses L (2001). The plasmamembrane calmodulin-dependent calcium pump: a major regulator of nitric oxide synthase I. $J$ Cell Biol 155, 201-205.

Schumacker PT (2003). Current paradigms in cellular oxygen sensing. Adv Exp Med Biol 543, 57-71.

Senftleben U, Cao Y, Xiao G, Greten FR, Krahn G, Bonizzi G, Chen Y, Hu Y, Fong A, Sun SC, \& Karin M (2001). Activation by IKK $\alpha$ of a second, evolutionary conserved, NF-кB signaling pathway. Science 293, 1495-1499.

Sharma VK, Ramesh V, Franzini-Armstrong C, \& Sheu SS (2000). Transport of $\mathrm{Ca}^{2+}$ from sarcoplasmic reticulum to mitochondria in rat ventricular myocytes. J Bioenerg Biomembr 32, 97-104.

Shatrov VA, Lehmann V, \& Chouaib S (1997). Sphingosine-1-phosphate mobilizes

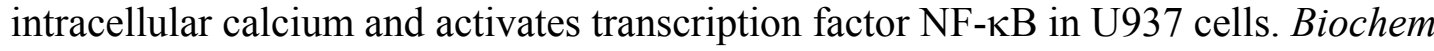
Biophys Res Commun 234, 121-124.

Shi XZ, Choudhury BK, Pasricha PJ, \& Sarna SK (2007). A novel role of VIP in colonic motility function: induction of excitation-transcription coupling in smooth muscle cells. Gastroenterology 132, 1388-1400.

Shi XZ, Pazdrak K, Saada N, Dai B, Palade P, \& Sarna SK (2005). Negative transcriptional regulation of human colonic smooth muscle $\mathrm{Ca}_{\mathrm{V}} 1.2$ channels by $\mathrm{p} 50$ and p65 subunits of nuclear factor-кB. Gastroenterology 129, 1518-1532.

Shichiri M, Hirata Y, Ando K, Emori T, Ohta K, Kimoto S, Ogura M, Inoue A, \& Marumo F (1990). Plasma endothelin levels in hypertension and chronic renal failure. Hypertension 15, 493-496. 
Shimamura K, Sekiguchi F, \& Sunano S (1999). Tension oscillation in arteries and its abnormality in hypertensive animals. Clin Exp Pharmacol Physiol 26, 275-284.

Simard JM \& Li X (2000). Functional integrity of endothelium determines $\mathrm{Ca}^{2+}$ channel availability in smooth muscle: involvement of nitric oxide. Pflugers Arch 439, 752-758.

Simpson PB, Mehotra S, Lange GD, \& Russell JT (1997). High density distribution of endoplasmic reticulum proteins and mitochondria at specialized $\mathrm{Ca}^{2+}$ release sites in oligodendrocyte processes. J Biol Chem 272, 22654-22661.

Sitsapesan R, McGarry SJ, \& Williams AJ (1995). Cyclic ADP-ribose, the ryanodine receptor and $\mathrm{Ca}^{2+}$ release. Trends Pharmacol Sci 16, 386-391.

Souza HP, Souza LC, Anastacio VM, Pereira AC, Junqueira ML, Krieger JE, da Luz PL, Augusto O, \& Laurindo FR (2000). Vascular oxidant stress early after balloon injury: evidence for increased NAD(P)H oxidoreductase activity. Free Radic Biol Med 28, 12321242.

Spat A, Szanda G, Csordas G, \& Hajnoczky G (2008). High- and low-calcium-dependent mechanisms of mitochondrial calcium signalling. Cell Calcium 44, 51-63.

Starkov AA \& Fiskum G (2003). Regulation of brain mitochondrial $\mathrm{H}_{2} \mathrm{O}_{2}$ production by membrane potential and $\mathrm{NAD}(\mathrm{P}) \mathrm{H}$ redox state. J Neurochem 86, 1101-1107.

Stewart DJ, Kubac G, Costello KB, \& Cernacek P (1991a). Increased plasma endothelin1 in the early hours of acute myocardial infarction. $J$ Am Coll Cardiol 18, 38-43.

Stewart DJ, Levy RD, Cernacek P, \& Langleben D (1991b). Increased plasma endothelin-1 in pulmonary hypertension: marker or mediator of disease? Ann Intern Med 114, 464-469.

Sun Z \& Andersson R (2002). NF-кB activation and inhibition: a review. Shock 18, 99106.

Sward K, Dreja K, Lindqvist A, Persson E, \& Hellstrand P (2002). Influence of mitochondrial inhibition on global and local $\left[\mathrm{Ca}^{2+}\right]_{\mathrm{i}}$ in rat tail artery. Circ Res 90, 792799.

Szabadkai G, Bianchi K, Varnai P, De Stefani D, Wieckowski MR, Cavagna D, Nagy AI, Balla T, \& Rizzuto R (2006). Chaperone-mediated coupling of endoplasmic reticulum and mitochondrial $\mathrm{Ca}^{2+}$ channels. J Cell Biol 175, 901-911.

Szado T, Kuo KH, Bernard-Helary K, Poburko D, Lee CH, Seow C, Ruegg UT, \& van Breemen C (2003). Agonist-induced mitochondrial $\mathrm{Ca}^{2+}$ transients in smooth muscle. FASEB J 17, 28-37. 
Takada Y, Mukhopadhyay A, Kundu GC, Mahabeleshwar GH, Singh S, \& Aggarwal BB

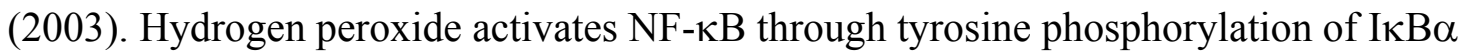
and serine phosphorylation of p65: evidence for the involvement of IкB $\alpha$ kinase and Syk protein-tyrosine kinase. J Biol Chem 278, 24233-24241.

Takei K, Stukenbrok H, Metcalf A, Mignery GA, Sudhof TC, Volpe P, \& De Camilli P (1992). $\mathrm{Ca}^{2+}$ stores in Purkinje neurons: endoplasmic reticulum subcompartments demonstrated by the heterogeneous distribution of the Ins $\mathrm{P}_{3}$ receptor, $\mathrm{Ca}^{2+}$-ATPase, and calsequestrin. $J$ Neurosci 12, 489-505.

Tan W \& Colombini M (2007). VDAC closure increases calcium ion flux. Biochim Biophys Acta 1768, 2510-2515.

Tang ZZ, Liang MC, Lu S, Yu D, Yu CY, Yue DT, \& Soong TW (2004). Transcript scanning reveals novel and extensive splice variations in human L-type voltage-gated calcium channel, $\mathrm{Ca}_{\mathrm{V}} 1.2 \alpha_{1}$ subunit. J Biol Chem 279, 44335-44343.

Ten RM, Paya CV, Israel N, Le BO, Mattei MG, Virelizier JL, Kourilsky P, \& Israel A (1992). The characterization of the promoter of the gene encoding the p50 subunit of NF$\mathrm{\kappa B}$ indicates that it participates in its own regulation. EMBO J 11, 195-203.

Thiel G, Mayer SI, Muller I, Stefano L, \& Rossler OG (2010). Egr-1-A Ca ${ }^{2+}$-regulated transcription factor. Cell Calcium 47, 397-403.

Touyz RM, Chen X, Tabet F, Yao G, He G, Quinn MT, Pagano PJ, \& Schiffrin EL (2002). Expression of a functionally active gp $91^{\text {phox }}$-containing neutrophil-type $\mathrm{NAD}(\mathrm{P}) \mathrm{H}$ oxidase in smooth muscle cells from human resistance arteries: regulation by angiotensin II. Circ Res 90, 1205-1213.

Touyz RM \& Schiffrin EL (2000). Signal transduction mechanisms mediating the physiological and pathophysiological actions of angiotensin II in vascular smooth muscle cells. Pharmacol Rev 52, 639-672.

Touyz RM \& Schiffrin EL (2008). Reactive oxygen species and hypertension: a complex association. Antioxid Redox Signal 10, 1041-1044.

Trenker M, Malli R, Fertschai I, Levak-Frank S, \& Graier WF (2007). Uncoupling proteins 2 and 3 are fundamental for mitochondrial $\mathrm{Ca}^{2+}$ uniport. Nat Cell Biol 9, 445452.

Triggle DJ (2006). L-type calcium channels. Curr Pharm Des 12, 443-457.

Trollinger DR, Cascio WE, \& Lemasters JJ (2000). Mitochondrial calcium transients in adult rabbit cardiac myocytes: inhibition by ruthenium red and artifacts caused by lysosomal loading of $\mathrm{Ca}^{2+}$-indicating fluorophores. Biophys $J$ 79, 39-50.

Turrens JF (2003). Mitochondrial formation of reactive oxygen species. J Physiol 552, 335-344. 
Vaithianathan T, Narayanan D, Asuncion-Chin MT, Jeyakumar LH, Liu J, Fleischer S, Jaggar JH, \& Dopico AM (2010). Subtype identification and functional characterization of ryanodine receptors in rat cerebral artery myocytes. Am J Physiol Cell Physiol 299, C264-C278.

Vangheluwe P, Schuermans M, Zador E, Waelkens E, Raeymaekers L, \& Wuytack F (2005). Sarcolipin and phospholamban mRNA and protein expression in cardiac and skeletal muscle of different species. Biochem J 389, 151-159.

Wackenfors A, Emilson M, Ingemansson R, Hortobagyi T, Szok D, Tajti J, Vecsei L, Edvinsson L, \& Malmsjo M (2004). Ischemic heart disease induces upregulation of endothelin receptor mRNA in human coronary arteries. Eur J Pharmacol 484, 103-109.

Wang H, Liu J, \& Wu L (2009). Methylglyoxal-induced mitochondrial dysfunction in vascular smooth muscle cells. Biochem Pharmacol 77, 1709-1716.

Wang HD, Pagano PJ, Du Y, Cayatte AJ, Quinn MT, Brecher P, \& Cohen RA (1998). Superoxide anion from the adventitia of the rat thoracic aorta inactivates nitric oxide. Circ Res 82, 810-818.

Wang Q, Hogg RC, \& Large WA (1992). Properties of spontaneous inward currents recorded in smooth muscle cells isolated from the rabbit portal vein. $J$ Physiol 451, 525537.

Wang W, Fang H, Groom L, Cheng A, Zhang W, Liu J, Wang X, Li K, Han P, Zheng M, Yin J, Wang W, Mattson MP, Kao JP, Lakatta EG, Sheu SS, Ouyang K, Chen J, Dirksen RT, \& Cheng H (2008a). Superoxide flashes in single mitochondria. Cell 134, 279-290.

Wang WZ, Pang L, \& Palade P (2008b). Angiotensin II causes endothelial-dependent increase in expression of $\mathrm{Ca}_{V} 1.2$ protein in cultured arteries. Eur J Pharmacol 599, 117 120.

Wang WZ, Saada N, Dai B, Pang L, \& Palade P (2006). Vascular-specific increase in exon $1 \mathrm{~B}$-encoded $\mathrm{Ca}_{\mathrm{v}} 1.2$ channels in spontaneously hypertensive rats. Am J Hypertens 19, 823-831.

Wang YX, Zheng YM, Abdullaev I, \& Kotlikoff MI (2003). Metabolic inhibition with cyanide induces calcium release in pulmonary artery myocytes and Xenopus oocytes. $\mathrm{Am}$ J Physiol Cell Physiol 284, C378-C388.

Wedgwood S, Dettman RW, \& Black SM (2001). ET-1 stimulates pulmonary arterial smooth muscle cell proliferation via induction of reactive oxygen species. Am J Physiol Lung Cell Mol Physiol 281, L1058-L1067.

Wellman GC \& Nelson MT (2003). Signaling between SR and plasmalemma in smooth muscle: sparks and the activation of $\mathrm{Ca}^{2+}$-sensitive ion channels. Cell Calcium 34, 211229. 
Welsh DG, Morielli AD, Nelson MT, \& Brayden JE (2002). Transient receptor potential channels regulate myogenic tone of resistance arteries. Circ Res 90, 248-250.

Wilkerson MK, Heppner TJ, Bonev AD, \& Nelson MT (2006). Inositol trisphosphate receptor calcium release is required for cerebral artery smooth muscle cell proliferation. Am J Physiol Heart Circ Physiol 290, H240-H247.

Wolin MS, Ahmad M, \& Gupte SA (2005). Oxidant and redox signaling in vascular oxygen sensing mechanisms: basic concepts, current controversies, and potential importance of cytosolic NAD(P)H. Am J Physiol Lung Cell Mol Physiol 289, L159-L173.

Wong RK, Pettit AI, Quinn PA, Jennings SC, Davies JE, \& Ng LL (2003). Advanced glycation end products stimulate an enhanced neutrophil respiratory burst mediated through the activation of cytosolic phospholipase A2 and generation of arachidonic acid. Circulation 108, 1858-1864.

Worley PF, Baraban JM, Supattapone S, Wilson VS, \& Snyder SH (1987).

Characterization of inositol trisphosphate receptor binding in brain. Regulation by $\mathrm{pH}$ and calcium. J Biol Chem 262, 12132-12136.

Wray S \& Burdyga T (2010). Sarcoplasmic reticulum function in smooth muscle. Physiol Rev 90, 113-178.

Wray S, Burdyga T, \& Noble K (2005). Calcium signalling in smooth muscle. Cell Calcium 38, 397-407.

Wu KD, Bungard D, \& Lytton J (2001). Regulation of SERCA Ca ${ }^{2+}$ pump expression by cytoplasmic $\mathrm{Ca}^{2+}$ in vascular smooth muscle cells. Am J Physiol Cell Physiol 280, C843C851.

Xi Q, Adebiyi A, Zhao G, Chapman KE, Waters CM, Hassid A, \& Jaggar JH (2008). IP 3 constricts cerebral arteries via $\mathrm{IP}_{3}$ receptor-mediated TRPC3 channel activation and independently of sarcoplasmic reticulum $\mathrm{Ca}^{2+}$ release. Circ Res 102, 1118-1126.

Xi Q, Cheranov SY, \& Jaggar JH (2005). Mitochondria-derived reactive oxygen species dilate cerebral arteries by activating $\mathrm{Ca}^{2+}$ sparks. Circ Res 97, 354-362.

Xu CB, Zheng JP, Zhang W, Zhang Y, \& Edvinsson L (2008). Lipid-soluble smoke particles upregulate vascular smooth muscle $\mathrm{ET}_{\mathrm{B}}$ receptors via activation of mitogen-

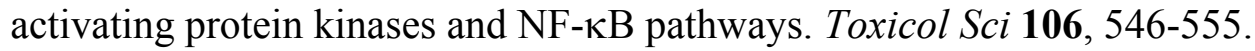

Yatomi Y (2006). Sphingosine 1-phosphate in vascular biology: possible therapeutic strategies to control vascular diseases. Curr Pharm Des 12, 575-587.

Zangar RC, Davydov DR, \& Verma S (2004). Mechanisms that regulate production of reactive oxygen species by cytochrome P450. Toxicol Appl Pharmacol 199, 316-331. 
Zhang WM, Yip KP, Lin MJ, Shimoda LA, Li WH, \& Sham JS (2003). ET-1 activates $\mathrm{Ca}^{2+}$ sparks in PASMC: local $\mathrm{Ca}^{2+}$ signaling between inositol trisphosphate and ryanodine receptors. Am J Physiol Lung Cell Mol Physiol 285, L680-L690.

Zhao G, Adebiyi A, Blaskova E, Xi Q, \& Jaggar JH (2008). Type 1 inositol 1,4,5trisphosphate receptors mediate UTP-induced cation currents, $\mathrm{Ca}^{2+}$ signals, and vasoconstriction in cerebral arteries. Am J Physiol Cell Physiol 295, C1376-C1384.

Zhu ZG, Wang MS, Jiang ZB, Jiang Z, Xu SX, Ren CY, \& Shi MX (1994). The dynamic change of plasma endothelin-1 during the perioperative period in patients with rheumatic valvular disease and secondary pulmonary hypertension. J Thorac Cardiovasc Surg 108, 960-968.

Zhuge R, Fogarty KE, Tuft RA, \& Walsh JV, Jr. (2002). Spontaneous transient outward currents arise from microdomains where $\mathrm{BK}$ channels are exposed to a mean $\mathrm{Ca}^{2+}$ concentration on the order of $10 \mu \mathrm{M}$ during a $\mathrm{Ca}^{2+}$ spark. J Gen Physiol 120, 15-27.

Zou AP, Ma YH, Sui ZH, Ortiz De Montellano PR, Clark JE, Masters BS, \& Roman RJ (1994). Effects of 17-octadecynoic acid, a suicide-substrate inhibitor of cytochrome P450 fatty acid $\omega$-hydroxylase, on renal function in rats. $J$ Pharmacol Exp Ther 268, 474-481. 


\section{VITA}

Damodaran Narayanan was born on December 25, 1979 in Chennai, India. He graduated from high school in 1997. He obtained his Bachelor of Medicine, Bachelor of Surgery (M.B.,B.S.) degree from Madras Medical College, affiliated to The Tamil Nadu Dr. M.G.R. Medical University in June 2004. He joined the Integrated Program in Biomedical Sciences (IPBS) at the University of Tennessee Health Science Center (UTHSC), Memphis in August 2005. He is a member of American Physiological Society and a founding member of Tennessee Physiological Society. He received the Dorothy K. and Daniel L. Gerwin Graduate Scholarship, awarded to the most outstanding Ph.D. student from the Department of Physiology, UTHSC in July 2008. He was also a recipient of a predoctoral fellowship (July 2009 - June 2010) from the American Heart Association (Greater Southeast Affiliate). He has also received two travel awards (John Autian Student Enrichment Fund) in 2009 and 2010 from the College of Graduate Health Sciences, UTHSC to present his research at Experimental Biology Meeting, an international scientific research conference. He was also awarded for best poster presentation by a senior Ph.D. graduate student at the Graduate Research Day, UTHSC in 2009 and 2010. He was awarded his Ph.D. in December 2010. 